\title{
Large artery properties : relation to cardiovascular risk factors and therapy
}

Citation for published version (APA):

Kool, M. J. F. (1995). Large artery properties : relation to cardiovascular risk factors and therapy. [Doctoral Thesis, Maastricht University]. Rijksuniversiteit Limburg. https://doi.org/10.26481/dis.19950921mk

Document status and date:

Published: 01/01/1995

DOI:

10.26481/dis.19950921mk

Document Version:

Publisher's PDF, also known as Version of record

\section{Please check the document version of this publication:}

- A submitted manuscript is the version of the article upon submission and before peer-review. There can be important differences between the submitted version and the official published version of record.

People interested in the research are advised to contact the author for the final version of the publication, or visit the DOI to the publisher's website.

- The final author version and the galley proof are versions of the publication after peer review.

- The final published version features the final layout of the paper including the volume, issue and page numbers.

Link to publication

\footnotetext{
General rights rights.

- You may freely distribute the URL identifying the publication in the public portal. please follow below link for the End User Agreement:

www.umlib.nl/taverne-license

Take down policy

If you believe that this document breaches copyright please contact us at:

repository@maastrichtuniversity.nl

providing details and we will investigate your claim.
}

Copyright and moral rights for the publications made accessible in the public portal are retained by the authors and/or other copyright owners and it is a condition of accessing publications that users recognise and abide by the legal requirements associated with these

- Users may download and print one copy of any publication from the public portal for the purpose of private study or research.

- You may not further distribute the material or use it for any profit-making activity or commercial gain

If the publication is distributed under the terms of Article $25 \mathrm{fa}$ of the Dutch Copyright Act, indicated by the "Taverne" license above, 


\section{LARGE ARTERY PROPERTIES}

relation to cardiovascular risk factors and therapy 
Publication of this thesis was financially supported by Bristol Myers Squibb The Netherlands, E. Merck Nederland B.V., Servier Nederland \& Servier R\&D Benelux and Pie Medical Equipment B.V. Financial support by the Netherlands Heart Foundation for the publication of this thesis is also gratefully acknowledged.

Omslagillustratie: mevr. Mimi Limpens 


\section{LARGE ARTERY PROPERTIES}

relation to cardiovascular risk factors and therapy

\section{Proefschrift}

ter verkrijging van de graad van doctor aan de Rijksuniversiteit Limburg te Maastricht, op gezag van de Rector Magnificus, Prof. mr. M.J. Cohen, volgens het besluit van het College van Dekanen, op donderdag 21 september 1995 om 14.00 uur

door

Mirian Josephina Francina Kool 


\section{Promotores:}

Prof, dr. H.A.J. Struijker Boudier

Prof. dr. R.S. Reneman

Prof. dr. ir. A.P.G. Hoeks

Co-promotor:

Dr. L.M.A.B. Van Bortel

Beoordelingscommissie:

Prof. dr. PW. de Leeuw (voorzitter)

Prof. dr. J. de Haan

Prof. dr. St. Laurent (Paris, France) 


\section{Generall introduction 娄 1}

1.1 Introduction to vessel wall properties of large arteries 2

1.2 Measurement of large artery wall properties in humans. 3 Definitions, determinants and techniques

1.3 Vessel wall properties in various conditions 9

1 Age 9

2 Gender 9

3 Riace and environmental factors 10

4 Physical activity 10

5 Obesity 10

6 Salt intake 11

1.4 Vessel wall properties and disease $\quad 11$

1 Essential hypertension 11

2 Borderline hypertension 12

3 Systolic hypertension 12

4 Atherosclerosis 13

5 Diabetes mellitus 13

6 Other diseases 14

1.5 Effects of phammacological interventions on vessel wall properties

1.6 Outline of this thesis $\quad 16$

2 Methods used for haemodynamic measurements 29

2.1 Vessel wall properties $\quad 30$

2.2 Venous compliance $\quad 32$

2.3 Cardiac output 33

2.4 Blood pressure and heart rate 33

2.5 Other measurements and analyses 33

3 Evaluation of reproducibility of a vessel wall movement detector system for assessment of llarge artery properties $\mathbf{3 5}$

4 Diurnal variation

4.1 Diurnal pattern of vessel wall properties of large arteries in healthy men 45

4.2 Diurnal variation in prorenin in relation to other humoral factors and haemodynamics 51

5 Short- and long-term effects of smoking on arterial wall properties in habitual smokers 亩 63

6 Vessel wall properties of large arteries in uncomplicated insulin-dependent diabetes mellitus (IDDM) 㴽75 
7 The influence of perindopril and the diuretic combination amiloride/hydrochlorothiazide on the vessel wall properties of large arteries in hypertensive patients 87

8 Does lowering of cholesterol levels influence functional properties of large arteries? 103

9 Acute and subacute effects of nicorandil and isosorbide dinitrate on vessel wall properties of large arteries and haemodynamics in healthy volunteers 115

10 General discussion 127

11 Summary 149

12 Samenvatting 153

Dankwoord 㽪 155

Publications 瀷 159

Curriculum vitae 167 


\section{CHAPTER 1}

GENERAL INTRODUCTION 


\section{Introduction to vessel wall properties of large arteries}

From a physiological point of view, systolic and diastolic blood pressure are determined by the mean arterial pressure and the pulse pressure oscillating around this mean arterial pressure.

Mean arterial pressure - the static component of blood pressure - is determined by cardiac output and systemic vascular resistance (148). Cardiac output is a function of heart rate and stroke volume. Stroke volume is determined by cardiac preload, afterload and contractility and diastolic ventricular compliance (78). Systemic vascular resistance is influenced by blood viscosity and the diameter, length and number of resistance vessels, according to Poisseuille's law (166). Res istance vessels are mainly capillaries, arterioles and small arteries.

Pulse pressure - the dynamic component of blood pressure - is determined by stroke volume, the velocily of ejection of the blood from the heart, reflected pulse waves and compliance of the arterial capacitance vessels (212). Arterial capacitance vessels are predominantly large arteries and to a certain degree small arteries. Consequently, for a given cardiac output, mean anterial pressure is largely determined by the diameter and length of the arterioles and capillaries (microcirculation), while pulse pressure is determined by large artery properties (macrocirculation).

Systolic blood pressure is more clasely related to pulse pressure, whille diastolic pressure better reflects mean arterial pressure $(208)$. Epidemiological studies $(105,206,229)$ have directed attention away from diastolic pressure towards systolic pressure. Systolic pressure level has been mentioned as an independent and - sometimes even more - important risk factor than diastolic blood pressure for cardiovascular mortality and morbidity (i.e. stroke, cardiac failure and left ventricular hypertrophy) (105). As a consequence of the findings of these epidemiological studies large arteries, which buffer the output of the heart and partly determine systolic pressure level (182), have increasingly become a subject of research.

The arterial system is a complex network of elastic and muscular tubes, which exerts a conduit and a cushioning function. Because of the conduit function, blood from the left ventricle is delivered to the peripheral tissues with a minimal fall in mean arterial blood pressure (216). The cushioning function means that the blood, ejected with each heart beat, is temporarily "stored" during systole (91). This enables a more continuous flow for tissue perfusion during diastole (Figure 1.1). Distensibility and compliance are vessel wall properties of large arteries that play an important role in the dynamic behaviour of these vessels. Distensibility is defined as the relative increase in arterial volume for a given increase in arterial pressure, given as ( $\triangle V N$ V) $\triangle \mathrm{P}$. Compliance is defined as the absolute increase in arterial volume for a given increase in arterial pressure $(\triangle V / \Delta P)$.

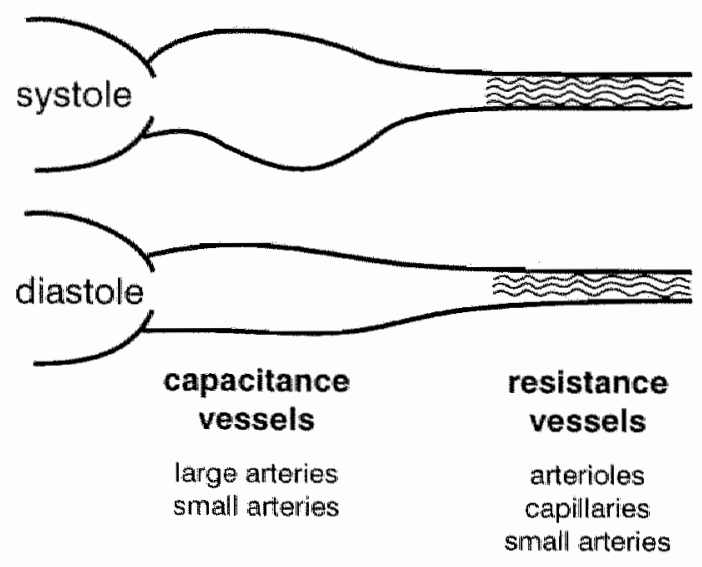

Figure 1.1. Cushioning function of arterial capacilance vessels. The blood ejected with each heart beat is lemporarily stored during systole. This enables a more continuous flow for tissue perfusion during diastole. The buffering lunction of large arteries depends on arteriall complitance. 
A decrease in arterial distensibility means a stiffer artery. In stiff arteries endothelial lesions may occur more rapidly. These lesions in tum may facilitate atherosclerotic changes and may lead to cardiovascular disease (65). A decrease in compliance is related to an increase in systolic blood pressure, pulse pressure and end-systolic stress, while diastolic pressure decreases $(65,72,208)$. Consequently a decrease in distensibility and compliance may increase the risk of cerebrovascular and cardiovascular disease (Table 1.1).

Table 1.1. Cansequences of a decrease in distensibility and compliance.

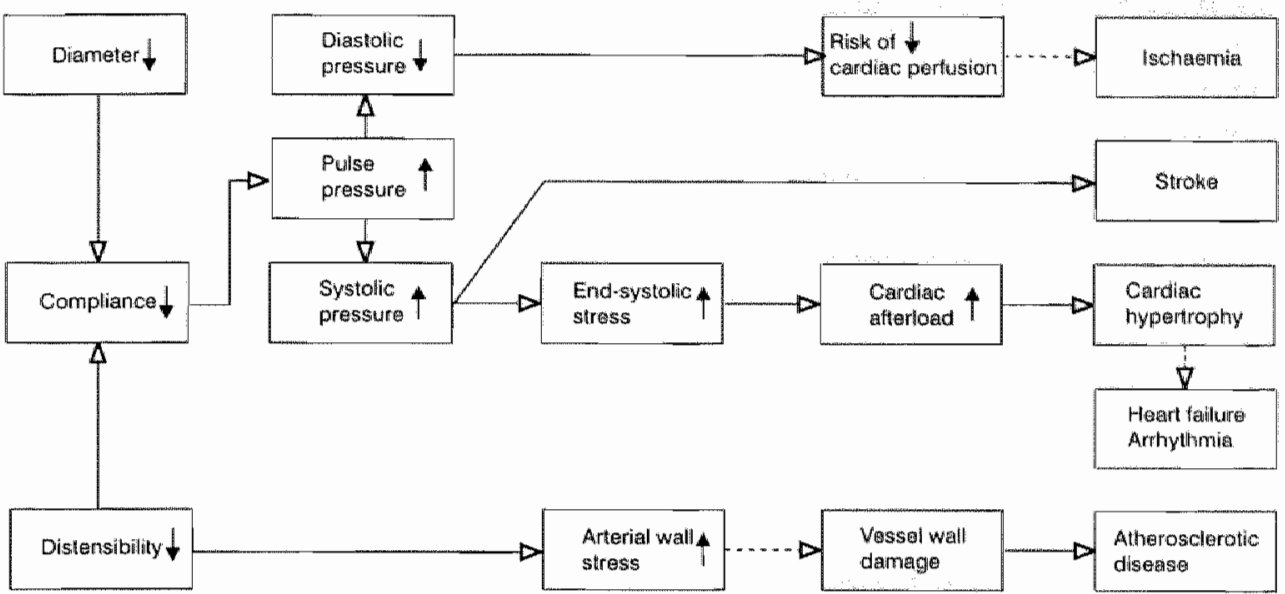

\subsection{Measurement of large artery wall properties in humans. Definitions, determinants and techriques}

In general, the arterial system is described as a Windkessel system (Figure 1.2.1) in which the distensible Windkessel functions as a cushion linked to peripheral resistance by a rigid conduit. Frank (63) extended this theory towards a basic arterial pulse with surmounted on it wave reflections that determine wave shape and behaviour.

Figure 1.2.1. Cushioning function of the arterial system according to the Windkessel concept. The distensible Windkessel (arterial distensibility) is linked to the nozzle (peripheral resistance) by the fire those acting as a rigid conduit (large arteries). The Windkessel smoothed oul the intermittent spurts from the pump so that water was delivered through the hose in a steady stream.

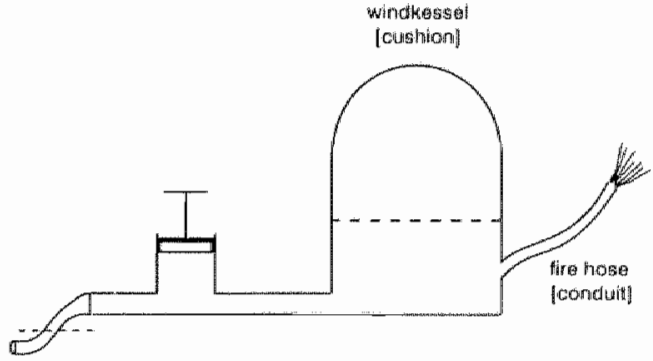


Disiensibility and compliance are important parameters of the dynamic behaviour of a large artery. In the literature, arterial compliance is often used for compliance as well as for distensibility. This can be explained by the fact that until a few years ago, no accurate means were available to measure distensibility and compliance separately. However, there is an obvious difference between them. Distensibility reflects the intrinsic elastic properties of the arterial wall and is directly related to circumferential strain. It describes the strain on the arterial wall exerted by the pressure on this wall (91). Compliance determines the buffering function of the arterial system: the ability of the arterial lumen to store the volume energy after the systolic flow jet from the heart (216).

According to Guyton (80), arterial compliance is related to arterial distensibility and arterial volume. Some problems may arise with regard to the investigation of arterial compliance. Therefore, the determinants of compliance have to be taken into account (Table 1.2.1).

Table 1.2.1. Determinants of arterial compliance according to the Guyton model.

\begin{tabular}{|c|c|c|}
\hline Arterial volume & $\begin{array}{l}\text { Arterial diameter } \\
\text { Vessel length }\end{array}$ & \\
\hline \multirow{2}{*}{ Arterial distensibility } & Mean arterial pressure & $\begin{array}{l}\text { Cardiac output } \\
\text { Systemic vascular resistance } \\
\text { Early pulse wave reflections }\end{array}$ \\
\hline & Arterial wall & $\begin{array}{l}\text { Elastin and collagen } \\
\text { Smooth musele tone } \\
\text { Wall thickness } \\
\text { Wall wicosily }\end{array}$ \\
\hline
\end{tabular}

Guyton model: arterial compliance $=$ arterial volume $x$ arterial distensibility $(80)$.

First, the capacity to store the blood volume from the systolic jet from the heart (arterial compliance) is determined as $\triangle V / \triangle P(201)$. The inability to measure arterial volume directly requires the use of simplified models. Most techniques assume that the change in volume is due to a change in arterial cross-section rather than a change in length of the artery (201). Therefore, cross-sectional compliance is defined as a change in cross-sectional area of the artery divided by the change in pressure $(\triangle A / \Delta P)$. As the artery is supposed to have a circular shape, changes in arterial diameter can be used to calculate arterial compliance $(\pi . \mathrm{D} \Delta \mathrm{D} / 2 \Delta \mathrm{P})$. These changes in arterial diameter now can be measured accurately $(90,94,117)$.

Secondly, mean arterial blood pressure and pulse pressure play a role. Changes in arterial compliance due to changes in pressure are said to be passive and reflect the effect of pressure acting on non-muscular components in the arterial wall (269). The two components of blood pressure are tightly interrelated (221). With a high mean arterial pressure or a high pulse pressure, as is seen in essential hypertension and isolated systolic hypertension respectively, arterial compliance is decreased $(216,221)$. At a high distending pressure the arterial wall gets stiffer (less compliant). The tension in the arterial wall is born predominantly by the less extensible collagen fibers. Apart trom the pressure effect "additional functional and/or structural alterations of the arterial wall are assumed in hypertensive patients, since at the same operating pressure compliance of hypertensive patients was reduced compared to normotensive subjects (221). 
Since wave reflection plays a role in governing pulse pressure, it has to be taken into account when studying arterial compliance. In general, a pressure wave travels along the arterial tree at a speed of $5-15 \mathrm{~m} / \mathrm{s}$. Important factors that affect wave propagation are peripheral resistance, pulse wave velocity, and, related to thil $s_{i}$ vessel wall properties of large arteries also play a role. The shape of the pulse wave has been related to body height (93), but largely depends on vascular impedance and for a minor part also on ventricular ejection (175). Arterial compliance is usually detemined at a certain site or segment of the arterial system. However, it differs along the arterial tree, because of differences in wave travelling properties (distensibility) and differences in arterial diameter (182). Al proximal sites arteries are of the elastic type, while at distal sites they are more of the muscular type. These naturally occurring difterences in vessel wall structure result in differences in distensibility along the arterial tree $(35,156,200)$. Early wave reflections may also influence arterial compliance. These early wave reflections are increased in patients with hypertension and in the elderly, resulting in an increased mean blood and pulse pressure, and consequently, a reduction of arterial compliance (180). Changes in impedance-producing early wave reflections - mainiy occur at arterial bifurcations and at sites where low resistance conduit arteries over a short distance terminate in high resistance arterioles.

Finally, the composition of the arterial wall plays an important role with respect to arterial compliance. It is known that the arterial wall consists of elastin and collagen and a smooth muscle component in the medial layer. At low pressures the relatively extensible elastin tibres "absorb" the stress on the arterial wall "while at higher pressures the non-extensible collagen fibres become more important. An increased influence of collagen may increase arterial wall stiffness (41). This means that the pressure-area curve might not be linear (Figure 1.2.2). In fact cross-sectional compliance is given by the slope of the pressure-area (and indirectly also pressure-diametery curve and can only be determined at a certain pressure (143).

Figure 1,2,2. Theoretical model of the presumed pressure/diameter relation foriginally pressuredvolume cune). Arterial compllance is defined as the slope of the curve, but may change at different pressures (182).

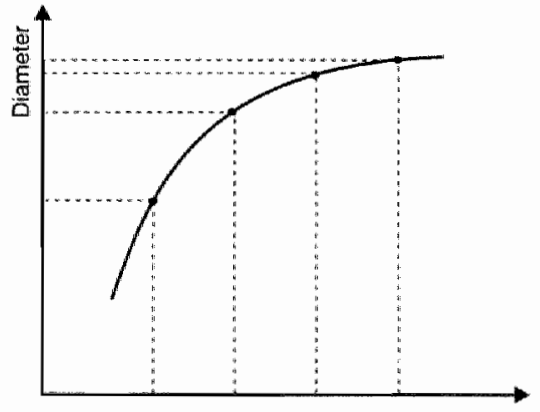

Pregsupe

In contrast to passive changes in arterial compliance (due to a change in pressure), active changes in compliance are caused by changes in smooth muscle tone, since smooth muscle fibres are sensitive to various vasoactive substances released by neurohumoral stimulation $(38,94)$. A change in smooth muscle tone may change arterial diameter for a given pressure and consequently influence arterial compliance $(53,177)$.

Pressure-volume relationships are also dependent on wall thickness and wall viscosity. Viscosity creates a lag between the stress on the wall and the change in arterial diameter (183). Since the wall thickness of elastic and muscular large arteries is small compared to their lumen radius (75) the influence of wall thickness on arterial compliance is considered relatively low. However, with increasing wall thickness 
compliance of large arteries is supposed to diminish $(73,74,123,124)$. Now different methods to assess arterial wall thickness are proposed based on ultrasound devices $(52,192,250,261)$. They indicate that ultrasonic wall thickness may be in close agreement with the histologically determined value (38).

Arterial compliance can be measured at different levels. Systemic arterial compliance gives an overall index of compliance in the whole arterial system and is an important factor in determining cardiac afterload. Regional arterial compliance - also described as volumetric distensibility - describes compliance in an arterial segment, such as the forearm, the leg or the aorta. With this approach generalised arterial stiffening can not be distinguished from a very localised stiffness. Lacal compliance - also described as cross-sectional distensibility - can be measured at various large arteries. At present, in humans local compliance of superficial large arteries; such as the carotid, brachial, radial and femoral arteries and compliance of the abdominal aorta have been investigated $(89,117,251)$.

Total systemic vascular compliance is difficult to measure directly in man, since the measurement requires sudden arrest of the heart and rapid distribution of blood between the arteries and the veins. Therefore, previously total systemic vascular compliance has been calculated as the ratio between changes in central venous pressure and changes in blood volume after rapid Dextran infusion $(120,147,222)$. Changes in total systemic vascular compliance may involve alterations in left ventricular diastolic compliance, venous or arterial compliance (218). For assessment of arterial compliance usually indirect techniques are used. In that case, propagative and non-propagative models are used to estimate compliance. The non-propagative models are based on the Windkessel concept, which assumes an infinite pulse wave velocity (Figure 1.2.1). These pressure-dependent methods define arterial compliance as the change in volume due to a change in pressure. Compliance then may be determined from the slope of the pressure-volume curve $(143,234)$. However, pressure changes do not occur simultaneously, pulse wave velocily varies along the arterial tree and pulse wave reflections are not accounted for with these methods. Propagative models, which are based on pulse wave velocity measurements, seem to offer more advantages.

Systemic arterial compliance is mostly determined from a Windkessel model of the arterial system in which the slope of the pressure/volume curve represents compliance. In that case, aortic as well as brachial pressure may be measured, generally with an unvasive technique. Volume changes may be derived from cardiac output measurements $(59,120)$. Although stroke volume is influenced by other haemodynamic factors the non-invasively determined stroke volume/pulse pressure ratio has also been used as a measure tor systemic compliance (165).

Riegional compliance is mostly estimated from pulse wave velocity measurements in combination with arterial diameter measurements. Various relationships are suggested in the literature to quantify the elastic behavioul" of (a segment of) an artery. The most important expressions used are shown in Table 1.2.2.

The Moens-Korteweg equation defines pulse wave velocity from Young's elastic modulus, wall thickness, blood density and the arterial radius. The Bramwell-Hill equation determines pulse wave velocity from changes in pressure and volume, related to the initial arterial volume $(36,167,176)$. Pulse wave velocity may also be measured with transit-time techniques. The time interval between the arrival of the arterial pulse at two sites of the arterial system and the distance between these sites are used to calculate pu se wave velocity $(44,176,182,266)$. Pulse wave velocity techniques have been applied to different arterial segments, such as the brachio-radial and carotido-femoral segment. In the latter, it is a surrogate for aortic distensibility. For the non-invasive determination of pulse wave velocity, ultrasound techniques have been employed. Based on the Doppler principle regional distensibility could be estimated (118). A disadvantage of this technique is that the distance between the sites of measurement should be long enough to avoid time resolution problems. Unfortunately, the method only provides an indirect measure of distensibility not of compliance. In addition, local inhomogeneities remain undetected (198). Only distensibility of a certain arterial segment can be studied. In that case, arterial compliance is equal to the product of arterial volume (or cross-sectional area per unit of length) and distensibility (pulse wave velocity). The pressure-strain elastic modulus (Peterson modulus) can be used (3) to assess arterial distensibility. The relationship between arterial distensibility and pulse wave velocity is given by the Young's elastic modulus, which 
Table 1.2.2. Expressions to qualify elastic behiviour of an antery.

\begin{tabular}{|c|c|}
\hline Moens-Korteweg & 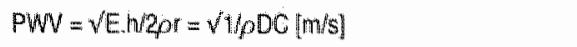 \\
\hline Bramwell-Hill & $P W V=0.357 . / V /(\Delta V \Delta P)[\mathrm{m} / \mathrm{s}]$ \\
\hline Transiti time techrique & $P W N=L T H / s]$ \\
\hline Elastic (Peterson) modulus & $E_{p}=(\mathrm{D} \cdot \Delta \mathrm{P} / \Delta \mathrm{D})=1 /(2 \mathrm{DC})[\mathrm{Pa}]$ \\
\hline Young's modulus & $E=p(\mathrm{PWN})^{2} \mathrm{D} / \mathrm{h}=(\mathrm{D} / \mathrm{h} / \mathrm{DC}[\mathrm{Pa}]$ \\
\hline Distensibility coetticient & $D C=(\Delta A / A) / \Delta P \approx 2(\Delta D / D) / \Delta P\left[P_{a}^{-1}\right]$ \\
\hline Compliance coefficient & $C C=(\Delta V / L) / \Delta P=\Delta A / \Delta P \approx \pi D \cdot \Delta D / 2 \Delta P\left[\mathrm{~mm}^{2} / \mathrm{kPa}\right]$ \\
\hline
\end{tabular}

$A$, cross-sectional area $\triangle A_{2}$ change in cross-sectional area during the heart cycle; $C$, compliance coefficient: $D_{\text {; }}$ end diastolic diameter, $\Delta \mathrm{D}$, change in arterial diameter from diastole to systole; $D C_{n}$ distensibility coefficient; $h_{n}$ wall thickness; $L$, length of arterial segment; $\Delta P_{8}$ pulse pressure, systolic minus diastolic pressure* $P W V ;$ pulse wave velocity; $\rho$, blood density; $T$, time delay needed for pulse wave to lravel between two atterial sites: $\checkmark$, arterial wolume: $\Delta V$ change in arterial volume.

represents arterial strain in relation to the thickness of the arterial wall (181). Finally, non-inwasive determination of regional aortic compliance has been described with magnetic resonance imaging techniques (168).

Techniques to measure non-invasively local compliance have been developed in the last two decades (Table 1.2.3). Arndt (4) was the first who used the change in distance between the ultrasound reflectians of the anterior and posierior arterial wall for measuring changes in arterial diameter during the cardiac cycle, to calculate local compliance. An A-mode technique was used, which resulted in an overestimation of arterial diameter and diameter change.

Table 1.2.3. Methods for non-invasive assesment of local compliance.

\begin{tabular}{|ll|}
$\checkmark$ Windkessel model $(44,120,143,234)$ & $\checkmark$ Coninuous wave Dopplor $(179)$ \\
$\checkmark$ Amode echo $(4)$ & $\checkmark$ Pulsed wave Doppler $(137,263)$ \\
$\checkmark$ B-mode echo $(21)$ & $\checkmark$ Multi-gate pulsed Doppler $(201)$ \\
$\checkmark$-mode echo $(29,38,58,202)$ & $\checkmark$ Dopplar-lracking $(92,95,251)$ \\
\hline
\end{tabular}

Later, a B-mode system has been developed to measure the relative increase in arterial diameter during the heart cycle (21). However, this is a time-consuming technique and the accuracy of the measurements is hampered by the spatial resolution of the echo-system.

Subsequently, M-mode techniques that could wisualize moving structures have been used $(29,58,202)$ to measure changes in arterial diameter. However also this technique is time-consuming and not accurate enough to study arterial compliance. In addition, any information about the distension waveform is lacking $(92)$ 
Furthermore, continuous wave and pulsed wave Doppler techniques have been used to detect vessel wall movements. The disadvantage of continuous Doppler systems is that they can not assess initial arterial diameter and may only measure vessel wall movements if both walls move with the same speed in opposite directions (179). With pulsed Doppler systems the detection of vessel wall movements is based on the positioning of wo sample volumes coinciding with the vessel wall or with the wall-blood intertace (263). The difference in displacement of the sample volumes describes the change in arterial diameter during the heart cycle, while the distance between the sample volumes gives the initial arterial diameter. Levenson et al developed a modified pulsed Doppler device in order to minimise the error resulting from the determination of the angle between the uttrasound beam and the vessel axis (137). Still this method may result in a slight overestimation of arterial diameter and mean blood flow velocity (224).

Multi-gated pulsed Doppler systems have been developed to measure arterial diameter and diameter changes on line (199). With this system the carotid and femoral artery have been inwestigated $(42,159)$. It has shown good accuracy, but a disadvantage of this technique is that the sample volume is fixed in size and position (198). Consequently, it becomes difficult to assess arterial distensibility, especially when the artery is moving. Hokanson was the first to use the phase of the radiofrequency (RF) signal and the positioning of windows at both arterial walls $(95,169)$. This method was far more accurate to detect diameter changes during the heart cycle. A few years later, Hoeks et al developed a system based on tracking the position of the vessel wall during the heart cycle, using this radiofrequency signal $(92,93)$. With the first devices sample volumes coinciding with the vessel walls were fixed (93), but later sample volumes could track the moving position of the anterior and posterior vessel wall by means of Doppler tracking (92). Arterial diameter (D) and change in arterial diameter during the heart cycle ( $\Delta D)$ can be measured with this system. Simultaneously blood pressure is recorded with a non-invasive device. From $D, \Delta D$ and pulse pressure, distensibility (coefficient) and cross-sectional compliance (coefficient) of superficial large arteries can be calculated. The vessel wall movernent detector system, as originally developed by Hoeks et al, is the system used in the current thesis (Chapter 3).

Recently, another A-mode ultrasonic echo-tracking device has been developed to measure the displacement of the arterial walls over the cardiac cycle and to derive from these parameters arterial compliance of distal large arteries (251). With this technique radial artery displacement is measured together with beat-lo-beat blood pressure at the finger with the Finapres device. The technique showed good reproducibility within this muscular artery $(230,255)$.

A problem with any compliance measurement technique is the assessment of blood pressure. Intra-arterial pressure measurements are hitherto considered as a gold standard for measurement of blood pressure. However, the technique is invasive and does not always allow pressure measurements at the site of the compliance measurement. (Semi)automated non-invasive pressure recording techniques are based on plethysmographic, auscultatory or oscillometric recordings $(32,184,189,207)$. Ideally, arterial wall distension measurements should be related to local blood pressure recordings obtained simultaneously, and at the same site. However, in practice this usually is not the case: a pressure recording as close as possible to the location of interest is chosen. For example, continuous non-invasive pressure recording at the finger tip with a Finapres device provides an accurate estimate of mean arteriall pressure, but an overestimation of radial pulse pressure $(55,96,186)$, since even over this short distance pulse pressure may change considerably due to pulse wave reflections.

It is generally accepted that in large arteries mean arterial pressure is quite constant, while pulse pressure may differ $(112,208)$. It is known that pulse wave reflections may occur in the carotid artery, while they are uncommon at the brachial site. When carotid pulse wave reflections are absent, there is a good correlation between pressure in the brachial and carotid artery (198). Then the differences between carotid and brachial pressure seem to be systematic. Until now, there is no accurate method to measure blood pressure non-invasely at the carotid and femoral arteries. Applanation tonometry (112) is a non-invasive technique that has been developed to measure pressure at the site of wall distension measurement. In the hand of well trained observers this technique has shown to be acceptable for recording of relative changes in 
pressure of superficial large arteries (111,122). A good correlation has been shown between brachial artery

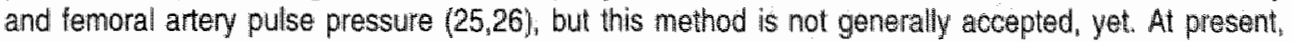
attempts are made to measure local pulse pressure and diameter simultaneously with ultrasound techniques, but these methods still have to be evaluated $(27,91,248)$.

\subsection{Vessel wall properties in various conditions}

1.3.3 Age-Arterial degeneration occurs with ageing and this produces a loss of arterial distensibility (elasticity). This may be responsible for an increase in systolic blood pressure. Results fram an in vitro study in 1922 have already demonstrated an increased stiffiness in human aorta and carotid, iliac, femoral arteries with ageing $(18,127)$. However, arteries show a stiffer behaviour in vitro than in vivo (77). In vivo, in general a decrease in compliance with advancing age, measured with different methods and at different sites, has been found $(46,269)$. The vascular system may be considered mature at the adolescent age with respect to distensibility and compliance (160), but the point from which compliance starts to decrease is not very well defined. It appears to be about the third decade of life (201), while autopsy studies show a decrease from the age of $20(173)$. Aortic compliance $(69,168)$, as well as compliance of other elastic $(22,201,204)$ and muscular large arteries decrease with age (169). At the same mean arterial pressure, the common carotid artery seems to be more influenced by age than the femoral artery (25). In addition, the effects of age do not appear to be similar in different populations (13) and may differ between sexes $(14,22,118)$. A decrease in compliance with ageing can not be fully explained by the presence of other diseases. For example, with hypertension $(97,158)$ and cardiomyopathy $(44)$ there is an age-related decrease in compliance, independent of the state of disease.

Most studies show that with advancing age the diameter of the arteries becomes enlarged, likely an adaptation to the decrease in distensibility in order to keep compliance constant. However, this effect of an increased diameter seems to be most pronounced in elastic arteries (carotid, aorta) and more variable at muscular sites (brachial, femoral) $(69,109)$. In addition, it has been shown that proximal arteries are more dilated with age and that distal arteries react more with thickening of the wall (127). The mechanism by which ageing can cause a decrease in distensibility and compliance is not fully clear. The study of the effect of ageing per se on cardiovascular structure and function is hindered by the occurrence of disease processes and lifestyle changes which are inextricably linked to ageing (longitudinal studies). Crosssectional studies on the effects of age are often biased due to natural selection within the population. However, some hypotheses can be formulated.

First, the fatiguing effects of cyclic stress on the elastic fibers may result in degeneration of these fibers with subsequent stretching and remodelling of the wall and dilation and stiffening of the artery $(180,209)$. In addition, the amount of collagen increases with age. The decrease in distensibility with age was proportional to the increase in collagen in the media and intima $(22,209)$. Tethering between elastin and collagen is also increased with age (22). Secondly, with age vascular smooth muscle cells accumulate in the walls of large arteries, which leads to a decrease in distensibility. Thirdly, atherosclerosis could play a role (209). However, in a population without atherosclerosis arterial compliance was also decreased with age, thus changes are not solely the result of atherosclerosis (14). Finally, early and enhanced wave reflection is seen with advancing age $(13,111)$, which could boost pulse pressure and decrease distensibility.

1.3.2 Gender - Although obvious differences between men and women with respect to the prevalence of cardiovascular disease have been demonstrated in epidemiological studies (107), this phenomenon has not been clarified. Men experience an excess morbidily and mortality through middle age as compared to women with regard to coronary heart disease. For cerebrovascular events adult men have also a higher 
risk compared to age-matched women (19). In large arteries, arterial diameter of elastic and muscular arteries were found smaller in women $(35,236)$. This is not a surprising finding, since the calibre of large vessels is influenced by body size (166). In several studies women showed a significant higher arterial distensibility of large arteries, when compared to men $(14,22,118,227)$. However, a decreased distensibility in women, irrespective of age, thas also been found (161). The mechanism by which gender differences lead to differences in vessel wall properties of large arteries is not clear, but sew hormones could play a role. Howewer, evidence for a clear relationship between female hormones and cardiovascular disease is lacking (39), because of many other confounding variables. The relation between vessel wall properties and gender seems to be rather complex.

3.3 Race and environmental factors - Levels of arterial blood pressure vary between different races and also the risk of complications of cardiovascullar disease is not uniformly distributed among different races (99). With regard to large arteries rural and urban communities in China differed in aortic pulse wave velocily $(14,16)$. In addition, accidental populations differ from oriental populations in aorta medial thickness at all ages. Chinese subjects showed a consistently lower medial thickness throughout the aortic trunk (14). Unfortunately, no histological examinations were performed with regard to the elastic and collagen components of the aortic wall.

3.4 Physical activity - Acute effects of dynamic exercise have shown an increase in arterial compliance in hypertensives (61). In normotensives and mildly hypertensive patients a decrease in aortic compliance wilth acute dynamic exercise has been reported $(171,178)$. Aortic distensibility was higher in athletes compared to matched controls (168). In trained cyclists compliance of the muscular arteries was larger compared to sedentary subjects, while the elastic arteries seemed relatively unaffected (115). This suggests a more generalised adaptation of muscular large arteries to regular exercise, although the reduction in blood pressure usually seen with training, may also play a role. Since arterial diameter of the exercising limb was. increased in the trained group, it was supposed that the supplying artery may have undergone structural adaptation. In hammer-throwers arterial compliance of the exercising extremity was also increased compared to the non-exercising site (70). In the non-exercising limb compliance was mainly improved by an increased distensibility (115).

Since most studies were cross-sectional studies the effect of training per se could only be suspected. In a short-term study a 4-week exercise training programme improved arterial compliance (40). After a subsequent 8 -week sedentary period compliance had returned to pretraining values. Since blood pressure also altered during the study, the effect could have been pressure related ( 40$)$. On the other hand, in a recent study 6 weeks of training reduced heart rate and improved cardiac function, but did not significantly affect blood pressure or vessel wall properties of elastic and muscular large arteries (262).

The mechanism behind the effects of exercise on the arterial system are not completely clear. Due to exercise various central and peripheral cardiovascular adlaptations occur (30). Functional and structural changes, directed towards a better perfusion of the exercising tissues, occur in small blood vessels (226). There may be a direct or indirect elfect of training on the arterial system. Increased distensibility might be due to a reduction in smooth muscle tone, associated with an exercise-related decrease in the production of angiotensin and/or a reduction in sympathetic tone. In addition, an increased production of vasodilator metabolites has been mentioned $(98,241,244)$. A reduction in blood pressure on itself may be of importance, too. Finally, a flow-dependent increased production of endothelial relaxing factors must be considered (195).

Obesity - In the Framingham study a relation between obesity and cardiovascular disease has been described (103). With respect to large arteries it was found that for the same blood pressure brachial artery diameter in obese subjects was not different from that in controls. Obese patients seem to have a more 
hyperkinetic circulation with a high blood flow and a locally diminished resistance with relative vasodilation (197). In that case, aortic distensibility did not differ between obese and non-obese subjects (170). However; Toto-Moukouo found a decreased distensibility in obese patients when compared to the non-obese. Body weight reduction led to an improvement in arterial wall properties (254). A recent study of Spek et al showed that in obese subjects distensibility, due to a larger diameter, was decreased in inuscular large aiteries, but not in elastic arteries (245). It is thypothesised that arterial tone might be decreased in obese subjects (245). However, sympathetic activity was not different between obese and non-obese subjects

(67). Data on structural changes in obese subjects are not known. Anyhow, increased arterial stiffness in obese patients may place them at a higher cardiovascular risk.

1.3.6 Salt intake - Epidemiological and interventional observations suggest a relation between dietary salt intake and blood pressure (150). Intravenous administration of isotonic saline increased systolic pressure and decreased forearm compliance in elderly subjects (146). Subjects with a low salt-intake showed a larger arterial diameter and a better arterial distensibility than those with a high salt-intake $(15,139,214)$. After 6 months of salt- restriction, distensibility improved, differences being most pronounced in the older age groups (15). In borderline hypertensive subjects it has been shown that for the same blood pressure and arterial diameter, vessel wall properties of the elastic and muscular large arteries were reduced in saltsensitive subjects when compared to salt-resistant persons (56). Different mechanisms have been proposed to explain the relation between arterial compliance and salt, such as an interaction with the renin-angiotensin system and the sympathetic nervous system (139), In addition, altered salt transport across the cell membrane and changes in the amount of cellular calcium might play a role (64).

\subsection{Vessel wall properties and disease}

Alteration in mechanical behaviour of the arterial wall has been demonstrated in several diseases, even at early stages of the disease. Although these changes do nol yield direct information about the composition of the arterial wall, early alterations in arterial elasticity may have consequences for therapy and predict the course of a disease or the development of complications.

1.4. Essential hypertension-Essential hypertension is a multifactorial disease. It has been hypothesised that both a genetic predisposition and environmental factors may result in the development of hypertension $(140,264)$. In the industrialised countries hypertension is an important risk factor of cardiovascular morbidity and mortality (99). The haemodynamic characteristics of hypertension have usually been attributed to an increased mean arterial pressure with an increase in total peripheral resistance (217). The latter may be due to rarefaction of arterioles and capillaries, increased wall thickness of arteries and arterioles, and decreased diameter of arterioles and small arteries $(62,82,130)$. Un addition to these changes in total peripheral resistance, the pulsatile component of blood pressure has received more attention in the last few years.

Large arteries do play an important role in the pathophysiolagy of hypertensive vascular disease. The conduit function is maintained till very advanced stages of the disease, but the buffering function (arterial compliance), which is related to elastic properties (arterial distensibility) and storage of blood flow (arterial volume), is altered even in the early phase of the disease.

Using a non-invasiwe technique, arterial wall properties were not found different between normotensives and hypertensives at identical distending pressures (79). suggesting that the stiffer arteries, associated with hypertension, are due to an elevated distending pressure. However, in this study changes in arterial volume were not considered. Recent data have also suggested that the stiffened arteries associated with 
hypertension are due to an elevated distending pressure rather than to intrinsic changes (123,125). In generai, arterial compliance has been shown to be reduced in essential hypertension.

Central aortic compliance $(97,143,151,165)$, as well as compliance of peripheral elastic $(33,215)$ and muscular $(58,135,154,224)$ large arteries have been shown to be decreased. On the one hand under isobaric conditions radial artery compliance in hypertensive patients was increased (125). On the other hand, a recent study could not demonstrate a difference for vessel wall properties of the muscular radial artery between hypertensive and normotensive subjects (84). From these studies it is concluded that arterial compliance is not decreased in hypertensive patients for a given blood pressure level. The difference between proximal large arteries and distal medium-sized arteries might be related to structural vascular changes observed with long-standing hypertension, but this is difficult to analyse (125).

Thus, although low arterial compliance of proximal large arteries seems to be a weil accepted finding in hypertension, the possibility that a decreased compliance could be the effect as well as the cause of the disease remains a matter of debate (232). In addition, other lactors than blood pressure also influence arterial compliance. Apart from ageing, additional intrinsic alterations in vessell wall properties, (adlaptive) functional or structural changes or primary abnormalities of the vessel wall must be considered. Functional changes such as an increased sympathetic tone, activation of the renin-angiotensin system, an altered prostaglandin system, and altered endothelial function all have been associated with a decreased compliance as seen in essential hypertension $(217,249)$. Structural changes such as an increase in the extracellular matrix, arterial wall thickness and smooth muscle mass increase - in which the vascular endothelium is involved - may also be important $(217,249)$. Arterial diameter increases in hypertension (97,224), possibly to compensate for a diminished distensibility and to maintain arterial compliance and blood flow within normal ranges.

In any case, the hypertension-related decrease in arterial compliance increases pulse pressure and systolic pressure, while it decreases diastolic pressure (212). Consequently, the risk for cerebrovascular complications increases. Cardiac perfusion will be negatively influenced and the development of cardiac hypertrophy may be enhanced $(185,225)$. Baroreceptor function may be altered and the development of age-related and atherosclerotic vascular changes may be facilitated $(35,65,198)$.

4.2 Borderline hypertension-According to the detinition of the WHO, borderline hypertension is defined as systolic/diastolic blood pressure between $140 / 90$ and $160 / 95 \mathrm{~mm} \mathrm{Hg}$ (270). Cardiovascular morbidity and mortality in borderline subjects exceeds the rates in normotensive subjects (102). Epidemiological data have shown that despite minimal blood pressure elevation, borderline hypertensive patients exhibit early changes in heart and blood vessels (101). It is assumed that there is a transition from a high cardiac output to a high vascular resistance in a later phase of the disease. The transition occurs through changes in structure and responisiveness of the cardiovascular system (100).

Independenlly of age and blood pressure, compliance of elastic and muscular large arteries has been found reduced in borderline hypertension $(157,233)$. This could result in faster ageing of large arteries in borderline hypertension (156). In contrast lo established hypertension, arterial diameter was not altered $(157,233)$. However, when borderline hypertensives were subdivided into a group with high and normal cardiac output, those with a high cardiac output showed a vasodilation of the brachial artery $(190,233)$. This might suggest that a change in diameter may be present, depending on the phase of borderline hypertension.

In prehypertensive patients, who have a parenteral history of hypertension been found to be decreased ( 260$)$.

3 Systolic hypertension - Systolic hypertension may exist as combined systolo-diastolic hypertension, but occurs also as isolated systolic hypertension. Isolated systolic hypertension (ISH) is defined as high systolic blood pressure ( $\geq 160 \mathrm{~mm} \mathrm{Hg}$ ), while diastolic blood pressure does not exceed $90 \mathrm{~mm} \mathrm{Hg}(104)$. It has been reported that more than $10 \%$ of persons in the US older than 65 years suffers from ISH (228). 
Isolated systolic hypertension forms an impontant and independent risk factor of cardiovascular morbidity and mortality. These patients are more prone to development of ventricular hypertrophy and stroke $(47,108,206)$.

In young patients ( $<35$ years) with isolated systolic hypertension arterial compliance remained within the normal range (240). A more rapid velocity of wentricular ejection during the first pait of syslole and an increased sympathetic tone are considered responsible for this phenomenon in young subjects. In older subjects, ISH appears to be largely the result of a greatly reduced arterial compliance along with a smaller but significant increase in peripheral resistance $(28,47,174,240)$. In addition, in these patients enhanced early wave rellections play a role. The stiffness of the arteries is accentuated because of the combined effect of age and elevaled blood pressure. Structural changes may be assumed because advancing age is associated with a loss of elastic fiber and an increase in collagen and calcium deposition in the arterial wall. Functional changes may consist of an increased responsiveness of arterial smooth muscles to adrenergic stimulation as a result of a decline in $\beta$-receptors with age (209).

1.4.4 Atherosclerosis - Atherosclerosis is a multifactorial disease. The presence of risk factors such as hypentension, hypercholesterolaemia, cigarette smoking and glucose intolerance may induce atherosclerotic changes (65). Atherosclerosis is responsible for a large part of cardiovascular morbidity and mortality. Chronic minimal endothelial injury plays a role in the onset of atherosclerosis $(65,66)$.

Atherosclerosis often has been associated with a decreased arterial compliance. Patients with coronary atherosclerotic disease showed an increased arterial stiffiness of the aorta $(87,168,246)$, while patients with carotid atherosclerotic disease also showed a decreased local distensibility $(87,162)$. Patients with familial hypercholesterolaemia even showed an increased aortic compliance in young subjects (129), but also in older individuals the aorta was found more distensible than in control subjects $(4 B)$. Since atherosclerosis may be characterised by atherosis in an early phase, followed by sclerosis as the disease progresses (116), these findings of an increased compliance might reflect an early stage of the disease. In turn, this would be compatible with experimental data, also showing an increased aortic compliance during the early phase of atherosclerosis and a decrease in compliance as atheromatosis progressed (172). Arterial diameter in atherosclerosis often remains unchanged. Probably atherosclerotic arteries undergo remodelling, which preserves the vascular lumen until the lesion becomes moderately advanced (86).

It has been hypothesised thal arterial stiffening may occur as a consequence of accumulation of collagen: loss of elastin, increased smooth muscle tone - through reduced endothelium-derived relaxing factor release - and increased sodium load (116).

1.4.5 Diabetes mellitus - Cardiovascular disease is an important complication in both insulin-dependent and non-insullin dependent diabetes mellitus $(106,196)$. Arterial diabetic disease is assumed to affect predominantly distal large arteries (205), but also proximal arteries may be involved (164). In general " distensibility of the femoral artery and aorta have been studied and found decreased in diabetic subjects $(128,144,253,256,258,259,265)$. However, in these studies age, duration of the disease, and the existence of complications may also have influenced arterial compliance (128). In addition, the pulse wave velocity techniques used in these studies do not necessarily give a correct estimate of arterial wall elasticity. because, depending on the technique, reflected pressure waves may also play a role. On the other hand, a recent studie in non-insulin dependent diabetes mellitus could not reveal differences in large artery compliance when compared to a matched control group. In addition, no positive correlation could be demonstrated between duration of disease or indices of glycemic control and arterial compliance (153).

The preferential increase in systolic blood pressure in diabetic subjects could suggest a premature ageing process of the arterial system with subsequent vascular rigidity (252). However, hemostatic abnormalities $(68,81)$, chronic hyperinsulinemia $(60,247)$ and long-standing hyperglycemia $(37,114)$ have also been mentioned as possible mechanisms to explain the increased arterial stiffness. 
1.4.6 Other diseases - in congestive heart falure aortic compliance and brachial artery compliance have been tound to be decreased $(5,54,119,187)$. However, others could not demonstrate a decrease in compliance $(17,120)$. The divergent data may reflect differences in other determinants of arterial wall properties, such as age, which was not examined in these studies. In addition, in some studies differences in hemodynamic parameters (i.e blood pressure) could have played a role.

Patients with end-stage renal failure showed a decreased distensibility of elastic and muscular large arteries, while arterial diameter was increased $(20,145)$. In these patients - with the same mean arterial pressure - pulse pressure and early wave reflections were increased compared to controls (145). This decrease in distensibility was related to other factors than blood pressure, age and metabolic disturbances $(146,152)$. Possible changes in sympathetic tone or the activity of the renin-angiotensin system have not been investigated in these studies. Dialysis-induced hypercalcaemia might be responsible for the decreased distensibility but the precise mechanisms are not clear yet (152).

Aortic distensibility has been found to be decreased in connective tissue diseases such as Marfan's syndrome (88). The amount of wave reflections was higher, while aortic root diameter was increased. Alterations in the organisation of the extracellular matrix with a fragmentation of elastic fibers in the aortic media are probably responsible for these changes (268).

In patients with pulmonary hypertension pulmonary artery distensibility has been found reduced (31). Pulmonary hypertension changes the structure of the pulmonary arteries, which may be associated with the decreased distensibility (83). Patients with arteriosclerosis obliterans of the lower limb show a greatly increased pulse pressure and a decrease un arterial compliance (213). This may be explained by structural allerations of the arterial wall, altered wave reflections and functional changes in vasomotor tone.

\subsection{Effects of pharmacological interventions on vessel wall properties}

Until recently, pharmacological approaches to the reduction of cardiac afterload in cardiovascular disease were confined to the effects of reduction in total peripheral resistance by reducing smooth muscle tone. However, this has not always led to a diminuition of target organ effects in cardiovascular disease $(51,191)$. Another possibility to reduce cardiac afterlaad is to improve vessel wall properties of large arteries which results in an increased buffering capacity of large arteries and a reduction in wave reflections with a decreased end-systolic pressure $(121,122)$.

It has been shown that well controlled hypertensives after 3 months of therapy had not only a lower blood pressure, but also a lower stiffness of the carotid artery when compared to untreated patients. However, several but not all classes of antihypertensive agents may improve arterial compliance (Table 1.5). In general, from the currently known first-line antihypertensive drugs in humans calciumantagonists and ACE inthibitors increased large artery compliance. Although there are some exceptions (eg, metoprolol), selective $\beta_{1}$-blockers and $\beta$-blockers with ancillary vasodilating properties and nitrates improved arterial wall properties. From the data available, it appeared that diuretics, vasodilators of the hydralazine group, the centrally acting $\alpha_{2}$-agonist clonidine and non-selective $\beta$-blockers in general did not affect arterial wall properties favorably. The effect of pure $\alpha$-blockers is not clearly investigated. Ketanserin $(\alpha$-blocker + serotonin-2 antagonist) improved arterial compliance, while urapidil $(\alpha$-blocker + central serotonin-1a agonist) did not change brachiall artery diameter and compliance. Labetolol ( $\alpha$ - and $\beta$-blocker) increased arterial compliance acutely. Pinacidi, a potassium channel opener, was able to decrease systemic vascular resistance and increased large artery compliance in healthy volunteers.

In addition to improvement of arterial compliance, a reduction in early wave reflections may be achieved with some antihypertensive agents $(110,113,122,267)$. Wave reflection may be modified through antihypertensive therapy by an influence on the intensity of the reflected wave and/or an influence on the timing of reflected waves. The first takes place at the arteriolar level through a diminished peripheral 


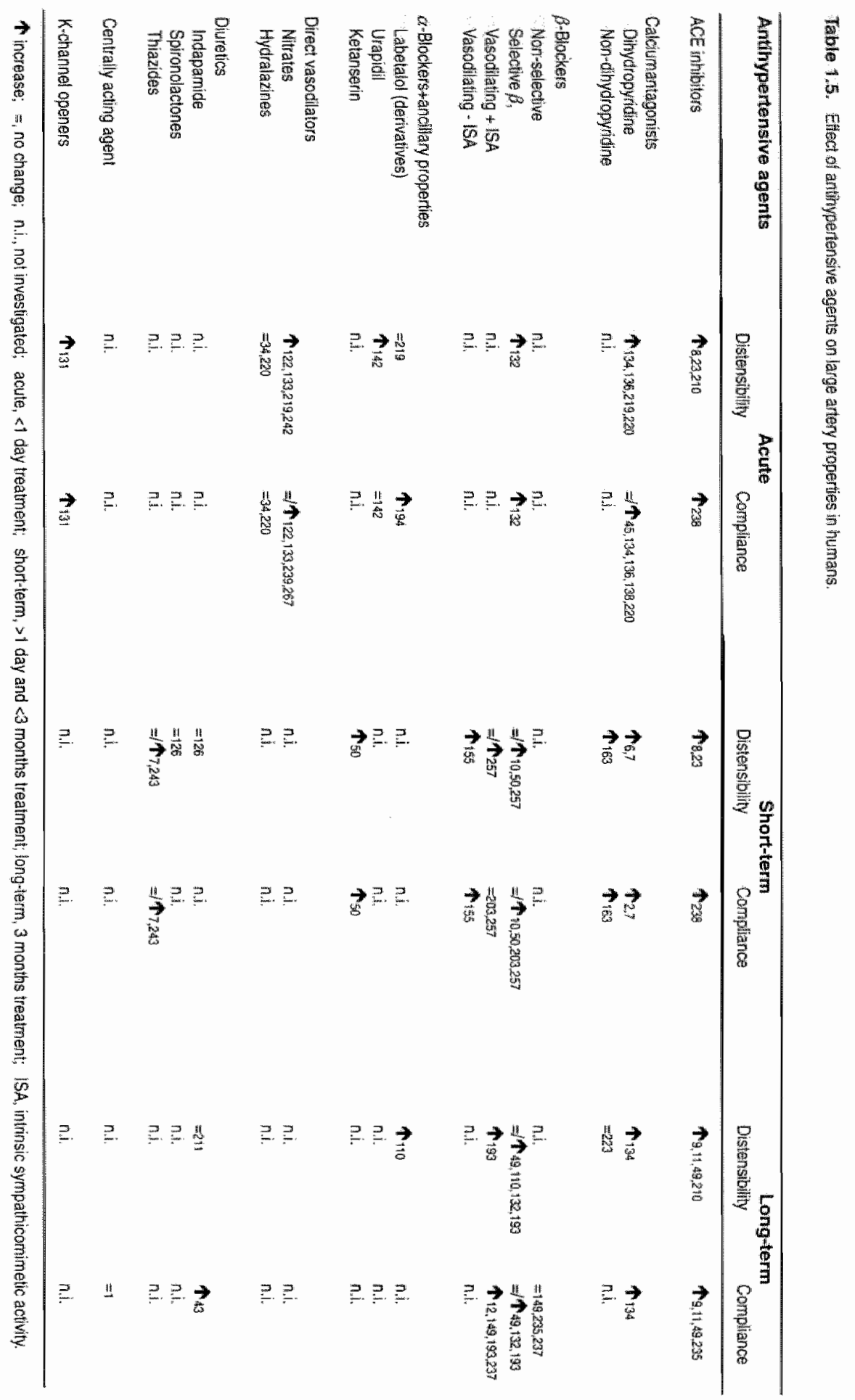


resistance and another pre-arteriolar calibre. The lafter occurs by an alteration in vessel wall properties $(13,121)$.

Thus, the effect of different anthypentensive drugs on large artery compliance is not uniform. A large part of the studies are acute or schort-tem studies up to 3 months of therapy. In these studies, changes in arterial compliance are likely to be due to functional rather than to structural changes.

Changes in arterial diameter and vessel wall properties are not only due to the fall in blood pressure, suggesting an increase in compliance through a passive reduction in pressure with a fransfer from the collagen to the elastin fibers. Additional factors such as drug-induced effects on smooth muscle, induction of counterregulatory mechanisms (sympathetic tone, renin-angiotensin system) and non-specific mechanisms related to the myogenic respons or flow-dependent endothelial vasodilation may also play a role (221). in general, there are two possible haemodynamic patterns following antihypertensiwe therapy: a decreased vascular resistance and an unchanged (even a tendency to a reduced) arterial compliance (thydralazine-like agents, propranolol) or a decreased vascular resistance and an increased arterial compliance (nitrates, ACE inhibitors, calcium antagonists) (221).

Chronic treatment with antihypertensive drugs $(57,188)$ may be able to induce structural changes in the arterial wall, but here also not every agent is equally beneficial. On the other hand, normalisation of arterial structure with chronic treatment may not always be beneficial if it is not accompanied by a decrease in blood pressure (24). Short and long-term drug-induced moditications in the buffering function of large arteries parallel the effects of drugs on cardiac mass (225). A few studies have shown that chronic antihypertensive treatment may result in adequate blood pressure lowering and a decrease in cardiac hypertrophy, whereas vascular structure seemed not affected $(11,72,76,141)$. However, in these studies no biopsies were taken. Histologic studies demonstrated that normalisation of blood pressure after treatment with various drugs for more than 3 months (85) did only partially reverse structural abnormalities in hypertensive patients. On the other hand, the results of a recent study af the effect of the ACE inhibitor perindopril versus the diuretic hydrochlorothiazide suggested that in hypertensive patients arterial wall hypertrophy of medium size arteries may regress under treatment, whereas this is more difficult to show at the site of the arteriales (71). In addition, chronic treatment ( 9 months) with perindopril showed a normalisation of the media/lumen ratio of subcutaneous resistance arteries in hypertensive patients (231).

\section{Outline of this thesis}

From the introductory part it can be concluded that wessel wall properties of large arteries - arterial compliance and distensibility - play an important role in cardiovascular disease. With a decrease in compliance and distensibility the risk of stroke and cardiac hypertrophy and failure are enhanced, while the development of atherosclerotic disease may be facilitated. During the last few decades a shift from invasive and in vitro research of vessel wall properties towards a non-invasive and in vivo approach has occurred. Ultrasound techniques to assess vessel wall properties directly seem to be the most promising and accurate methods. The studies as presented in this thesis were intended to obtain more information on vessel wall properties of different large anteries in humans as assessed with a newly developed vessel wall movement detector system based on an echo Doppler tracking principle. The elastic common carotid artery, which is prone to atherosclerosis, was studied. In addition, a muscular artery known for its early atherasclerotic changes (common femoral artery) and a muscular artery where atherosclerosis is uncommon (brachial artery) were investigated.

The methods used in the studies of the present thesis are described in Chapter 2. In vitro experiments have shown that diameter changes of the order of a few microns can be resolved with this device (92).

In Chapter 3 reproducibility measurements of the new technique in man are described in order to assess intraobserver and interobserver variability as well as intra and intersession variability. Diurnal variation in blood pressure and heart rate are well-known phenomema. Whether vessel wall properties also show a 
diurnal variation has been investigated in healthy volunteers (Chapler 4). Changes in arterial parameters were compared to changes in blood pressure and cardiac function. In addition, a possible relation with fluctuations in plasma levels of noradrenalin, atrial natriuretic factor, renin and prorenin is studied.

From the multiple risk factors for cardiovascular disease, smoking and the presence of hypertension and diabetes mellitus are very important. First, vessel wall properties are compared between habitual smokers and non-smokers (Chapter 5). Then the short-term effects of smoking on haemodynamic function and vessel wall properties are investigated.

Since insulin-dependent diabetes mellitus is associated with a high cardiovascular disease and previous data are not consistent, young uncomplicated insulin-dependent diabetic subjects are compared to healthy volunteers (Chapter 6). In the last part of this thesis the effect of therapy on vessel wall properties is evaluated. It is a well-known finding that under various pathological states vessel wall properties are diminished. Hypertension is a disease in which vessell wall properties of large arteries are found to be diminished. Studies with antihypertensive drugs have shown that not all drugs favourably influence vessel wall properties. However, most studies with antihypertensive agents are acute studies. In Chapter 7 the effects of a 6 month treatment with an ACE inhibitor versus a diuretic agent are investigated in order to get more data with regard to long-term effects on functional and structural properties of large arteries. Hypercholesterolaemia is also \& risk factor for atherosclerosis and may induce endothelial dysfunction. Physical factors might induce intimal lesions and subsequently development of an atherosclerotic plaque prone to plaque rupture. With progressive atherosclerotic disease arterial stiffness will increase and also the risk for plaque rupture. Therefore, the effect of an eight-week treatment with a cholesterol lowering therapy on vessel wall properties of large arteries, blood pressulie and cardiac lunction has been studied (Chapter 8). It is the aim of this studly to assess only functional changes. Structural changes are probably not evaluated since the study is of relatively short duration. Finally, the effects of a potassium channel opener are compared with those of a nitrate in healthy volunteers (Chapter 91. Acute and subacute effects on vessel wall properties and other haemodynamic parameters are assessed.

Finally, in Chapter 10 the results of the studies described in the previous chapters are discussed and recommendations for future research are given.

\section{References}

1. Achimastos $A$, Girerd $X$, Simon $A C$, Pithois-Merti $I$, Levenson $J$. The efficen of a transderimal formulation of clonidine in mitd to moderate hypertension and its effects on the arterial and venous vasculature of the forearm. Eur J Cln Pharmacol $1987 ; 33: 111-14$.

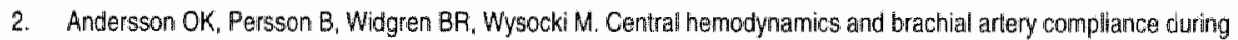
therapy with isradipine, a new calcium antagonist. $\downarrow$ Cardiovasc Pharnacol 1990;15 (Suppl. 1) :87.89.

3. Arcaro $G$, Laurent $S$, Jondeau $G$, Hoeks AP, Salar ME. Stiffness of the common carolid artery in treated hypertensive patients. J Hypertens 1991;9:947-54.

4. Andt JO, Klauske d, Mersch F. The diameter of the intact carotid artery in man and its change with pulse pressure. Pilugers Airch 1968:301:230-40.

5. Arnolld JM, Marchion GE, Imrie JR, Burton GL, Pflugfelder PW, Kostuk WJ. Large artery function in patients with chronic heart lailure. Circulation 1991;84:2418-25.

6. Asmar A, Benetos A, Ghodsi N, Meillhac B, Sallar M. Hmodynamique artrielle rgionale et circulation carotidienne dans l'hypertension artrielle essentielle. Application la nitrendipine chez le sujet ag de plus de 40 ans. Presse Md 1993.22 :11770-75. 
7. Asmar RG, Benetos $A_{8}$ Chacuche-Teyara $K$, Raveau-Landon CM, Safar WE. Comparison of effects of felodipine versus hydrochlorotinizide on arterial diameter and puise wave velocity in essential hypertension. An J Cardial $1993: 72$ $794-98$.

8. Asmar RG, tannascoli F, Benetos $A$, Safar ME. Dose optimization study of arterial changes associated with angiotensin converting enzyme inhibition in hypentension. J Hypertens 1992; 10 (Suppi. 5) :513.19.

9. Asmar RG, Joumo HJ, Lacolley PJ, Santoni JP. Billaud E, Levy BI, Safar ME. Treatment for one year with perindopril: effect on cardiac mass and arterial compliance in essential hypertension. 4 Hypertens 1988;6 (Suppl. 3) :S33-39.

10. Asmar RG, Kerihuel $\mathrm{JC}$, Girerd XJ. Safar ME. Effect of bisoprolol on blood pressure and arterial hemodynamics in systemic hypertension. Am J Cardiol 1991;68:61-64:

11. Asmar PG, Pannier B, Santoni JP, Laurent S, London GM, Lewy BI, Saiar ME. Reversion of cardiac hypertrophy and reduced arterial compliance after converting enzyme inhibition in essential hypertension. Circulation 1988;78:94:-50.

12. Afterhög JH, Duner $H$, Pernow B. Hemodynamic effect of fong-term treatment with pindolol in essential hypentersion with special reference to the resistance and capacitance vessels of the forearm. Acta Med Scand 1977;202:517,21.

13. Avolio A, Ageing and wave reflection. 4 Hypertens 1992:10 (suppl 6): $\mathrm{S} 83-86$.

14. Avolio $\mathrm{AP}$, Chen $\mathrm{SG}_{3}$, Wang $\mathrm{AP}$, Zhang $\mathrm{CL}, \mathrm{Li} M \mathrm{~F}_{v}$ O'Rourke $M \mathrm{~F}$. Effects of aging on changing arterial compliance and left wentricular load in a northern chinese urban community. Circulation 1983;68:50-58.

15. Avolio AP, Clyde KM, Beard TC, Cooke HM, Ho KKL, O'Pourke MF. Improved arterial distensibility in nomolensive subjects on a low salt diet. Arteriascierosis 1986;6:166-69.

16. Avolio $A P_{1}$, Deng FQ, Li WQ Luo YF, Huang $Z \mathrm{D}$, Xing $L F$, O'Pourke MF. Effects of aging on arterial distensibility in populations with high and low prevalence of hypertension: a comparison between urban and rural communities in China. Circulation 1985;71:202-10.

17. Babalis $\mathrm{D}_{11}$ Levy Bl, Azancot I, Masquet C, Beaufils P. Ventricular lunction and arterial compliance in patients with congeslive cardiomyopathy. Int J Carciol 1984,5:361-64.

18. Bader H. Dependence of wall stress in the human thoracic aorta on age and pressure. Circ Res 1967;20:354-61.

19. Bamford J, Sandercock $F$, Dennis M, Warlow $C_{\text {, }}$ Jones $L$. McPherson $K$, Vessey M, Fowler $G$, Molyneux $A$, Hughes $T$, Burn J. Wade D. A prospeclive study of acute cerebrovascular disease in community: the Oxtordshire Community Stroke Project 1981-86. I Methodology, demography and incident cases of first-ever stroke. I Neurol Neurosurg Psychiatry 1988:51;1373-80.

20. Barenbrock M, Spieker C, Laske V, Baungart P, Hoeks APG, Zidek W, Rahn KH. Effect of long-term hemodialysis on arterial compliance in end-slage renal failure. Nephron 1993;65:249-53.

21. Barth JD, Blankenhorm DH, Wickham $E_{4}$ Lai JV, Chin HP. Seizer RH. Quantitalive ultrasound pulsation study in human carotid artery disease. Arteriosclerosis 1988:8:778-81.

22. Buskett لل, Lewis RR, Beasly MG, Gosling RG. Changes in carotid artery compliance with age. Age Ageing 1990:19 $241 \cdot 46$.

23. Benelos $A$, Asmar $A$, Vasmant $D$, Thiry $P_{\text {in }}$ Safar M. Long lasting arterial effecls of the ACE inhibitor ramiprit. J Hum Hypertens 1991:5:363-68.

24. Bentotos $A_{n}$ Bouaziz H, Alballadejo P, Lewy BI, Safar ME. Physiclogical and pharmacological changes in the carotid artery pressure-yolume curve in situ in rats. J Hypertens 1992; 10 (Suppl. 6) :S127-31.

25. Benetos $A$, Laurent S, Hooks AP, Boutouyrie PH, Safar ME. Arerial alterations with aging and high blood pressure. A noninwasive study of carolid and femroral arteries. Arterioscler Thromb 1993:13:90-97.

26. Benetos $A, T$ soucaris-Kupler $D$, Favereau $X$, Corcos $T$, Satar M. Carolid artery tonometry: an accurate non-invasive method far central aortic pulise pressure evaluation. J Hypertens 1991:9 (suppl.6):5144-45.

27. Benthin M, Dah! $P$, Ruzicka $R$, Lindström $K$. Calculation of pulse-wave velocity using cross-correlation effects of rellexes in the arterial tree. Uitrasound Med Bial 1991;17:461-69.

28. Berger DS, Li JK. Concurrent compliance reduction and increased peripheral resistance in the manifestation af isolated sysiolic hypertension. Am J Cardiol 1990;65:67-7\%.

29. Blankenhorn DH, Chin HP, Conover D.J, Nessim SA. Uttrasound observation on pulsalion in human carotid artery lesions. Uitrasound Med Biol 198:14:583-87.

30. Blomqvist CG, Saltin B. Cardiovescular adaptations to physical training. Annu Rev Physiol 1983,45:169-89 
31. Bogren HG, Mohiaddin RH, KIpstein PK. Fimin DN, Underwood RS, Rees SF, Longmore DB. The function of the aorta in ischemic heart disease: a magnetic resonance and angiographic showy of aortic compliance and biood thow pattems. Am Heart J $1989 ; 118: 234447$.

32. Borow KM, Newburger JW. Noninwasive estimation of central aortic pressure using the oscillometric method tor analyzing systemic arten pulsatle blood flow: comparative study of indirect systolic, diastolic, and mean brachial antery pressure with simultaneous direct ascending aortic pressure measurements. Am Heart J 1982;103:979.86.

33. Bouthier J Benetos A, Simon A, Levenson J, Satar M. Pulsed Doppler evaluation of diameter, blood velocity and blood flow of common carotid artery in sustained essential hypertension. J Cardiovasc Pharmacol 1985;7 (Suppl. 21) :\$99-\$104.

34. Bouthier $J A_{*}$, Satar ME, Curien ND, London GM, Levenson JA, Simon AC. Effect of cadralazine on brachial artery hemodynamics and foream venous tone in essential hypertension. Cin Phamacol Ther 1986;39:82-88.

35. Boutouyrie P, Launent S, Benetos A, Girerd Xل, Hoeks APG, Safar ME. Opposing effects of ageing on distal and proximal large arteries in hypertensives. J Hypertens 1992;10 (Suppl. 6) :S87-91.

36. Bramwell JC, Hill AV. The velocity of the pulse wave in man. Proc R Soc Lond B 1922;93:298-306.

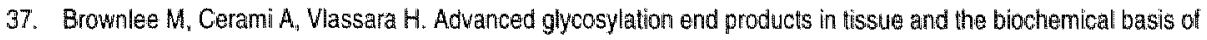
diabetic complications. N Engl J Med 1988;318:1315-21.

38. Buntin $\mathrm{CM}$, Siver FH. Noninvasive assessment of mechanical propenties of peripheral arteries. Ann Biomed Eng $1990 ; 18: 549-66$

39. Bush TL. The epidemiology of cardiovascular disease in postmenopausal women. Ann N Y Acad Sci 1990;592:263-71.

40. Canteron JD, Dart AM. Exercise training increases total systemic arterial compliance in humans. Am J Physiol $1994,266 \cdot 1693 \cdot 701$.

41. Caputo L, Tedigui A, Poitevin P, Levy B. In witto assessment of diameter-pressure relationship in carotid arteries trom normotensive and spontaneously hypertensive rals. J Hypertens 1992;10 (Suppl. 6) :527-30.

42. Caro CG, Lever MJ, Parker KH. Fish PJ. Effect of cigarette smoking on the pattern of arterial blood flow: possiblo insight into mechanisms underlying the development of arteriosclerosis. Lancet $1987 ;$;ll: $11-13$,

43. Carretta R, Fabris B, Bardelu M, Muiesan S, Fischetti F, Vran F, Bianchetti A, Campanacci L. Arterial compliance and baroreceptor sensitivity after chronic treatment with indapamide. J Hum Hypertens 1988;2:171-75.

44. Carroll JD, Shroff S, Wirth P, Halsted M, Rajfer SI. Arterial mechanical properties in dilated cardiomyopathy. J Clin Invest 1991:87:1002-9.

45. Chang $\mathrm{KO}_{3} \mathrm{Hsieh} \mathrm{KS}_{\text {}} \mathrm{KuO}$ TS, Chen HI. Effects of niledipine on systemic hydraulic vascular load in patients with hypertension. Cardiowasc Res 1990;24:719-26.

46. Cown JN, Finketstein SM. Abnomalities of vascullar compliance in hypertension, aging and heart lailure. J Hypertens $1992 ; 10$ (Suppl. 6) :S61-64.

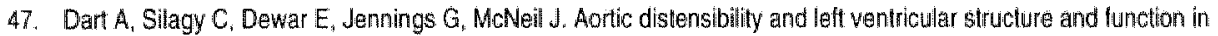
isolated systolic thypertension. Eur Heart J 1993;14:1465; 70.

48. Dart AM, Lacombe F, Yeoh $J K$, Cameron JD, Jennings $G L$, Lauter $E_{n}$ Esmore DS. Aortic dislensibility in patients with isolated hypercholesterolaemia, coronary artery disease, or cardiac tiransplant. Lancel 1991;3361 (l):270-73.

49. De Cesaris $\mathrm{R}$, Ranieri G, Filiti W, Andriani A, Bontantino MV. Forearm arterial distensibility in patients with hypertension: Comparative effects of long-term ACE inhibition and -blocking. Clin Pharmacol Ther 1993;53:360-67:

50. De Luca N, Rosiello G, Crispino M, Wolpe M. Galletti $P$, Buzzetti G, Trimarco B. Eflects of chronic antihypertensiwe treatment with ketanserin versus metoprolol on blood pressure and large arleries" compliance in humans; a cross-over double-blind study. J Clin Pharmacoll 1988;28:332-38.

51. Devereux RB. Toward a more complete understanding of left ventricular afterlioad. Am Coll Cardiol 1991:17:122-24.

52. Devereux RB, Waeber B, Roman M. Conclusions on the measurement of arterial wall thickness: anvatomic, physiologic and methodologlc considerations. J Hypertens 1992;10 (Suppl, 6):S119-21.

53. Dobrin PB, Rovick AA. Intluence of vascular smooth muscle on contractile mechanisms and elasticity of arteries. Am d Physiol 1969;217:1644-51.

54. Domingo E, Gilabert MR, Alio J. Angel J, Soler-Soler J. Effect of drugs on a nonirvasive index of arterial compliance in healthy and heart tallure patients. Cathet Cardiowasc Diagn 199:24:93-98. 


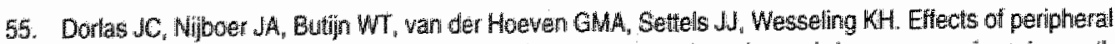
vasoconstrition on the blood pressure in the tinger, measured continuousty by a nes noninvasive method the Finapres). Anesthesiology $1905 ; 62: 342 \cdot 45$.

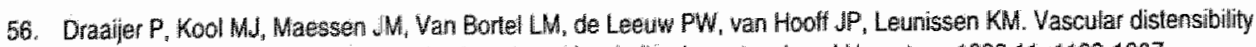
and complance in sialtsensilve and sallitesistant borderline hypertension. J Hypertens 1993:11:1199-1207.

57. Dzau WJ, Giboons GH. Cell biology of vascular hypertrophy in systemic hypertension. Am J Cardio: 1988:62:30G-5G

58. Eishaer H, Christensen T, Pedersen EB. Abnomal structure and increased stiffness of the femoral arterial wall in young palients with sustained hypertension. II Intern Med 1989;226:235-40.

59. Ferguson du, Randali O. Hemodynamic correlates of arterial compliance. Cathet Cardiovasc Diagn 1986; 12:376-80,

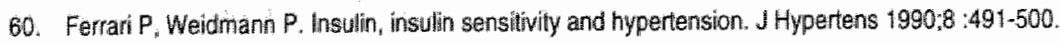

61. Feske $W$, Finkelstein $S M$, Francis $G$, Cohm $\mathrm{N}$. Arterial vascular compliance response to exercise in hypertension. Bioned Scil Instrum 1988;24:161-65.

62. Folkow B. Siructural factors the vascular wall. Consequences of treatment. Hypertension 1983,5 (1HI):III58-62.

63. Frank O. Die Theorie der Pulswellen. Z Biol 1926;25:91-130.

64. Friedman SM. Salt sensitiwity and cell permeability. J Hypertens 1991;9:789-98.

65. Fuster $\mathrm{V}, \mathrm{Badimon} \mathrm{L}$, Badimon $\mathrm{J} J$, Chesebro $\mathrm{JH}$. The pathogenesis of coronary artery disease and the acute coronary syridromes. N Engl J Med 1992;326 :242-50,

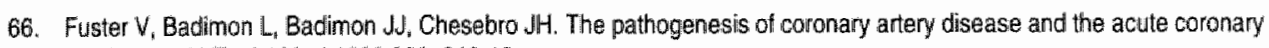
syndranes. N Engl J Med 1992;326:310*18.

67. Galitzky J, Barbe P, Rivire D, Senard JM, Lafontan M, Tran MA, Berlan M. Evaluation al sympathetic nervous system activity and alpha2-adrenergic receptivity in obesie subjects. IUPHAR abstract book $1990: 1494-95$.

68. Ganda OP. Pathogenesis of macrowascular disease in the human diabetic. Diabetes 1980,29:931-42.

69. Gerstenblith G. Frederiksen J, Yin FCP. Fortuin NJ, Lakatta EG, Weisteld ML. Echocardiographic assessment of a normal aging population. Cinculation 1977:56:27:3-78.

70. Giannattasio $\mathrm{C}$, Cattaneo BM, Mangoni AA, Carugo $\mathrm{S}$, Sampieri L, Cuspidi $\mathrm{C}$, Grassi G, Mancia G. Changes in arterial compliance induced by physical training in hammer-throwers. J Hypertens 1992;10 (Suppl. 6):S53-55:

71. Girero X, Giannatassio C, Copie X, Cawiezel B, Mourad J, Chalon S, Laloux B, Safar M, Mancia G, Laurent S. Reduction of radial artery mass after pharmacological treatment in older essential hypertensives. J Hypertens 1994:12 (Suppl. 3) :\$4.

72. Girerd $X$, Laurent $S$, Pannier B, Asmar $\mathrm{B}$, Safar M. Arterial distensibility and left wentricular hypentrophy in patients with sustained essential hypertemsion. Am Heart al $1991 ; 122: 1210-14$.

79. Gilterd $X_{1}$ Mourad JJ, Acar $C_{4}$ Heudes D, Chiche $S_{n}$ Bruneval $P$, Mignol JP, Billaud E, Satar M, Laurent S. Naninvasive measurement of medium-sized artery intima-media thickness in humans: in vitro validation. J Vasc Res 1994;31 $: 114-20$.

74. Giverd X, Mourad JW, Cople X, Moulin $C_{1}$, Acar $C_{11}$ Salar $M$, Laurent $S$. Noninvasive detection of an increased vasciular mass in curtreated hypertensive patients. Am J Hypertens 1994:7 :1076-84.

75. Glagov $S_{i}$ Vito R, Giddens DP, Zarins CK. Micro-architecture and composition of antery walls; relationship to location, diameter and the distribution of mechanical stress. J Hypertens 1992;10 (Suppi. 6) :S101-4.

76. Gohlke P. Stoll M. Lamberty V, Mattfeid T, Mall $G_{n}$ van Even $P$. Martorana $P$, Unger T. Cardiac and vascular effects of chronic angolensin converting enzyme inhibition at subanthypertensive doses. J Hypertens 1992;10 (Suppl. 6) $514 \pi, 44$.

77. Gow BS, Hadfisld CD. The elasticity of camine and human coronary arteries with reference to postmortem changes. Cîric Res 1979:45:588-94.

78. Greenway CV, Laut WW. Blood volume, the venous system, preload, and cardiac output. Can 3 Physiol Pharmaco $1986 ; 64: 383-87$

79. Gribbin B. Pickering TG, Sleight P. Anterial distensibility in normal and hypentensive man. Clin Soi 1979;56:413-17.

10. Guyton AC. Physics of blood, blood flow, and pressure hemodynamics. In: Drebelbis D, ed. Textbook of medical physiology 7 th ed. Philadelphia: W.B. Saunders Company, $1986: 218-229$. 
81. Hallusika PV. Rogers RC, Laadholt CQ, Colwell JA Increased platelet thromboxane symthesis in thabetes mellitus. J Lab Clin Med 1981,97:87-96.

Q2. Harper RN, Moore MA, Marr MC, Watts LE, Hutchins PM. Arteriolar rarefaction in the coninumetiva of human essential hypertensives. Microwasc Res 1978;16:369-72.

83. Harris $P$. Heath D. The effects of hypentension on the structure of the elastic pulmonary arteries in: Harris P, Heath D. eds. The human pumonary circulation 3rd ed. London: Churchill Livingstone, $1986: 273.83$.

84. Hayoz D, Rulschmann B, Perret F, Niederberger M, Tardy Y, Mooser V, Nussberger d, Waeber B; Brunner HF, Conduit artery compliance and distensibility are not necessarily reduced in hypertension. Hypertension 1992,20:1-6.

85. Heagerty AM, Bund SJ, Aakkjaer C. Effects of drug treatment on human resistance arteriole morphology in essential thypertension: dreck evidence for structural remodelling of resistance vessets. Lancet 1988;1:1209-12.

86. Heistad CD, Lopez AG, Baumbach GL. Hemodynamic determinamts of vascular changes in hypertension and atherosclerosis. Hypertension $1991 ; 17$ (III) : $: 117-11111$.

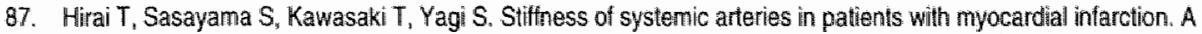
noninwasive method to predict severity of coronary atherosclerosis. Circulation 1989;80:78-86.

88. Hirata K, Triposkiadis F, Sparks E, Bowen ل, Wooley CF, Boudoulas H. The Martan syndrome: abnormal aortic elastic properties. J Am Coll Cardiol 1991;18:57-63.

89. Hoeks APG. Non-invasive study of the lacal mechanical arterial characteristics in humans. In: Salar ME, O'Rourke MF, eds. The arterial system in hypertension 1 st ed. Dordrech/Boston/London: Kuwer Acaclemic Publishar, $1993: 119 \cdot 34$.

90. Hoeks APG, Brands P.J, Reneman RS. Tecturicall aspects of compliance assessment. Arch Mal Coeur Vaiss 1991:84 :77-81

91. Hoeks APG, Brands PJ. Reneman RS. Assessment of the arterial distension waveform using Doppler signal processing. J Hypertems 1992;10 (Suppl.6) :S119.22.

92. Hoeks APG, Brands PJ, Smeets FAM, Reneman RS. Assessment of the distensibility of superficilat arteries. Ultrasound Med Biol 1990;16:121-28.

93. Hoeks APG, Ruissen C., Hick P, Reneman RS. Transcutaneous detection of relative changes in antery diameter. Ultrasound Med Biol 1985;11:51-59,

94. Hofstra $L_{1}$ Willigers JM, Huvers. FC, Schaper NC, Kester ADM, Kitslaar PJEHM, Hoeks APG. Short-1erm variation in the elastic properties of a muscular artery in thumans. Clin Sci 1994;86:567-74.

95. Hokanson DE, Mozersky DJ, Sumner DS, Strandness. DE. A phase-locked echo tracking system for recording anterial diameter changes in viwo. \Appl Physiol 1972;32:728-33.

96. Idema RW, wan den Meiracker AH, Imholz BPM, Man in "t Veld AJ, Settels Jل, Ritsema wan Eck Hل „Schalekamp MADH. Comparison of Finapies non-inwasive beat-10-beal finger blood pressure with intrabrachinartary pressure during and after bicycle ergometry. J Hypertens 1989;7 (Suppl. 6) :\$58-59.

97. Isnard RN, Pannier BM, Laurent S, London GM, Diebold B, Satar ME. Pulsatile diameter and elastic mod ulus of the aortic arch in essential hypertension: a monimvasive study. J Ann Coll Cardiol 1989;13;399-405.

98. Jennings $G$, Nelson $L$, Nestel $P$, Esler $M_{1}$ Komer $P$, Burtor $D$, Bazelmans d. The elfects of changes in physical actiwly on major cardiovascular risk lactors, hemodynamics, sympathetic functian and glucose utilization in man: a controlled study of four lewels of activity. Circulation 1986;73:30-40.

99. 1988 Joint National Committee. The 1988 report of the joint national committee on detection, evaluation, and treatment of high blood pressure. Arch Intern Med 1988" 148:1023-37.

100. Mulus S. Transition from thigh cardiac output to elevated vascular resistance in hypertemsion. Am Heant $\ 1988^{\prime} 116$ 600-606.

101. Julus $S_{1}$ Jamerson K, Mejia A, Krause L. Schork N, Jones $K$. The association of borderline hypertension with larget organ changes and higher coronary risk. JAMA $1990 ; 264: 354-58$.

102. Julius $S_{1}$ Schork MA. Borderline hypertension: a critical review. J Chron Dis 1971,23:723-54.

103. Kannel WB, Brand N, Skinmer JJ, Dawber TF, McNamara PM. The relation of adiposity to blood pressure and development of hypertension: the Framingham study. Ann Intern Med 1967;67:48-59.

104. Kannel WB, Dawber TA, McGee DL. Perspectives on systolic hypertension. The Framingham sludy. Circulation $1980 ; 61-6: 1179-82$ 


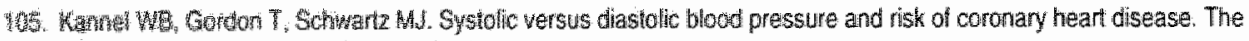

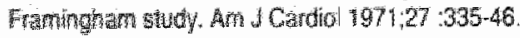

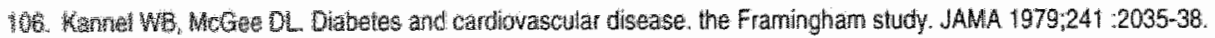

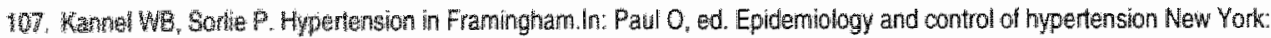
town and Sirathon, $1975-553-92$.

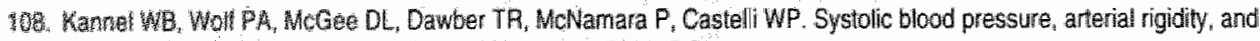

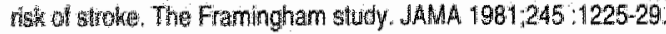

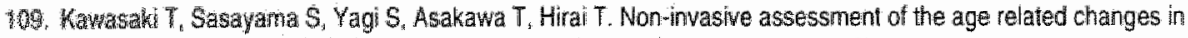
sthess of mator brandhes of the human arteries. Cardiovasc Res 1987,21:678-87.

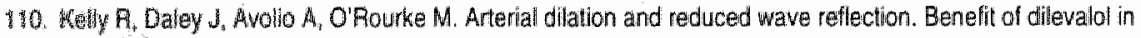
aypertenson. Hyportension 1989;14:14-21.

11. Kelly $\mathrm{A}$, Hayward $\mathrm{C}$, Awolio $A, \mathrm{O}^{\prime}$ Rourke M. Noninvasive detemination of age-related changes in the human arterial pulse. Circulation 1989,80:1652-59.

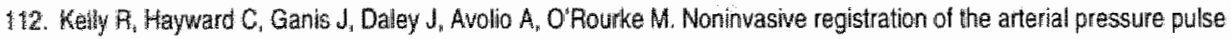
wavelorm using high-fidelity applanation tonometry. J Vase Med Biol 1989; 1:142-49.

13. Kelly PP, Gibbs HH, O'Rourke MF, Daley JE, Mang K, Morgan JJ, Avolio AP. Nitroglycerin has more favourable effects. on left wentricular alterload than apparent from measurement of pressure in a peripheral antery. Eur Heart $\mathrm{d} 1990 ; 11$ $: 130.44$.

13. Kobuchi $Y$, Lee WS, Pratt RE, Glucose directly stimulates the growth of wascular smooth muscle cells in culture. $J$ Hyperterts 1992:10 (Supp). 4):S100.

115. Kool M.JF, Struijker-Boudier HA, Winen JA, Haeks APG, Van Bortel LM. Effects of diumal vaniablity and exercise thaining on properties of large atteries. J Hypertens 1992;10 (Suppl. 6 : :S49-52.

116. Kramsch DM, Blankenhom DH. Regression of atherosclerosis: which components regress and what intuences their reversal. Wen Klin Wochenscht 1992;104:2-9.

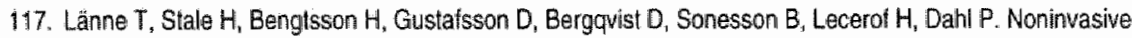
measurement of diameter changes in the distal abdominal aorta in man. Ultrasound Med Biol 1992;18;451-57.

116. Laogun AA, Gosling RG. In vivo arterial compliance in man. Clin Phys Physiol Meas 1982:3:201-12.

119. Laskey WK, Kussmaul WG. Arterial wave reflection in heart fallure. Circulation 1987;75:711-22.

120. Laskey WK, Parker HG, Ferrari VA, Kussmaul WG, Noordergraal A. Estmation of total systemic arterial compliance in humans. J Appl Physiol 1990;69:112-19.

121. Laurent S. Reduction of artarial wall mechanical stress as a goall for antihypertensive treatment. $J$ Cardiovasc Pharmacol 1994:23 (Suppl. 5) : $\$ 3541$.

122. Laurent $S$, Arcaro $G$, Benetos $A$, Latleche $A$, Hoeks $A$, Satar M. Mechanism of nitrate-induced improvement on arterial compliance depends on vascular lerritory. J Cardiovasc Pharmacol 1992;19:641-49.

123. Laurent $S_{i}$ Caviezel B. Beck $L$, Girgrd $X$, Billaud E, Boulouyrie P. Hoeks $A_{4}$ Salar M. Carotid artery distensibility and dislending pressure in hypertenstue humans. Hypertension 1994:23:876; 83 .

124. Laurent S, Girerd X, Mourad W, Lacolley P, Beck L, Boutouyrie P, Mignot JP, Safar M. Elastic modullus of the radial arteryw wall material is not increased in patients with essentia hypertension. Arterioscler Thromb 1994;14:1223.31.

125. Laurent S, Hayoz D, Trazi S Boutouyrie P, Waeber B, Omboni S, Brunner HA, Mancia G, Salar M. Isobaric compliance of the radial artery is increased in patients with essential hypertension. H Hyperiens 1993; $1: 89-98$.

126. Laurent S, Lacolley PM, Cuche Jh, Safar ME. Influence of diuretics on brachial artery diameter and dislensiblity in hypertensive patients. Fundam Glin Pharmacol 1990;4:685-93.

127. Learoyd BN, Taylor MG. Alterations with age in the viscoelastic properties of human arterial walls. Circ Hes 1966;1B 278-92

128. Lehmann ED, Cosling RG, Snksen PH. Arterial wall compliance un diabeles. Oiabetic Med 1992;9:114-19.

129. Lehmann ED, Watts GF, Fatemi-Langroudi B, Gosling RG. Aortic compliance in young patients with heterozygous damitial hypercholesterolaemia. Clin Sci 1992;83:717-21. 
130. Le Noble JLML, Smith TL, Hutchins PM, Struyker-Boudier HAJ. Michovascular atterations in adull conscious spontaneousiy hypertensive rats. Hypertension 1990;15:415-19.

131. Levenson J.Bouthier J, Chau NP, Rolan E, Smon AC. Effiects of nicorantil on arterial and wenous vessels of the Jorearm in systemic hypertension. Am J Cardiol 1989;63:401-3. J.

132. Lewenson J, Le Quan Sang KH, Dewnck MA, Gitel R, Simon A. The role of antityperiensive drugs in oounteracting adwerse influence on large arteries. Am Heart J 1987:11,4:992-97.

133. Lewenson J, Sinon A. Bouthier J, Benetos A, Satar ME. Isosotbide dinitrale and pulsatile anterial hatemodymamic wariables in hypertension. Eur Heart $J 1986 ; 7$ :898-903.

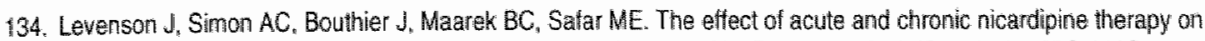
forearm arterial haemodynamics in essential hypertension. Br $\downarrow$ Clin Pharm 1985;20 (Suppl, 9):1075-1135.

135. Lewenson $\rrbracket_{1}$ Simon $\mathrm{AC}$, Bouthier JD. Benetos $A$. Salar ME Post-synaptic alpha-blockade and brachial artery compliance in essential hypertension. J Hypertems 1984;2:37-41.

136. Levenson J, Simon AC. Safar ME. Bouthier J, Marek BC. Large arteries in hypertension; acute effects of a new calcium antry blocker, nitrendipine. J Cardiowasc Pharmacol 1984;6 (Suppl. 7 ) :S1006-10.

137. Levenson IA, Peronneau PA, Simon A, Safar ME. Pulsed Doppler: deternination of diameter, blond flow velocity, and volume flow of brachial artery in man. Cardiowasc Res 1981;15:164:70.

138. Levenson JA, Satar ME, Simon AC, Boutier JA, Griener L. Systemic and arterial hemodynamic effecis of nifedipine 120 $\mathrm{mg}$ ) in mitid-to-moderate hypertension. Hypertension 1983:5 (Suppl. V): V57-60.

139. Levenson JA, Simon AC, Maarek BE, Gitelman RJ, Fiessinger JN, Safar ME. Regional compliance of brachial artery and saline infusion in patients with arteriasclerosis obliterans. Arteriosclerasis $1985,5: 80 \cdot 87$.

140. Lever AF. Harrap SB. Essential hypertension: a disorder of growth with origins in childhood ? J Hyperlens $1992 ; 10$ :101-20.

141. Levy Bl, Michel J, Salzmann JL, Azizi M, Poitewin P, Camilleri .JP, Safar ME. Arierial ellects of angiotensin converting enzyme inhibition in renovascular and spontaneously hypertensive rats. J Hypertens 1988:6 (Suppl. 3) :S23-25.

142. Lew $B$ I, Poitevin P, Safar ME. Effects of urapidil on the mechanical properties of the arterial wall in hypertension. Drugs 1990,40 (Suppl. 4):9-13.

143. Liv ZR, Ting CT, Zhu SX, Yin FC. Aortic compliance in thuman hypertension. Hypertension 1989:14:129-36.

144. Lo CS, Relf IFN, Myers KA, Wahlqvist ML. Doppler ulltrasound recognition of precinical changes in arterial wall diabetio subjects: compliance and pulse-wave damping. Diabetes Care 1986,9:27.31.

145. London G, Guerin A, Pannier B, Marchais S, Benetos A, Safar M. Increased systolic pressure in chronic uremia. Aole of arterial wave reflections. Hypertension $1992,20: 10 \cdot 19$

146. London GM, Marchais S., Salar ME, Genesi Af", Guerin AP, Metivier F, Chedid K, London AM. Aorlic and large alteny compliance in end-stage tenal failure. Kidney : Int 1990:37:137-42.

147. London GM, Satar ME, Simon AC, Alexandre JM, Levenson JA, Weiss YA. Total ettective sompliance, cardiac oulput and fluid wolumes in essential hypertension. Circulation 1978:57:995-1000.

148. Lund Johansen P, Omwik P. Hemodynarnic patterns of untreated hypertensive disease. In: Latagh JH, Brenner BM, eds. Hypertension, Pathophysiology, Diagnosis and Management New York: Rawen Press, 1990;305-28.

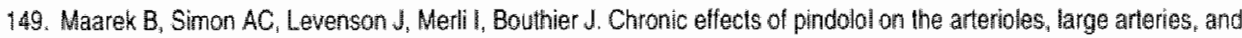
weins of the forearm in mild to moderate essential hypertension. Clin Pharmacol Ther 1986;39:403-8.

150. MacGregor GA. Sodium is more important than calcium in essential hypertension. Hypertension 1985;7:628 40.

151. Mackour MA, Levenson J, Bravo EL, Simon $A_{k}$ Fouad-Tarazi FM. Preload, adrenergic activity and aontic compliance in nomal and hypertensike patients. Ans 4 Hypertens 1989:118:1243-47.

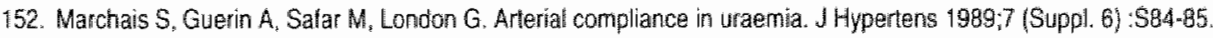

153. McWeigh $G$, Brennan $G_{s}$ Hayes $R$, Cohr J, Finkelstein $S$. Wascular abnormalities in ron-insulin-dependent diabetes mettitus identilled by arterial waveform aratysis. Am I Med 1993;95:424-30.

154. MoVeigh GE, Burns DE, Finkelstein SM, McDonald KM, Mock JE, Feske W, Carlyle PF, Flack J, Grimm F, Conn JM. Reduced vascular compliance as a marker for essential hypertension. Am J Hyperdens 1991;4:245-51. 


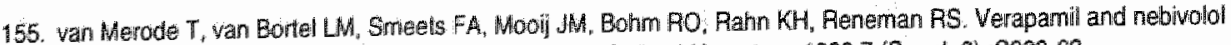
improve carotid antery distensibitity in hypertens

158. wan Merode T, Brands PJ, Hocks APG. Renenan RS. Faster aging of the carotid artery biturcation in borderline hypertensive subjects. J Hypertens 1993:11:171-76.

157. Wan Merode T, Hick PJJ, Hoeks APG, Rahn KH, Reneman RS. Vessel wall properties of the carotid artery in normotensive and borderline hypertensive young male votunteers. J Hypertens 1987,5 (Suppl. 5) :S471-73.

158. van Merode T, Hick PJJ, Hoeks APG, Rahn KiH, Reneman RS. Carotid artery wall properties in nomotensive and borderline hypentensive subjects of variouss ages. Ultrasound Med Biol 1988;:14:563-69.

159. wan Merode T, Hick PJJ. Hoeks APG, Reneman AS. The diagnosis of minor to moderate atherosclerotic lesions in the carotid artery bifurcation by means of speciral broadening combined with the direct detection of flow disturbances using a mulli-gate pulsed doppler system. Ultrasound Med Bioi 1988;14:459-64.

160. van Merode $T$, Hick PJJ, Hoeks APG, Reneman RS. Noninwasive assessment of artery wall properties in children aged $4-19$ years. Pediatr Pes $1988 ; 25: 94-96$

161. van Merode T. Hick PJJ, Hoeks APG, Smeets FAM, Reneman RS. Differences in carotid artery wall properties between presumed-healthy men and women. Ultrasound Mled Biol 1988; 14:571-74.

162. van Merode $T$, Lodder J, Smeets FA, Hoeks AP, Reneman RS. Accurate noninvasive method to diagnose minor atherosclerotic lesions in carotid artery bub. Stroke 1989;20:1336-40.

163. van Merode T, Van Bortel L, Smeets FAM, Bhm Fi, Mooy J, Rahn KH, Reneman FIS. The effect of verapamil on carotid artery distensibility and cross-sectional compliance in hypertensive patients. J Cardiovasc Pharmacol 1989;15:109-13.

164. Mertin PK, Renton S, Fisher $C$, Nicholaides $A$, Elkeles RS. Arterial wall abnormalities in type 1 and type 2 diabetes. Diabetic Med 1992;9 (Suppl. 1) :30A.

165. Messerli FH, Frohlich ED, Ventura HO. Arterial compliance in essential hypertension. J Cardiovasc Pharmacol 1985;7 (Suppl, 2) :S33-35.

166. Milnor WR. Normal hemodynamic state lin: Milnor WR, ed. Hemodynamics Baltimore: Williams and Wilkins, 1982: $135-56$.

167. Moens. Die Pulscurve. EJ Brill, Leiden, 1878.

168. Mohiaddin RH, Underwood SP, Bogren HG, Firmin DN, Klipstein RH, Rees RS, Longmore DB. Regional aortic compliance studied by magnetic resonance imaging; the effects of age, training and coronary artery disease. Br Heart $J$ $1989 ; 62: 90-96$.

169. Mozersky DJ, Sumner DS, Hakanson DE Strandness DE. Transcutaneous measurement of the elastic properties of the human femoral artery. Circulation 1972:46:948-55.

170. Mujais SK, Tarazi AC, Dustan HP, Fouad FM, Bravo EL. Hypertension in obese patients: hemodynamic and volume studies. Hypertension 1982;4:84:92.

171. Murgo JP, Westehol N, Giolma JP, Altcbeli SA. Effects of exercise on aortic input impedance and pressure wave forms in normai humans. Circ Res 1981;48: :334-43

172. Newman DL, Gosling RG, Bowden NLR. Changes in aortic distensibility and area ratio with the development of atherosclerosis. Atherosclerosis $1971: 14: 231-40$.

173. Newman $\mathrm{DL}_{\text {. }}$ Lallemand $\mathrm{RC}$. The effect of age on the distensibility of the abdominal aorta of man. Surg Gynecol Obstel $1970 \div 147: 211-14$.

174: Nichols WW, Nicolini FA. Pepine CJ. Determinants of isolated systolic hypertension in the elderly. J Hypertens 1992, 10 (Suppl. 6) : $\$ 73-77$

175. Nichols WW, O'Rourke MF. Contours of pressure and flow waves in arteries. In: Nichols WW, O'Rourke MF, eds. Mc Donald's Blood Flow in Arteries. Theoretic, experimental and clinical principles 3rd ed. London: E. Arnold, $1990 ; 216-50$

176. Nichols WW, O"Rourke MF. Properties of the arterial wall. In: Nichols WW, O'Rourke.MF, eds. Mc Donald's Bload Flow in Arteries. Theoretic, experimental and clinical principles 3rd ed. London: E. Arnold, 1990:77-124.

177. Nichols WW, ORourke MF. Pullsatile pressure/tlow relations.In: Nichols WW, ORourke MF, eds. Mc Donald's Blood Flow in Arteries. Theoretic, experimental and clinical principles 3rd ed. London: E. Arnold, $1990: 125-42$.

178. Nichols WW, Pepine $\mathrm{CJ}_{4}$ Feldman RL, Christie LG, Conti CR. Exercise induced changes in aortic input impedance in mild hypertension. Circulation 1980;62 (suppl III) : III-258. 
179. Olsen CF. Doppler ultrasound: A technique for obtaining anterial wall motion paranaters. IEEE Trans Biomed Eng $1977.5 U-24: 354-58$.

180. ORourke M. Arterial stiffness, systolic blood pressure, and logical treatment of arterial hyperterision. Hypertems bon $1990 ; 15: 339-47$.

181. ORourke M. Arterial compliance and wave reftection. Arch Mal Coeur Vaiss 1991:84:45-48.

182. ORourke MF. Function of arteries as vascular conduits.In: O'Rourke MF, ad. Anterial function in healith and disease Edinburgh London Mellboume New York: Churchill Livingstone, 1982:53-64.

183. O'Rourke MF. Arterial mechanics and wave reflection with antihypertensive therapy. J Hypertens 1992;10 (Suppl. 5) :S43-49.

184. Pace NL. East TO. Simultaneous comparison of intraarterial, oscillometric, and finapres monitoring during anesihesia. Anesth Analg 1991"73:213-20.

185. Pannier B, Brunel P, EI Aroussy W, Lacolley P, Safar ME. Pulse pressure and echocardiographic findings in essential hypertension. J Hypertens 1989;7:127-32.

186. Parati $G$, Casadel $R$, Groppelli $A$, Dif Rienzo $M$, Mancia $G$. Comparision of finger and intra-arterial blood pressure monitoring at rest and during laboratony testing Hypertension 1989,$13 ; 647-55$.

187. Pepine CJ Nichols WW, Conti CR. Aortic input impedlance in heart failure. Circulation 1978;58:460-65.

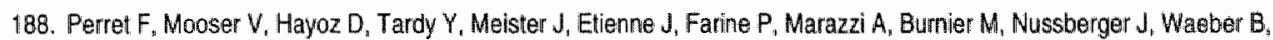
Brunner HA. Evaluation of arterial compliance-pressure curves. Etfect of antihypertensive drugs. Hypertension $1991 ; 18(11), \| 11-77-11-83$.

189. Pessenhofer $\mathrm{H}$. Single cull comparison of two methods for indirect measurement of arterial blood pressure: standard auscultatory method wersus aulamatic oscillametric method. Basic Res Cardiol 1986;81:101-9.

190. Petrin J, Egan BM, Julus S. Increased beta-adrenergic tone enhances arterial compliance in hyperkimetic borderline hypertension. J Hypertens 1989;7 (Suppl. 6) :S78-79.

191. Pfeffer MIA, Pfeffer JM. Left ventricular hypertrophy in hypertension. N Engl 4 Med 1980;323:1276-79.

192. Pignoli $P$, Tremoli E. Poli A, Oreste P, Paoletti $R$. Intimal plus medial thickness of the arterial wall: a direct measurement with ultrasound imaging. Circulation 1986;74:1399-1406.

193. Pithois-Merli I, Levenson l, Filliti V. Simon A. Comparative long-term vasoactive effects of atenolol and carteolol on the properties of the small and large arteries of the upper extremities in human essential hypertension. Clin Pharmacol Ther $1989: 46: 686-92$.

194. Pithois-Merti IM, Cournot AX, Georges DR, Pappo M, Salar ME. Acule effect of labetalol on hypertensive brachial artery. J Clin Hypentens 1987,3:479-86.

195. Pohi U, Holtz J, Busse R, Bassenge E. Crucial role of endothelium in the wasodilator responge to increased llow in wivo. Hypertension $1986,8: 37 \div 44$

196. Pyôrälä K. Diabetes and coronary artery disease: what a coincidence? J Cardiovasc Pharmacol 1990;16 (Suppl. 9) :S8in S14.

197. Raison JM, Safar ME, Cambien FA, London GM. Forearm haemodynamics in obese normotensive and hypertensive subjects. J Hypertens 1986;6:299-303.

198. Reneman AS, van Merode T, Brands PJ, Hoeks APG. Inhomogeneities in arterial wall properties under romal and pathological conditions. J Hypertens 1992;10 (Supp: 6) :S35-40.

199. Reneman AS, varn Merode T. Hick P. Hoeks AP. Cardiowascular applications of multi-gate pulsed Doppler systems. Uitrasound Med Biol 1986;12:357-70.

200. Reneman HS, van Merode T, Hick P, Hoeks APG. Flow velocity patterns in and distensibility of the carotid antery twulb in subjects of various ages. Circulation $1985 ; 71: 500-509$.

201. Reneman RS, vam Merode T, Hick P. Muytjens AMM, Hoeks. APG. Age-related changes in carotid artery wall propertices in men. Ultrasound Med Biol 1985;12:465-71.

202. Poman MJ, Pini Ri, Pickering TG, Devereux. AB. Non-inwasive measurements of arterial compliance in hypertensive: compared with normotensive adults. IJ Hypertens 1992;10 (Suppl. 6) :S115-18. 
203. Roman $\mathrm{O}$, Meza $\mathrm{N}$, Klenner $\mathrm{C}$. Effect of celiprolol on large and small arteries of the forearm circulation in hypertensive patients. Cardiovase Drugs Ther 1990,4:745-49.

204. Rowe JW. Clinical consequences of age-related impaiments in vascular compliance. Ain J Cardiol 1987:60 :68G-71G.

205. Rubba $P$. Riccardi $G$, Pauciullo $P$, Vaccaro O, Carbone $L$, Mancini M. Different localizalion of early anterial lesions in insulin-dependent diabeles melitus and in lamilial hypercholesterolemia. Metabolism 1989;38 962-66.

206. Rutan GH, Kuller LH, Neaton JD, Wentworth DN, McDonald RH, Smith WM. Mortaltity associaied with diastolic hyperiension and isolated systolic hypertension among men screened for the Multiple Risk Factor Intervention Trial. Circulation $1988 ; 77: 504-14$.

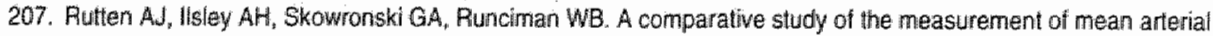
pressure using automatic oscillometers, arterial cannulation and auscultation. Anaesth Intensive Care 1986;14:58-65.

208. Safar M. Therapeutic trials and large anteries in hypertension. Am Heart J 1988;115:702-10.

209. Safar M. Ageing and its effects on the cardiovascular system. Drugs 1990;39 (Suppl. 1) 1-8.

210. Salar M, Asmar R, Bouthier J, Lacolley P, Laurent S. Converting enzyme inhibition and the contumon carotid circulation in older patients with sustained essential hypertension. Eur Heart d 1988;9 (Suppi. D) :75-78.

211. Safar M, Laurent S, Safavian A, Pannier B, Asmar R. Sadium and large anteries in hypertension. Effects af indapamide. Am J Med 1988;84 (Suppl: 1B) :15-19.

212. Safar ME. Pulse Pressure in essential hypertension: clinical and therapeutical implications. J Hypertens 1989;7:769-76.

213. Salar ME. Arteriosclerosis obliterans of the lower limbs as a model of peripheral wascular disease with hypertersion. J Cardiovase Pharmacol 1991:18 (Suppl. 4) :573-77.

214. Safar ME. Asmar R, Benetos A, Levy BI, London GM. Sodium, large arteries, and diuretic compounds in hypentension. Am J Med Sci 1994;307 (Suppl. 1) :S3-S8.

215. Safar ME, Laurent $S$, Benetos $A$, London GM. The comman carotid circulation in patients with essential hypertension. Stroke 198:19:1198-1202.

216. Salar ME, Laurent S, Landon GM. The arterial system in hypertension. In: Safar M, ed. Clinical research in essential hypertension 1st ed. Stuttgart: Schattauer, $1989: 115 * 33$

217. Safar ME, Levy BI, Laurent S, London GM. Hypertension and the arterial system: clinical and therapeutic aspects. J Hypertens 1990;8 (Suppl. 7) :S113-19.

218. Safar ME, London GM. Arterial and venous compliance in sustained essential hypertension. Hypertension 1987;10 :133-39.

219. Salar ME, London GM. Asmar RG, Hugues CJ, Laurent SA. An indirect approach for the study of the elastic modulus of the brachial artery in patients with essential hypertension. Cardiovasc Fes 1986:20:569-67.

220. Salar ME, London GM, Bouthier JA, Levenson JA, Laurent S. Brachial artery cross-sectional area and distensibility before and after arteriolar vasodilatation in men with sustained essential hypertension. J Cardiowasc Pharmacol 1987,9
734.42.

221. Satar ME, London GM, Laurent S. Hypertension and the arterial wall. High blood press 1993:2 (Suppl. 1) $32-40$ 222. Safar ME, London GM, Levensoni JA, Simon AC, Chau NP. Aapid dextran infusion in essential hypertension.
Hypertension $1979 ; 1: 615-23$.

223. Safar ME, Panmier BP, Lacolley PJ, Levy BI, Cardiac mass and aorlic distensibility following calcium blockade in hypertension. JCardiowasc Pharmacol 1991; 17 (Suppl. 2) :\$75-80.

224. Satar ME, Peronneau PA, Lewenson JA, Toto-Moukouo IA, Simon AC. Pulsed dopplen diameter, blond flow welocity and volumic flow of the brachial antery in sustained essential hypertension. Circulatian 1981;63:393-400.

225. Safar ME, Toto-Moukouo UJ, Bouthier JA, Asmar RE, Lewenson JA, Simon AC, London GM. Arterial dynamics, carciac hypertrophy, and antihypertensive treatment. Circulation $1987 ; 75$ (Suppl. i) :1156-61.

226. Schever J, Tipton CM. Cardiovascular adaptations 10 physical training. Annu Rev Physiol 1977:39:221-51.

227. Schimmler W. Untersuchungen zu Elastizittsproblemen der Aorta. Aich Kreislaufforschung 1965;47:189-233.

228. Schoenberger $₫ A$. Epidemiology of systolic and diastolic systemic pressure elevation in the elderly. Am I Cardiol 
229. SHEP Cooperative Research Group. Frevention of stroke by antihypertensive drug treatment hild ofder persons with isolated systolic hypertension. JAMA 1991:265:3255-64.

230. Siche J. De Gaudemaris $\mathbb{R}$, Riachi M, Mallion J. Relationship between low frequency oscillations of blood pressure and changes im arterial diameler. J Hypertens $1992 ; 10$ (Suppl. 6) : $\$ 45-48$.

231. Sithm 1, Schroeder AP, Aalkjaer $C_{2}$ Holm M, Morn B, Mulvany MJ, Thygesen K. Lederballe O. Normaliation of media to lumen ratio of human subcutaneous arteries during antihypertensive treatment with a perindopril based regimen. Eur Heart $31993 ; 14: 520$.

232. Simon A, Levenson J. Use of arterial compiance for evaluation of hypertension. Am al Hypertens 1991;4:97*105.

233. Simon A, Levenson J, Bouthier J, Maarek B. Haemodynamic basis of early modifications of the large arteries in borderline hypertension. J Hypertens $1987,5: 179-84$.

234. Simon AC, Laurent S, Levenson JA, Bouthier JE, Satar ME. Estimation of forearm arterial compliance in nomal and hypertensive men from simultaneous pressure and flow measurements in the brachial artery, using a pulsed Doppler device and a first-order arterial model during ditastole. Cardiovasc Res 1983;17:331-38.

235. Simon $\mathrm{AC}_{\mathrm{B}}$ Levenson J. Bouthier JD, Safar ME. Effects of chronic administration of enalapril and propranolol on the large arteries in essential hypertension. J Cardiovasc Pharmacol 1985;7;856-61.

236. Simon AC. Levenson J, Cambien F, Bouthier J. Combined effects of gender and hypertersion on the geometric designi of large arteries. Sexual differences in normal and hypertensive forearm anteries. Am J Hypertens 1988;1:119:23.

237. Simon $\mathrm{AC}_{\mathrm{n}}$ Levenson J, Pithois-Merli I. Large anteries in hypertension: heterogenous haemodynamic response to beta-adrenoceptor antagonists with and without intrinsic sympathomimetic activity. Br J Cin Pharm 1987,24:45S-9S.

238. Simom $\mathrm{AC}_{n}$ Levenson JA, Bouthier $\mathrm{JL}$, Satar ME. Captopril induced changes in large arteries in essential hypentension. Am J Med 1984; $76: 71-75$.

239. Simon AC, Levenson JA, Levy BY, Bouthier JE, Peronneau PP, Salar ME. Effect af nitroglycerin on peripheral large arteries in hypertension. Br J Clin Pharm 1982;14:241-46.

240. Simon AC, Levenson JA, Satar ME. Hemodynamic mechanisms of and therapeutic approach to systolic hypertension. J Cardiovasc Pharmacol 1985;7 (Suppl. 2) :S22-27.

241. Sinoway LI, Musch $\mathbb{T l}_{\text {, Minotii }} \mathrm{R}_{\mathrm{i}}$, Zelis $\mathrm{R}$. Enhanced maximal metabolic vasodilatation in the dominant foreams of tennis players. J Appl Physiol 1986:61:673-78,

242. Smullyan $\mathrm{H}_{*}$ Mookherjee $\mathrm{S}_{3}$ Warner RA. The effect of nitroglycerin on forearim arterial distensibility. Circulation $1986 ; 73$ "1264-69.

243. Smulyan $H_{n}$ Vardan $S_{n}$ Griffiths $A_{*}$ Gribbin B. Forearm arterial distensibility in systolic hypertension. J Am Coll Cardiol $1984 ; 3: 387-93$.

244. Somers VK, Leo KC, Shields $\mathrm{R}$, Clary M. Mark AL. Forearm endurance training attenuates sympatinetic nervo response to isometric handgrip in normal humans. J Appl Physiol 1992;72:1039-43.

245. Spek, JJ, Hoeks APG. Struiker Boudier HAJ, Van Bortel LMAB. Differences in vessel wall properties of large arteries in obese and lean subjects. J Hypertens 1994;12 (Suppl. 3) :S210;P1157.

246. Stefanadis C, Wooley CF, Bush CA, Kolbash AJ, Boudoulas H. Aontic distensibility abnormalites in coronary arteny disease. Am J Cardiol 1987;59:1300-1304.

247. Stout RW. Insulin as a milogenic factor: role in the pathogenesis of cardiowascular disease. Am J Med 1991;90 (Suppl. 2A] $: 625 \times 5 S$.

248. Strujk PC. Wladimirofl JW. Hop WCJ. Simonazzi E. Pulse pressure assessment in the human fetal descending aorta. Ultrasound Med Biol 1992;18:39-43.

249. Struyker Boudier HAJ, Van Bortel LMAB, De Mey JCR. Renodeling of the vascular tree in hypertension: drug effects. TIPS $1990 ; 11: 240-45$

250. Tandy Y, Hawoz D. Mignot JP. Richard P, Brunner HA, Meister JJ. Dynamic non-invasive measurements of arterial diameter and wall thickness. J Hypentens 1992;10 (Suppl. 6) :S105-9.

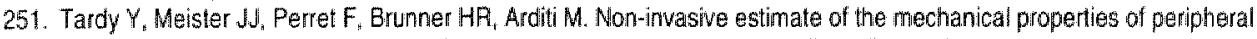
arteries from ultrasonic and photoplethysmographic measurements. Clin Phys Physiol Meas 1991; $12: 39-54$.

252. Teuscher $A_{f}$ Egger M, Herman JB. Diabetes and hypertension. Blood pressure in clinical diabetic patients and a control population. Arch Intern Med 1989;149:1942-45. 
253. Thordarson $H_{1}$ Thorgeirsson $G$, Helgagon $T$. Aortic stithess in insulin-dependent diabetics: an echocardiographic sturdy. Daterelic Mad 1986, $3: 40.54$

254. Toto-Moukouo J. Achimastos A, Asmar RG. Hugues CU, Salar ME. Pulse wave velocity in patients with obesity and hypertension. Am Heart $1986 ; 112: 136-40$.

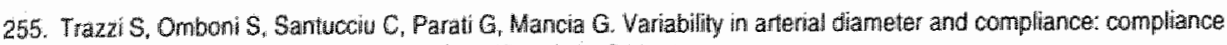
modulation reserve. J Hyperters 1992:10 (Suppl. 6 ) : $\$ 41-43$

256. Treese $N$, Ungern-Stemberg $v$ A, Cordes U. Beyer J. hnfluence of norepinephrine on vessel geometry of the intact femoral arery in juvenile insuline-dependent diabetics. Evidence of eary diabetic angiopathy in ceniral arteries. $Z$ Kardiol $1982 ; 71: 60-64$.

257. Trimarco $B$, Lembo $G$, De Luca N, Ricciardelli $B$, Rosiello $G$, Volpe M. Orofino $G$, Condorelli M. Ettects of celiprolol on systemic and forearm circulation in hypertensive palients: a doutbie-blind cross-over study versus metoprclol. 3 Clin Pharmacol 1987;27:593-600.

25B. Van de Water JM, Falchuk SC. Toh SH, Indech RB. Noninvasive assessment of vascular disease in the lower limbs of diabetics J Cardiovasc Surg 1980;21:469-74.

259. Wahlquist ML. Lo CS, Myers KA, Simpson RW. Simpson JM. Putatiwe determinants of arterial wall compliance in NIDDM. Diabeles Care 1988:11:787-90.

260. Weber MA, Smith DHG, Natel JM, Graettinger WF. Arterial properties of early hypertension. JHum Hypertens $1991 ; 5$ .417-23.

261. Wendehag 1, Whindund O, Wikstrand J. Arterial wall thickness in familial hypercholesterolemia. Arteriosclen Thromb $1992 ; 12: 70-77$.

262. Wijnen JA, Kool MJ, Kooman JP, van Baak H, Hoeks AP, Struijker Boudier HA, Van Bontel LM, Vessel wall properties of large arteries and endurance training. J Hypertens 1993:11 (Suppi. 5) :S88-89.

263. Wild E, Knutti JW, Allen HW, Meindl JD. Dynamics and limitations of blood/muscle intertace detection using Doppler power relurns. IEEE Trans Biomed Eng 1980;27:565-73.

264. Williams RR, Hunt SC, Hasstedt S., Hopkins PN, Wu LL, Berry TD, Stulls BM, Barlow GK, Schumacher MC, Lition RP. Lalbuel JM. Are there interactions and rolations between genetic and enwironmental factors predisposing lo high blood pressure? Hypertension 1991;18(|l) : :29-37.

205. Woolam Gil, Schnur PL., Vallbona $\mathrm{C}_{n}$ Holf HE. The pulse wave velocily as an early indicator of atheroscierosis in diabetic subjects. Circullation 1962;25:533-39.

266. Wright JS, Cruickshank JK, Kontis S, Dor C, Gosling AG. Aortic compliance measured by non-invasive Doppler ultrasound: descriplion of a method and its reproducibility. Clin Sci 1990;79:463-66.

267. Yaginuma T, Awolio A, O'Rourke M. Nichols W, Morgan dw, Roy $P_{1}$ Baron D, Bramson d, Feneley M. Effect of glyceryl

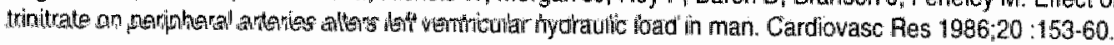

268. Yin FCP, Bin KP, Ting CT, Pyeritz RE. Arterial hemodynamic indexes in Martan's syndrome. Circulation $1989 ; 79$ 854-62

269. Yin FCP. Ting CT. Compliance changes in physiological and pathological states. JHypertens 1992; 10 (Suppl. 6) $: \$ 31=33$

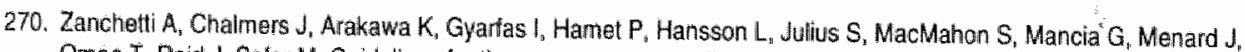
Oma $T$, Reid $J$, Safar Mudelines for the management of mild hypertension. Memonand um from a WHO/ SH meeting. ISH Hypertension news 1993;une:3-15. 


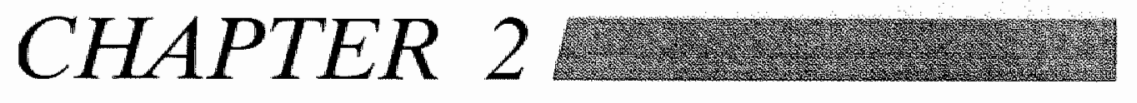

METHODS USED FOR HAEMODYNAMIC MEASUREMENTS 


\section{Vessel wall properties}

The vessel wall movement detector system as used in the present thesis was developed by Hoeks et al (6). The system consists of a conventional B-mode echo imaging system (Ultramark V; ATL, Bothell, Washington, USA) and a data acquistion system connected to a personal computer. With a $7.5 \mathrm{MHz}$ Iransducer a two dinensional B-mode inage is created from the vessel of interest (Figure 2.1.1). An M-line perpendicular to the vessel is selected. After the echo system is switched to M-mode, storage of data starts. During $5-6$ cardiac cycles radiofrequency (RF) signals are digitised and temporarily stored in an 1 Mbyte memory. The R-top of the simultaneously recorded electrocardiogram (ECG) was used as a trigger to maintain a constant time-relationship between the distension measurement of the vessel and the ECG. The first AF line acquired is used to identify the wall lumen interfaces. The position of the anterior and posterior vessel walls are marked by the observer using two data windows on the first RF signal stored (Figure 2.1.2). Line atter line the data are transferred to a personal computer. The distance between both

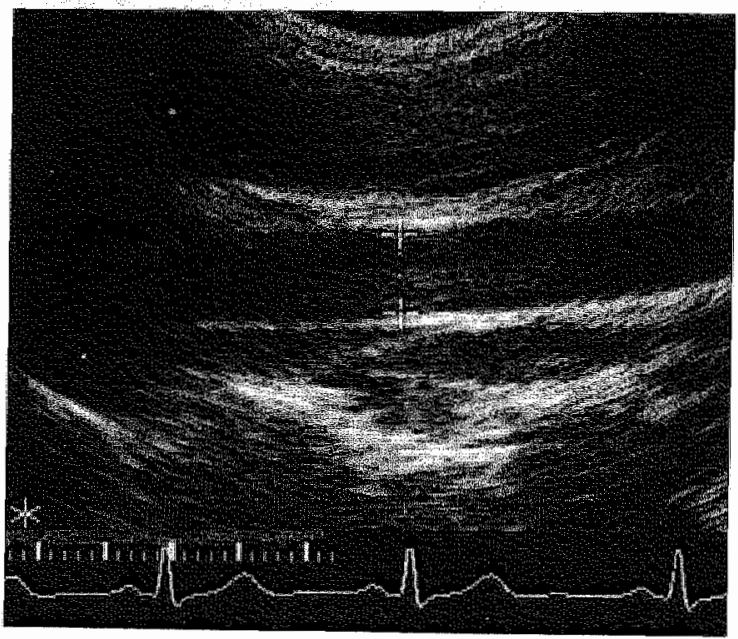

Figure 2.1.1. B-mode two-dimensional image of the common carotid artery of a presumed young healthy volunteer.

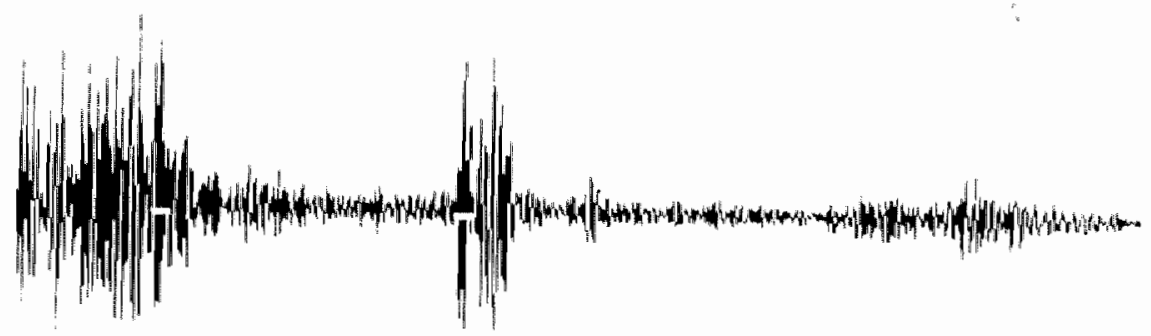

Figure 2.1.2. An example of a radiotregency (RF) signal as a function of depth obtained from the common carotic artery of a presumed healthy woltunteer. The anterior and posterior walls are marked by the relatively large signal and represent the initial diameter. The white boxes at the baseline indicate the sample wolumes. 


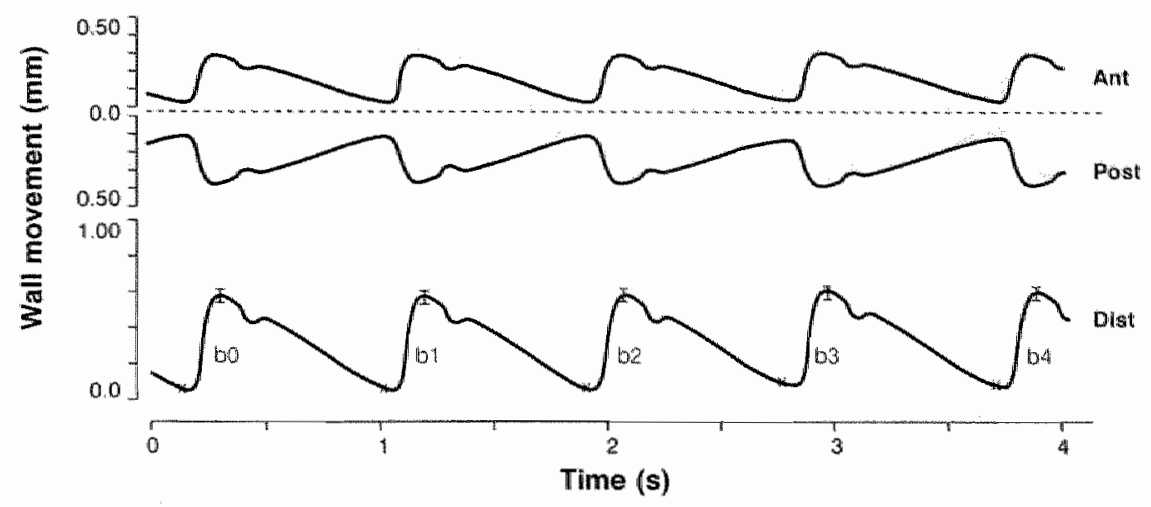

Figure 2.1.3. Displacement waveform of the anterior (top tracing) and posterior (middle tracing) wall of the common carotid artery during 5 heart cycles. The difference between these two results in the distension waveform (bottom tracing). The cross indicates the occurrence of the EGG trigger. Ant=anterion wall movement; Post=posterior wall movement; Dist=distension change in diameter during the heart cycle.

sample volumes corresponds to the initial diameter of the vessel lumen (minimum diameter at end oilastole). The cumulative change in phase between the successive RF lines is calculated for the anterior and posterior wall windows, where the position of the sample gates is continuously adjusted according to the detecied displacement (tracking principle). After processing all lines, the displacement waveform of the arterial walls is displayed on the screen (Figure 2.1.3). The distension waveform, i.e. the change in diameter as a function of time, is obtained by subtracting the posterior displacement wavelorm from the anterior waveform (difference in displacement between the anterior and posterior wall). The above procedure is an off-line analysis and provides data on arterial diastolic diameter (D) and distension ( $\triangle D$ ) for each captured beat. An advantage of this approach is that a change in mean position of the artery caused by probe movements and/or changes in vessel position will not really influence the outcome of the measurement. The assumption is made that the increase in arterial volume during systole is caused by an increase in cross-sectional area rather than by a change in arterial length $(L)(11,12)$. Distensibility is defined as the relative change in cross-sectional area $(\triangle \mathrm{A} / \mathrm{A})$ per unit of pressure. Compliance coefficient is the change in volume per unit of length divided by the change in pressure (cross-sectional compliance). Campliance is related to distensibility and arterial wolume (5). To minimise fluctuations over a short period of time (7) data represent the mean of about 15 heart beats ( 3 recordings). Consequently, arterial diameter and change in diameter during the heart cycle $(\Delta D$, distension) were recorded during approximately $5.6 \mathrm{~s}$ and the means of 3 consecutive measurements were laken as the patient's reading. If within one measurement of approximately 5 heart beats parameters differed more than 10\%, probably due to motion artifacts, the measurement was not accepted. Simultaneously with the vessel wall measurements arm blood pressure was recorded with a Dinamap (see section 2.4). Pulse pressure is defined as systollic minus diastolic pressure. From vessel wall motion data $(D, \Delta D)$ and pulse pressure $(\Delta P)_{n}$ vessel wall properties were calculated according to the following equations (12):

$$
\begin{aligned}
& D C(\text { distensibility coefficient })=(\Delta \mathrm{A} / \mathrm{A}) / \Delta \mathrm{P} \approx 2 \cdot(\Delta \mathrm{D} / \mathrm{D}) / \Delta \mathrm{P} \\
& \mathrm{CC}(\mathrm{compliance} \text { coefficient })=(\Delta \mathrm{L} / \mathrm{L}) \Delta \mathrm{P}=\Delta \mathrm{A} / \Delta \mathrm{P} \approx \pi \mathrm{D} \cdot \Delta \mathrm{D} / 2 \Delta \mathrm{P}=\mathrm{DC} \cdot \mathrm{A}
\end{aligned}
$$

Distensibility reflects the elastic properties of the arterial wall, while compliance reflects the buffering capacily of the arterial system. With this device vessel wall properties of superficial large arteries were 
measured (carotid, femoral, brachial arteries). With the same device the time required for the upslope from the $10 \%$ to the $90 \%$ level (rise time) could be derived from the distension waveform. In addition, the delay time from the A-top of the ECG to the $10 \%$ level of the ascending limb of the distension waveform can be assessed. The delay time estimates the transit time between the heart and the site of recording, taking into account the electro-mechanical dissociation component. The delay time of the carotid and femoral arteries was used as an estimate of carotido-femoral transil time. For each heart beat these delay times are given by the device with a technical accuracy of $2 \mathrm{~ms}$. The delay time $(T)$ of the carotid and femoral arteries was used as an estimate of carotida-femoral transit time. The distances from the upper side of the stemum to the site of measurement in the neck (carotid artery) and the groin (femoral artery) were determined with a tape measurer. The difference between these two distances was used as the length ( $L$ ) of the arterial segment corresponding to the carotido-femoral transit time (1). The distance between the upper side of the sternum and the carotid artery was subtracted from the total distance in order to take into account pulse wave travelling in the opposite direction (9). The average pulse wave velocity (PWV) in this arterial segment can be estimated from the following formula:

$$
\text { PWV }=L / T
$$

where PWV provides an estimation of the stiffness of the aortic pathway (10). Reflection waves in the femoral artery do not disturb this observation since they always arrive latter thian the $10 \%$ level of the ascending limb of the distension curve. An in vitro study showed that with this device arterial wall displacements of a few micrometers may be measured. However, the accuracy and reproducibility in vivo may differ from these in vitro data (chapter 3). Additional pro's and cons of the technique are also described in chapter 3 .

\subsection{Venous compliance}

Apart from arterial compliance, venous compliance is also important. Venous compliance determines the volume-pressure relationship of the haemodynamically active part of the venous system in the resting state. It is determined by the visco-elastic properties of the venous wall, which is mainly composed from collagen, elastin and smooth muscle with a thin endothelial layer (8). The pressiure-volume relationship has been lound linear over the physiological range of pressures. From these curves the unstressed volume can be derived. The unstressed volume describes the haemodynamically inactive compartment, which is $60 \%$ of total blood volume. Mobilisation of the unstressed volume may be achieved by venous tone influenced by sympathetic activity $(4,13)$. Venous compliance may differ in different wenous vascular beds (4). In addition to a change in venous compliance, a change in unstressed volume may contribute to a change in venous pressure, which is an important determinant of cardiac preload. In the present thesis mercury straim-gauge venous occlusion plethysmography was used (Periflow; Janssen Scientific instruments, Beerse, Belgium), as described by Forconi gt al (3) to assess venous hemodynamics. With this technique a cuff, placed around the most voluminous part of the upper extremity, was inflated to occlude the venous circulation. This results in an increase in volume of the extremity since only arterial inflow and not venous outtlow is possible. The volume changes are estimated by recording changes in electrical resistance of a mercury thread which is applied to the extremity. The increase in electrical resistance is directly related to changes in limb volume (3). A cannula was inserted into an antecubital vein to record venous pressure. The unstressed venous volume was determined by the distension of the forearm at an intravenous pressure of $10 \mathrm{~mm} \mathrm{Hg}$. Venous compliance was defined as the slope of the pressure-volume curve, as determined with linear regression analysis. With plethysmography only relative changes (per $100 \mathrm{~m} /$ tissue) can be assessed. In addition,
only compliance of muscular and cutaneous veins can be measured. 


\subsection{Cardiac output}

Cardiac output, together with peripheral resistance determines mean arterial pressure (MAP). Several invasive techniques to assess cardiac output are well known. However, in the last fow decades also non-invasive techniques have been developed. In the present thesis, an echo Doppler technique has been used (Ultramark V; ATL, Bothel, Washington, USA). With the patient in left lateral position aortic diameter (AD) was measured from a standard 2-dimensional long-axis parastemal view at the silte of the aortic annulus. Maximal blood flow velocity at the site of the aortic valve was measured with a continuous wave transducer (1.9 MHZ). Heart rate was derived from a simultaneously recorded ECG. Stroke volume was calculated from the aortic diameter (AD) and the velocity time integrals. (FVI) over the aorlic valve as $0.25 \pi(\mathrm{AD})^{2} \times \mathrm{FV}$. Cardiac output was defined as stroke volume $\mathrm{x}$ heart rate. The mean of 6 heart beats was taken as the patient's reading. Cardiac output and stroke volume were divided by body sufface (2) to compute cardiac index and stroke index, respectively. Systemic vascular resistance index was defined as mean arterial pressure/cardiac index.

\subsection{Blood pressure and heart rate}

Supine blood pressure and heart rate were measured non-invasively at the left brachial artery, using a semi-automated oscillometric device (Dinamap; Critikon, Tampa, Florida, USA). Depending on the study every 1 to 3 minutes recordings were made. Approximately 10 recordings were averaged and taken as the patient"s reading. Pulse pressure $(\Delta \mathrm{P})$ was defined as systollic (SBP) minus diastolic (DBP) blood pressure.

\subsection{Other measurements and analyses}

All other methodologies used in the studies of this thesis as well as the methods of data analysis are presented in the methods sections of each individual chapter.

\section{References}

1. Demolis $\mathrm{PD}, \mathrm{Asmar} \mathrm{RG}_{3}$ Levy $\mathrm{BI}$, Safar ME. Non-invasive evaluation of the conduit function and the butfering function of large arteries in mani. Clin Physiol 1991;11:553-64.

2. Du Bois D, Du Bois EF. A formula to estimate the approximate surtace area if height and weight be known. Arch Intern Med 1916:17:863-71.

3. Forconi $S$, Jagenau $A_{n}$ Guerrini $M$, Pecchi $S$, Cappell $R$. Strain gauge plettysmography in the study of circtation of the llimbsi. Angiology 1979;30:487-97.

4. Greenway CW, Lautt WW. Blood wolume, the venous system, preload, and cardiac oulpul. Can J Physiol Pharmacol $1986,64: 383-87$

5. Guyton AC. Physics of blood, blood low, and pressure: hemodynamics ln: Drebelbis D, ed. Textbook of medical physiology 7th ed. Philadelphia: W.B. Saunders Company, $1986: 213-229$. 
6. Hogiks APG, Brands PJ, Smeets FAM, Reneman PS. Assessment of the distensibility of superficial anteries. Ulirasound Med Bio 1990;16:121-28.

7. Holstra $L_{r}$, Willigers JM, Huvers FC, Schaper NC, Kester $A D M_{3}$ Kitstaar PJEHM, Hoeks APG. Shart-term variation in the elastic properties of a muscular artery in humans. Clin Sci 1994;86:567-74.

8. Junqueira, LJ, Cameiro,J. Basic Histology. 4th ed. Lange Medical Publications, Los Altos, 1983.

9. London GM, Marchais SJ, Safar ME, Genest AF, Guerin AP, Metivier F, Chedid K, London AM. Aortic and large artery conipliance in end-stage rerial failure. Kidney Int 1590;37:137-42.

10. ORourke MF. Function of arteries as vascular conduits. In: O'Rourke MF, ed. Arterial function in health and disease Edinburgh London Melbourne New York: Churchill Livingstone, $1982: 53-64$

11. Reneman RS, van Merode T, Hick P, Hoeks APG. Cardiovascular applications of multi-gate pulsed doppler systems. Ultrasound Med Biol 1986:12:357-70.

12. Reneman AS, Van Merode T, Hick P, Muytjens AMM, Hoeks APG. Age-related changes in carotid artery wall properties in men. Ulitrasound Med Bin 1986:12:465-71.

13. Rithe CF. Venous system: physiology of capacilance vessels. In: Hanobook of Physiology Vol 3, Peripheral eirculation and organ blood flow. Bethesda: Americar: Physiological Sociely, 1983:397-452. 


\section{CHAPTER 3}

EVALUATION OF REPRODUCIBILITY OF A VESSEL WALL MOVEMENT DETECTOR SYSTEM FOR ASSESSMENT OF LARGE ARTERY PROPERTIES

M.J.F. Kool, *T. van Merode, *R.S. Reneman, * A.P.G. Hoeks, H.A.J Struijker Boudier, and L.M.A.B. Van Bortel

Departments of Pharmacology, "Physiology and * Biophysics, Cardiowasular Research Institute Maastricht, University of Limburg, the Netherlands

Based on Cardiovascular Research 1994, 28:610-614 


\section{Summary}

Arterial distensibility (DC) and compliance (CC) are vessel wall properties of large arteries that can be measured non-invasively with a custom made vessel wall movement detector system (VWMDS). This study investigates reproducibility of this device in 10 volunteers.

To investigate intraobsenver intrasession and intraobserver intersession variability, arterial diameter (D) and relative change in diameter during the heart cycle ( $\triangle D / D)$ were measured in the elastic common carotid artery, and in the muscular femoral and brachial arteries. Interobserver intrasession variability was examined in the common carotid artery by two observers, while interobserver variability an the same image was assessed for the common carotid and femoral arteries. Variability was expressed as the coefficient of variation.

For the common carotid artery, intraobserver intrasession variability was $7.9 \pm 1.6 \%(\Delta D / D), 4.5 \pm 1.1 \%$ (D) $8.3 \pm 1.3 \%(\mathrm{DC})$, and $9.1 \pm 2.6 \%(\mathrm{CC})$, respectively. In the femoral artery it was $12.4 \pm 2.2 \%(\Delta \mathrm{D} / \mathrm{D})$, $2.7 \pm 0.6 \%(\mathrm{D}), 13.4 \pm 2.2 \%(\mathrm{DC})$, and $12.5 \pm 2.1 \%(\mathrm{CC})$. For the brachial artery it was $13.4 \pm 2.8 \%(\Delta \mathrm{D} / \mathrm{D})$, $2.5 \pm 0.5 \%(\mathrm{D}), 16.1 \pm 2.5 \%(\mathrm{DC})$, and $15.6 \pm 2.6 \%$ (CC). Intraobserver intersession variability was comparable to intraobserver intrasession variability for all vessels. Interobserver intrasession variability for the common carotid artery was $11.3 \pm 2.6 \%(\triangle D / D)$ and $8.6 \pm 1.9 \%(D)$, but was larger for $D C$ and $C C$. Interobsever variability on the same image was $<5 \%$ for the common carotid and femoral arteries.

In conclusion, the vessel wall movement detector system has a good technical reproducibility. Intraobserver intrasession and intersession variability are comparable , and are larger in muscular arteries. This might be due to a larger variation in tone of these arteries, which are under permanent neurohumoral control. Interobsenver intrasession variability was larger than intraobserver variability and might be influenced by differences in observers' skill and spontaneous variation in vessel wall properties. 


\section{Introduction}

Distensibility and compliance are vessel wall properties of large arteries. The relative change in arterial diameter, due to the change in local blood pressure during systole, is determined by arterial distensibility. Distensibility is an one-dimensional parameter, reflecting the elastic properties of the arterial wall. The capacity to store the blood volume, ejected with each heart beat, is determined by arterial compliance (three-dimensional parameter).

Knowledge about vessel wall properties is likely to be valuable in the management of cardiovascular diseases. For example, when compliance is decreased, the afterload for the heart is likely to increase with a subsequent higher risk for cardiac hypertrophy and heart failure $(23,30,32)$. With a lower compliance, pulse pressure increases, as does systolic blood pressure. Consequently, the risk for stroke will be enhanced (14). A decreased compliance might also play a role in the onset of atherosclerosis $(6,10,35)$. Compliance and distensibility are decreased in essential hypertension $(31,34)$ and also in borderline $(16,37)$ hypertensive patients. With increasing age arteries become stiffer, resulting in a diminished distensibility and compliance (17).

In the past, data on mechanical properties of large arteries have been derived from studies on isolated vessels $(3,19)$. It has been demonstrated that these data underestimate the real vessel wall movements in vivo (7). In vivo, arterial compliance has been estimated from pressure-volume/diameter cunves in animals that were studied with invasive techniques or under conditions of anaesthesia $(1,22)$. However, these data cannot fully be extrapolated to the human situation in vivo. In addition, regional pulse wave velocity measurements have been widely used to assess distensibility of a certain arterial segment. However, with this technique no direct data on arterial compliance can be obtained (29), while there is some debate on its variability $(29,33)$.

A tew years ago ultrasound devices became available to study vessell wall properties of large arteries non-invasively $(2,5,8,15,18,27)$. In addition, arterial diameter-pressure curves were analysed by combined photoplethysmographic and ultrassonic recordings (36). Hoeks et al (13) have developed a vessel wall movement detector system that allows accurate non-invasive assessment of the arterial diameter and relative diameter changes during the cardiac cycle. The first device of this kind used wall velocities in static sample volumes in a multigate pulsed Doppler system to measure on line relative changes in arterial diameter during the heart cycle (26). The second generation device directly employes the radiofrequency signal of tracking sample volumes to detect changes in arterial diameter. The accuracy of this device is improved. In vitro experiments have demonstrated that the latter technique can resolve diameter changes of the order of a few microns (13). Vessel wall movements of superficial arteries, such as the carotid, the femoral and the brachial arteries can be sludied with this system.

The aim of the present study was to evaluate the reproducibility of the new technique in man. Therefore, reproducibility measurements were performed in healthy wolunteers to assess intraobsever intrasession and intersession variability, as well as interobserver variability.

\section{Methods}

Subjects - Intraobserver intrasession and intersession variability was investigated in 10 healthy volunteers, nine males and one female. Mean age was 38 years (17-56), mean weight $72 \mathrm{~kg}(55.87)$ and mean height $175 \mathrm{~cm}(161-186)$. Interobserver variability was investigated in 10 healthy male volunteers. The mean age of these subjects was 38 years (21-57), mean weight was $76 \mathrm{~kg}(59.87)$ and mean height $176 \mathrm{~cm}(161-184)$. The mean values of vessell wall measurements of each measured vessel are given in Table 1. 
Table 1. Mean values of vessel wall parameters in heathy volunteers.

\begin{tabular}{|c|c|c|c|c|}
\hline & $\Delta D(\mu m)$ & $\mathrm{D}(\mathrm{mm})$ & $\operatorname{DC}\left(10^{-3} / \mathrm{kPa}\right)$ & $\mathrm{cc}\left(\mathrm{mm}^{2} / \mathrm{kPa}\right)$ \\
\hline & \multicolumn{4}{|c|}{ Intraobserver values } \\
\hline Common carnotid arsery & $504 \pm 31$ & $6.90 \pm 0.17$ & $22.8 \pm 1.3$ & $0.84 \pm 0.04$ \\
\hline Femoraí artery & $575 \pm 27$ & $8.98 \pm 0.30$ & $21.0 \pm 1.7$ & $1.28 \pm 0.09$ \\
\hline \multirow[t]{2}{*}{ Brachial artery } & $424 \pm 23$ & $4.43 \pm 0.07$ & $30.5 \pm 2$. & $0.47 \pm 0.03$ \\
\hline & \multicolumn{4}{|c|}{ Interobserver values } \\
\hline Common carotid antery & $409+32$ & $6.24 \pm 0.16$ & $23.6 \pm 1.4$ & $0.70 \pm 0.03$ \\
\hline
\end{tabular}

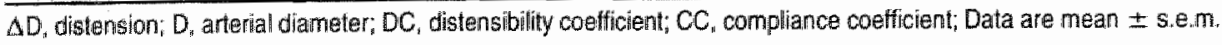

Study design - The designs for the different parts of the study are shown in Figure 1. All measurements were performed in a recumbent position after $15 \mathrm{~min}$ of supine rest. Simultaneously with the vessel wall measurements arterial blood pressure was recorded, using a non-invasive device as described below.

\section{Intraobserver intrasession variability (Figure 1A)}

Within che session three repeated measurements of the right elastic common carotid artery, and of the right muscular common femoral and brachial arteries were taken in random order. After each measurement, the volurteer regained his original position and ultrasound gel was removed trom the skin to blind the observer for the site of the previous measurement.

\section{Intraobserver intersession variability (Figure $1 B$ )}

For intersession variability, common carotid, femoral, and brachial arteries of the volunteers were examined twice, with an interval of at least 4 days between the two sessions. To avoid an influence of diurnal variation each subject was studied at the same time of the day.

\section{Interabserver intrasession variability (Figure 1C)}

Interobserver variability of common carotid artery was assessed between two observers. In five subjects one observer started the measurements, while the other five were measured first by the second observer.

\section{Interobsenver variability on the same radiofrequency signal (Figure 1D)}

Finally, interobserver variability on the same radiofrequency (RF) signal was carried out. Aiternately, each observer made five recordings of common carotid and femoral arteries in one subject. The two observers independently processed the RF signal of each recording.

Methods and Equipment - The vessel wall movement detector system has been described in detail in Chapter 2. Briefly, with a $7.5 \mathrm{MHz}$ transducer a two dimensional B-mode image is created from the vessel of interest. An M-line perpendicular to the vessel axis is selected. After the echo system is switched to M-mode storage of data starts. During 5-6 cardiac cycles radiofrequency (RF) signals are digitised and temporarily stored in an 1 Mbyte memory. The position of the anterior and posterior vessel walls are marked manually by the observer by setting two data windows on the first RF signal stared. Line after line the data are transferred to a personal computer. The cumulative change in phase between the successive RF lines is calculated for both the anterior and posterior wall windows, where the position of the sample windows 
A. Intraobserver intrasession variability $(n=10)$

15: supine rest $\mid$\begin{tabular}{c}
$x$ \\
\cline { 2 - 2 }
\end{tabular}

B. Intraobserver intersession variability $(n=10)$

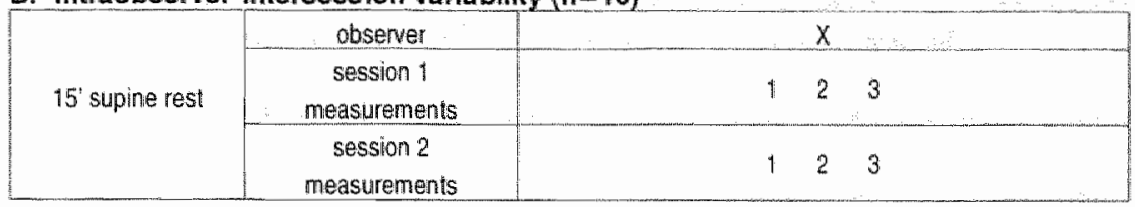

\section{Interobserver intrasession variability $(n=10)$}

\begin{tabular}{|c|c|c|c|c|c|c|c|}
\hline \multirow{4}{*}{$15^{\prime}$ supine rest } & obsener & \multicolumn{3}{|c|}{$x$} & \multicolumn{3}{|c|}{$Y^{\prime}$} \\
\hline & $\begin{array}{c}\text { measurements } \\
n=5\end{array}$ & & 2 & 3 & & 2 & 3 \\
\hline & observer & \multicolumn{3}{|c|}{$Y$} & \multicolumn{3}{|c|}{$x$} \\
\hline & $\begin{array}{c}\text { measurements } \\
n=5\end{array}$ & & 2 & 3 & & 2 & 3 \\
\hline
\end{tabular}

\section{Interobserver variability on same RF signal $(n=1)$}

15 supine rest

observer measurements

\begin{tabular}{|c|c|c|c|c|c|c|c|c|c|}
\hline$X Y$ & $Y X$ & $X Y$ & $Y X$ & $X Y$ & $Y X$ & $X Y$ & $Y X$ & $X Y$ & $Y X$ \\
\hline 1 & 2 & 3 & 4 & 5 & 6 & 7 & 8 & 9 & 10 \\
\hline
\end{tabular}

Figure 1. Situdy protocol for assessment of reproducibility (see text for details).

$X=0$ bserver $X_{i} Y=$ obsenver $Y \cdot X Y=$ measurement by obsenver $X$ and $R F$ signal processed by observer $X$, lollowed by processing of the same RF signal by observer $Y$; $Y X=$ measurement by observer $Y$ and RF signall processed by observer $Y$, followed by processing of the same RF signal by obsenver $X$.

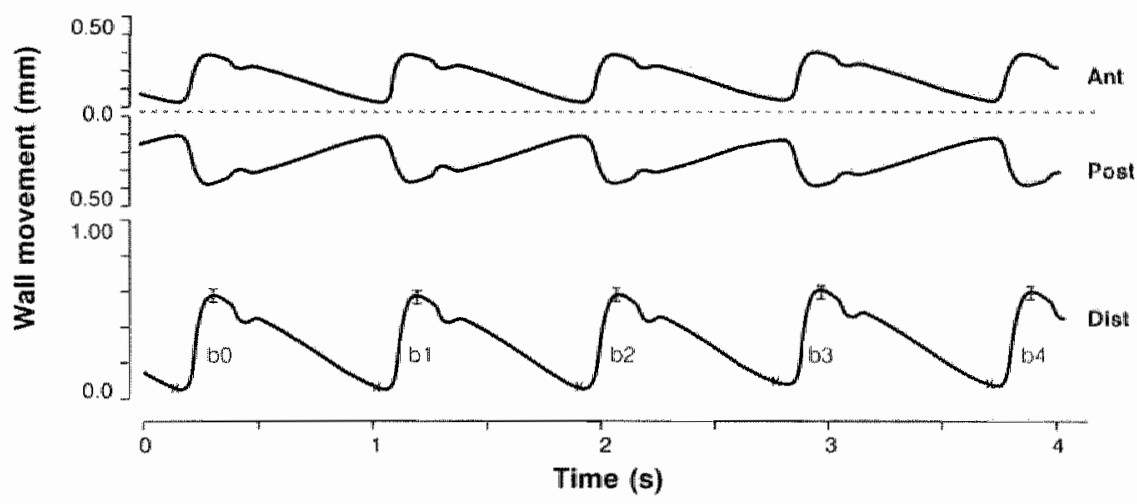

Figure 2. Recording of the vessel wall movement of the common carotid artery during five hearl cyclas. Ant, anterior wall movement; Post, posterior wall movement; Oist; distension: change in diameter during ithe heart cycle. 
is continuously adjusted according to the detected displacement (tracking). After processing all ines, the displacemerit of the arterial walls is displayed (Figure 2). The difference in displacement between the anterior and posterior wall represents arterial distension, which is the change in diameter during the heart cycle. This procedure is an off-line analysis and provides data on arterial diastolic diameter (D) and distension $(\triangle D)$ for each captured heart beal.

Arm blood pressure was recorded non-invasively at the left brachial artery, using the Dinamap (Chapter 2). Blood pressure was measured every 2 min and the mean of all recordings was taken. From arterial diameter , distension and pulse pressure, vessel wall properties were calculated according to the equations mentioned in Chapter 2.

Data analysis - With respect to intraobserver intrasession variability, the coefficient of variation (CV) between the three measurements of each vessel and between the three pulse pressure recordings was calculated for each subject (mean/standard deviation) and expressed as a percentage. Each measurement was the mean of approximately 5 heart beats.

Intraobsevver intersession variability was calculated for each wolunteer as the coefficient of variation between the mean of three recordings (on average 15 heart beats) of each wessel and of pulse pressure at the first and second session. For each subject the mean of three recordings of the common carotid aitery and of pulse pressure for abserver 1 and 2 was compared to estimate interobserver intrasession variability. Interobserver variability on the same RF signal was assessed as the coefficient of variation between the observers for each recording of the common carotid and femoral artery. Finally, variability is presented as the mean \pm s.e.m. coefficienl of varialion. Statistical differences between the mean coefficients of variation for the different parameters were analysed with a Mann-Whitney test.

\section{Results}

The results for the variability of the vessel wall measurements are shown in Table 2 .

Intraobserver variability. Intraobserver intrasession and intersession variability was less than $10 \%$ for the common carotid artery. In the femoral and brachial arteries intraobserver variability within one session and between two sessions was $<5 \%$ for arterial diameter. The variability in distension, distensibility and compliance was on the average 10 to $15 \%$ in these arteries.

Interobserver variability. Interobserver intrasession variability in the common carotid artery was on the average $10 \%$ for arterial diameter and distension, but was higher for distensibility and compliance $(20 \%)$. Interobsenver variability on the same RF signal was less than $5 \%$ for all parameters in the carotid and the femoral artery.

Mean pulse pressure was $48 \pm 1.5 \mathrm{mmHg}$ for the intraobserver, and $49 \pm 2 \mathrm{mmHg}$ for the interobserver measurements. Pulse pressure variability was $3.3 \pm 0.6 \%$ within one session, $4.7 \pm 0.9 \%$ between two sessions, and $4 \pm 1.0 \%$ when interobserver variability was assessed.

\section{Discussion}

In the past, wiltrasound techniques (B-mode, M-mode, continuous wave Doppler, pulsed Doppler, multigate pulsed Doppler) have been developed to measure arterial diameter and to detect diameter changes "in order to estimate vessel wall properties of large arteries.

When applied to images in B-mode, these measurements are time consuming and inaccurate, due to the limited spatial resolution of the echo system (11). Wall movements derived from M-mode recordings $(2,18)$ 
Tabel 2. Mean coefficient of variation $(\%)$ in measurements of wessel wall properties with WWMOS

\begin{tabular}{|c|c|c|c|c|}
\hline & $\Delta D$ & D & $\mathrm{DC}$ & $\mathrm{co}$ \\
\hline \multicolumn{5}{|c|}{ Intraobserver intrasession wariability } \\
\hline Common carotid artery & $7.9 \pm 1.6$ & $4.5 \pm 1.1$ & $8.3 \pm 1,3$ & $9.1 \pm 2.6$ \\
\hline Common lemoral artery & $24 \pm 2.2$ & $2.7 \pm 0.6$ & $13.4 \pm 22$ & $125=2$ \\
\hline Brachial artery & $13.4 \pm 2.8$ & $2.5 \pm 0.5$ & $16.1 \pm 2.5$ & $156+26$ \\
\hline \multicolumn{5}{|c|}{ Intraobsener intersession variability } \\
\hline Common carotid artery & $9.2 \pm 0.9$ & $2.1 \pm 0.5$ & $7.1 \pm 2.2$ & $8.5 \pm 1.5$ \\
\hline Common lemoral artery & $12.8 \pm 3.0$ & $3.0 \pm 1.1$ & $15.2 \pm 3.7$ & $142 \pm 25$ \\
\hline Brachial artery & $12: 52.8$ & $3.3 \pm 0.6$ & $14.2 \pm 2.5$ & $12.6 \pm 2.8$ \\
\hline \multicolumn{5}{|c|}{ Interabserver intrasession variability } \\
\hline Common carotid artery & $11.3 \pm 2.6$ & $8.6 \pm 1.9$ & $16.9 \pm 2.8$ & $24.9 \pm 8.5$ \\
\hline \multicolumn{5}{|c|}{ Interobsenver wariability same RF signal } \\
\hline Common carotid artery & $3.4 \pm 0.7$ & $2.1 \pm 0.6$ & $4.3 \pm 0.8$ & $4.0 \pm 0.9$ \\
\hline Common temoral artery & $2.9 \pm 0.9$ & $2.5 \pm 0.7$ & $3.9 \pm 1.6$ & $4.3 \pm 1.8$ \\
\hline
\end{tabular}

WWMDS, vessel wall movement delector sysiem; $\triangle D$, distension; $D$, arterial diameter: $D C$, dislensibility coefficient: $\mathrm{CC}$, compliance coefficient. Data are mean \pm s.e.m.

also suffer from an insufficient resolution, in particular when the adventitia and intima induce distinct echoes (11). Continuous wave Doppler systems can be used to detect vessel wall motion (20), but they can only do so under the assumption that both walls move with the same speed in opposite directions. In addition, these systems do not provide information on the initial arterial diameter. With the pulsed Doppler technique blood flow velocities are measured and changes in the width of the velocity profile can be used to determine changes in arterial diameter (39). Therefore, this approach is only applicable to arteries with both systolic and diastolic flow. Multigate puised Doppler systems may be suitable for delection of changes in arterial diameter (25), but here the assumption must be made that the anterior and posterior walls of the vessel do not leave the sample volumes coinciding with the vessel walls. As the artery as a whole may move and the position of the probe may vary, this assumption will not always be valid. Also structures in the vicinily of the arterial wall may enter the sample volume and hence disturb accurate measurements. The vessel wall movement detector system, as used in this study, overcomes many of these problems. The method is based on phase tracking of the radiofrequency signals as arising from the arterial walls.

In clinical and experimental studies a new measurement technique has to be compared with a gold standard in order to prove its value. However, a gold standard for our technique does not exist. Nevertheless, reproducibility tests can be carried out without such a standard.

The vessel wall movement detector system, as used in this study, has a good technical reproducibility. This has been shown in in vitro experiments (13) and is supported in the present study by the low coefficient of variation found for interobserver variability on the same RF signal.

Intraobserver intrasession variability for the common carotid artery was lower than $10 \%$ for all parameters. Variability in arterial distension was slightly higher in the muscular femoral and brachial arteries, but variability in arterial diameter was even less in the muscular arteries than in the elastic carotid artery. A 
higher skill needed for proper measurements on the muscular arteries may be responsible for this phenomenon, but it might also be explained by a larger spontaneous variation in tone in muscular arteries, since these are under permanent neurohumoral control (5).

Because subjects are often examined on different days, intraobserver intersession wariability was also studied. For no parameter did the variability between wo sessions change much from intraobsenver intrasession variability. On the average the elastic artery again showed less variability than the muscular arteries.

Interobserver intrasession variability was only examined in one artery, since there was a difference in skill beiween the two observers for the other arteries. Variability between the observers was within the same range (approximately 10\%) for the actually measured parameters (distension and diameter). It tended to be larger for the calculated parameters (distensibility, compliance), although these differences were not statistically significant. This finding is not unexpected, since variation of each parameter used in the calculation $(D, \triangle D)$ can increase the variation of the result ( $D C, C C)$.

Interobserver variability tended to be larger than intraobserver variability and for $D C$ this difference reached the level of statistical significance $(p<0.05)$. This aspect could be due to different reasons. Firsily, interobserver variability might be influenced by differences in abservers' skill. With regard to this skill, for example the creation of $\mathrm{B}$-mode and $\mathrm{M}$-mode images, and the pressure of the transducer on the skin are important. Both high and low pressure applied to the skin can diminish reproducibility. The minimal pressure necessary to obtain reliable measurements requires training of the observer. Secondly, short-term variations in vessel wall properties themselves may also contribute to the variability. In addition, variations in local pulse pressure might have influenced interobserver variability. Since variability in pulse pressure was only $4 \%$, this will not have had much influence on variability. Finally, it was thought that a different interpretation of the RF signal could enhance interobserver variability. However, when calculations were made on the same image, the coefficient of variation was less than $5 \%$ for all parameters and thus this factor only seems to influence variability slightly.

The advantage of the current method is that it is rather insensitive to interaction of echo signals from closely related objects. Interference of echo signals influences the overall amplitude and may therefore result in a wrong estimation of displacement as a function of time (13). Since the vessel wall movement detector system is not based on amplitude tracking, but on detecting phase differences in the RF signal, the measurement of changes in arterial diameter is more accurate. The technique in its present form does not allow real time calculations. However, off-line postprocessing restricts the recording time, resulting in less abserver bias. With an-line postprocessing the observer has to perform calculations and simultaneously the transducer must be kept immobile for a limited period of time. This enhances the risk for observer bias. Another advantage of off-line analysis is that computations can be repeated on the same RF signal if the observer is not satisfied with the distension waveform abitained.

Pulse pressure was measured non-invasively with a Dinamap. Assessment of pulse pressure with this device has shown a good correlation with invasive intra-arterial pressure monitoring and with other non-invasive pressure recording techniques $(4,21,24,28)$. Non-invasive monitoring of local pulse pressure at the site of measurement is not possible yet, but a positive relationship has been found between pulse pressure in the brachial artery and the distension in the common carotid artery (25). New techniques to assess local pulse pressure are being developed, but they still need evaluation (12).

In conclusion, the present study has shown that with the recently developed vessel wall movement detector

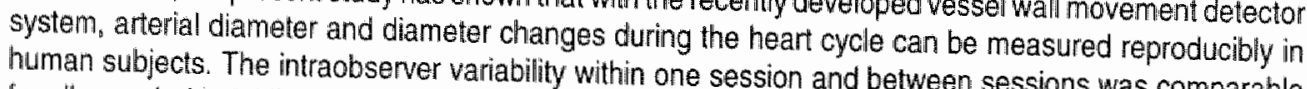
for all vessels. Variability was larger in the muscular femoral and brachial arteries than in the comparable artery, but overall the results were quite reproducible. Interobserver intrasesion than in the elastic carotid CCA was around $10 \%$ for the actually measured variability for the calculated parameters disten parameters $D$ and $\triangle D$. On the other hand, interobserver variability. This stresses the need for adequate training compliance was higher than intraobserver 
haemodynamic variations might also play a role. In any case, the interpretation of the RF signal seemed not to contribute substantially to the differences between the observers in the present situdy.

This non-invasive method measures arterial distensibility and compliance more directly than previous techniques. In addition, it can be applied to a wide range of vessels. Compared to other haemodynamic techniques $(9,38)$, the measurements with the vessel wall movement detector system seem quite reproducible. The vessel wall movement detector system may therefore be a valuable tool for evaluation of vessel wall properties of large arteries.

\section{References}

1. Altura BT, Altura BM. Pentobarbital and contraction of vascular smooth muscle. Am J Physiol 1975:229:1635-40.

2. Amdt $, \mathrm{NO}, \mathrm{Kla}$ auske $\mathrm{J}$, Mersch $\mathrm{F}$. The diameter of the intact carotid artery in man and its change wilh pulse pressure. Pftugers Arch 1968;301:230-40.

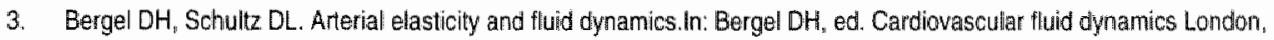
New York: Academic Press, $1972: 3-36$.

4. Borow KM, Newburger JW. Noninwasive estimation of central aartic pressure using the oscillometric method for analyzing systemic artery pulsatile blood flow: comparative study of indirect systolic, diastolic, and mean brachial artery pressure with simultaneous direct ascending aortic pressure measurements. Am Heart J 1982;103:879-86.

5. Demolis PD, Asmar RG, Levy BI, Safar ME. Non-invasive evaluation of the conduit function and the buffering function of large arteries in iman. Clin Physiol 1991:11:553-64.

6. Farrar DJ, Bond MG, Fllley WA, Sawyer JK. Anatomic correlales of aortic pulse wave velocity and carotid artery elasticify during atherosclerosis progression and regression in monkeys. Circulation 1991;83:1754*63.

7. Gow BS, Hadfield CD. The elasticity of canine and human coronary arteries with reference to postrnortem changes. Circ Res 1979;45:588-94.

8. Gustalsson D, Stale $\mathrm{H}_{3}$ Bjorkman J, Gennser G. Derivation of haemodynamic information Irom ultrasonic recordings of aortic diameter changes. Ultrasound Med Bioll 1989;15:189-99,

9. Haites, NE, Mowat DHR, McLenman FM, Rawles JM. How far is cardiac output? Lancet $1984 ; 2(8410): 1025 \cdot 27$.

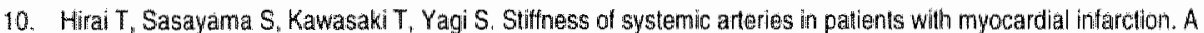
nonimasive method to predict severity of coronary atherosclerosis. Circulation 1989;80:78-86.

11. Hoeks APG Brands PJ, Reneman RS. Technical aspects of compliance assessment. Arch Mal Coeur Vaiss 1991,84 :77-81.

12. Hoeks, APG, Brands PJ, Reneman AS. Assessment of the arterial distension waveform using Doppler signal processing. J Hypertens $1992 ; 10$ (Supp). 6) :S19-22.

13. Hoeks APG, Brands PJ, Smeets FAM, Reneman RS. Assessment of the distensibility of superficial arteries. Ultrasound Med Biol 1990;16:121-28.

14. Kannel WB, WolI PA, McGee DL, Dawber TR, McNarnara P. Castelli WP. Systolic blood pressure, arterial rigidity, and risk of stroke. The Framingham study. JAMA 1981;245:1225-29.

15. Levenson JA, Peronneau PA, Simon A, Satar ME. Pulsed Doppler, determination of diameter, blood flow velocity, and: wolume flow of brachial artery in man. Cardiowasc Res $1981 ; 15: 164-70$.

16. Wan Merode T. Hick PJ, Hoeks APG, Rahn KH, Reneman RS, Vessel wall properties of the carolid artery in normotensive and borderline hypertensive young male volunteers. J Hypertens 1987;5 (Suppl, 5) :S471-73.

17. van Merode T, Hick P.J, Hoeks APG. Fahn KH, Reneman RS. Carotid artery wall properties in nomotensive and borderline hypertensive subjects of various ages. Ultrasound Med Binal 1988;14:563-69. 
18. Mozersiny DJ, Summer DS, Howanson DE, Strandness DE. Transcutaneous measurement of the ejastic properties of the humean Hemoral antery. Cilculation $1972,46,94855$.

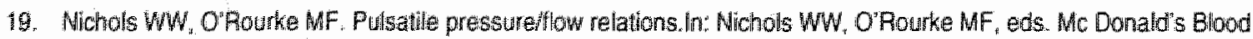
Flow in Arteries. Theorelic expermental and clinical principles 3rd ed London: E. Arrold, 1990:125-42.

20. Oisen CF. Doppler uhrasound: A lechnique for obtaining antera! wall motion parameters. UEEE Trans Biomed Eng $1977,5 \cup-24,354-58$

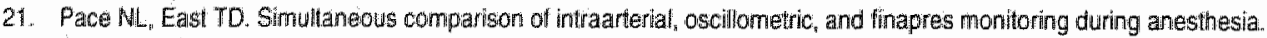
Anesith Arialig $1991,73,213-20$.

22. Pagan M Schwarz PJ, Bishop WS, Malitani A. Reflex sympathetic changes in aontic diastolic pressure-diametef relationship. Am of Physiol $1975,229: 28690$.

23. Pannier BM, London GM. Safar ME. The possible impact of arterial complitance on cardiac hypertrophy in arterial hypertersion. Scand J Clin Lab hrvest 1989;49 (Suppl. 196) :22-27.

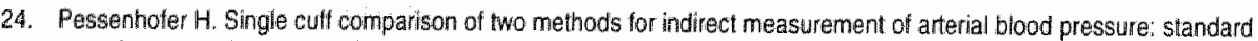
auscultalory method versus automatic ascillometric method. Basic Res Cardiol 1986:81:101-9.

25. Reneman RS, van Merode T, Hick P. Hoeks AP. Cardiovascular applications of multi-gate pulsed Doppler systems. Ulliasound Med Biol 1986;12:357-70.

26. Reneman FS, Wan Merode T, Hick P. Muytiens AMM, Hoeks APG. Age-related changes in carotid anteny wall properties in men. Utrasound Med Biol 1986;12;465-71.

27. Ritey WA, Bames RW, Evans GW, Burke GL. Uitrasonic measurement of the elastic modulus of the common carotid artery. The atheroscierosis risk in communities (AFIC) study. Stroke 1992,23:952-56.

28. Rutten AJ, Ilsley AH, Skowronski GA, Runciman WB. A comparalive study of the measurement of mean arterial pressure using aulomatic oscillometers, arterial cannulation and auscultation. Anaesth Intensive Care 1986;14 :58-65.

29. Safar M. Therapeutic trials and large arteries in hypertension. Am Heart J 1988;115:702-10.

30. Satar ME Pannier BP, Lacolley PJ, Levy Bl. Cardiac mass and aortic distensibility following calcium blockade in hypertension. J Cardiovasc Phamacol 1991:17 (Suppl. 2) :575-80.

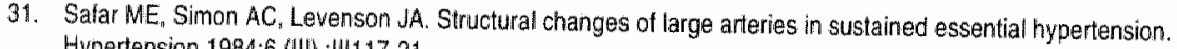
Hypertension $1984 ; 6$ (III): :111117-21.

32. Safar ME, Toto-Moukouo JU, Bouthier JA, Asmar RE, Levenson JA, Simon AC, London GM. Arterial dynamics, cardiac hypertrophy, and antihyperlensive treatment. Circulation 1987;75 (Suppl. I) :1156-61.

33. Simon A, Levenson J. Use of arterial compliance for evaluation of hypertension. Am J Hypertens 1991;4:97-105.

34. Simon AC, Laurent $S_{1}$ Levenson JA, Bouthier JE, Safar ME, Estimation of forearm arterial compliance in normal and hypertensive men trom simultaneous pressure and flow measurements in the brachial artery, using a pulsed Doppler device and if tirst-order arterial model during diastole. Cardiovasc Res $1983 ; 17: 331-38$.

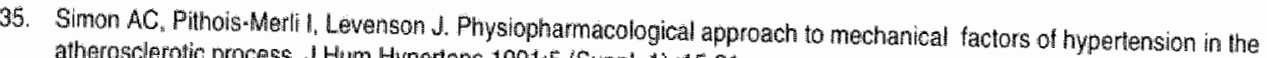
atherosclerotic process. I Hum Hypertens 1991:5 (Suppl. 1]: 15-21.

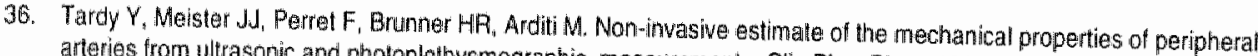
arteries from ultrasonic and photoplethysmographic measurements. Clin Phys Physiol Meas 1991:12:39-54.

37. Ventura M, Messerti FH, Oignan W, Suarez DH, Dreslinski GR, Dunn FG, Reisin E, Frohlich ED. Impaired systemic arterial complance in borderithe hypertension. Am Heart J $1984 ; 108: 132-35$

38. White SW, Owail AW, de Leew PW, Traugot FM, Brown WJ, Porges WL, Cottee DB. Impedance cardiography for cardiac output measurement: an evaluation of accuracy and limitations In: Robertson JIS, Birkenhger WH, eds. Cardiac
output measurement Corsendonk, Belgium; Janssem Biomedical Science Series, 1990:79-92. 39. Wildi $\mathrm{E}$, Knulthi JW, Allen HV, Meind J D Dynamics and limitations of blood/muscle intertace detection using Doppler
pow rer returns. IEEE Trans Biomed Eng 1980,27:565-73. 


\section{CHAPTER 4.1}

DIURNAL PATTERN OF VESSEL WALL PROPERTIES OF LARGE ARTERIES IN HEALTHY MEN

Mirian J. Kooil, Joseph A. Wijnen, Arnold P. Hoeks, Harry A. StruilikerBoudier, and Luc M. Van Bortel

Departments of Pharmacology, Diwision of Clinical Pharmacology and "Department of Biophysics, University of Limburg, the Netherlands

Based on J Hypertens 1991, 9 (suppl6): \$108-S109 


\section{Summary}

Diumal variation in blood pressure and heart rate is well documented. Vessel wall properties (distensibility and compliance) are important determinants of pulse pressure and, therefore, may also fluctuate throughout the day. In 12 healthy male volunteers (19-29 years) arterial diameter (D) and change in diameter during the heart cycle $(\Delta \mathrm{D}$, distension) of the elastic common carotid artery $(C \mathrm{CA})$ and the muscular brachial artery (BA) were studied non-invasively with a vessel wall movement detector system. Vessel wall properties were measured every two hours. Simultaneously arm blood pressure was measured every hour with a semi-automated device. From diameter, distension and pulse pressure ${ }_{n}$ distensibility and compliance were calculated.

Blood pressure (day: $118 \pm 3 / 66 \pm 1 \mathrm{mmHg}$ ) was significantly ( $p<0.05$ ) lower during the night (night:113 \pm 4 l $64 \pm 2 \mathrm{mmHg}$ ) : Pulse pressure (day:52 $22 \mathrm{mmHg}$ ) was also lower at night ( $49 \pm 2 \mathrm{mmHg}$; p0.01). Diameter of CCA (day:6.47 $\pm 0.12 \mathrm{~mm}$ ) increased during the night $(6.64 \pm 0.11 \mathrm{~mm} ; p<0.05)$. Similar changes were seen for diameter of the brachial artery. Distensibility of CCA and BA tended to decrease at night (n.s.), while compliance of both arteries was preserved during the night.

In conclusion, a diurnall pattern in arterial diameter and distensibility of elastic and muscular large arteries was found. Compliance, the buffering capacily of larger arteries, was preserved at night. 


\section{Introduction}

Large arteries have a conduit and a buffering function (9). They transform the systolic flow jet from the heart into a more continuous flow for tissue perfusion. Arterial distensibility and compliance are vessel wall properties that determine the buffering function of large arteries. These properties can now be measured non-invasively with ultrasound techniques (3). A decrease in arterial distensibility and compliance increases pulse pressure and left ventricular load ${ }_{n}$ and may play a role in the onset of atherosclerosis (7).

Diurnal variability in arterial blood pressure and heart function has been well documented (5). Whether vessel wall properties also show a circadian pattern has not been studied. In the present study, therefore, we investiglated the fluctuations of vessel wall properties of large arteries in healthy volunteers over a 24-hour period.

\section{Subjects and methods}

Subjects - Twelve healthy male volunteers entered the study, aged 22 years (range 19-29 years), weighing $71 \mathrm{~kg}$ (48-92 kg) and standing $184 \mathrm{~cm}$ tall (165-192 cm).

Study design-After an overmight fast, the subjects came to the laboratory for 26 hours. Standard meals were given at 9 a.m., 1 and 7 p.m. During the night (11 p.m. to 8 a.m.) the volunteers stayed in bed. All haemodynamic measurements were performed in the recumbent position after 15 minutes of supine rest. Blood pressure was measured at 1 -hour intervals and vessel wall properties at 2-hour intervals. Vessel wall properties of the elastic right common carotid artery (CCA) and the muscular right brachial artery (BA) were assessed with the vessel wall movement detector system, as described in Chapter 2.

Simultaneously with the recordings of vessel wall movement, arm blood pressure was measured every 2 minutes, using a Dinamap (Chapter 2). Vessel wall properties distensibility and compliance were calculated according to the equations mentioned in Chapter 2.

Data analysis - Mean values during the day (08:00 to 23:00) and the night (midnight to 07:00) were calculated for each subject. Statistical analysis of day-night differences was performed with the non-para. metric matched paired, signed-rank Wilcoxon test. $p<0.05$ was considered statistically significant. Twenty four-hour cunves were created for vessel wall properties of the inwestigated arteries. They show the average data at each time point during the observation period. The data are presented as means \pm s.e.m.

\section{Results}

Table 1 summarises day-night changes in blood pressure and vessel wall properties. Systolic and diastolic blood pressure (day:118 $\pm 3 / 66 \pm 1 ;$ night: $113 \pm 4 / 64 \pm 2 \mathrm{mmHg}$ ) and pulse pressure (day:52 \pm 2 ; night: $49 \pm 2 \mathrm{mmHg}$ ) were lower at night ( $p<0.05$ and $p<0.01$, respectively). The 24-hour curve of blood pressure followed the well-known day-night pattern and rose when the volunteers awoke, but were still in bed.

Figure 1 shows day-night changes on vessel wall properties of the common carotid and brachial artery. In addition, the 24-hour curve of the common carotid artery is shown. The 24-hour profile of the brachiall artery is similar to this pattern. 


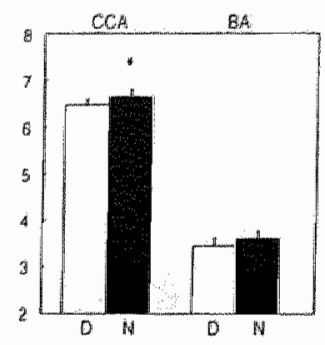

1A. Diameter (mm)

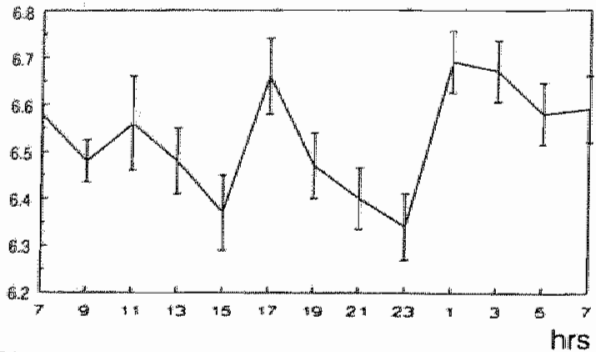

1B. Change in diameter ( $(\mathrm{m})$
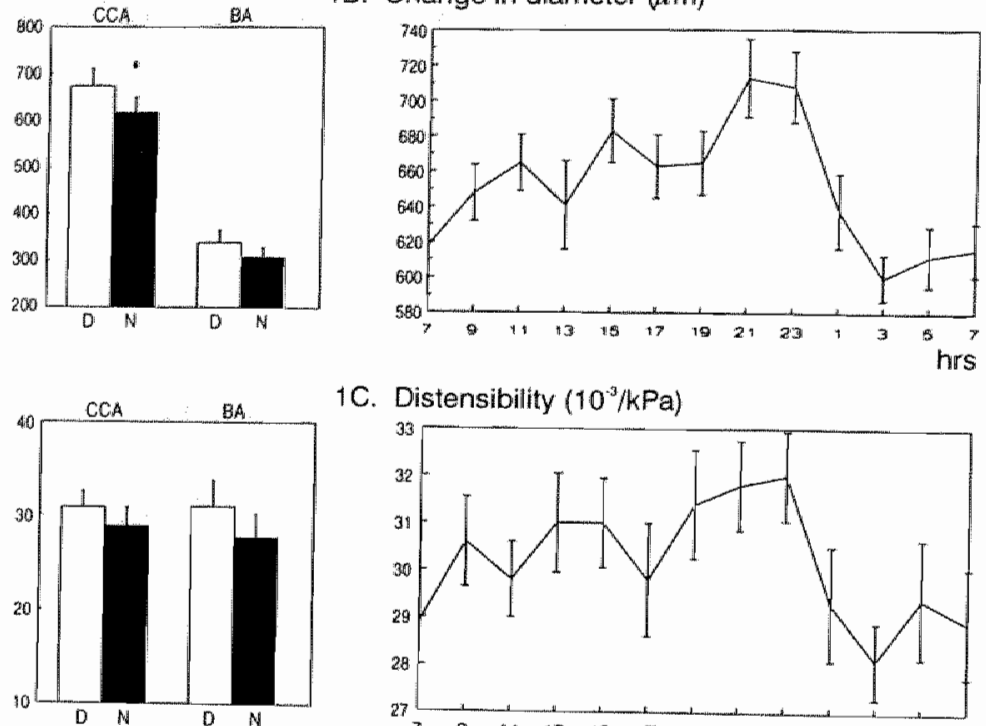

1C. Distensibility $\left(10^{3} / \mathrm{kPa}\right)$
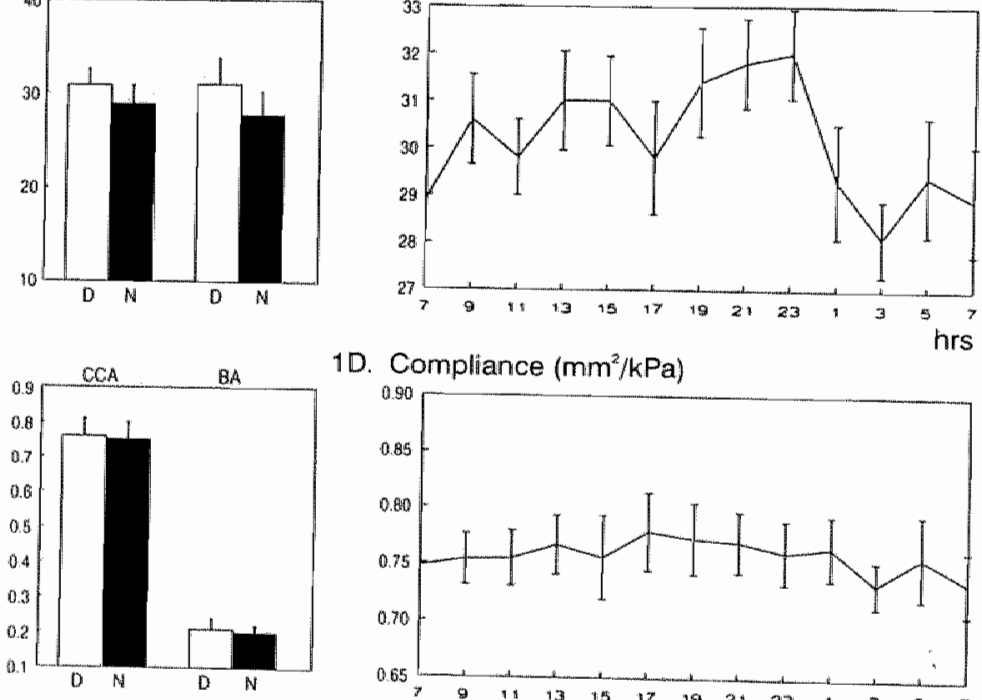

1D. Compliance $\left(\mathrm{mm}^{2} / \mathrm{kPa}\right)$

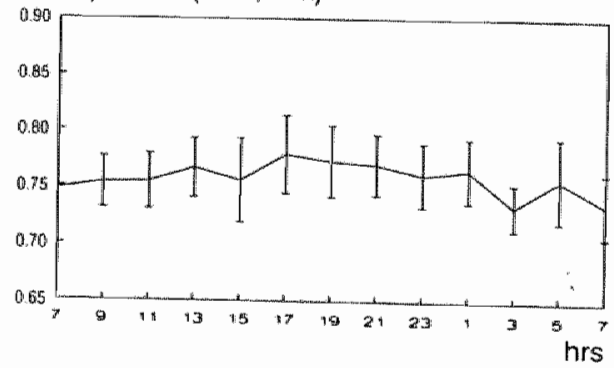

Figure 1. A) Lett panel day-night difference in arterial diameter of the common carotid artery (CCA) and brachial artery (BA): Fight panel: diurnal variation in arterial diameter of $C C A ; B$ ) Left panel: day-night difference in change in diameler during the heart cycle of the common carotid artery (CCA) and brachial artery (BA); Right panet diurnal variation in change in diameter during the heart cycle of $\mathrm{CCA}_{\text {" }}$ C) Left panel day-night difference in distensibility of the common carotid artery (CCA) and brachial artery (BA); Right panel diurnal variation in dislensibility of $\left.C \mathrm{CA}_{\mathrm{B}} \mathrm{D}\right)$ Left panet. day-night difference in compliance of the common carotid artery (CCA) and brachial artery (BA); Right pamel: diurnal wariation in compliance of CCA.

Data are mean \pm s.e.m.; $\mathrm{J}=\mathrm{D}$ (day); $\mathbf{D}=\mathrm{N}$ (night); " $\mathrm{p}<0,05$ (difference between mean day and mean night values) 


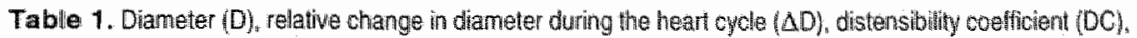
and compliance coefficient ( $\mathrm{CC}$ ) of the fight common carotid artery (CCA) and the right brachial antery (BA).

\begin{tabular}{|c|c|c|}
\hline & Day & Night \\
\hline $\mathrm{BP}(\mathrm{mm} \mathrm{Hg})$ & $118 \pm 3 / 66 \pm 1$ & $113 \pm 64=2$ \\
\hline$\triangle P(\mathrm{~mm} \mathrm{Hg})$ & $52 \pm 2$ & $49 \pm 2^{* *}$ \\
\hline $\mathrm{D}_{\mathrm{CcA}}(\mathrm{mm})$ & $6.47 \pm 0.12$ & $6.64 \pm 0.11^{\circ}$ \\
\hline $\mathrm{D}_{\text {ex }}(\mathrm{mm})$ & $3.45 \pm 0.17$ & $3.60 \pm 0.16$ \\
\hline$\Delta \mathrm{D}_{\mathrm{CCM}}(\mathrm{um})$ & $674 \pm 37$ & $617 \pm 33^{2}$ \\
\hline$\Delta \mathrm{D}_{\mathrm{Qg},}(\mathrm{um})$ & $340 \pm 26$ & $308 \pm 24$ \\
\hline$D C_{\mathrm{Com}^{\mathrm{A}}}\left(10^{3} \mathrm{~s} \mathrm{kPa}\right)$ & $30.9 \pm 1.7$ & $28.9 \pm 2.0$ \\
\hline $\mathrm{DC}_{\mathrm{BA}}\left(10^{-3 / \mathrm{kPa}}\right)$ & $31.0 \pm 28$ & $27.7 \pm 2.5$ \\
\hline $\mathrm{CC}_{\mathrm{CCA}}\left(\mathrm{mm}^{2} / \mathrm{kPa}\right)$ & $0.76 \pm 0.05$ & $0.75 \pm 0.05$ \\
\hline $\mathrm{CC}_{\mathrm{BM}}(\mathrm{mm} 2 / \mathrm{kPa})$ & $0.21 \pm 0.03$ & $0.20 \pm 0.02$ \\
\hline
\end{tabular}

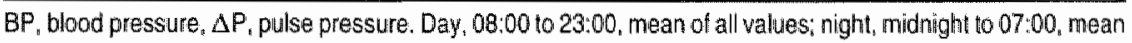
of all values. "p<0.05, $* 0<0.01$.

At night the diameter of the elastic common carotid artery was larger (day:6.47 \pm 0.12 ; night:6.64 \pm 0.11 $\mathrm{mm} ; \mathrm{p}<0.05$ ), while its distension decreased (day:674 \pm 37 ; night:617 $\pm 33 \mu \mathrm{m} ; \mathrm{p}<0.05$ ). Although not statistically significant, similar changes were seen for the muscular brachial artery: an increased arterial diameter (day: $3.45 \pm 0.17$; night: $3.60 \pm 0.16 \mathrm{~mm}$ ) and a decreased distension (day: $340 \pm 26 ;$ night:308 \pm 21 $\mu \mathrm{m}$ ) at night. Apart from the value at 5 p.m., which was an outlyer, the 24-hour curve nicely showes that during night arterial diameter increased and distension decreased.

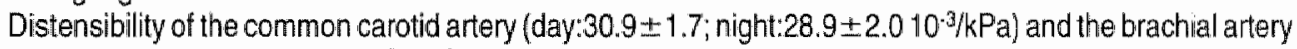
(day:31.0 $0 \pm 2.8$; night: $27.7 \pm 2.510^{-3} / \mathrm{kPa}$ ) tended to decrease at night. At night, all values for distensibility were lower than during the day. Carotid artery compliance (day:0.76 $\pm 0.05 ;$ might:0.75 $\pm 0.05 \mathrm{~mm}^{2} / \mathrm{kPa}$ ) and brachial artery compliance (day:0.21 \pm 0.03 ; night: $0.20 \pm 0.02 \mathrm{~mm}^{2} / \mathrm{kPa}$ ) hardly changed between day and night. The 24-hour curve on compliance confirms these data.

\section{Discussion}

Like prewious work $(5,6,8)$, this study showed a decrease in blood pressure and pulse pressure al night. In the present study the subjects were not physically active and were examined in the supine position. This might explain the relative small day-night differences in blood pressure compared with other studies $(1,2, B)$. The diameter of the elastic common carotid artery increased at night, despite a lower nocturnal blood pressure. This vasodilation might be due to a lower sympathetic tone at night (2 24$)$. In contrast, the relative change in diameter of the common carotid artery during the heart cycle decreased al night, which could be explained by a smaller nocturnal pulse pressure and a decrease in distemsibility. Although not statistically significant, this smaller distensibility may have been due to an already larger diastolic diameter all night. As a result of a smaller distensibility and a larger diastolic diameter, vascular compliance did not change, since from the equation for compliance (Chapter 2), compliance can also be defined as $D C \times D^{2} \times \pi / 4$. This indicates that the buffering function of large arteries is preserved at night. 
Similar changes in vessel wall properties were seen in the brachial artery, also suggesting the presence of a day-might pattern. These changes were no: statistically significant because of a larger short-term intra-individual variation in the diameter and in the relative change in diameter during the heart cycle. It is not clear whether this larger variation in the vessel wall properties of the brachial artery is caused by a lechnical difficulty in the recording procedure or reflects a real haemodynamic variation in the muscular arteries, which are predominantly under neurohumoral control (10).

In conclusion, the results of the present study indicate the presence of a diumal pattern in the diameter and distensibility of muscular as well as elastic arteries. The day-night pattern of distensibility was similar to the durnal variation in blood pressure, while day-night changes in arterial diameter were inversely related to blood pressure. Compliance of large anteries barely changed during the night. This suggests that, despite diumal change in elastic properties, the buffering function of large arteries is preserved throughout the day:

\section{References}

1. Clank LA, Denby L, Pregbon D, Harshtield GA, Pickering TG. Blank $S$, Laragh $H_{H}$. A quantitative analysis of the effects of activity and the of day on the diumal variations of blocd pressure. J Chron Dis 1987:40:67:-81.

2. Funtan $R$, Guzzeti $S$. Crivellaro W, Dassi $S$, Tinelli M, Baselli $G$, Cerutti S. Lombardi F, Pagani M, Malliani A. Continuous 24 hour assessment of the neural regulation of sysitemic arterial pressure and RR variabilities in ambulant subjects. Circulation: $1930 ; 81: 537-47$.

3. Hoeks APG, Brands PU, Smeets FAM. Reneman AS. Assessment of the distensibility of superficial arteries. Ultrasound Med Bol 1990; $16 \cdot 121,28$.

4. Lissell CA, Lightman SL, Multen PE, Brown MJ, Causon RC. Circadian thythms of epinephrine and norepinephrine in man. 5 Chn Endocrino Metab 1985,60:1210-15

5. Wharraig H, Bishop CN, Rattery EB. Circadian variation of blood-pressure. Lancet 1978; :795-97.

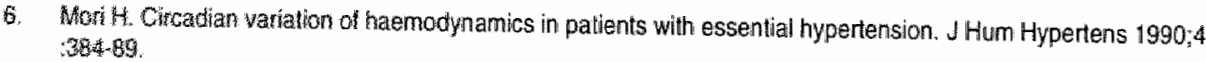

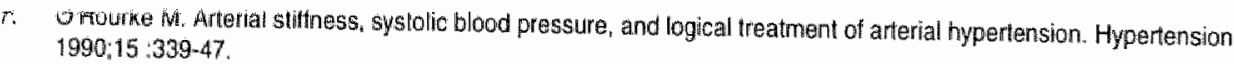
8. Pickering TG, Harshlield GA, Kleinert HD, Blank $\mathrm{S}$, Laragh JH. Blood pressure during normal daily activities, sleep, and
axcercise. JAMA 1982:247:992-96.

9. Satar M. Therapeutic trials and large arteries in hypertension. Am Heart d 1988;115:702-10.

10. Satar ME, London GM. Arterial and verous compliance in sustained assential hypertension. Hypertension 1987;10
$: 133-39$. 


\section{CHAPTER 4.2}

DIURNAL VARIATION IN PRORENIN IN RELATION TO OTHER HUMORAL FACTORS AND HAEMODYNAMICS

Mirian J. Kool, Joseph A. Wijnen, Frans H. Derkx, Hariry A. Struijker Boudier, and Luc M.

Van Bortel

Departments of Pharmacology, Cardiowascular Research lnstitute Maastricht, University of Limburg, and Department of Internat Medicine, Erasmus University, Rotterdam, The Netherlands

Based on A I H 1994, 7: 723-730 


\section{Summary}

Diumal variation has been demonstrated for blood pressure and heart funciion. Several hormones iniluence these haemodynamic parameters. This study investigates the diumal variation in plasma prorenin in relation to renin, atrial natriuretic peptide (ANP), noradrenalin and haemodynamic changes. Circulating plasma prorenin may be able to serve as a marker for the activity of the local renin-angiotensin system. In 12 healthy male volunteers who were allowed to carry out quiet activity, haemodynamic factors and the plasma levels of hormones were monitored at 2 -hour intervals lor 26 hours. Blood pressure was measured every hour.

In accordance with the literature, during the night blood pressure (4\%), cardiac index (19\%), stroke index $(10 \%)$, and heart rate $(10 \%)$ decreased in a classic day-night pattern. Systemic vascular resistance increased during the night (23\%). No classic day-night pattern was found for ANP, although it increased $(15 \%)$ at night and showed a peak early in the night. This peak seemed to be influenced by posture. A classic day-night pattern was demonstrated for noradrenalin and prorenin. Noradrenalin was lower (18\%) at night and increased as soon as the subjects awoke, while they were still in bed. Therefore, plasma noradrenalin levels seemed to be related to awakening. Plasma prorenin decreased at night $(6 \%)$. Renin fluctuated throughout the day, but showed no clear day-night pattern.

In conclusion, renin fluctuated throughout the day and did not show a classic day-night patterm. In contrast. prorenin fluctuated less and showed $6 \%$ higher levels during the day compared to the night. The origin and clinical significance of this small diumal variation in prorenin is not clear yet. 


\section{Introduction}

Cardiovascular function is influenced by several hormones. Neurohumoral factors such as cortisol and aldosterone may influence haemodynamic variations in humans $(11,16)$. Catecholamines and the reninangiotensin system contribute significantly to the regulation of cardiovascular haemodynamics. Except for prorenin, diurnal variation of these hormones has been extensively investigated $(13,14,18,25,34)$.

Like catecholamines, which are released at two sites, the adrenal medulla and nerve endings, there are two forms of the renin-angiotensin system (RAS). However, the significance of the various components of the RAS is not yet fully understood. The classic circulating RAS is a real endocrine system. The components of the circulating RAS originate from various organs (kidneys, lungs, liver) and are released into the circulation. On the other hand, local renin-angiotensin systems have been demonstrated in extrarenal tissues, such as the human reproductive organs $(37)$ and blood vessels $(10,29)$. In addition, in animal studies the existence of a local RAS in the heart, brain, blood vessels, adrenal gland and testes has been demonstrated (37), but its presence in the corresponding human tissues (29) is less clear. With regard to haemodynamics, it has been suggested that the local wascular RAS may be particularly important in the long-term control of the cardiovascullar system, while the circulating system could provide short-term renal and circulatory homeostasis (10). The main source for circulating renin is the kidney (15). Animall studies and in vitro data suggest that renin may also be produced locally, i.e., in the heart and the vessel walls $(5,10,29)$, but there are no data available from human in vivo studies. Renin may be synthesised in the vascular wall itself (20) or may be taken up from the plasma into the arterial wall (10). The majority of circulating renin is present in the inactive form prorenin (7). Prorenin levels in plasma are 10 times higher than renin levels (37). The clinical importance of prorenin has not yel been fully established. Prorenin has always been thought to be the inactive precursor of renin, but a more direct and active role has recently been claimed for prorenin in the generation of angiotensin I $6,7,37)$. Like renin, the majority of prorenin (two-thirds) is produced in the kidney. Some authors have postulated that one-third of prorenin is synthesised at tissue sites, mainly in the reproductive organs $(15,37)$.

It has been assumed that the kidney-derived prorenin reaches the circulation and may - directly or indirectly - lead to the formation of local angiotensin I (Agl) and angiotensin II (Agll) (1). Prorenin from extrarenal tissues could result in direct local generation of $\mathrm{Agl}$ and $\mathrm{Agll}(15,37)$. In addition, animal data provide no evidence for the conversion of prorenin to renin in the circulation or that circulating prorenin has the same physiological properties as renin (24). Prorenin may serve as a reservoir of potential renin, have a transport function for renin or act directly on the cardiovascular system (31). It has also been suggested that prorenin may play a locally protective vasodilator role, opposing the vasoconstrictive role played by the renin system. This would ensure adequate blood flow within certain tissues. Thus, prorenin has been considered to have an autoregulatory function (23). Recent work has also shown that prorenin may cause vascular damage as a resull of hyperpertusion injury (23). Various states of disease have been linked with enhanced prorenin concentrations ( 7 ). After bilateral nephrectomy, substantial amounts of prorenin could be detected, while renin levels were low. Therefore, plasma concentrations of prorenin are suggested as a marker for the activity of the local RAS (37).

Both the systemic and local RAS lead to the formation of Agll, a potent vasoconstrictor with effects on body Iluid homeostasis, vascular tone, myocardial function, and cardiovascular structure $(10,17)$.

Taken together, prorenin is thought to play an important role in carciovascular haemodynamics. A diurnal wariation in blood pressure (26), angina pectoris (40), and myocardial intarction (45) has been described earlier. The relationships between these variations and other hormones have been investigated $(11,12,16,34)$, but the relationship with prorenin is not known.

The present study inwestigates the fluctuations of prorenin throughout the day in relation to the diurnall wariation in remin, atrial natriuretic peptide (ANP), noradrenalin and haemodynamic changes. It is hypothesised that prorenin plays a role in cardiovascular pathophysiology and therefore variations in prorenin may interfere with haemodynamic control. 


\section{Subjects and methods}

Subjects - Twelwe healthy male wolunteers, aged 19 to 29 years, with weights ranging from 48 to $92 \mathrm{~kg}$ and heights from 165 to $192 \mathrm{~cm}$, participated in the study. Young male volunteers were chosen to avoid the well-known effects of age and the menstrual cycle on prorenin levels $(7,15)$.

Study Design - The volunteers came to the laboratory after an overnight fast and remained in a quiet room for 26 hours. Before the start of the study an intravenous catheter was applied to the left forearm. All haemodynamic examinations were performed in the recumbent position after $15 \mathrm{~min}$ of supine rest and blood samples were taken after at least 40 min of supine rest. Between the examination periods volunteers were allowed to carry out quiet activities, eg, reading, studying, quiet walking. Between 23:00 and 07:00 they stayed in bed. At 07:00 the subjects were wakened. Standard meals were given at 09:00, 13:00, and 19:00. Salt intake was within the normal range (6 g/day). Subjects did not change their dietary habits. There was no salt restriction that could have activated the renir-angiotensin system. Smoking and the use of caffeine were not allowed.

Blood pressure was measured every hour. Heart function was investigated at 2-hour intervals and plasma samples were also collecied every 2 hours. The study was approved by the Medical Ethics Committee of the University of Limburg. Written informed consent was received from all subjects.

Methods - Arm blood pressure was recorded non-inwasively with a semi-automated device at the left brachial artery as described in Chapter 2 (Dinamap; Critikon, Tampa, Florida, USA). Recordings were performed every $2 \mathrm{~min}$ for $20 \mathrm{~min}$ and the mean of 10 recordings was taken.

Cardiac index, stroke index, and heart rate were monitored non-invasively on a beat-to-beat basis with bioimpedance electrocardiography (NCCOM3-A7; BoMed Medical Manufacturing Ltd, Irvine, California, USA), as described previously (28). Cardiac index, stroke index and heart rate were measured continuously for $20 \mathrm{~min}$. The systemic vascular resistance index was calculated as the ratio of mean arterial pressure and cardiac index.

Venous blood samples for determination of ANP, noradrenatin, renin, and prorenin were taken with the subjects in the recumbent position from an indwelling catheter. Blood samples were collected in 5-ml polystyrene tubes (ANP, renin) and 10-ml (noradrenalin) polystyrene chilled tubes, kept on ice water. Tubes for ANP and renin contained EDTA (1 $\mathrm{mg}$ ). Those for noradrenalin were heparinised and contained $12 \mathrm{mg}$ of givtathione. For ANP the peptidase inhibitor aprotinin $(10,000 \mathrm{U} /)$ was added. After collection the samples were centrifuged immediately at $4^{\circ} \mathrm{C}$ for $30 \mathrm{~min}$ at $1500 \mathrm{~g}$ for moradrenalin and for 15 minutes at $1500 \mathrm{~g}$ for the other hormones. Plasma was stored at $-70^{\circ} \mathrm{C}$ until assayed.

ANP was determined with an indirect RIA (INC-star; Stillwater, USA) after extraction on SepPak C18 cartridges (Waters associates; Milford, Massachusets, USA). The intra-assay coefficient of variation was $8.6 \%$ and the interassay coefficient of variation $11.6 \%(41)$. Renin and prorenin were quantified with an indirect RIA as described by Derkx et al (8). Fenin and prorenin concentrations as measured by this method have proven to give a valid estimate of the real prorenin content in human plasma. The risk of cryoactivation of a small portion of the prorenin may be neglected ${ }_{1}$ as the period between collection and centrifuging of the blood was less than 15 minutes. In addition, a protease inhibitor was used $(7,8)$. Normal ranges for renin $(4.8$ to 71.4 mean $16.9 \mu \mathrm{U} / \mathrm{ml})$ and prorenin ( 77 to 354 ; mean $171 \mu \mathrm{U} / \mathrm{ml})$ have been published previousiy (7). Noradrenalin levels were measured by means of HPLC with fluorescence detection, according to Van der Hoom et al (42). The intra-assay coefficient of variation was $4.0 \%$ and the interassay coefficient of variation $6.9 \%$. The detection limit was $20 \mathrm{pg} / \mathrm{ml}$. In addition, diurnalvariation in plasma volume was monitored indirectly, using plasma albumin levels.

Data Analysis - The first measurements, at 09:00, were used to familiarise the subjects with the procedure. The analysis was based on the measurements from 11:00 until 09:00 the next day. Mean 
daytime values (08:00 to 23:00) and mean nighttime values (midnight to 07:00) were calculated for each subject. Day-night differences were analysed with the non-parametric matched, paired, signed-rank Wicoxon test. $p<0.05$ was considered statistically significant.

Twenty four-hour curves were created for each parameter. They show the average data at each time point during the observation period. A classic day-night pattern is defined as the well-known day-night difference in blood pressure with higher values during the day than during the night. All results are presented as mean \pm s.e.m.

\section{Results}

Table 1 gives a summary of day-night changes in haemodynamic and hormonal parameters. Figure 1 shows the data for arterial blood pressure.

Table 1. Day-night differences in haenodynamics and hormonal parameters.

\begin{tabular}{|c|c|c|}
\hline & Day & Night \\
\hline \multicolumn{3}{|l|}{ Haemodynamics } \\
\hline Blood pressure (mmHg) & $118 \pm 3 / 66 \pm 1$ & $113 \pm 4 / 64 \pm 2$ \\
\hline Mean arterial pressure $(\mathrm{mmHg})$ & $83 \pm 2$ & $80 \pm 2^{* *}$ \\
\hline Cardiac index (U/min.man $)$ & $4.2 \pm 0.2$ & $3.4 \pm 0.1^{* * *}$ \\
\hline Stoke index $\left(\mathrm{mL} / \mathrm{m}^{2}\right\}$ & $70 \pm 4$ & $63 \pm 3^{* n *}$ \\
\hline Heart rate (beatsimin) & $62 \pm 2$ & $55 \pm 2^{* * *}$ \\
\hline SVRI (dyn.S. $\left.\mathrm{cm}^{-5} . \mathrm{m}^{2}\right)$ & $1622 \pm 78$ & $1993 \pm 103^{* * *}$ \\
\hline \multicolumn{3}{|l|}{ Hormones } \\
\hline ANP $(\mathrm{pg} / \mathrm{mL})$ & $16.8 \pm 1.8$ & $19.1 \pm 2.0^{\circ}$ \\
\hline Noradrenalin $(\mathrm{pg} / \mathrm{mL})$ & $129 \pm 9$ & $106 \pm 11^{\text {tth }}$ \\
\hline PRA (pmol/mLh) & $1.1 \pm 0.2$ & $1.2 \pm 0.2$ \\
\hline Plasma renin $(w \mathrm{U} / \mathrm{mL})$ & $18.0 \pm 2.5$ & $19.7 \pm 2.0$ \\
\hline Prorenin $(a \mathrm{U} / \mathrm{mL} \mathrm{L})$ & $173 \pm 17$ & \\
\hline
\end{tabular}

ANP, Atrial natriuretic peptide; PRA, plasma renin activity; SVRI, systemic wascular resistance index. Data are mean \pm s.e.m; " p<0.05," p<0.01," $" p<0.001$.
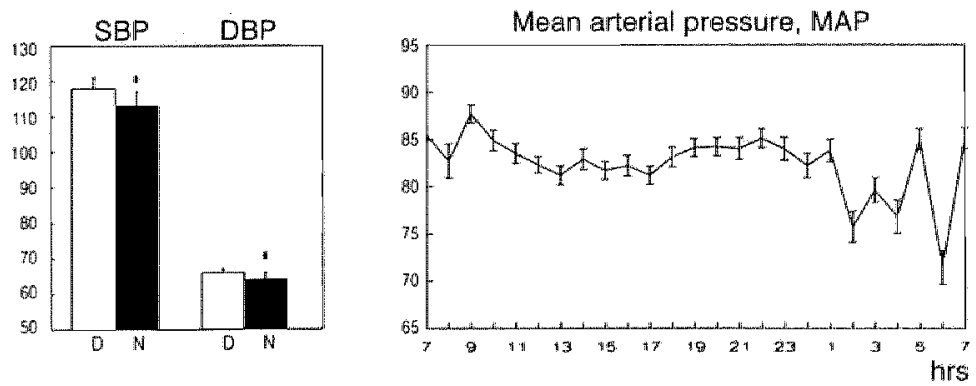

Figure 1. Diumal variation in arterial blood pressure. SBP, systolic blood pressure; DBP, diastolic blood pressure; dalla are mean \pm s.e.m. $\square=D($ day); $=\mathbb{N}$ (night); $p<0.05$ (difference between mean day and mean night values). 


\section{Cardiac index $(\mathrm{L} / \mathrm{min} \cdot \mathrm{m})$}
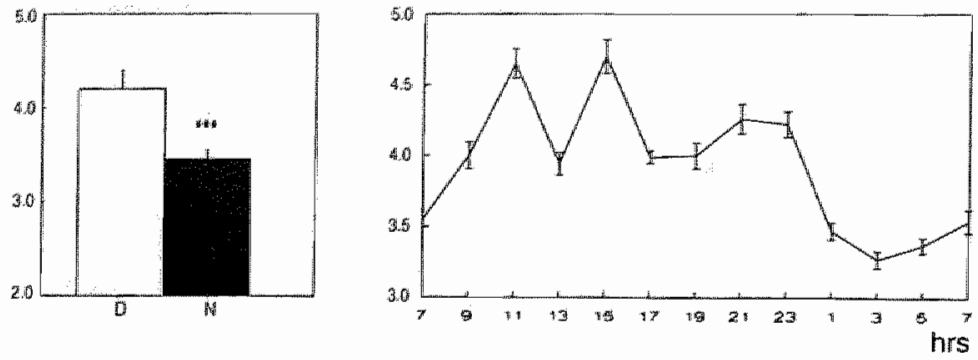

Stroke index $\left(\mathrm{mL} / \mathrm{m}^{2}\right)$
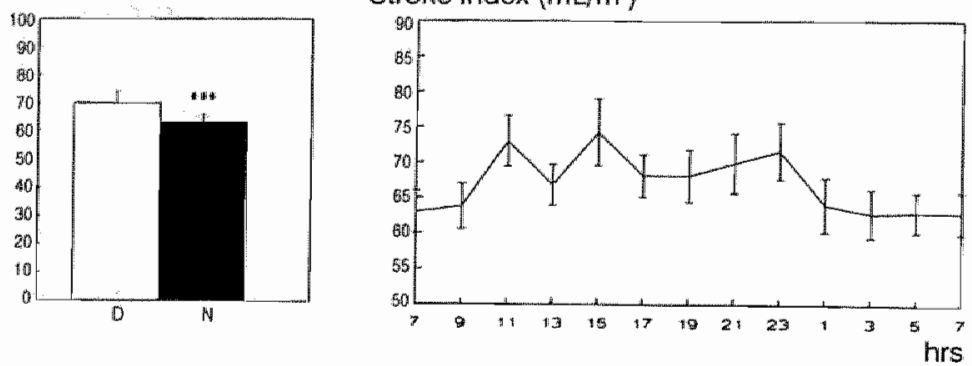

Heart rate (beats/min)
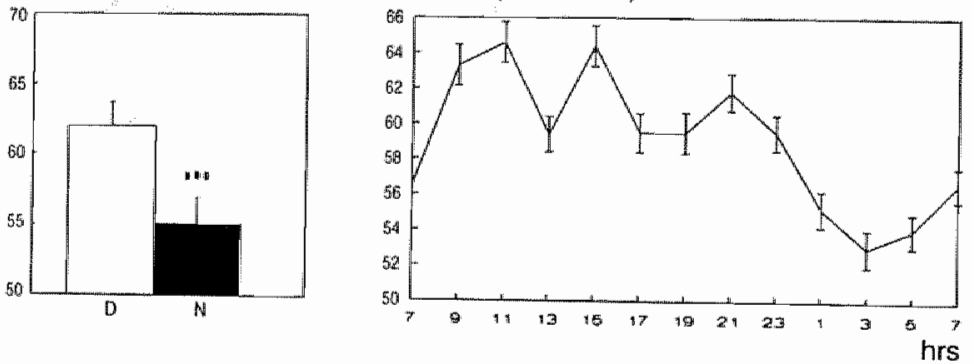

Figure 2. Diumal variation in cardiac function; data are mean $\pm s . e . m$. $\square=D($ day); $\mathbf{m = N}$ (night): *** $p<0.001$ (difference between mean day and mean night values).

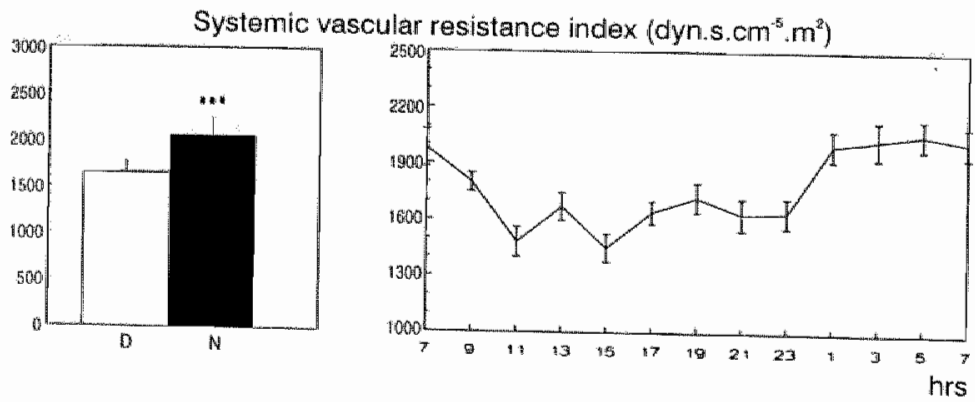
Figure 3. Diurnal variation in systemic vascular resistance index; data are mean \pm s.e.m.; $\square=D$ (day); $=N$
(night): ${ }^{* *} p<0.001$ (difference between mean day and mean night values). 
Atrial natriuretic peptide $(\mathrm{pg} / \mathrm{mL})$
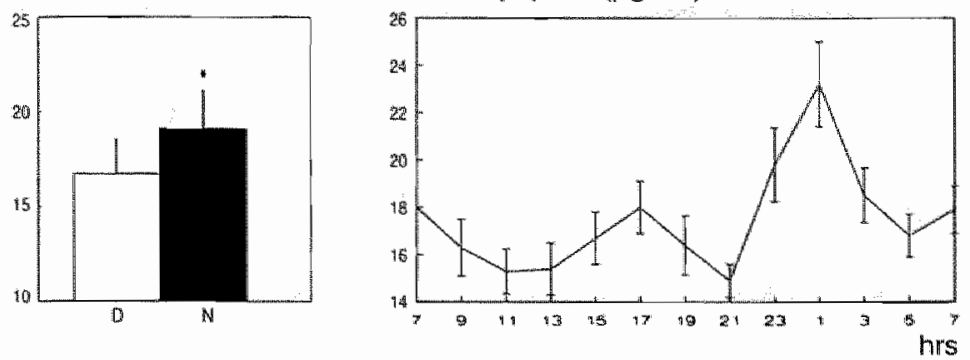

Noradrenalin (pg/mL)
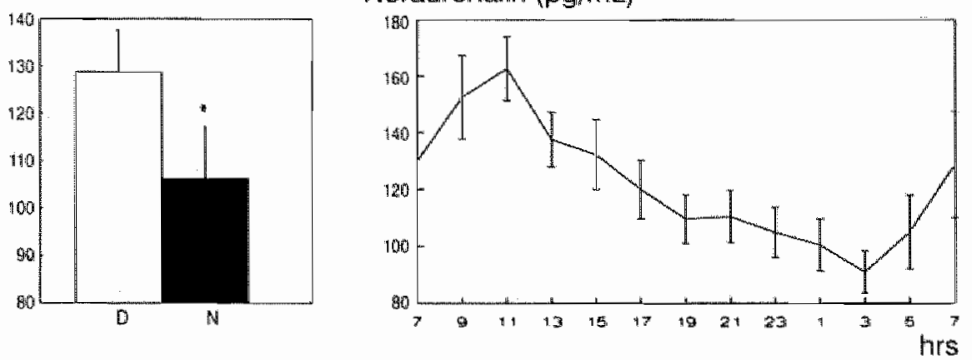

Renin $(u U / m L)$
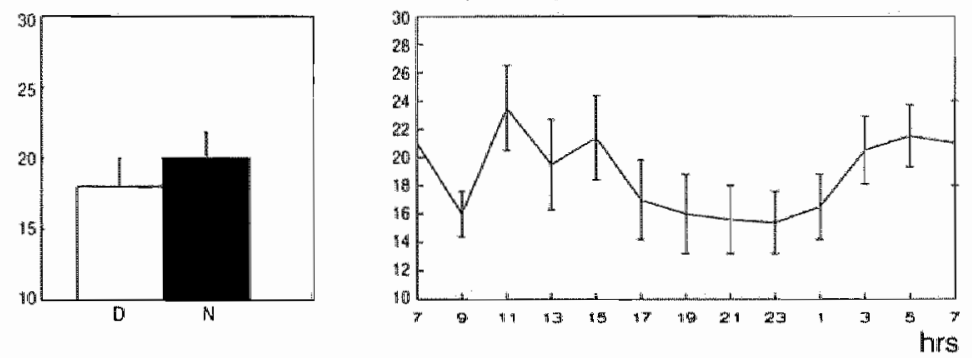

Prorenin $(\alpha \mathrm{U} / \mathrm{mL})$
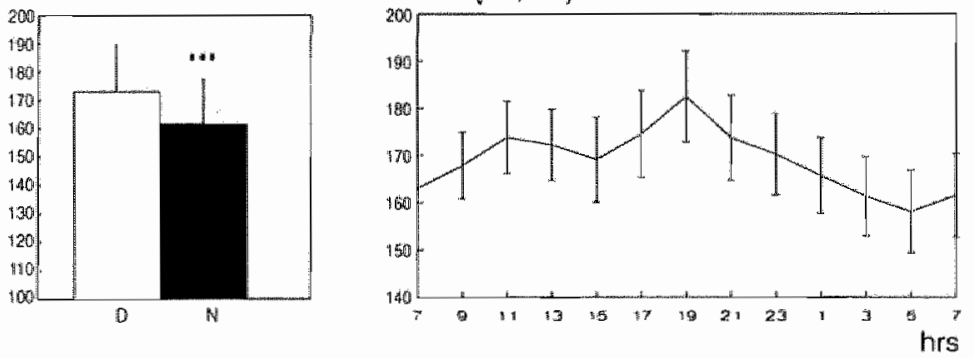

Figure 4. Diurnal variation in hormones; dala are mean \pm s.e.m. ; $\square=\mathbb{D}$ (day); $\square=\mathbb{N}$ (night); " $p<0.05$, $* * 0<001$ (difference between mean day and mean night values). 
Systolic and diastolic pressure (day: $118 \pm 3 / 661$; night: $113 \pm 4 / 64 \pm 2 \mathrm{mmHg}$ ) decreased at night $(\mathrm{p}<0.05$ ). Mean arterial pressure (day: $83 \pm 2$, night: $80 \pm 2 \mathrm{~mm} \mathrm{Hg}$ ) was also lower $(p<0.01$ ) during the night. Apart from the value at $05: 00$, the 24 -hour curve of blood pressure followed the well-known day-nighi patiern. Blood pressure rose sharply at 07:00, when the volunteers were awake, but still in bed. The cardiac index (day: $4.2 \pm 0.2$; night: $3.4 \pm 0.1 \mathrm{~L} / \mathrm{min}^{2} \mathrm{~m}^{2}$ ), stroke index (day: $70 \pm 4 ;$ night: $63 \pm 3 \mathrm{~mL} / \mathrm{m}^{2}$ ), and heart rate (day: $62 \pm 2$; night: $55 \pm 2$ beatsimin) decreased significantly $(p<0.001)$ at night (Figure 2). These parameters demonstrated a day-night pattern, similar to the classic blood pressure cycle, with a decrease after the subjects went to bed and an increase after awakening.

The systemic vascular resistance index (Figure 3) was higher at night (day: 1622 \pm 78 ; night: 1993 103 dyn. s. $\left.\mathrm{cm}^{-5} . \mathrm{m}^{2} ; \mathrm{p}<0.001\right)$. Systemic vascular resistance index showed an inverse day-night pattem as soon as the volunteers fell asleep there was a steep increase in vascular resistance and the values remained elevated during the night.

Plasma albumin levels did not differ between day $(39.9 \pm 0.6 \mathrm{~g} / \mathrm{L})$ and night $(39.3 \pm 0.4 \mathrm{~g} / \mathrm{L})$, and in fact varied little. There was a slight increase in albumin at 03:00,3\% higher than other albumin levels during the night. Hormonal changes are depicted in Figure 4. ANP increased at night (day: 16.6 1.8 ; night: $19.1 \pm 2.0 \mathrm{pg} / \mathrm{mL} ; \mathrm{p}<0.05$ ) with a peak 2 hours after the subjects assumed a constant recumbent position. Noradrenalin (day: $129 \pm 9$; might: $106 \pm 11 \mathrm{pg} / \mathrm{mL}$ ) decreased during the night $(\mathrm{p}<0.01)$. This is also clear from the 24-hour curve. A marked increase in noradrenalin was already present when the subjects woke up, while still in bed. The mean plasma renin concentration (day: $18.0 \pm 2.5$; night: $19.7 \pm 2.0 \mu \mathrm{U} / \mathrm{mL}$ ) did not differ significantly between day and night. Renin fluctuated throughout the day, with peaks, at 05:00, 11:00, and 15:00, but showed no clear day-night pattern. In contrast to renin prorenin levels (day: 173 \pm 17 ; night: $162 \pm 16 \mu \mathrm{U} / \mathrm{mL}$ ) were decreased $(\mathrm{p}<0.001)$ at night. Prorenin showed an obvious day-night pattern with all values at night lower than during the day.

\section{Discussion}

In accordance with other authors $(26,27)$, the present study showed clear day-night differences in haemodynamics. Systolic, diastolic and mean arterial pressure decreased at night, but this decrease $(5 \%)$ was somewhat smaller than those found by others $(26,33)$. The small diumal variation in blood pressure could be due to 1) the non-invasive blood pressure monitoring (32) or 2) the subjects' low level of physical activity in the laboratory (33).

A crucial point in the present study is whether the volunteers slept well. Although not objectively controlled, the volunteers apparently had an undisturbed sleep and clear day-night differences in haemodynamics were observed. If it is assumed that the volunteers did not sleep well, then, with an undisturbed sleep, even larger day-night changes would be expected.

Bioimpedance electrocardiography is an elegant method for cardiac monitoring during the night since sleep is not disturbed by the measurements. The feasibility and reproducibility of the technique has proven to be good in healthy subjects and in patients with cardiac disease (28). In general, the correlation with other techniques (i.e., thermodilution, echo Doppler) is high $(28,44)$. In the present study, the cardiac index decreased markedly at night (19\%) as a result of a diminished stroke valume (10\%) and a lower heart rate $(10 \%)$. These changes may be due to a lower sympathetic activity during night $(12,25)$. The cardiac index, heart rate and stroke volume rose after breakfast and lunch, while vascular resistance decreased. A postprandial high output-low resistance state has also been reported by other authors (19). As in the current study, blood pressure and plasma catecholamines generally do not change after the ingestion of food (19,25). The most likely explanation for the postprandial increase in cardiac output and reduction in total peripheral resistance is a redistribution of blood volume to the splanchnic vascular bed. The cause of the nocturnal increase (23\%) in total peripheral resistance is less clear. Studlies in humans (27) and animals $(38,39)$ have also reported a significant increase in systemic vascular resistance together with low cardiac 
output at night. Talan and Engel have postulated that this low output high resistance state may be mediated by a redistribution of blood and by a reduction in total blood volume (39). The higher peripheral resistance at night suggests a vasoconstriction of the smaller blood vessels. A nocturnal increase in the diameter of large arteries has been described (21), suggesting that large and small vessels do not behave similarly. Some authors have recently reported diumal variation in plasma wolume (2), suggesting that the hormonal changes might, at least in part, be due to haemodilution. However, in the present study no day-night differences were found in plasma albumin levels, which can serve also as a measure of plasma volume, so haemodilution is not likely to have been a factor.

ANP was higher (15\%) at night, but had no classic day-night pattern and was not obviously related to haemodynamic changes. The ANP variation seems to be influenced by body posture, as ANP showed a peak 2 hours after the subjects assumed a constant recumbent position. A peak of ANP early in the night has also been described by others $(4,9,34)$. In addition, an independent effect of posture on ANP levels . possibly due to a circulatory overload, but not related to changes in plasma volume - has been demonstrated (30\%).

Noradrenalin decreased significantly at night $(18 \%)$. This might reflect a lower sympathetic activity, as described previausly (12). Noradrenalin levels rose when the subjects awoke, while they were still in bed. The increase in noradrenalin was positively related to the blood pressure increase at the same time. This was also found in other studies, which measured an increase in noradrenalin of about $30 \%$ with awakening, while no changes were found in noradrenalin levels between the different sleep stages (25). Indeed, Furlan et al (12) found increased sympathetic activity immediately after awakening. Renin levels and (although not shown) plasma renin activity varied throughout the day, but no clear day-night pattern could be demonstrated. Variations in renin levels were probably not due to changes in posture $(3,34)$, because subjects were in the supine position for at least $45 \mathrm{~min}$. No clear explanation for the two peaks during the day was found. An influence from eating might be supposed, but no peak was found with the evening meal. It has been suggested that the peak in the second part of the night might be an adaptive mechanism of the body to prevent further natriuresis as caused by the preceding elevated ANP level $(4,9)$. However, it has also been suggested that the variation in renin may be associated with a diurnal variation in renal perfusion (22). Several interactions between the hormones measured in the present study may be of importance $(10,35,43)$.

This study is the first to describe a diurnal variation in prorenin. In contrast to renim, circulating plasma prorenin showed a classic day-night pattern with all values at night being lower (6\%) than during the day. Prorenin seems not to be influenced by posture, as it began to decrease before the subjects toak up a constant recumbent position. Besides, it was always measured after at least 40 min of supine rest. An interaction between ANP and the renin-angiotensin system has been presumed (36), but data are not consistent (35). From these data it is not clear whether the efiect of ANP on plasma renin activity is a direct or indirect feature. In the present study, no relation between proremin and ANP could be detected. However it might be that other factors, such as neurohormones, may play an underlying regulalory role.

The lower circulating prorenin at night may be due to a decireased renal or extrarenal release or to enhanced clearance. With regard to this, different pathways could be posited. Decreased production of prorenin or an increased breakdown of prorenin at night might decrease renin, and subsequently Agl and Agll formation, leading to less vasoconstriction. On the other hand, prorenin has been proposed as a vasodilating agent (23). Consequently, a decrease in prorenin could result in more vasoconsiriction. In addition, an enhanced local uptake of prorenin could lead to higher plasma clearance at night. As a result, more $\mathrm{Agl}$ and Agll could be formed al night, which would lead to more vasoconstriction. Thus, if prorenin contributes to the increased peripheral resistance at night, the latter two possibilities might be involved. In conclusion, the present study showed a classic diurnal pattern for blood pressure, heart rate and cardiac function, with decreased values at night. This could be due to a lower sympathetic activily during the night. On the other hand, an inverse diumal pattern was seen for systemic vascular resistance: resistance increased at night. ANP and renin had no classic day-night pattern, but mean ANP levels were higher at night, while renin did not differ between day and night. ANP seemed to be influenced by body posture, as 
it reached a peak after the subjects were in a constant recumbent position. For plasma noradrenalin a classic day-night pattern could be demonstrated. Noradrenalin increased after awakening, when the subjects were still in bed. In contrast to renin, prorenin showed a classic day-night pattern, with lowervalues at night than during the day. The origin and significance of the diumal variation in prorenin is not yet clear. If the lower levels of prorenin contribute to the nocturnal increase in peripheral resistance, the possible direct vasadilating effect of prorenin at night might be surmised to play a role.

\section{References}

1. Admirala PJJ, Derk FHM, Danser AHJ, Pietemain H, Schalekamp MADH. Intrarenal de now production of angiotensin I in subjects with renal artery stenosis. Hypertension $1990 ; 16: 555-63$.

2. Bell GM, Allas SA, Pecker M, Sealey JE. James G, Laragh JH. Durnal and positural wariations in plasma atrial natriuretic factor, plasma guanosine $3^{\prime \prime} 5^{\prime \prime}$-cyclic monophosphate and sodium excretion. Clin Sci 1990:79:371-76.

3. Chat NP, chanudet $X$, Larroque $P$. Inverse relationship between upright plasma renin activity and twenty-four hour blood pressure variability in borclerine hypertension. J Hypertens $1990 ; 8: 913-18$.

4. Colantonio D. Is atrial natriuretic peptide important in the circadian rhythm of arterial blood pressure? Am J Cardiol $1989 ; 63: 1166$.

5. Danser AHJ, Koning MMG, Admiraal P.J, Sassen LMA, Derkx FHM, Verdouw PD, Schalekamp MADH. Production of angiotensims I and il at vissue siles in intact pigs. Am J Physiol 1992;263:H429-437.

6. Derkx FHM, Deinum J, Lipowski M, Verhaar M. Fischli W, Schalekamp MADH Nonproteolytic "activation " of prorenin by active site-directed renin inhibitors as demonstrated by renin-specific monoclonal antibody. J Biol Chem $1992 ; 267$ .22837-42.

7. Derkx FHM, Schalekamp MADH, Human prorenin: pathophysiology and clinical implications. Clin Exp Hypertens [A]
$1938 ; A 10: 1213-25$.

B. Derkx FHM, Stuenkel C. Schalekamp MPA, Visser W, Huisveld JH, Schalekamp MADH. Ummunoreactive renin, prorenim, and enzymatically active renin in plasma during pregnancy and in women taking oral contraceptives. $J$ Clin
Endocrinol Metab 1986:63:1008-15. 9. Donckier d, Anderson $J V_{t}$ Yeo T, Bloom SR. Diumal thythm in the plasma concentration of alrial natriuretic peptide. N
Engl JMed 1986;315:710-11.

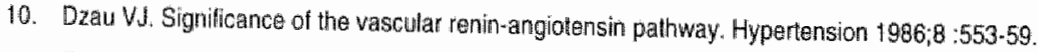

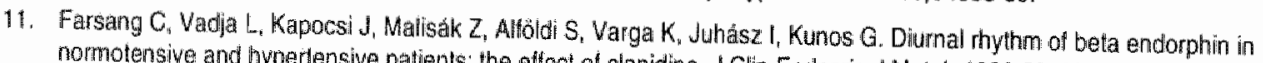
normotensive and hypertensive patients: the aftect of clonidine. J Clin Endacrinol Metab 1983,56:865-67.

12. Furlan R, Criwellaro W, Dell'Orto S, Gentle E, Piazza S, Pagani MR, Tinelli M, Cerutti S, Lombardi F, Ragani M, Mallani A. Circadian changes in vascilar sympathetic activity in ambulant subjects. J Hypertens 19897 (Suppl. 6)
$.530-31$.

13. Gordon FD. Wotfe LK, Island DP, Liddla GW. A diurnal rhythm in plasma renin activity in man. J Clin invesi 1966;45
$: 1587-95$.

14. Haberg $F$, Comelissen $G$, Marte - Sorenson $K$. lmportant thme, through not causal, relations in atrial natriuretic peptide cortisol and renin. Chronobiologia $1986,13: 361-64$.

15. Hsweh WA. Baxter JD. Humam prorenin. Hypertension 1991:17:469.79.

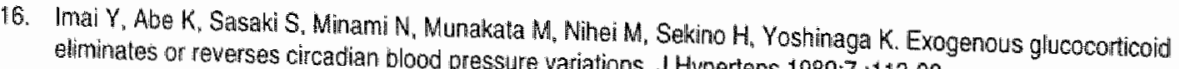
eliminates or reverses circadian blood pressure variations. J Hypertens 1989:7:113-20.

17. Johnston Cl. Biochemistry and phamacology of the renin-angiotenisin system. Drugs 1990;39 (Suppl. 1): 21-31. 
18. Katz FH, Romfh P, Smith JA. Diumal variation of plasma aldosterone, contsol and renin achivily in supine man. J Ohin Endocrinol Wetalb $1975 ; 40: 125-34$.

19. Kelbaek $H$, Munck $O$. Christensen NJ, Godtrendsen J. Central haemodynamic changes after a mea Br. Heart J $1989,611: 506 \% 9$.

20. Kifor 1, Dzau V1. Endlothelial renin - angiotensin pathway; evidence for intracellular synthesis and secretion of angiotensins. Circ Res $1987 ; 60: 422-28$.

21. Kool My, Winnen JA, Hoeks AP, Stiruyker-Boudier HA, Van Bortel LM. Diurnal pattern of vessel-wall properties of large arteries in healtry men. J Hypertens 1991;9 (Suppl. 6) :S108-109.

22. Koopman MG, Koomen GCM, Krediet RT, de Moor EAM, Hoek. FJ, Arisz L. Circadian rhythm of glomerular fitration rate in nomal individuals. Clin Sci 1989;77:105-11.

23. Laragh JH. The renin system and four lines of hypertension research. Nephron heterogene ily, the calcium conmection, the prorenin wasodilator limb, and plasma renin and heart attack. Hypertemsion 1992;20:267-79.

24. Lenz $T$, Sealey JE, Maack $T_{\text {n }}$ James GD, Heinrikson RL, Marion D, Laragh JH. Hallife, hemodynamic, renal, and hormonal effects of prorenin in cynomolgus monkeys. Am Ji Physioll 199\%:260:R804-10.

25. Linsell CR, Lightman SL, Mullen PE, Brown MJ, Causon RC. Circadian thythms of epinephrine and norepinephrime in man. J Clin Endocrinol Metab 1985;60:1210-15.

26. Millar-Craig MW, Bishop CN, Rattery EB. Circadian variation of blood-pressure. Laricel 1978; :795-97.

27. Mori H. Circadian wariation of haemodynamics in patients with essential hypertensijan. J Hum Hypertens 1990;4 :384-89.

28. Northridige DB, Findlay JN, Wilson $\rfloor$, Hendersion E, Dargie HJ. Non-inwasive determination of cardiac output by Doppler echocardiography and electrical bioimpedance. Br Heart J 1990;63:93-97.

29. Okamura T, Aimi Y, Kimura H, Murakami K, Toda N. Existence of renin in the endothelium of thuman artery. $\mathrm{J}$ Hypertens $1992: 10: 49-53$.

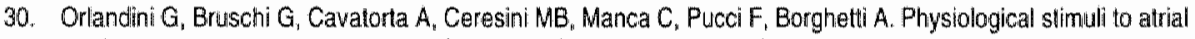
matruretic peptide secretion in hormal humans. J Hypertens 1987;5 (Supp). 5 ) :S67-70

31. Osmond DH, Sealey JE, McKenzie JK. Activation and function of prorening different viewpoints. Can J Physiol Pharmacol 1991:91:1308-14:

32. Parati $G$, Pomidossi $G$, Casadei $R$, Mancia $G$. Lack of alerting reactions to intemiltent cuff inllations during non-inwasive blood pressure monitoring. Hypertension 1985;7:597-601.

33. Pickering TG. The influence of daily activity on ambulatory blood pressure. Am Heart d 1988;116:1141-45.

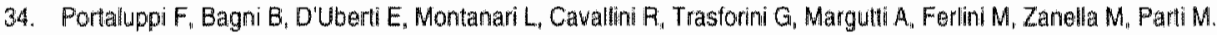
Gircadian hythms of atrial natriuretic peptide, renin, aldosterone ${ }_{i}$ cortisof blood pressure and heart rate in notimal and hypertensive subjects. J Hypertens 1990;8:85-95.

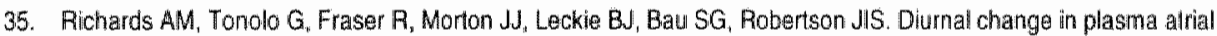
natriuretic peptide concentrations. Clin Sci 1987:73:489-95.

36. Roy LE, Ogilwe RJ, Larochelle P, Hamef P, Leenen FHH. Cardiac and vascular eflects of atrial natriuretic taclor and sodium nitroprusside in healthy men. Circulation 1989,79:383-92.

37. Sealey JE, Rubattu S. Prorenin and renin as separate mediators of tissue and circulating systems. Am J Hypertens $1989 ; 2: 358-66$.

38. Smith TL, Coleman TG, Stanek KA, Murphy Wh. Hemodynamic monitoring tor $24 \mathrm{~h}$ in unanesthetized rats. Am J Physiol $1987 ; 253: H 1335-41$.

39. Salan MI, Engel BT. Effect of sympathetic blockade on diumal wariation of hemodynamic patterns. Am J Physiol $1989 ; 256: R 778 m 85$

40. Taylor CR. Hodge EM, White DA, the Amlodipine angina study group. Circadian thythm of angina: similarily to circadian rhythms ol myocardial infarction, ischemic ST segment depression, and sudden cardiac death. Am Haart J $1989: 118: 1098-99$

41. Van Bortel LMAB, Schiffers PMH, Böhm ROB, Mooij JMV, Struijker-Boudier HA.J. The influence of chronic treatment with verapamil on plasma atrial natruretic peptide levels in young and elderly hypertensfive patients. Eur $J$ Clin Pharmacol 1990,39 (Suppl. 1) :S39-40. 


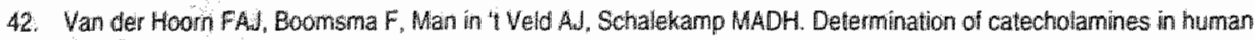
plasma by high and an established method with electrochemical detection. 3 Chromatogr $1989,487: 17-28$.

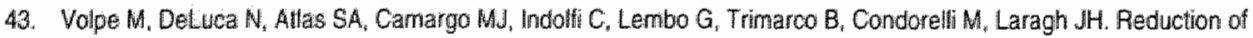
atrial natruretic factor circuating levels by endogenous sympathetic activation in hypertensive patients. Circulation $9988.77 .997-1002$.

44. Watley HWKNGT, Tsao Y. Breckenirige AM. Comparison and reproducibility of transthoracic bioimpedance and dual beam Doppler ultrasound measumement of cardiac function in healthy volunteers. Br J Clin Pharm 1991,32:275-82.

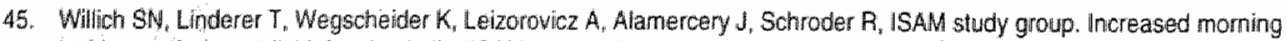
incidence of myocardial infarction in the ISAM sludy: absence with prior $\beta$-blockade. Circulation 1989:80:853-58. 


\section{CHAPTER 5}

SHORT- AND LONG-TERM EFFECTS OF SMOKING ON ARTERIAL WALL PROPERTIES IN HABITUAL SMOKERS

Mirian J.F. Kool, *Arnold P.G. Hoeks, Harry A.J. Struijker Boudier, **Robert S. Reneman, and Luc M.A.B. Van Bortel

Departments of Pharmacology, Division of Clinical Pharmacologw, Departments of * Biophysics and * Physiology Cardiovasular Riesearch Institute Maastricht, University of Limburg, Maastricht, The Netherlands 


\section{Summary}

This study investigated the short-term effects of smoking on haemodynamic function and distensibility and compliance of large arteries in habitual smokers. In addition, the effect of smoking was not measured in non-smokers, but vessel wall properties were compared between smokers and non-smokers (basal state). Smoking is a well-knowm risk factor for atherosclerosis. Loss of distensibility and compliance of large arteries may play a role in the onset of atherosclerosis.

The distensibility and compliance coefficients of the common carotid and brachial arteries were determined from the arterial wall displacement during systale and the end-diastolic diameter by using a vessel wall movement detector and from the pulse pressure as assessed in the upper arm. Cardiac function (cardiac output, stroke volume) was measured with Doppler echocardiography. Systemic vascular resistance was calculated as mean arterial pressure divided by cardiac output.

In habitual smokers, smoking one cigarette caused a sharp increase in blood pressure (6\%) and heart rate $(14 \%)$. Cardiac index increased $(16 \%)$, mainly because of the marked increase in heart rate. Stroke volume and systemic vascular resistance indexes did not change significantly. Smoking enhanced forearm blood flow after wrist occlusion $(17 \%)$, but total forearm blood flow was unchanged, suggesting an increase in muscle blood flow and a decrease in skin flow. Because of higher blood pressure, the diameter of the elastic common carotid artery increased by $3 \%$ (passive phenomenon). Distensibility of the carotid artery decreased $(7 \%)$ and, as a result, carotid compliance was preserved. in contrast, despite higher blood pressure, the diameter of the muscular brachial artery did not change, suggesting an increased vascular tone. Brachial distensibility and compliance decreased (18\% and $19 \%$, respectively).

In steady state, habitual smokers were comparable to non-smokers with regard to blood pressure, cardiac function, vascular resistance and vessel wall properties of large arteries. Heart rate was higher in habitual smokers (14\%).

In conclusion, these data indicate that in habitual smokers, smoking one cigarette causes short-term increases in arterial wall stiffness that might be harmful to the artery and increase the risk for plaque rupture. Except for a higher heart rate, no obwious long-term effect of smoking was observed on haemodynamic variables and arterial stiffness. Because acute cardiovascular events are mainly due to plaque rupture, the short-term effects of smoking might be a more important risk than long-term effects for these acute ischaemic events. 


\section{Introduction}

In western countries cigarette smoking is a major risk factor for cardovascular mortality and morbidity independent of other risk faciors, such as hypertension, hypercholesterolaemia and diabetes mellitus (21). Hammond and Horn (17) have linked smoking to coronary artery disease and atherosclerosis. Since the time of these original observations the prevalence of smoking and montality from coronary heart disease have declined, but $25 \%$ of all cardiovascular deaths in the developed countries are still attribulable to cigarette smoking (27). Even in countries where the incidence of coronary heart disease is relatively low, smoking shows a relation to cardiovascular disease (22), and even passive smoking has been reported to increase the risk of death from ischaemic heart disease and myocardial infarction (14). Epidemiological studies have demonstrated a close association of smoking not only with coronary heart disease (27) but also with stroke (7), sudden death (21) and occlusive peripheral arterial disease (24). In addition, cigaretle smoking seems to interact with hypertension, as indicated in the large hypertension trials in which one third of hypertensive men are smokers $(5,9)$.

All studies have demonstrated a dose dependency of smoking and cardiovascular risk, but the risk appears not obviously related to the duration of the smoking habit (3). The Framingham study has shown that for each 10 cigarettes/day, cardiovascular mortality in men is increased by $18 \%$ and in women with $31 \%$ (21). However, the effect of smoking on cardiowascular disease seems to be reversible. In the Framingham study those who refrained from smoking had a $50 \%$ reduction in the risk for coronary heart disease. The risk for cardiovascular death in smokers was comparable to that of non-smokers within one year after cessation, although for peripheral arterial disease the risk was not completely reversed (21). From the aforementioned studies, it can be concluded that cigarette smoking unfavourably affects the cardiovascular system by increasing the risk for atherosclerosis and cardiovascular events.

Increased arterial wall stiffness might play an important role in atherosclerotic disease and the occurrence of acute coronary events $(10,32)$. Arterial distensibility and compliance are important determinants of the load on the arterial wall. These vessel wall properties can now be assessed non-invasively with a vessel wall movement detector system. In the present study, the short-term effect of smoking on large arteries and ather haemadynamic data was investigated in habitual smokers (Study 1). In addition, these variables were compared with those in non-smoking subjects (Studly 2).

\section{Methods}

Subjects - Fourteen healthy smokers participated in the study. They had been smaking an average of 23 cigarettes/day (range 13 to 60 ) for 17 years (range 5 to 30 ). The short-term effects of smoking (Study 1) were studied in 12 of them. In addition, smokers were compared with 14 healthy persons who had never smoked (Study 2). The groups were matched lor gender, age, weight, height and physical activity. Demographic data are shown in Table 1.

Study design - The subjects were not allowed to use caffeine-containing beverages or meals, and the smokers had to refrain from smoking for at least 4 hours before examination. All haemodynamic measurements were performed after 15 to 20 min of supine rest in a quiet room $\left(23 \pm 1^{\circ} \mathrm{C}\right)$. Written informed consent was obtained from all subjects. 
Table 1. Danographic data for Smokers and Non-smokers.

\begin{tabular}{lcc}
\hline & Smoker $(\mathrm{m}) 14)$ & Non-smokers $(\mathrm{n}=14)$ \\
\hline Gender & 9 Males 15 Females & 9 Males/5 Females \\
Age (years) & $37(25-55)$ & $37(25-54)$ \\
Weight $(\mathrm{kg})$ & $73(55-88)$ & $72(52-93)$ \\
Height $(\mathrm{cm})$ & $175(158-186)$ & $174(161-183)$ \\
BSA $\left(\mathrm{m}^{2}\right)$ & $19(1.6-2.1)$ & $1.9(1.6-2.0)$
\end{tabular}

Values in parentheses are ranges. BSA, body surface area, calleulated acconding to the formula of Du Bois and Du Bois (Arch intern Med 1916;17:863-871).

\section{Study 1}

Measurements were performed before and immediately after smoking one cigarette containing $1.3 \mathrm{mg}$ of nicotine (Caballera filter). The cigarelle was smaked under standardised conditions: every $20 \mathrm{~s}$, a puff of $5 \mathrm{~s}$ was taken, and the whole cigarette had to be smoked within $5 \mathrm{~min}$.

Vessel wall properties of the right elastic common carotid artery and the right muscular brachial artery were measured in separate sessions. Simultaneously, blood pressure and heart rate were recorded every minute. In addition, cardiac function and forearm blood flow were determined before and after smaking.

\section{Sludy 2.}

With the same techniques used in study 1, vessel wall properties of the carotid and brachial arteries and cardiac function were assessed in smokers and non-smokers. Blood pressure and heart rate were recorded every $2 \mathrm{~min}$.

Measurements of haemodynamic function and vessel wall properties - Arm blood pressure and heart rate were measured with a Dinamap (Chapter 2) on the left arm. Vessel wall properties were measured in the recumbent pasition with the vessel wall movement detector system, as described in Chapter 2. Briefly, with this system, arterial diameter (D) and the distension during the cardiac cycle ( $\Delta D)$ were measured for 5 to $6 \mathrm{~s}$. The in vitro accuracy of the device is $3 \mu \mathrm{m}$ for distension and $100 \mu \mathrm{m}$ for arterial diameter. Reproducibility of the system is good (Chapter 3). The means of three consecutive measurements were taken. Vessel wall properties were calculated from arterial diameter, distension and pulse pressure ${ }_{a}$ according to the equations mentioned in Chapter 2.

Cardiac output was examined in the left lateral position, using Doppler echocardiography and forearm blood flow was determined by mercury strain gauge plethysmography (Chapter 2).

Concerning plethysmography, the whole arm was placed in an incubator to keep environmental temperature constant $\left(28^{\circ} \mathrm{C}\right)$. in addition, the skin temperature of this arm was controlled by a skin electrode thermometer. In all subjects, skin temperature was similar before and after smoking (mean temperature $\left.32.4^{\circ} \mathrm{C}\right)$. Hand circulation was eliminated by inflating a wrist cuff to suprasystolic pressure $(220 \mathrm{~mm} \mathrm{Hg})$ for $4 \mathrm{~min}$. After stabilization, a basal value was obtained without $(5 \mathrm{~min})$ and with $(4 \mathrm{~min})$ wrist occlusion. Only the last $3 \mathrm{~min}$ after wrist occlusion were used for evaluation. 
Data analysis - The short-term effects of smoking in the smoking group (Study 1) were analysed with the non-parametric, matched paired signed-rank Wilcoxon test. Comparisons between smokers and non-smokers in Study 2 were made by the non-parametric Mann-Whitney U-test. Results of both studies are presented as means \pm s.e.m. $p<0.05$ was considered statistically significant.

\section{Results}

\section{Study 1}

Results for blood pressure, cardiac function and plethysmography are presented in Table 2. After smoking, systolic and diastolic blood pressure increased significantly. Mean arterial pressure and heart rate were also elevated. Changes in pulse pressure were not statistically significant. Cardiac index increased after smoking, but stroke and systemic vascular resistance indexes were almost the same before and after smoking. Total forearm blood flow did not change after smoking. However, blood flow increased after wrist occlusion.

Table 2. Effect of one cigarette on haemodynamic variables.

\begin{tabular}{|c|c|c|}
\hline & Before smoking & After smoking \\
\hline \multicolumn{3}{|l|}{ Pressures (mmHg) } \\
\hline Systolic & $112 \pm 2$ & $918 \pm 3^{* * *}$ \\
\hline Diastolic & $69 \pm 1$ & $73 \pm 1^{* * * *}$ \\
\hline Mean arterial & $83 \pm 2$ & $B 8 \pm 2^{* * *}$ \\
\hline Pullse & $43 \pm 2$ & $45 \pm 2$ \\
\hline Heart rate (beats/min) & $64 \pm 3$ & $73 \pm 2^{* 4 *}$ \\
\hline \multicolumn{3}{|l|}{ Cardiac function } \\
\hline Cardlac index $\left(\mathrm{Lmin}_{\mathrm{m}} \mathrm{m}^{2}\right)$ & $3.1 \pm 0.1$ & $3.6 \pm 0.10^{*}$ \\
\hline Stroke index $\left(m L m^{2}\right)$ & $48 \pm 2$ & $47+2$ \\
\hline SVRI (dyn:s.cm $\mathrm{cm}^{2}$ ) & $1751 \pm 94$ & $1699 \pm 81$ \\
\hline \multicolumn{3}{|l|}{ Forearm blood llow } \\
\hline Tatal forearm blood flow (mL/100mL.min) & $4.6 \pm 0.7$ & $4.5 \pm 0.5$ \\
\hline Flow atter wrist occlusion (mL/100mL,min) & $2.7 \pm 0.2$ & $3.2 \pm 0.2^{*}$ \\
\hline
\end{tabular}

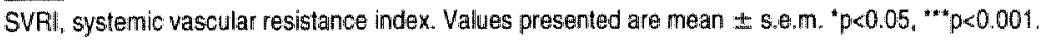

Data for vessel wall properties are shown in Figure 1. After smoking, the arterial diameter of the common carotid artery increased slightly (before smoking 6.01 \pm 0.17 , after smoking $6.17 \pm 0.2 \mathrm{~mm}, 0<0.05$ ), and carotid distensibility tended to decrease (before $30.6 \pm 1.2$, after $28.5 \pm 1.610^{-3} / \mathrm{kPa}, p=0.06$ ). Arterial distension decreased significantly (before $518 \pm 30$, after $488 \pm 28 \mu \mathrm{m}, \mathrm{p}<0.05$ ). Compliance of the carotid 

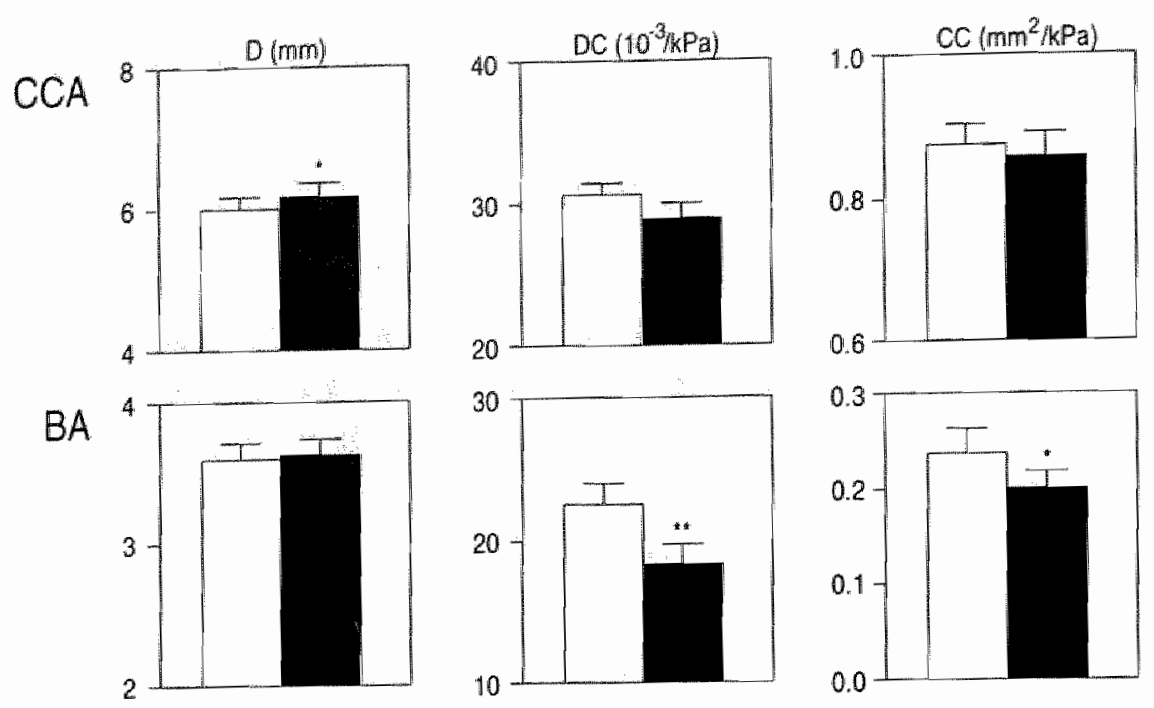

Figure 1. The short-term eflect of smoking on vessel wall properties of large anteries before (D) and after (1) smoking one cigarette, $\mathrm{DC}$, distensibility coefficient; $\mathrm{CC}$, compliance coetficient; $\mathrm{CCA}$, common carotid artery" $\mathrm{BA}$, brachial artery. Data are mean \pm s.e.m. "p<0,05, " $p<0$.01 (difference between period belore and after smoking).

artery was preserved after smoking (before $0.87 \pm 0.05$, after $0.85 \pm 0.06 \mathrm{~mm}^{2} / \mathrm{kPa}$ ). Brachial artery diameter did not change after smoking (before $3.65 \pm 0.12$, after $3.67 \pm 0.15 \mathrm{~mm}$ ), whereas arterial distension decreased (before $229 \pm 22$, after $195 \pm 18 \mu \mathrm{m}, \mathrm{p}<0.01$ ). Distensibility (before $22.5 \pm 2.3$, after $18.4 \pm 2.010^{\circ} \cdot 3 / \mathrm{kPa}, \mathrm{p}<0.01$ ) and compliance (belore $0.24 \pm 0.03$, after $0.20 \pm 0.02 \mathrm{~mm}^{2} / \mathrm{kPa}, p<0.05$ ) decreased in the brachial artery.

\section{Study 2}

Table 3 shows the haemodynamic data in smokers and non-smokers. Blood pressure (systolic, diastolic mean and pulse pressures) and cardiac, stroke and systemic vascular resistance indexes did not differ between smokers and non-smokers. Vessel wall properties (diameter, distension, distensibility, compliance) of the elastic common carotid and muscular brachial arteries were also camparable between the two groups. However, heart rate was higher in smokers ( $71 \pm 3$ beats/min) than in non-smokers ( $61 \pm 3$ beats/min, $0<0.05$ ). 
Table 3. Haemodynamic data for Smokers and Non-smokers.

\begin{tabular}{|c|c|c|}
\hline & Smokers & Non-smokers \\
\hline \multicolumn{3}{|l|}{ Pressures (mmHg) } \\
\hline Systolic & $117 \pm 3$ & $116 \pm 3$ \\
\hline Diastolic & $71 \pm 2$ & $73 \pm 1$ \\
\hline Mean arterial & $87 \pm 2$ & $87 \pm 2$ \\
\hline Pulse & $46 \pm 2$ & $43 \pm 3$ \\
\hline Heart rate (beats/min) & $71 \pm 3$ & $61 \pm 3^{*}$ \\
\hline \multicolumn{3}{|l|}{ Cardiac function } \\
\hline Cardiac index $\left(L / m i n . m^{2}\right)$ & $3.2 \pm 0.1$ & $3.0 \pm 0.1$ \\
\hline Stroke index $\left(\mathrm{mL} / \mathrm{m}^{2}\right)$ & $45 \pm 1$ & $51 \pm 2$ \\
\hline SVRI (dyn.s.cm. $\left.\mathrm{cm}^{-5} \cdot \mathrm{m}^{2}\right)$ & $2131 \pm 95$ & $2346 \pm 129$ \\
\hline \multicolumn{3}{|l|}{ Vessel wall properties } \\
\hline \multicolumn{3}{|l|}{ Carotid artery } \\
\hline Diamefer (mm) & $6.05 \pm 0.17$ & $5.88 \pm 0.1$ \\
\hline Distension (um) & $488 \pm 38$ & $421 \pm 32$ \\
\hline$D C\left(10^{-3 / k P a}\right)$ & $27.1 \pm 2.2$ & $25.8 \pm 2.3$ \\
\hline $\mathrm{CC}\left(\mathrm{mm}^{2} / \mathrm{kPa}\right)$ & $0.78 \pm 0.07$ & $0.69 \pm 0.06$ \\
\hline \multicolumn{3}{|l|}{ Brachial artery } \\
\hline Diameter (mm) & $3.56 \pm 0.11$ & $3.67 \pm 0.13$ \\
\hline Distension (um) & $202 \pm 19$ & $242 \pm 26$ \\
\hline$D C\left(10^{3 / 3 P a}\right)$ & $19.1 \pm 1.8$ & $23.5 \pm 2.2$ \\
\hline $\mathrm{CC}\left(\mathrm{mm}^{2} / \mathrm{kPa}\right)$ & $0.19 \pm 0.02$ & $0.25 \pm 0.03$ \\
\hline
\end{tabular}

SVRI, systemic vascular resistance index, $D C$, distensibility coefficient; $\mathrm{CC}_{\text {, }}$ compliance coefficient; Values presented are mean \pm s.e.m. " $p<0.05$.

\section{Discussion}

Tobacco contains as many as 4,000 constituents. At present, nicotine is regarded as mainly responsible for the short-term haemodynamic effects of smoking. Nicotine has a biphasic effect. At low doses it causes ganglionic stimulation, with release of noradrenalin from nerve endings, release of adrenalin from the adrenal medulla and an enhanced neural discharge in the central nervous system. At high doses, ganglionic blockade, vagal stimulation or direct depression of the brain may result in opposite effects. The ultimate response is the net result of the stimulating and depressing effects of nicotine in each organ (31). In the present study, sham smoking experiments were not performed because previous studies in general could not demonstrate any effect of sham smoking $(6,15)$. To achieve full regression of tolerance with nicotine (3), a 4-hour non-smoking period before examination was chosen. In general, heart rate increases 1 to 2 min after the start of smoking, and the effect lasts for $75 \mathrm{~min}$ (4), with a peak value after 5 to $10 \mathrm{~min}$ (34). Our examinations were performed after 5 min of smoking, which was at peak effect. 
Long-term effect - In habitual smokers, smoking one cigarette caused a sharp increase in blood pressure $(6 \%)$ and heart rate $(14 \%)$. Cardiac index increased $(16 \%)$, primarily due to a higher heart rate, whereas systemic vascular resistance was not altered. Forearm blood flow increased (17\%) after wrist occlusion but remained unchanged withoul wrist occlusion. This observation suggests an increase in muscle blood llow and a reduced skin flow. Athough published data are not always conclusive with regard to the effects of smoking, our findings are consistent with other studies $(18,28,34)$. As in our study, in these studies the increment in blood pressure generally is lower than the increase in heart rate. Taken together; these haemodynamic effects of smoking can be explained by the nicotine-induced sympathetic activation. Nicotine induces the release of both adrenalin and noradrenalin. Because efferent sympathetic nerve activity has been shown to be reduced in smoking (15), the increase in plasma catecholamines (8) instead reflects stimulation of the adrenal medulla or interaction with peripheral mechanisms (eg, a reduced noradrenalin clearance) (15). The net effect of smoking will be dependent on the mixed effects of adrenalin and noradrenalin at the different organ levels (33).

Short-term effect - Smoking one cigarette clearly influenced vessel wall properties of the elastic common carotid and muscular brachial arteries, although these vessels were affected differently. The arterial diameter of the carotid artery increased slightly $(3 \%)$ after smoking. The vasodilation might be considered a passive phenomenon because in the same period arterial blood pressure was also higher. Distensibility of the carotid artery decreased atter smoking (7\%), and compliance of this artery was preserved because the decrease in distensibility was associated with an increased diastolic diameter. In contrast, the diameter of the brachial artery did not change after smoking despite a higher blood pressure. This finding suggests an active mechanism, such as elevated vascular tone of this muscular artery. Elevated muscular tone could be due to an increase in plasma catecholamines. Because total forearm flow did not change, a flow-dependent effect is not likely. Distensibility of this artery decreased markedly (18\%). Because of an unchanged diameter and decreased distensibility, arterial compliance of the brachial artery was significantly reduced under these circumstances $(19 \%)$. The differences between the common carotid and brachial arteries may be due to a difference in muscular content of the arterial wall in these arteries. In addition, it may be that with a larger diameter the carotid artery could distend less, resulting in a decreased distensibility.

These findings indicate increased arterial wall stiffness after smoking. Other studies using indirect techniques, such as pulse wave velocity (4) and multigate pulsed Doppler (6) "also found transitory increases in stiffness of radial and femoral arteries after smoking, without changes in arterial diameter of these muscular arteries (13).

After a 4-hour nom-smoking period, heart rate at rest was higher in habitual smokers than in non-smokers. The difference could not be explained by differences in physical activity level in the two groups because, on average, smokers and non-smokers performed the same daily work and their sports activities were comparable. In previous studies, in long-term smokers (16) the heart rate has been persistently found to be elevated during abstinence, as a kind of withdrawal phenomenon. Blood pressure in the smokers in our study was not different from that in non-smokers. Other studies have been inconsistent with regard to blood pressure in habitual smokers. Overall $(2,16)$, casual as well as ambulatory blood pressure values in habituals smokers have previously been found to be lower or similar to values in non-smokers. In the present study, cardiac function was comparable in smokers and non-smokers. Previous data on vascular resistance and cardiac function in long-term smokers are scanty, although long-term smoking has been associated with a reduced stroke volume (19). In the present smoking group, stroke volume was slightly reduced, but not significantly different from vallues in the control group. Vessel wall properties of the elastic and muscular large arteries were similar in habitual smokers and non-smokers. Although no other published clata are available for differences in vessel wall properties, particularly at the microcirculatory and arteriolar levels, functional and structural differences coulld not be demonstrated between smokers and non-smokers $(12,18)$. Thus, although the risk for cardiovascular disease is increased in habitual smokers $(21,27)$, no 
effect on haemodynamic variables could be detected in this group of young habitual smokers in the present study.

Although smoking is related to atherosclerotic disease, little is known about the underlying mechanisms. Postmortem studies have shown that atherosclerotic lesions are more common in the aorta and the iliac. cerebral and coronary arteries of smokers than of non-smokers, although findings in the latter vessels are inconsistent. In vivo, atherosclerotic disease was more extensively present in the carotid arteries af smokers than of non-smokers (23). In addition, the effect seems to be age dependent because young smokers had far fewer lesions than older smokers (30). It cannot be excluded thall changes in vessel wall properties could not yet be detected in the relatively young group of smokers in the present study.

Smoking may promote atherogenesis by different mechanisms, such as 1) a higher blood pressure, 2) a direct toxic effect of nicotine on the endothelium (10), 3) increased permeability of the arterial wall and 4) reduced clearance properties of the wall (1). Other risk factors for atherosclerosis may also be involved in the hazardous effects of smoking, such as an unfavourably changed lipid profile $(25,34)$, increased blood viscosity and alterations in platelet function and haemostasis $(20,26,34)$.

In addition, according to the current view of atherosclerotic disease, plaque rupture is an important feature. It has been demonstrated that most of the acute coronary syndromes are due to the disruption of small, non-stenotic plaques (11). These small plaques are generally not detected with the present diagnostic techniques and might already be present in young smokers (11). Increased anterial wall stiffness, increased blood pressure and a higher heart rate are short-term effects of smoking that enhance the load on the vessel wall. In addition, at the site of athercsclerotic plaques, the distribution of circumferential and tensile stress is altered, which might further increase the load at the plaque (29). The smoking-induced increased load at the atherosclerotic plaque may induce plaque rupture and lead to acute ischaemic events.

In conclusion, in habitual smokers, one cigarette induced haemodynamic changes compatible with a nicotine-induced sympathetic activation. In addition, smoking caused a short-term increase in arterial wall stiffness of both elastic and muscular arteries. Habitual smokers did not differ from non-smokers in haemodynamic variables and properties of large arteries. Nevertheless, these young smokers might still be at risk for cardiovascular complications of atherosclerotic disease because each cigarette causes a short-term increase in the load on the arterial wall that might result in atherosclerotic plaque rupture and subsequent ischaemic events.

\section{References}

1. Alen DR, Browse NL. The effect of cigarette smoke, nicotine and carbon monoxide on arterial wall permeability and arterial wall uptake of 1251 -fibrinogen. Adv Exp Med Biol 1990;273:95-106.

2. Asmar RGi, Girerd XJ, Brahimi M, Safavian $\mathrm{A}_{\mathrm{n}}$ Safar ME. Ambulatory blood pressure measurement, smoking amd abnormalities of glucose and lipid melabolis,m in essential hypertension. J Hypertens 1992;10:181-87.

3. Benowitz NL. Pharmacological aspects of cigarelte smoking and nicotine addiction. N Engl J Med 1988;319:1318-30.

4. Berlin I, Cournot A. Penout P. Duchier J, Safar M. Peripheral haemodynamic effects of smoking in habitual smokers. A methodological study. Eur J Clin Pharmatol 1990;38:57-60.

5. Bohler FR, Vesanen $K$, Watters $J T$, Boll $P$. Impact of smoking on heart attacks, strokes, blood pressure contro, drug dose, and quality of lite aspects in the International Prospective Primary Prevention Study in Hyperiension. Arv Heart $J$ $1988 ; 115 \cdot 282-87$

6. Caro $\mathrm{CG}_{\text {. }}$ Lever MJ. Parker KH. Fish PJ. Ettect of ciganette smoking on the pattern of arterial blood llow: possible insight into mechanisms underlying the development of arteriosclerosis, Larcet 1987:11:11-13. 
7. Cruickshank $M$, Neat-Dwyer $G$, Dorance DE, Hayes $Y$. Patel S. Acute eftects of smoking on blood pressure and cerebral bood flow. 1 Hum Hypentens $1989,3: 4,43 \times 49$.

8. Cryer PE, Haymond MW, Santiago UV, Shah SD. Morepinephrine and epinephome release and adrenergic mediation of snokingassociated themodynamic and metabolic events. N Engl I Med 1976,295-573-77.

9. Doltery $\mathrm{C}$, Brennan PJ. The Medical Research Councl Hypertension Trial: The smoking patient. Am Heart $\mathrm{J} 1988,115$ :276-80.

10. Fuster $W$, Badimon L, Badimon Jw, Chesebro JH. The pathogenesis of cononary artery disease and the acute coronary Syndromes. $M$ Engl Med $1992,32 B$ :242-50.

11. Fuster $\mathrm{V}$, Badimon L, Badiman $\mathrm{J}$, Chesebro JH. The pathogenesis of coronary artery disease and the acute coronary syndromes. N Engl a Med 1992,326:310 18 .

12. Gaster P. Wideo-nallold microscopy and local cold test morphological and hemodynamic correlates in 124 healthy subjects. Vasai $1991,20,244-51$.

13. Giannattasio C, Cattaneo BM, Carugo S, Mangoni AA, Grassi G, Mancia G. Cigarette smoking (CS) and radial artery (RA) compliance in man. J Hypertens 1992;10 (Suppl. 4):S94.

14. Glank $S A_{1}$ Parmley WW. Passive smoking and heart disease. Epidemiology, physiology and biochemistry. Circulation $1991: 83: 1 \cdot 12$

15. Grassi $G$, Seravalle G, Calhoun DA, Bolla G, Mancia G. Cigarette smoking and the adrenergic nervous systern. Clin Exp Hypertens [A] 1992,A14:251-60

16. Green MS, Jitha E, Luz Y. Blood pressure in smokers and nonsmokers: epidemiologic findings. Am Heart $J 1986,111$ .932 40.

17. Hammond EC, Horn D. Smoking and death rates - Report on forty-four months al follow-up of 187,783 men. JAMA $1958,166: 1294-1308$.

18. Jacobs $M C$, Lenders $J$ Kapma JA, Smits $P$. Thien $T$. The effect of smoking on vascular relaxation. Pharmaceut Whbi Sci Ed 1991:13 (Suppl. L)':L4.

19. Jain AC, Bowyer AF, Marshall R, Asato H. Left ventricular function atter cigarette smoking by chronic smokers: comparison of normal subjects and patients with coronary antery disease. Am J Cardiol 1977,39:27:31.

20. Kannel WB, D'Agositino RB, Belanger AJ. Fibrinogen, cigarrette smoking, and risk of cardiowascular disease: insights from the Framingham study. Am Heart J 1987;113;1006-10.

21. Kannel WB, Higgins M. Smoking and hypertension as predictors of cardiowascular risk in population studies. $J$ Hypertens 1990;8 (Suppl. 5) :S3-S8.

22. Kiyohara $Y$, Ueda K, Fujishima M. Smoking and cardiowascular disease in the general papulation in Japan. J Hypertens
1990;8 (Suppl 5) :S9-S15.

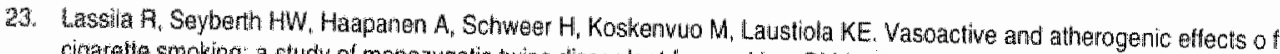
cigerelte smoking: astudy of monozygotic twins discordant for smoking. BMJ 1988:297:955-57.

24. Lepantalo M. Lassila A. Smoking and occh usive arterial disease. Eur ل Surg 1991;157:83-187.

$25_{3}$ Mos OD. Lipid eifects of smoking. Am Heart J 1988;115:272-75.

26. Nowat J, Murray J, Oales JA, FitzGerald GA. Biochemical evidence of a chronic abnomality in platelet and wascular tunction in healthy individuals who smoke cigarettes. Circulation $1987 ; 76: 6-14$.

27. Peto R. Lopez A, Boreham J, Thun $M_{n}$ Heath $C$. Mortality trom tobacco in developed countries: indirect estimation from national wital statistics. Lancet $1992,339: 1268-78$. 28. Fichardson D. Effects of tobacco smoke inhallation on capillary blood flow in human skin. Arch Emw Health $1987 ; 42$
$: 19-25$. 29. Richardson PD, Daries MJ. Born GVR. Influence of plaque configuration and stress distribution on fissuring of cononary
atherosclerotic placues. Lancel 1989,21 okt:941-44.

30. Strong JP, Fichards ML. Cigarette smoking and atherosclerosis in autopsied men. Atherosclerosis $1976.23: 451-76$.

31. Taylor P. Ganglionic slimulating and blocking agents. In. Goodman Giman A, Goodman LS, Rall TW. Murad F, eds. Goodman and Gilman's the phamacological basis of therapeutics 7 th ed. New York: Macmillan Publishing Company,
1985: $215 \% 21$. 
32. Van Bortel LM, Hoeks APG, Kool MJF. Strujker-Boudier HA. lntioduction to large artery properties as a targel for risik reduction by antihypertersive therapy. "Hypertens $1992 ; 10$ (Suppl 6) :S123-26.

33. Weiner $N$. Norepinephrine, epinephrine, and the sympathonimetic amines. In: Gowdman Gilman $A_{i}$ Goodman $L S_{k}$ Rall TW, Murad F, eds. Goodman and Gilman's The Phamacological Basis of Therapeutics 7th ed. New York: MacMillan Publishing Company, $1985: 145-80$.

34. Winniford MD. Smoking and cardiovaseutar function. IHypertens 1990;8 (Suppt. 5) : S177-23. 


\section{CHAPTER 6}

VESSEL WALL PROPERTIES OF LARGE ARTERIES IN UNCOMPLICATED INSULIN-DEPENDENT DIABETES MELLITUS (IDDM)

Mirrian J. Kool, Jan Lambert, Coen D. Stohouwer, Arnold P. Hoeks, Harry A. Struijker Boudier, andi Luc M. Van Bortel

Departments of Pharmacology, Division of Clinical Pharmacology, Department of *Biophysics. Cardiovasullar Research Institute Maastricht, University of Limburg, Maastricht, and Departments of Internal Medicine, Institute for Cardiovascular Research, Free University Hospital, Amsterdam, The Netherlands

Based on Diabetes Care $1995,18: 618-624$ 


\section{Summary}

Patients with insulin-dependent diabetes mellitus (IDDM) are athigh risk for cardiovascular disease. Arterial distensibility and compliance are vessel wall properties of large arteries. Altered large artery wall properties can be an early feature of vascular dysfunction. This study investigates vessel wall properties in 30 patienis with uncomplicated IDDM and 30 matched healthy control subjects.

Vessel wall properties of the elastic common carotid (CCA), and the muscular femoral (FA) and brachial arteries $(B A)$ were measured with a vessel wall movement detector system. Blood pressure and heart rate were recorded simultaneously with a semi-automated device. Aortic pulse wave velocity was estimated from the carotido-femoral transit time.

Blood pressure (IDCM patients: $118 \pm 2 / 69 \pm 1 \mathrm{mmHg}$ ), pulse pressure (IDDM patients:49 $41 \mathrm{mmHg}$ ) and heart rate (IDDM patients:65 22 beats/min) were similar in IDOM patients and control subjects. No statistically significant changes between IDDM and control subjects were found for diameter, distensibility and compliance of the elastic common carotid artery and the muscular brachial artery. Distensibility (IDDM patients: $16.9 \pm 1.2 ;$ Control subjects:22.4 $\pm 2.210^{-3} / \mathrm{kPa}$ ) of the muscular femoral artery was decreased in IDDM ( $p<0.05$ ). However, femoral artery compliance (IDDM patients:0.80 \pm 0.05 ; Control subjects: $0.94 \pm$ $0.07 \mathrm{~mm}^{2} / \mathrm{kPa}$ ) and femoral artery diameter (IDDM patients: $7.87 \pm 0.20$. Control subjects: $7.57 \pm 0.20 \mathrm{~mm}$ ) did not differ statistically between IDDM patients and control subjects. Aortic pulse wave velocity was the same in IDDM patients and control subjects (IDDM patients:5.1 $\pm 0.1 \mathrm{~m} / \mathrm{s}$ ). No relation was found between vessel wall properties and duration of disease, actual glucose level, and HbA1c for all three arteries (CCA, $B A$, and FA). But the groups might have been too small to draw definite conclusions.

In conclusion, the results of the present study show that in this group of patients with uncomplicated IDDM, vessel wall properties of elastic and muscular large arteries were not obviously reduced when compared with healthy controls. However, distensibility of the femoral artery was lower in IDDM. Early atherosclerotic changes in IDDM frequently occur at this site. A difference related to the duration of diabetes could not be excluded. 


\section{Introduction}

Today, approximately one of 300 people will acquire insulin-dependent diabetes mellitus (IDDM) (35). in patients with IDDM morbidity and mortality are higher than in non-diabetic patients, with $75 \%$ of total diabeles-related mortality being due to macrovascular disease $(2,13)$, ln young patients with IDDM, the extent of coronary artery lesions in autopsy material has been shown to be increased (4). In addition, in IDDM the prevalence of hypertension is about twofold higher than in healthy control subjects (8). Systolic blood pressure is more involved than diastolic blood pressure, as shown by the high prevalence of isolated systolic hypertension in young diabetic patients (8). High systolic blood pressure is a well-known risk factor for cardiovascular disease (28).

Systolic hypertension in IDDM patients suggests premature ageing of the arterial system and vascular pigidity. Vascular rigidity may increase vascular stress and endothelial damage. The latter factor is kmown to promote atherosclerotic disease in large arteries (11). The positive correlation found in IDDM between systolic blood pressure and von Willebrand factor - a marker for endothelial damage - supports this hypothesis (30). Compliance and distensibility are vessel wall properties of large arteries that determine the buffering capacity and elastic properties of the arterial wall. Recently, Hoeks et al (14) have developed a vessel wall movement detector system by which vessel wall properties of superficial large arteries can be measured accurately and non-invasively.

The aim of the present study was to investigate whether vessel wall properties of large arteries in young subjects with uncomplicated IDDM are already altered before organ damage is present. Therefore, large antery properties in IDDM were compared with those in apparently healthy control subjects. In addition, differences in these parameters between short-term and long-term IDDM were evaluated. The relation between vessel wall properties and duration of disease, actual glucose levels, and $\mathrm{HbA}$ 1c was investigated.

\section{Subjects and methods}

Subjects - The study population consisted of 30 patients with uncomplicated IDDM (19 men and 11 women) from an outpatient clinic. Insulin-dependent diabetes was defined as onset before 40 years of age

Table 1. Patient and control group characteristics.

\begin{tabular}{|c|c|c|}
\hline & IDDM palients & Control subjects \\
\hline Gender & 19 men/11 women & 19 men/1/ women \\
\hline Age (years) & $26(16-37)$ & $26(17-37)$ \\
\hline Weight (kg) & $74.2(54-92)$ & $74.4(52-98)$ \\
\hline Height (cm) & $100(155-196)$ & $180(162-201)$ \\
\hline Smokers & 8 & 8 \\
\hline Cigarettes/day & $12(4-25)$ & $12(5-20)$ \\
\hline Oral anticonceptives & $n=9$ & $n=6$ \\
\hline Duration of IDDM (years) & $9.7(0.5-2.3 .5)$ & MA \\
\hline Glucose (mmolil) & $9.3(2.2 \cdot 18.5)$ & NA \\
\hline $\mathrm{HOA} 10(\%)$ & $7.8(5.7 .11 .2)$ & NA \\
\hline
\end{tabular}

Datla are means (ranges); HDDM, insulin-dependent diabetes mellitus: $N A$, not applicable fnot measured. 
in combination with insulin dependence from diagnosis. Uncomplicated IDDM was defined as diabetes without retinopathy (fundoscopy), nephropathy (urinary abumin secretion < $30 \mathrm{mg} / 24$ hour), or clinical signs of neuropathy. The median duration of diabetes was 9 years $(0.5-23.5$ years). The control group included 30 ( 19 men and 11 women) apparently healthy volunteers. The two groups were matched for sex; age, weight, height, and blood pressure.

The IDDM group was divided into wo subgroups, which were comparable except for the duration of the disease: 13 patients with short-term (defined as $\leq 9$ years, the median duration of diabetes in the study population) and 17 with long-term (defined as $>9$ years, the median duration of diabeles in the study population) IDDM were analysed. Patient and control group characteristics are shown in Table 1.

None of the subjects was taking any drugs except for insulin (IDDM patients) and oral contraceptives (nine female diabetic subjects and six female control subjectsy. Pregnancy was an exclusion criterion. All patients received appropriate insulin treatment and a diet. Patients regularly controlled their own blood glucose levels. Fasting glucose levels were reported between 3 and $10 \mathrm{mmol} / \mathrm{L}$. None of the subjects showed clinical signs of hypoglycaemia during the examination period.

The study was performed in accordance with the principles of the Declaration of Helsinki (revised 1983) and was approved by the Ethical Committee. Informed consent was obtained from all subjects.

Study design and methods - All subjects refrained from smoking or consuming caffeine for at least iwo hours belore examination. All haemodynamic measurements were performed after al least $15 \mathrm{~min}$ of supine rest in a quiet room. All measurements were made by the same observer.

\section{Blood pressure and heart rale}

Blood pressure and heart rate were recorded every 3 min on the left arm with a semi-automated device (Chapter 2) and the mean of these recordings (approximately 9) was taken as the patient's reading.

\section{Vessel wall properties}

Vessel wall properties of the right elastic common carotid artery (CCA), and the right muscular common femoral (FA) and brachial (BA) arteries were assessed with the patient in the recumbent position with the vessel wall movement detector system, as described in Chapter 2.

From anterial diameter, distension and pulse pressure, vessel wall properties were calculated with the equations mentioned in Chapter 2. The system used in the present study has been validated previously and has shown acceptable reproducibility (Chapter 3 ).

The delay time of the carotid and femoral arteries was used as an estimate of carotido-femoral transit time (Chapter 2). The average pulse wave velocity in the carotido femoral segment provides an estimation of the stiffness of the aortic pathway (21). Only 25 subjects in each group were studied for aortic pulse wave velocity, since the length of the arterial segment in 5 patients was not available.

\section{Laboralon lests}

Atter the haemodynamic measurements, the aclual blood glucose level was determined (One Touch 2', Lifescar, Tilburg, The Netherlands). Gilycolysated haemoglobin (HbAlc) was measured by high pertor. mance liquid chromatogrpahy (HPLC; normal range 4.3-6.1\%; intra-assay variation $2.6 \%$ ) and obtained within 3 months before the start of the study.

Data analysis - Differences between diabetic and control subjects were analysed by a Student's t-test for unpaired data. Correlations were made between vessel wall properties of the three arteries and $\mathrm{HbA1C}$, plasma glucose levels, and duration of diabetes using Spearman's correlation coefficient. Results are presented as means \pm s.e.m. $p<0.05$ was considered statistically significant. 


\section{Results}

The diabetic group did not differ from the control group with regard to gender, age, weight, height and smoking habits. None of the patients or control subjects was hypertensive (defined as $<160 / 95 \mathrm{mmHg}$ ) at the time of the study. Patients had neither a history of coronary heart disease nor peripheral arterial disease, nor could overt atherosclerotic lesions be detected with B-mode scanning at the time of examination. Intima-media thickness was not measured, since there is as yet no consensus about the accuracy of this parameter with the current techniques $(7,25,31,39)$.

According to the $\mathrm{HbA1c}$-levels $(7.8 \pm 0.3 \%)$, short-term regulation of IDDM was fair. Actual blood glucose levels $(9.3 \pm 0.9 \mathrm{mmol} / \mathrm{L})$ showed a large interindividual variation (Table 1).

Haemodynamic data in IDDM patients and control subjects are presented in Tabie 2. Blood pressure, pulse pressure, and heart rate were comparable in both groups. No statistically significant differences existed between IDDM patients and control subjects for arterial diameter, distension "distensibility, and compliance of the elastic comman carotid artery. Brachial artery diameter as well as brachial distension, distensibility and compliance were comparable for the two groups. Femoral artery distensibility was decreased $(p<0.05)$ in IDDM patients, but femoral artery diameter and compliance did not differ between the two groups. Aortic pulse wave velocity was similar in IDDM patients and control subjects. Arterial diameter, distensibility and compliance of the carotid artery were related neither to the duration of the disease nor to the aclual glucose level (Figure 1).

Table 2. Haemodynamic data in HDDM patients and healthy control sulajects,

\begin{tabular}{|c|c|c|}
\hline & IDDM patlents & Control subjects \\
\hline \multicolumn{3}{|l|}{ Blood pressure, heart rate } \\
\hline Blood pressure (mmHg) & $118 \pm 2 / 69 \pm 1$ & $115 \pm 2 / 68 \pm 1$ \\
\hline Pulse pressure (mmHg) & $49 \pm 1$ & $48 \pm 2$ \\
\hline Heart rate (beats/min) & $65 \pm 2$ & $62 \pm 2$ \\
\hline \multicolumn{3}{|l|}{ Vessel wall properties } \\
\hline \multicolumn{3}{|l|}{ Common carotid artery } \\
\hline Diameter (mm) & $5.79 \pm 0.08$ & $5.51 \pm 0.05$ \\
\hline Distension (um) & $547 \pm 211$ & $537 \pm 30$ \\
\hline $\mathrm{DG} / 10^{\circ} / \mathrm{kPa}$ & $29.7 \pm 1.4$ & $30.3 \pm 1.3$ \\
\hline $\mathrm{CC}\left(\mathrm{mm}^{2} \mathrm{f} \mathrm{kPa}\right)$ & $0.77 \pm 0.03$ & $0.75 \pm 0.03$ \\
\hline \multicolumn{3}{|l|}{ Common femoral artery } \\
\hline Diameter (mm) & $7.87 \pm 0.20$ & $7.57 \pm 0.20$ \\
\hline Distension $(u m)$ & $416 \pm 23$ & $498 \pm 39$ \\
\hline DC $\left[10^{3} / \mathrm{kPa}\right\rfloor$ & $16.9 \pm 1.2$ & $22.4 \pm 2.2^{\circ}$ \\
\hline $\mathrm{CC}\left(\mathrm{mm}^{2} / \mathrm{kPa}\right)$ & $0.80 \pm 0.05$ & $0.94 \pm 0.07$ \\
\hline \multicolumn{3}{|l|}{ Brachial artery } \\
\hline Diameler $(\mathrm{mm})$ & $3.40 \pm 0.08$ & $3.43 \pm 0.07$ \\
\hline Dislemsion $(u \mathrm{~m})$ & $263 \pm 11$ & $260 \pm 16$ \\
\hline DC $\left(10^{-3} / \mathrm{kPa}^{2}\right)$ & $24.3 \pm 1.1$ & $24.9 \pm 1.8$ \\
\hline $\mathrm{CC}\left(\mathrm{mm}^{2} \mathrm{kPa}\right)$ & $0.22 \pm 0.01$ & $0.23 \pm 0.02$ \\
\hline Aortic PWN (mis) & $5.1 \pm 0.1(n=25)$ & $5.2 \pm 0.1(n=2.5)$ \\
\hline
\end{tabular}

Data are mean \# s.e.m.; IDDM, insulin-dependent diabeles mellitus; DC, distensibility cobfficient: $C$. compliance caefficient; PWV puse wave velocity: "p<0.05. 
1a. Diameter CCA vs. duration diabetes
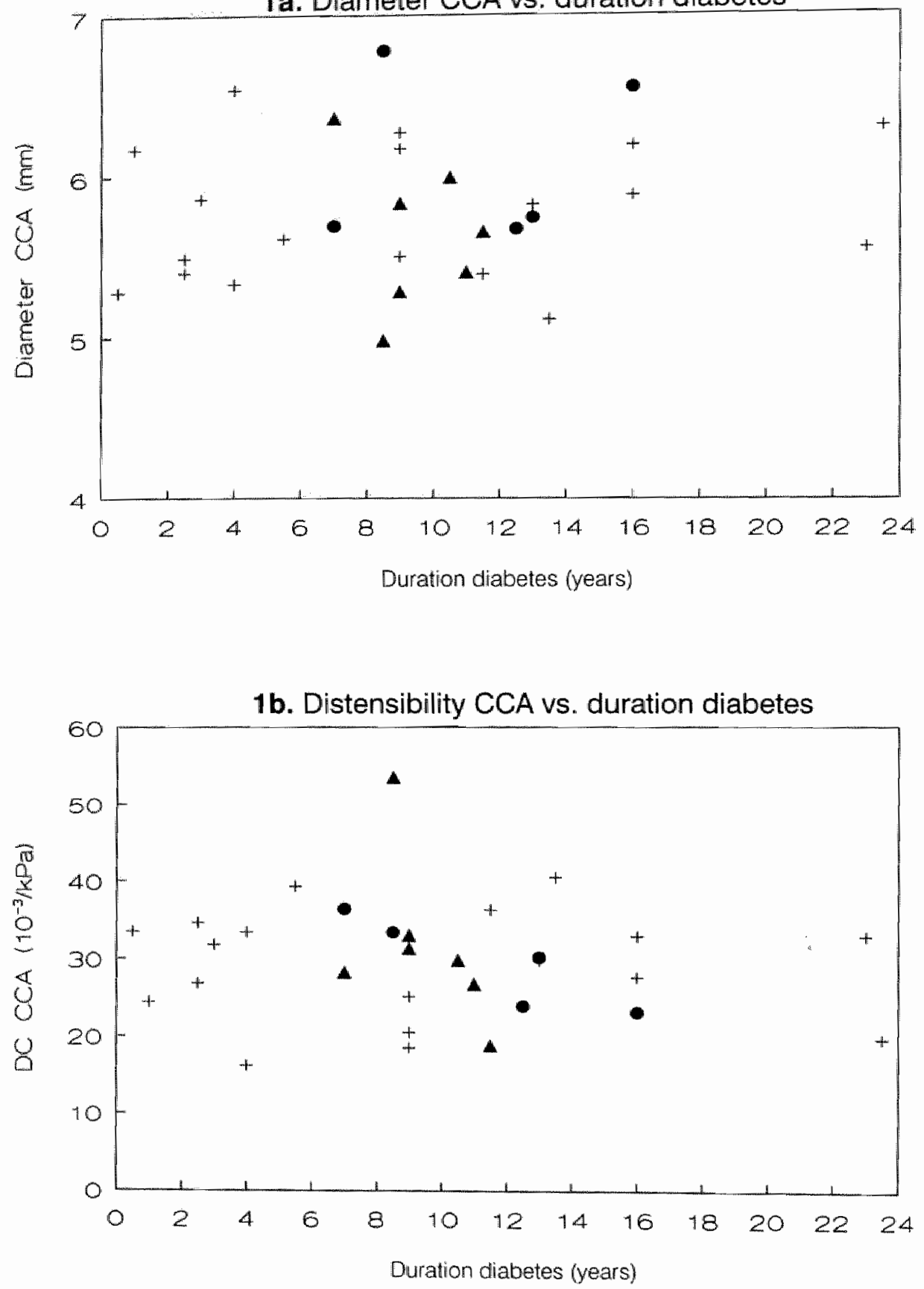


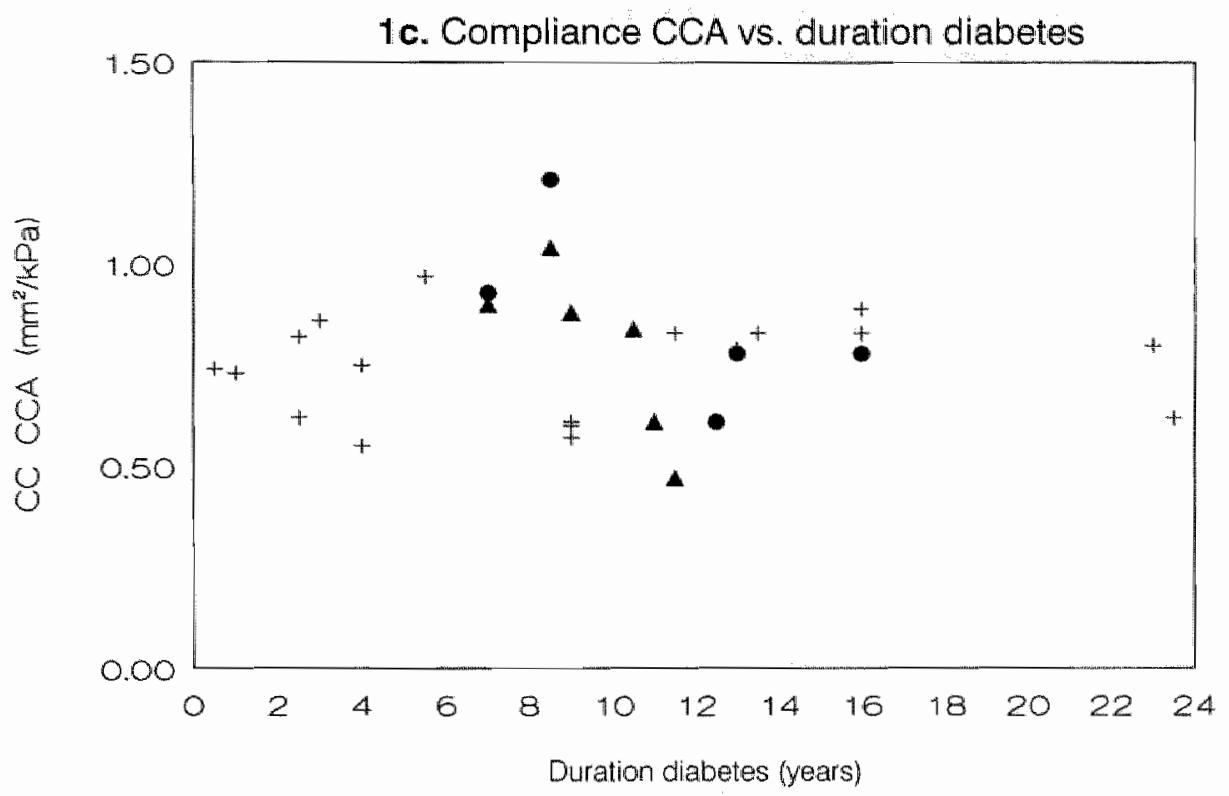

Figure: 1. Relation between duration of diabeles and arterial diameter (a), distensibility (b), and compliance (c) of the carotid artery (CCA). DC, disfensibility coefficient; $C C_{v}$ compliance coelficient.

+ subjects with glucose 4-10 mmolli; 0 subjects with glucose < 4 mmolli: $\boldsymbol{\Delta}$ subjects with gilucose $>10$ mmol/L as measured with Liliescan.

In addition, no significant relation could be demonstrated between $\mathrm{HbA1c}$ and diameter $(r=-0,17)$, distensibility $(r=0.04)$ and compliance $(r=0.04)$ of the common carotid artery. The same pattern was found for the muscular femoral and brachial arteries.

Haemodynamic data and vessel wall properties in patients with short-term and long-term IDDM are shown in Table 3. No statistically significant differences were observed between the two subgroups for all parameters. 
Table 3. Haemodyamic differences between shortemint ang-tem IDOM patients.

\begin{tabular}{|c|c|c|}
\hline & $\angle 9$ years IDDM & $>9$ years IDDM \\
\hline \multicolumn{3}{|l|}{ Blood pressure, hear rate } \\
\hline Blood pressure ammHa) & $119 \pm 369=2$ & $115 \pm 2168 \pm 1$ \\
\hline Pulse pressure (mmHg) & $50 \pm 2$ & $48 \pm 2$ \\
\hline Heart rate [beats/min] & $64 \pm 2$ & $62 \pm 2$ \\
\hline \multicolumn{3}{|l|}{ Wessel wall properties } \\
\hline \multicolumn{3}{|l|}{ Common carotid artery } \\
\hline Diameter (mm) & $5.82 \pm 0.15$ & $5.78 \pm 0.10$ \\
\hline Distencion (um) & $592 \pm 36$ & $513 \pm 24$ \\
\hline $\mathrm{DC}(10 \mathrm{~s} / \mathrm{kPa})$ & $31.7 \pm 26$ & $28.2 \pm 1.5$ \\
\hline $\mathrm{CC}\left(\mathrm{mm} \mathrm{m}^{2} \mathrm{kPa}\right)$ & $0.82 \pm 0.05$ & $0.73 \pm 0.03$ \\
\hline \multicolumn{3}{|l|}{ Common femoral artery } \\
\hline Diameter (mm) & $8.12 \pm 0.30$ & $7.68 \pm 0.27$ \\
\hline Distension (um) & $407 \pm 32$ & $423 \pm 33$ \\
\hline$D C\left(10^{-3 / k P a}\right)$ & $15.5 \pm 1.5$ & $18.0 \pm 1.7$ \\
\hline $\mathrm{CO}\left(\mathrm{mm} \mathrm{m}^{2} / \mathrm{kPa}\right)$ & $0.80 \pm 0.08$ & $0.80 \pm 0.06$ \\
\hline \multicolumn{3}{|l|}{ Brachial artery } \\
\hline Diameler (mmi) & $3.45 \pm 0.10$ & $3.36 \pm 0.12$ \\
\hline Distansion (um) & $266 \pm 16$ & $260: \pm 17$ \\
\hline$D C\left(10^{-3} f_{k P a}\right)$ & $23.6 \pm 1.4$ & $24.9 \pm 1.7$ \\
\hline $\mathrm{CC}\left(\mathrm{m} \mathrm{m}^{2} / \mathrm{kPa}\right)$ & $0.22 \pm 0.02$ & $0.21 \pm 0.01$ \\
\hline Aartic PWW (m/s) & $4.9 \pm 0.2(n=11)$ & $5.3 \pm 0.1(n=14)$ \\
\hline
\end{tabular}

Dalla are mean $\pm \$ . e . m_{n} ; I D D M$, insulin-dependent diabetes mellitus; $D C$, distensibility coefficient; $C C$, compliance coefficient, PWV pulse wave velocity: " $0<0.05$.

\section{Discussion}

In the present study, patients with uncomplicated IDDM were compared with matched healthy control subjects. Blood pressure, pulse pressure, and heart rate neither were different between patients and controls nor were different between short-term (defined as $\leq 9$ years duration of disease) and long-term (defined as $>9$ years duration of disease) IDDM. None of the patients suffered from hypertension.

Microangiopathic changes are a well-known complication in diabetic subjects (24), but macrovascular pathological changes are also an important feature of IDDM. It is hypothesised that a close correlation exists between microvascular and macrovascular changes in IDDM $\{5,30)$. However, most data about diabetes and vascular compliance are based on studies with non-insulin-dependent diabetes mellitus (NIDOM) patients. Large artery disease in IDDM is supposed to affect predominantly distal arteries (27). Rubba et al (27) showed that early arterial disease was enhanced in IDDM patients compared with control subjects, but it is not known whether these patients had microalbumimuria or to what extent they had other complications. In this study, abnormalities mainly consisted of stenosing lesions in the femoral, popliteal and tibial arteries, while pelvic vessel disease was nearly absent. But, also in the proximal common carotid artery of IDDM patients more atherosclerotic changes were found than in control subjects (20). 
Changes in the vessel wall properties of large arteries might play a role in arterial ageing and might facilitate development of atherasclerotic disease, which is a major complication in diabetic subjects (1). Changes in vessel wall properties (distensibility and compliance) may be an early feature of vascular dystunction. Such changes might be expressed differently in elastic and muscular large arteries. Therefore, vessel wall properties of the elastic common carotid artery and the muscular femoral and brachial arteries were studied. Several authors have investigated the elastic behaviour of large arteries in diabetic patients. In general, distensibility was found to be decreased $(16,22,26,29,32,34,41)$. In contrast, Lehmann et al showed a higher aortic distensibility in young patients with uncomplicated IDDM one year after diagnosis, when compared with age-and sex-matched control subjects (18). However, these subjects were not matched for blood pressure and this could have influenced the results.

Most of the above cited studies used the pulse wave velocity technique, which is only an indirect measure of arterial distensibility (14,32). In addition, the results were often based on observations in a poorly defined population of mixed IDDM and NIDDM patients, with a large age distribution, with and without complications, treated with a variety of regimens, and with a highly variable duration of disease. Therefore, these data are difficult to interpret and may not be comparable with ours. The only studies available with regard to IDDM also use other techniques to assess large artery properties $(18,32)$. The minimal change in aortic distensibility in these studies was $32 \%$. In the present study, a larger sample size (30 subjects per group) was used. This made it possible to demonstrate with a power of $80 \%$ a difference in distensibility of $5 \%$ for the aorta, of $10 \%$ for the common carotid artery, and of $15 \%$ for the brachial and femoral arteries. In the present study, no gross changes in arteriall wall properties could be demonstrated between IDDM patients and a matched control group. Arterial diameter, distensibility and compliance of the elastic and muscular arteries, as well as aortic pulse wave velocity - a measure of aortic distensibility - were not statistically significantly affected by diabetes. Using the data of the present study for sample size calculation, we calculated that more than 52,000 subjects should be included in each group to find a significant difference $(p<0.05)$ with an $80 \%$ power. With such a number of patients, there is the question whether these statistical differences are also clinically relevant. In contrast, previous studies studying arterial compliance in different groups of diabetics have shown statistical differences with relatively small numbers of patients. $(18,19,32,37,38)$.

Nevertheless, in the present study some trends could be seen. Arterial diameter of the carotid and femoral arteries were slightly larger in IDDM patients. During the early stages of atherosclerotic disease, arterial diameter indeed may become increased $(10,40)$. Since the carotid and femoral arteries, in contrast to the brachial artery, are most prone to atherosclerosis in diabetic patients, the presence of early-still below the dection limit of B-mode scanning - atherosclerosis cannot be excluded. In addition, femoral artery distensibility was considerably decreased and compliance of the femoral artery also tender to be diminished in IDDM patients compared with controls ( $25 \%$ vs. $15 \%$, respectively). This might be due to wascular dysfunction, and endothelial changes in particular could be suspected. It is not clear whether this increased stiffness of the femoral artery is also an early feature of atherosclerolic disease.

in the present study, heart rate did not differ between IDDM patients and control subjects, although data from the literature have shown increased basal heart rate and decreased heart rate variability in IDDM patients $(9,15,17,33,43)$. The higher heart rate in diabetics has been related to the presence of autonomic neuropathy and other microwascular complications (33). In addition, the presence of microalbuminuria is closely related to autonomic neuropathy in $\operatorname{IDDM}(17,23,43)$. Microalbuminuria was absent in all IDDM patients in the present study. Therefore, the low heart rate of the diabetic subjects in our study can be explained by the thoroughly selected group of patients with uncomplicated IDDM without microalbuminuria and autonomic neuropathy, whereas it is not probable that a high fitness level of the IDDM patients plays a major role.

Like the previous studies, IDDM patients with a highly variable duration of disease were investigated, and this might have equalised possible differences between IDDM patients and control subjects, if duration of the disease has any influence. But within the subgroups of patients with short-term and long-term disease, we were unable to demonstrate obvious differences. Nevertheless, the arterial diameters of the three 
arteries were slightly smaller in long-term IDDM. Distensibility and compliance of the elastic common carotid artery tended to be decreased, and aortic distensibility also tended to be diminished in lang-term IDDM, while vessel wall properties of the muscular arteries were less affected. Thus, despite the small number of subjects in each subgroup, some trends were visible. Therefore, a possible influence of the duration of the disease caninot be excluded.

At present, it is not completely clear how large arteries are influenced by diabetes in case of IDDM, but various mechanisms have been postulated. Changes in various vascular hormones and haemostatic abnomalities in IDDM have been extensively investigated, but their role has not been clarified yet $(8,12)$. Injury to the vascular endothelium, resulting in endothelial dystunction, may play an important role in the pathogenesis of small and large vessel disease in diabetes (5). Hyperinsulinaemia may also occur in IDDM $(6,42)$ and has been indirectly associated with increased arterial wall stiffness, narrowing of the vascular lumen, and increased vascular resistance (1). It is well known that chronic hyperglycaemia is an important cause for the development of diabetic complications $(3,36)$. Longstanding hyperglycaemia has been proposed as an independent cardiovascular risk factor (8). One of the pathophysiological consequences of hyperglycaemia is the formation of advanced glycosylation end-products (AGE). Accumulation of AGE products may impair endothelial function and increase vascular permeability. in addition, the extracellular matrix is irreversibly changed via increased cross-linking between collagen fibrils (3). This results in a stiffer vessel that might become more sensitive to endothelial injury and subsequent atherosclerosis $(3,36)$. In the present study, no clear evidence was found for a relation between the actual glucose levels or $\mathrm{HbA}$.lc and arterial wall haemodynamics.

In conclusion, femoral artery distensibility was decreased in a group of patients with uncomplicated IODM. These data suggest early, still not detectable, diabetes-induced vascular disease of the femoral artery. No gross changes in haemodynamics and vessel wall properties of other elastic and muscular large arteries could be demonstrated when compared with a matched control group.

No obvious relation was found between vessel wall properties and the duration of the disease, the actual glucose level, and $\mathrm{HbA} 1 \mathrm{c}$, but since the groups were small, a mild influence of the duration of diabetes cannot be excluded.

\section{References}

1. Bierman EL. Atherogenesis in diabetes. Arterioscler Thromb 1992;12:647-56.

2. Borch-Johnsen $K$, Nissen $H$, Salling $N$, Henriksen E, Kreiner $S$, Deckert T, Nerup J. The natural history of insulin-dependent diabetes in Denmark. 2. Long-tem surviwal: who and why. Diabetic Med $1987: 4: 211-16$

3. Brownlee $M$, Cerami $A$, Vlassara $H$. Advanced glycosylation end products in lissue and the biochemical basis of diabotic complications. N Engl J Med 1988;318:1315.21.

4. Cral FV, Roberts WC. The oxtramural and int amural coronary arteries in juvenille diabeles mellitus, Am J Med 1978,64 $.220-30$.

5. Deckert T. Feldt-Aasmussen B, Borch-Johnsen $K_{n}$ Jensen T, Kotoed-Enevoldsen A. Albuminuria reflects widespread vascular damage. The Steno hypothesis. Diabetologia 1989;32:219-26.

6. DeFromzo RA, Hender $R_{4}$ Simonson D. Insulin resistance is a prominent feature of insulin-dependent diabetes. Diabetes 1982,31:795-801.

7. Devereux $\mathrm{AB}$, Waeber B. Roman MJ. Conclusions on the meastrement of arterial wall thickness: anatomic, physiologic and methodologic considerations. J Hypertens 1992:10 (Suppl. 6) :S 19-21.

8. Epstein M, Sowers JR. Diabetes mellitus and hypertension. Hypertemsion 1992;19;403-18. 
9. Ewing DU, Neilson JMM, Shapiro CM, Stewart JA, Reid W. Twenty four hour heart rate variability elfects of posture, sieep, and fime of day inealthy controls and comparison with bedside tests of autonomic function in diabelic patients Br Heart J 1991;65:239-44.

10. Filitit $V$, Giral P. Simon $A_{3}$, Merli 1 "Del Pino M, Levenson J. Enhanced constriction of the peripheral large artery h response lo acute indziction of a low-flow state in human hypercholesterolemia. Arterioscter Thromb 1991; 1:161-66.

11. Fuster V, Badimon L, Badimon لJ, Chesebro JH. The pathogenesis of coronany arteny disease and the acute coronary synidromes. N Engl iJ Med $1992_{2} 326: 242-50$.

12. Ganda OP. Pathogenesis of macrovascular disease in the human diabetic. Diabetes $1980,29: 931-42$

13. Green A, Borch-Johnsen K. Andersen PK, Hougaard P. Keiding N, Kreiner $S$, Deckert T. Felative mortality of type 1 (insulim-dependenty diabetes in Denmark: 1933-1981. Diabetologia \$985;28:339-42.

14. Hoeks APG, Brands PJ, Smeets FAM, Reneman RS. Assessment of the distensibility of superticial arteries. Ultrasound Med Biol 1990;16:121 28 .

15. Jensen $T$, Richter EA, Feldt-Rasmussen $B$, Kelbaek $H$, Deckert $T$. Impaired aerobic work capacity in insulim dependent diabetics with increased urinary albumin excretion. BMJ 1988:296 :1352-54.

16. Katz HP, Cheilin MD, Wasser AH. Observations on the pulse wave velocity and tissue biopsy in children with diabeles mellitus. Bull Johns Hopkins Hosp 1970;127:336.

17. Kelbaek H, Jensen $T$, Feldt-Rasmussen $B$, Christensen MJ, Richter EA, Deckert $T$, Nielsen SL. Impaired left-ventricular function in insulin-cependent diabetic patients with increased urinary albumin excretion. Scand $J$ Clin Lab Invest $1991: 51: 467 \times 73$.

18. Lehmann ED, Gosling RG, Snksen PH. Arterial wall compliance in ciabetes. Diabetic Med 1992:9:114-19.

19. Lo CS. Rell IRN, Myers KA, Wahiqvist ML. Doppler ultrasound recognition of precilinical changes in arterial wall diabetic subjects: compliance and pulsenwave damping. Diabetes Care 1986:9:27-31.

20. Merrin PK, Renton S, Fisher C, Nicholaides A, Elkeles RS. Arterial wall abnormalities in type 1 and lype 2 diabetes. Diabetic Med 1992;9 (Suppl. 1):30A.

21. ORourke MF. Function of arteries as vascular conduits, lin: O'Rourke MF, ed. Arterial function in health and disease Edinburgh Londan Melbourne New York: Churchill Livingstone 1982 :53-64.

22. Oxlund $H_{1}$ Rasmussen $L M$, Andreassen $T T$, Heickendorff $L$. Increased aprtic stiffness in patients with Type 1 (insulini-dependent) diabetes mellilus. Diabetologia 1989;32:748-52.

23. Parving HH, Hommel $E_{4}$ Mathiesen $E_{1}$ Skott $P$, Edsberg $B$, Bahnsen $M$, Lauritzen M, Hougaard $P$, Lauritzen $E$. Prevalence of miaroalbuminuria arterial hypertension, retinopathy and neuropathy in patients wilh insulin dependeni diabetes. BMJ $1988 ; 296: 156-60$.

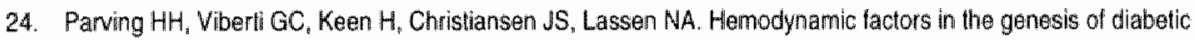
microangiopathy. Metabolism 1983;32:943-49.

25. Pignoll P, Tremoli E, Poli A, Oreste P, Paoletti $R$. Intimal pius medial thickness of the arterial wall: a direct measurement with ultrasound imaging. Circulation 1986;74:1399-1406.

26. Pillsbury $\mathrm{HC}_{\mathrm{B}}$ Hung W, Kyle MC, Freis ED. Arterial pulse waves and velocity and systolic time intervals in diabetic children. Am Heart J 1974:87:783-90.

27. Rubba P, Riccardi G, Pauciullo P. Vaccaro O Carbone L, Mancini M. Different localization of early arterial lesions in insulin-dependent diabetes melitus and in familial hypercholesterolemia. Metabolism 1989;38:962 66 .

28. Rutan GH, Kuller LH Neaton JD, Wentworth DN, MCDonald RH, Smith WM. Mortality associated with diastolic hypertension and isolated systolic hypertension among men screened for the Multiple Ristl. Factor Intervention Trial. Circulation $1988 ; 77: 504-14$.

29. Scarpello JHB, Martin TFP. Ward JO. Ultrasound measurements of pulse-wave welocity in the peripheral arteries of diabetic subjects. Clin Sci 1980;58:53-57.

30. Stehouwer CDA, Zellenrath $P_{2}$ Polak $B_{i}$ Baarsma GS, Nauta JJP, Donker A.JM. Von Willebrand factor and early diabetic retinopathy: no evidence for a relationship in patients with type 1 (insulin-deperidenl) diabetes mellitus and normal urinary albumin excretion. Diabetologia 1992;35:555-59.

31. Tardy $Y$, Hayoz D, Mignot, JP, Richard P, Brumer HR, Meister JJ. Dynamic non invasive measurements of arterial diameter and wall thickness. JHHpertens $1992 ; 10$ (Suppl. 6) :S105-9. 
32. Thordarson H. Thorgeirsson G. Helgason T. Aortic stiffness in insulin-dependent diabetics: an echocardiographic study. Diabetic Med 1986,3:449-54

33. Thuesen $\mathrm{L}_{\text {i }}$ Christiansen $\mathrm{JS}$, Mogensen $\mathrm{CE}$, Henningsen $\mathrm{P}$. Cardiac hyperfunction in insulin-dependent diabetic patients developing microvascular complications. Diabetes 1988; $37: 851-56$.

34. Treese $N$, Ungern-Sternberg v $A_{\text {, }}$ Cordes $U$, Beyer J. Influence of norepinephrine on vessel geometry of the intact femoral artery in juverille insuline-dependent diabetics. Evidence of early diabetic angiopathy in central arteries. $Z$ Kardiol 1982;71:60-64.

35. Vaandrager GJ, Bruining GJ, Veenhof FJ, Drayer NM. Incidence of childhood diabetes in the Netherlands: a decrease from north to south in North-Western Europe? Diabetologia 1984;27:203-7.

36. Vlassara $H_{1}$ Browinlee $M_{4}$ Cerami A. Nonenzymatic glycosylation: role in the pathogenesis of diabetic complications. Clin Chem 1986;32:B37-41.

37. Wahiquist ML, Lo CS, Myers KA. Fish intake and arterial wall characteristics in healthy people and diabetic patients. Lancet 1989;21 okt :944-46.

38. Wahlquist ML, Lo CS, Myers KA, Simpson RW, Simpson JM. Putative determinants of arterial wall compliance in NiDDM. Diabeles Care 1988;11:787-90.

39. Wendelhag I, Wiklund $O$, Wikstrand J. Anterial wall thickness in familial hypercholesterolemia. Arterioscler Thromb $1992 ; 12: 70-77$

40. Wikstrand J, Wiklund $\mathrm{O}$. Frontiers in cardiovascular science, Quantiliative measurements of atherosclerotic manilestations in humans. Arterioscler Thromb 1992;12 :114-19.

41. Woolam GL, Schinur PL, Vallbona $\mathrm{C}_{\text {. }}$ Hoff HE. The pulse wave velacity as an early indicator of atherosclerosis in diabetic subjects. Circulation 1962:25:533-39.

42. Yki-Järwinen $\mathrm{H}_{8}$ Koilvisto VA. Natural course of insulin resistance in type I diabetes. N Engl J Med 1986;315:224-30.

43. Zander $E$, Schulz B, Heinke P, Grimmberger $E$, Zander $G$, Gottschling HD. Importance of cardiovascular autonomic dysfunction in IDDM subjects with diabetic nephropathy. Diabeles. Care 1989;12:259-64. 


\section{CHAPTER 7}

THE INFLUENCE OF PERINDOPRIL AND THE DIURETIC COMBINATION AMILORIDE/HYDROCHLOROTHIAZIDE ON THE VESSEL WALL PROPERTIES OF LARGE ARTERIES IN HYPERTENSIVE PATIENTS

Mirian J.F. Kool, *Frans A.T. Lustermans, ** Johan G.S. Breed, Harry A.J. Struijker Boudier, ***Arnold P.G. Hoeks, "Robert S. Reneman, and Luc M.A.B. Van Bortel

Departments of Pharmacology, ${ }^{*}$ Physiology, ***Bophysics, Cardiovasular Research Institute Maastricht, University of Limburg, Departments of Internal Medicine, ${ }^{*}$ De Wever Hospital Heerlen and **St. Jansgasthuis Weert, the Netherlands

Based on J Hypertens 1995 (in press) 


\section{Summary}

The aim of the present study was to compare cardiowascular effects of a 6 -month treatment with the ACE inthibitor perindopril $(P)$ or with the diuretic amiloride/hydrochlorothiazide $(A / H)$ and to study possible persistence of the observed treatment effects after discontinuation of the antihypertensive therapy.

A placebo run-in period was followed by an active treatment phase during 6 months in 41 patients with essential hypertension, according to a double-blind, randomised, paraliel design. Patients received perindoprill $4 \mathrm{mg}$ o.d. or $\mathrm{A} / \mathrm{H} 2.5 / 25 \mathrm{mg}$ a.d. Subsequently, patients were studied during a 3-month single blind placebo run-out period.

After 6 months of treatment ${ }$ supine systolic blood pressure was reduced $(p<0.01)$ by $P(11 \%)$ and $\mathrm{A} / \mathrm{H}$ $(8 \%)$. Diastolic blood pressure decreased more $(p<0.05)$ with $P(8 \%)$ than with $A / H(4 \%)$. Cardiac index increased with $P(6 \%)$, due to an increased stroke index $(5 \%)$, while during $\mathrm{A} / \mathrm{H}$ cardiac function was unchanged. Systemic vascular resistance index decreased more $(p<0.05)$ with $\mathrm{P}(14 \%)$ than with $\mathrm{A} / \mathrm{H}(8 \%)$, indicating a more pronounced vasadilation of small vessels with $P$. Effects on diameter of the elastic common carotid artery (CCA) and the muscular femoral (FA) and brachial (BA) arteries did not differ between $P$ and $A / H$. Distensibility of CCA was significantly enhanced by $P(16 \%)$, but unchanged with $A / H$ $(1 \%)$. The difference between $P$ and $A / H$ for carotid distensibility was statistically significant $(p<0.01)$. Compliance of CCA tended to be more increased $(P=0.067)$ with $P(7 \%)$ than with $\mathrm{A} / \mathrm{H}$, which induced a decrease $(5 \%$, n.s.) in carotid compliance. After withdrawal of therapy, for both $\mathrm{P}$ and A/H all treatmentinduced changes reversed to pre-treatment values within 7 weeks.

In conclusion, these data show that distensibility of the elastic common carotid artery was increased by perindopril, but not by amiloride/hydrochlorothiazide. Large artery properties of the muscular arteries and systemic vascular resistance improved with both drugs, but in general the changes were more pronounced with perindopril than with amiloricie/hydrochlorothiazide.. These results indicate a more pronaunced effect of perindoprill at both the macro and microcirculatory level, which consequently will lead to a larger decrease in cardiac afterload. After discontinuation of therapy all parameters returned to baseline values within 7 weeks. 


\section{Introduction}

From epidemiological studies it is known that hypertension is related to a high candiovascular risk (14). In hypertension functional and structural changes of the cardiovascular system are observed (27). Changes at the level of the arterioles result in an enthanced peripheral resistance with an elevation of mean arterial pressure (24). However, the increase in peripheral resistance is not the leading cause of death in hypertension. Hypertension-related mortality is primarily due to changes in large arteries, leading to stroke, cardiac failure and myocardial infarction (14). Vessel wall properties of large arteries (distensibility and compliance) may play an important role in the ill-effects of hypertension. Distensibility reflects the elastic properties of the arterial wall, while compliance determines the capacity of large arteries to store the blood volume, ejected with each heart beat. In essential hypertension the elastic and buffering function of the arterial system is diminished (24). This can be due to the higher blood pressure and is not necessarily due to alterations in intrinsic properties, at least for the radial artery (12). For a given stroke volume, a decrease in arterial distensibility and compliance and increased pulse wave reflections, will enhance pulse pressure. Increased pulse pressure has been associated with increased cardiovascular morbidity $(14,19)$.

Thiazide diuretics are frequently used in the management of hypertension, but the influence of diuretics on vessel wall properties of large arteries has not been extensively investigated. One short-term study in systolic hypertension suggested an increase in arterial compliance with thiazides (32).

Converting enzyme inhibitors not only decrease blood pressure, but they may also be more effective in reversing cardiac hypertrophy than other antihypertensive drugs (11). ACE inhibitors improved vessel wall properties of human large arteries $(3,4,23,25,30,31$, but these are all short-term or uncontrolled studies. Animal data have shown a regression of structural changes in the vessel wall with these compounds (17) and human data suggested a regression of structural changes in arterioles (29). If such a change also occurs in the vessel wall of large arteries in humans, (partial) improvement of large artery properties after withdrawal of the drug might persist.

Therefore, the aim of the present study was to compare the long-term effects of antihypertensive treatment with the ACE intibitor perindopril to treatment with the diuretic amiloride/hydrochlorothiazide. Apart from the effects on blood pressure, heart rate and cardiac function, effects on vessel wall properties of 3 different arteries were evaluated: the elastic common carotid artery and the muscular common femoral and brachial arteries. A secondary aim was to determine if, after withdrawal of the chronic treatment, the observed effects on vessel wall properties persist.

\section{Patients and methods}

Patients - 86 Outpatients with mild to moderate essential hypertension were selected for the study. Patients had to be between 18 and 65 years of age. Patients were excluded for the following reasons: secondary and malignant hypertension, congestive heart failure, severe cardiopulmonary disease, myocardial infarction or cerebrovascular accident within the pas! 6 months, overt atherosclerolic lesions, diabetes mellitus treated with insulin or oral antidiabetics, significant renal or hepatic disease (serum creatinime $>180 \mu$ mol $l_{i}$ ALAT and $\gamma$-GT 2 x upper normal limit), abnormal plasma protein values, and serum potassium $>5.5 \mathrm{mmol} / \mathrm{l}$. Concomitant medication that may affect blood pressure (eg, antidepressants, nitrates, corticasteroids etc) or treatment with an ACE inhibitor $<3$ months prior to the study was not allowed. Pregnant or nursing women, patients with severe concurrent disease, and patients with known adverse reactions to ACE inhibitors or diuretics were also excluded. After $B$ weeks of single blind placebo-treatment 41 patients were found eligible for inclusion.

The two treatment groups consisted of 20 patients (14 males, 6 females) in the perindopril group and 21 (10 males, 11 females) in the amiloride/hydrochlorothiazide $(A / H)$ group. Demographic dala are shown in 
Table 1. Demographic data at beseline (Heek of.

\begin{tabular}{lcc}
\hline & Perindopril & Amiloride/HCTZ \\
\hline Number of patients & 20 & 21 \\
Maleilemale & $14 / 6$ & $10 / 11$ \\
Age (years) & $50(34-63)$ & $52(35-63)$ \\
Weight (kg) & $78.7(48.0-101.0)$ & $76.5(58.0-99.5)$ \\
Heighit (cm) & $171(155-182)$ & $169(153-18.2)$ \\
Body surface area $\left(\mathrm{m}^{2}\right)$ & $1.9(1.5-2.2)$ & $1.9(1.6-2.2)$ \\
\hline
\end{tabular}

HCTZ, hydrochlorothiazide; Dala are mean (range).

Table 1. Two smokers were present in the perindopril group and 4 in the A/H group, which smoked on average 11 and 16 cigarettes a day, respectively. Seven patients in the perindopril group and 10 in the AH group had an allcohol consumption of more than one glass per day. Alcohol consumption never exceeded 4 glasses per day. In the perindopril group 17 subjects and in the A/H group 18 subjects were previlously treated with antihypertensive drugs. The mean duration of thypertension was $8.1(0.8-16.6)$ years in the perindopril group and $7.5(0.6-30.0)$ years in the A/H group. Thirteen patients in the perindopril group and eight in the AlH group used a salt restricting diet.

Study design - The study was a multicentre double-blind, randomised, paraliel study. Throughout the study patients were not allowed to change their normal diet and daily salt intake.

\section{Single-blind placebo run-in period (week -6 to 0)}

A general physical and routine laboratory examination was carried out and a full medical history was taken at the first visit (week -6). Blood pressure, cardiac function and vessel wall measurements were pertormed to familiarise to the examination procedures. An electrocardiogram was performed and an echographic screening of the carotid and femoral arteries was made to exclude overt atherosclerotic lesions. All previous antihypertensive therapy was withdrawn within the first week of the run-in period and all other forbidden medications were discontinued. Patients received placebo once daily in the morning for 6 weeks. At week $-4 .-1$ and 0 body weight "blood pressure, heart rate, and clinical acceptability were determined. Vessel wall properties and cardiac function were assessed at week -1 and 0 and blood samples were taken at week -1. Patients were excluded if sitting diastolic blood pressure (DBP) was $>110 \mathrm{mmHg}$ or sitting sysiolic blood pressure (SBP) was $>180 \mathrm{mmHg}$, or because of development of the aforementioned exclusion crileria.

\section{Double-blind active treatment period (week a to 24)}

After 6 weeks placebo, patients with a sitting DBP between 95 and $110 \mathrm{mmiHg}$ were included (mean of 3 measurements at week -1 and 0 ). They were randomly assigned to either oral treatment with $4 \mathrm{mg}$ perindopril or $2.5 \mathrm{mg} / 25 \mathrm{mg}$ AH for 6 months. After 1 or 3 months the dose was doubled once if sitting DBP was $\geq 90 \mathrm{mmHg}$. Major exclusion criteria were a sitting DBP $>110 \mathrm{mmHg}$ (at maximal dose), or $>100$ $\mathrm{mmHg}$ after 3 months. Treatment was also discontinued in patients that developed serious adverse effects 
or met other exclusion criteria, or in the case of poor patient compliance. Weight, blood pressure, heart rate and clinical acceptability were assessed at each visit during the active treatment period (week 4,12 and 24). Routine laboratory tests, vessel wall measurements and cardiac function were performed after 3 and 6 months of active treatment (week 12 and 24 , respectively).

\section{Single placebo run-out period (week 24 to 37 )}

After 6 months of active treatment, the therapy was stopped and replaced by a single-blind placebo run-out period up to 3 months, depending on DBP levels. Placebo was used once daily "corresponding to the dase in the active treatment phase. Patients were examined at week 30 and 37 . If, after 7 weeks of placebo, sitting DBP was $>110 \mathrm{mmHg}$ or SBP was $>180 \mathrm{mmHg}$, or when other exclusion criteria developed, the patient was withdrawn.

The study was performed in accordance with the principles of the Declaration of Helsinki (revised 1983) and was approved by the Ethical Committees of each participating centre. Intormed consent was obtained from all patients.

Methods - All haemodynamic measurements were performed after at least 15 min of supine rest in a quiet room. For each patient measurements were carried out at the same time of the day. All measurements were made by the same observer.

\section{Blood pressure and heart rate}

Sitting blood pressure was measured on the same arm at the end of each visit with a mercury sphygmomanometer. Korotkoff phase V (disappearance of sound) was used to define DBP. The mean of 3 measurements with at least a 1 min interval was taken as the patient"s reading. Sitting heart rate was determined at the end of each visit by palpation of the radial artery for $30 \mathrm{sec}$. Simultaneously with the vessel wall measurements, supine systolic, diastolic and mean arterial blood pressure (MAP) were recorded every 3 min on the left arm with a Dinamap (Chapter 2) and the mean of these recordings (at least 9) was taken as the patient"s reading.

\section{Vessel wall properties}

Vessel wall properties of the right elastic common carotid artery (CCA), and the right muscular common femoral (FA) and brachial (BA) arteries were assessed in recumbent position with the vessel wall movement detector system, described in Chapter 2. From arterial diameter, distension and pulse pressure, vessel wall properties, distensibility and compliance, were calculated with the equations mentioned in Chapter 2.

\section{Cardiac function}

Cardiac function was measured with the patient in left laleral position, using an echo Doppler technique (Chapter 2).

\section{Laboratory tests.}

Venous blood samples were analysed for potassium, sodium, uric acid, creatinine, glucose, transaminases (ALAT, ASAT), $\gamma-$ GT, alkaline phosphatase, protein and albumin.

\section{Drugadherence}

Patients were asked for their drug adherence at each visit. In addition, the number of capsules returned at the end of each treatment period was counted. 


\begin{abstract}
Data analysis - With regard to body weight, blood pressure, heart rate, vessel wall measurements and cardiac function the mean of two consecutive sessions at the end of each period was taken: placebo run-in period (week - 1 and 0 ), active treatment (week 11 and 12 ; week 23 and 24), and placebo run-out period (week 30 and 31 " week 36 and 37 ). Initial comparability of the 2 treatment groups at inclusion was assessed by a Student's 1 - test for unpaired observations (quantitative criteria) and by a $\chi^{2}$-lest (qualitative criteria). During the active treatment period and during run-out, changes over time within each treatment group as well as comparisons between the 2 treatment groups were assessed with a 2-way ANONA. In case of a significant time course effect additional Newman-Keuls tests were performed at each time point. Data are presented as mean \pm s.e.m. p<0.05 was considered statistically significant.
\end{abstract}

\title{
Results
}

At baseline (week 0), no significant differences existed between the two study groups with regard to demographic data (Table 1), haemodynamics and laboratory values. Six patients in the perindopril group and eight in the diuretic group used concomitant medication at baseline and this was not changed throughout the study. Medication consisted of NSAID's, cholesterol lowering drugs, benzodiazepines, allopurinol, levothyroxine, fydroxycobalamin, carbasalate calcium and paracetamol.

During the active treatment period (week 0 to 24), drug adherence was high in both groups (mean $99 \%$, range $80 \%-115 \%$ ). The total number of drop-outs was similar for the 2 drugs: 2 in patients treated with perindopril (1 undesirable adverse effect; 1 with sitting DBP $>100 \mathrm{mmHg}$ after 3 months treatment), and 1 in the diuretic group (sitting DBP >100 $\mathrm{mmHg}$ after 3 months treatment). Based on sitting DBP, the dose was doubled in 27 out of 41 patients $(13 \mathrm{P}, 14 \mathrm{~A} / \mathrm{H})$ after 1 month, while 29 out of 38 patients completed the study with a double dose $(13 \mathrm{P}, 16 \mathrm{~A} / \mathrm{H})$.

The changes in laboratory values - including serum potassium - were not clinically signilicant, except for uric acid, which was elevated more during $\mathrm{A} / \mathrm{H}(17 \%)$ than during $\mathrm{P}(1 \%)$ treatment. Weight decreased during treatment with $\mathrm{A} / \mathrm{H}(2 \%)$ and $\mathrm{P}(1 \%)$, the effect being most obvious during the first 3 months of treatment.

Results on blood pressure and cardiac function are shown in Table 2. After 6 months of treatment with perindoprill, sitting SBP and DBP decreased $(10 \%, 11 \%$, respectively). Supine SBP and DBP were reduced $(11 \%, 8 \%$, respectively), as well as supine pulse pressure $(15 \%)$ and supine mean arterial pressure $(9 \%)$. Heart rate was unchanged. With $\mathrm{A} / \mathrm{H}$ sitting SBP and DBP decreased $(11 \%, 9 \%$, respectively). Supine blood pressure was also lower atter A/H (SBP 8\%; DBP 4\%). Supine pulse pressure and mean arterial pressure decreased by $14 \%$ and $5 \%$, respectively. Hoart rate remained unchanged. Supine DBP was significantly more reduced $(p<0.05)$ after perindopril than after the diuretic. At the end of the active ireatment period $13(34 \%)$ patients had a sitting DBP $\leq 90 \mathrm{mmHg}, 5(28 \%)$ with perindopril and $8(40 \%)$ in the diuretic
group.

With perindopril cardiac index and stroke index increased slightly, $6 \%$ and $5 \%$, respectively. AH did not induce changes in cardiac index or stroke index. Systemic wascular resistance index decreased with both $\mathrm{P}(13 \%)$ and $\mathrm{A} / \mathrm{H}(8 \%)$, but the decrease was significantly larger with perindopril $(p<0.05)$.

Data on vessel wall properties are shown in Figures 1-3. Compared to baseline (TO), after 6 months of treatment (T6) with perindopril, the diameter of the common carotid artery (CCA) decreased with $P$ (T0:6.54 $\pm 0.19 ; T 6: 6.37 \pm 0.18 \mathrm{~mm} ; \mathrm{p}<0.01)$. After $P$, distensibility $\left(T 0: 14.7 \pm 0.9 ; T 6: 17.0 \pm 0.710^{-3} \mathrm{kPa}\right.$; $p<0.01)$ and compliance of the CCA (TD:0.51 $\left.\pm 0.05 ; T 6: 0.54 \pm 0.03 \mathrm{~mm}^{2} / \mathrm{kPa} ; \mathrm{p}=0.01\right)$ were increased. With the diuretic, the diameter of CCA decreased (T0:6.54 $\pm 0.15 ; T 6: 6.32 \pm 0.15 \mathrm{~mm} ; p<0.05$ ), but the distensibility of the CCA remained unchanged (TO:13.5 $20.8: T 6: 13.7 \pm 0.710 .3 \mathrm{kPa}$ ). The effect of $P$ was with P for carolid compliance. 
Tabile 2. Changes in blood pressure and cardiac lunetion during treatment (thatied dose) with perimcopoll wersus amiloride/hydrochlorothiazice and during placebo pun-out

\begin{tabular}{|c|c|c|c|c|c|c|}
\hline & & Baseline & $\begin{array}{l}\text { Treatment } \\
3 \text { manths }\end{array}$ & $\begin{array}{l}\text { Treatment } \\
6 \text { months }\end{array}$ & $\begin{array}{l}\text { Run-oul } \\
7 \text { weeks }\end{array}$ & $\begin{array}{l}\text { Run-out } \\
13 \text { weeks }\end{array}$ \\
\hline \multicolumn{7}{|l|}{ Blood pressure } \\
\hline \multirow{2}{*}{$S B P_{\text {sititing }}(m m H g)$} & $P$ & $150 \pm 2$ & $131 \pm 2^{* *}$ & $135 \pm 2^{* * *}$ & $148 \pm 2^{m}$ & $150 \pm 2^{* *}$ \\
\hline & $\mathrm{A} / \mathrm{H}$ & $156 \pm 2$ & $136 \pm 2^{* *}$ & $138 \pm 2^{+*}$ & $153 \pm 2^{-}$ & $15,4 \pm 3^{* *}$ \\
\hline \multirow{2}{*}{$\mathrm{DBP}_{\text {sitting }}(\mathrm{mmHg})$} & $P$ & $104 \pm 1$ & $90 \pm 1^{*: 2}$ & $93 \pm 11+$ & $102 \pm 1=$ & $103 \pm 1^{2 *}$ \\
\hline & $\mathrm{A} / \mathrm{H}$ & $103 \pm 1$ & $92 \pm 2^{* *}$ & $94 \pm 2^{*+}$ & $100 \pm 1=$ & $102 \pm 1$ \\
\hline \multirow{2}{*}{$\mathrm{SBP}_{\text {suping }}(\mathrm{mmH})$} & $P$ & $142 \pm 3$ & $124 \pm 2^{* *}$ & $127 \pm 3^{* *}$ & $142 \pm 3^{=}$ & $142 \pm 2^{4}$ \\
\hline & AMH & $143 \pm 2$ & $129 \pm 3^{* *}$ & $132 \pm 3^{*+7}$ & $142 \pm 3^{-}$ & $144 \pm 3^{4}$ \\
\hline \multirow[t]{2}{*}{$\mathrm{DBP}_{\text {supine }}(\mathrm{mmmHg})$} & $\mathrm{P}$ & $89 \pm 1$ & $80 \pm 1^{* *}$ & $82 \pm 1+4$ & $90 \pm 2^{-}$ & $89 \pm 2^{* 4}$ \\
\hline & AlH & $86 \pm 1$ & $81 \pm 2^{* *}$ & $83 \pm 2^{* *}$ & $85 \pm 2^{-}$ & $87 \pm 2^{* 4}$ \\
\hline \multirow[t]{2}{*}{$\Delta P_{\text {supine }}(\mathrm{mmHg})$} & $\mathbf{P}$ & $53 \pm 2$ & $44 \pm 1^{* *}$ & $45 \pm 2^{* *}$ & $53 \pm 2=$ & $54 \pm 2^{n+}$ \\
\hline & AH & $57 \pm 2$ & $48 \pm 2^{* *}$ & $49 \pm 2^{+*}$ & $57 \pm 2=$ & $57 \pm 3^{* \star}$ \\
\hline \multirow[t]{2}{*}{$M A P_{\text {supine }}(\mathrm{mm} H \mathrm{Hg})$} & $P$ & $106 \pm 2$ & $94 \pm 2^{* *}$ & $97 \pm 2^{* 4}$ & $407 \pm 2$ & $107 \pm 2^{24}$ \\
\hline & AlH & $105 \pm 2$ & $97 \pm 2^{* *}$ & $99 \pm 2^{*+}$ & $104 \pm 2^{-}$ & $106 \pm 2^{2 *}$ \\
\hline \multicolumn{7}{|l|}{ Cardiac function } \\
\hline \multirow[t]{2}{*}{ Heart rate (beatsimin) } & $\mathrm{P}$ & $68 \pm 2$ & $69 \pm 2$ & $69 \pm 2$ & $70 \pm 2$ & $69 \pm 2$ \\
\hline & AMH & $70 \pm 2$ & $68 \pm 2$ & $71 \pm 2$ & $68 \pm 2$ & $71 \pm 2$ \\
\hline \multirow[t]{2}{*}{ Cardiac index $\left(\mathrm{L} / \mathrm{min} \cdot \mathrm{m}^{2}\right)$} & $P$ & $3.2 \pm 0.1$ & $3.4 \pm 0.1$ & $3.4 \pm 0.1^{*}$ & $3.4 \pm 0.1$ & $3.4 \pm 0.1$ \\
\hline & A/H & $3.3 \pm 0.1$ & $3.2 \pm 0.1$ & $3.4 \pm 0.1$ & $3.3 \pm 0.1$ & $3.3 \pm 0.1$ \\
\hline \multirow[t]{2}{*}{ Stroke index $\left(\mathrm{mL}^{\prime} \mathrm{m}^{2}\right)$} & $\mathrm{P}$ & $48 \pm 2$ & $49 \pm 2$ & $50 \pm 2^{4}$ & $50 \pm 2$ & $49 \pm 2$ \\
\hline & AH & $47 \pm 1$ & $47 \pm 1$ & $47 \pm 1$ & $49 \pm 1$ & $48 \pm 2$ \\
\hline \multirow[t]{2}{*}{ SVAl (dyn.s.cm $\left.{ }^{-5} \mathrm{~m}^{2}\right)$} & $\mathrm{P}$ & $2704 \pm 102$ & $2298 \pm 90^{* *}$ & $2341 \pm 108^{* 4}$ & $2572 \pm 119=$ & $2620 \pm 110^{\circ}$ \\
\hline & AlH & $2611 \pm 80$ & $2476 \pm 83$ & $2402 \pm 91$ & $2584 \pm 73^{\prime \prime}$ & $2581 \pm 93^{*}$ \\
\hline
\end{tabular}

P:Perindopril, $n=18$ (active treatment period), $n=17$ (placebo run-out); $A / H$ : amiloride/hydrochlorothiazide, $n=20$ (active lreatment period), $n=19$ (placebo run-out); $S B P$, systolic blood pressure; DBP, diastolic blood pressure; $\triangle P$; pullse pressure; MAP, mean arlerial pressure; SVRl, systemic vascular resistance index. Dala are mean $\pm 5.6 . \mathrm{m}$.

"p<0.05, "p<0.01, 3 months of treallment versus basine; "p<0.05, "p<0.01, 6 months of theatment versus baseline; "p<0.05, $-p<0.01,7$ weeks of placebo run-out versus 6 months of active treatment" $p<0.05,{ }^{-4} p<0.01,13$ weeks of placebo rum-0ut versus 6 months of active treatment; $p<0.05$ difference between $P$ and $\mathrm{A} / \mathrm{H}$. 

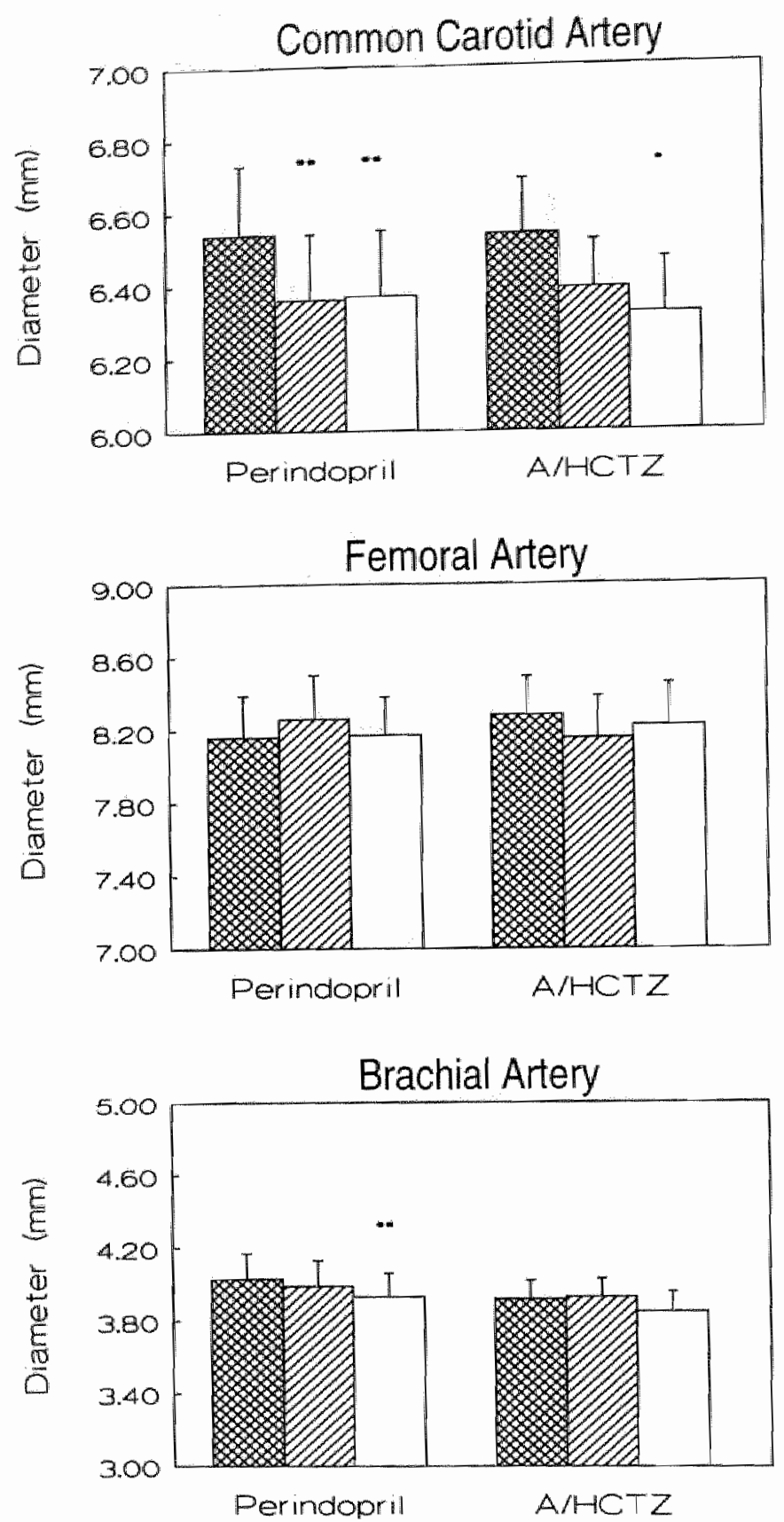

Fig une 1. Changes in arteriai diameter during treatment with perindopril and amiloride/hydrochlorothiazide. Perindopril, $\mathrm{n}=18$; AHCTZ, amiloride/hydrochlorothiazide, $n=20$. Data are mean $\pm s . e, m$.; $" p<0.05, " * 0<0.01$, differences versus baseline. 区X T0, baseline. $\square Z \backslash 3$, after 3 months active treatment. $\square$ To, atter 6 months active treatment. 

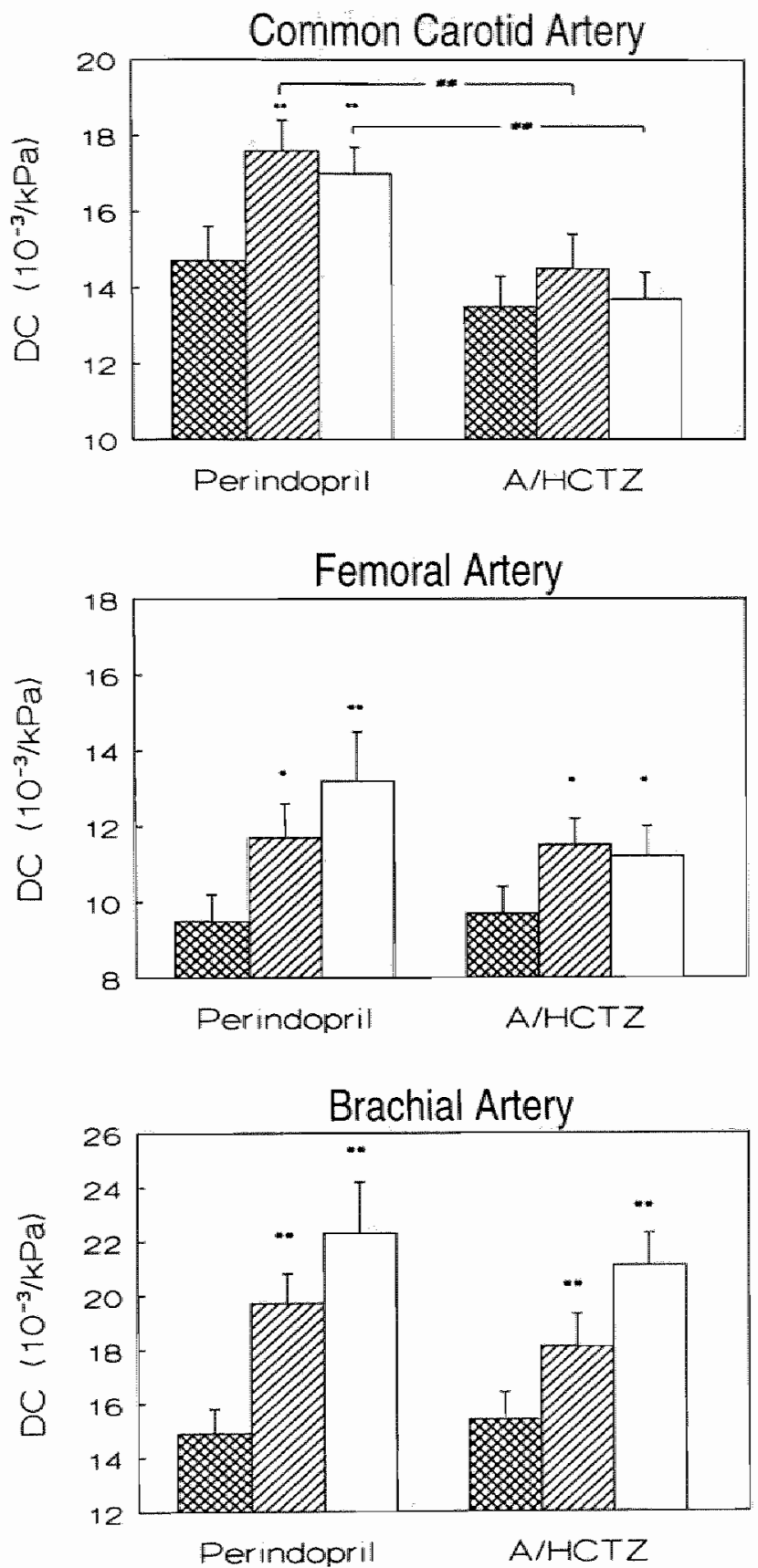

Figure 2. Changes in arterial distensibility during treatment with perindopril and amiloride/hydrochlorothiazide. Perindopril, $n=18$; A.HCTZ, amiloride/hydrochlorothiazide, $n=20$. DC, distensibility coefficient. Dala ate mean $\pm 5 . e$.m., "p<0.05, " $p<0.01$, differences versus baseline; \#\# $p<0.01$, differences between perindorpil and $\mathrm{A} / \mathrm{HCTZ}$.

Q To, baseline. $\mathrm{CZ}$ T3, after 3 months active treatment.

T6, after 6 months active treatment. 

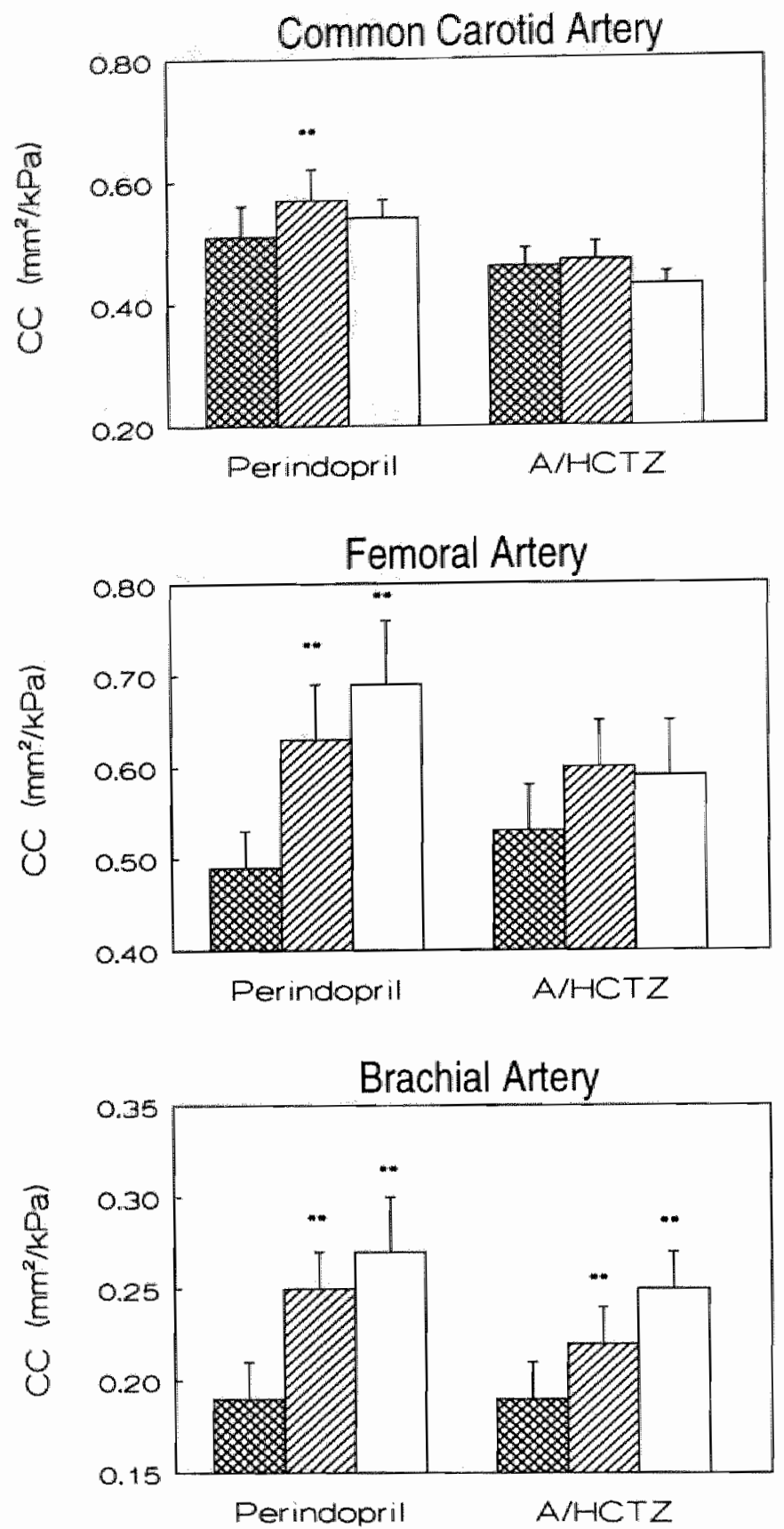

Figure 3. Chenges in arterial compliance during treatment with perindopril and amiloride/hydrochlorothiazide. Perindopril, $m=18$; AiHCTZ, amiloride hydrochlorothiazide, $n=20 . C_{n}$ compliance coefticient Data are mean \pm s.e.m. $" p<0.05, " p<0.01$, differences versus baseline;

XX To, baseline, $\square \square$ T3, atter 3 months active treatment. $\square T 6$, atter 6 months active treatment. 
During the whole treatment period the diameter of the common femoral artery (FA) remained unchanged with $P(T 0: 8.16 \pm 0.23 ; T 6: 8.17 \pm 0.21 \mathrm{~mm})$. Distensibility $\left(T 0: 9.5 \pm 0.7 ; T 6: 13.2 \pm 1.310^{-3} / \mathrm{kPa} ; \mathrm{p}=0.002\right)$ and compliance $\left(T 0: 0.49 \pm 0.04 ; T 6: 0.68 \pm 0.07 \mathrm{~mm}^{2} / \mathrm{kPa} ; \mathrm{p} \times 0.001\right)$ of the FA increased significantly with $P$. The diameter of the FA was not changed by $A / H(T 0: 8.28 \pm 0.21 ; T 6.8 .22 \pm 0.23 \mathrm{~mm})$. Distensibility of FA increased after $\mathrm{AH}\left(\mathrm{TO} 0.9 .7 \pm 0.7 ; \mathrm{T} 6: 11.2 \pm 0.810^{-3} / \mathrm{kPa} ; \mathrm{p}<0.05\right)$. Percentual changes in femoral distensibility and compliance were approximately three times higher with $P(39 \%$ and $40 \%$, respectively) than with $\mathrm{A} / \mathrm{H}(15 \%$ and $13 \%$, respectively). The diameter of the brachial artery (BA) slightly decreased

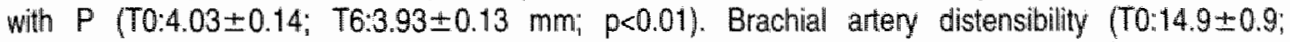
$\left.T 6.22 .3 \pm 1.910^{-3} / \mathrm{kPa} ; \mathrm{p}<0.01\right)$ and compliance of $\mathrm{BA}\left(\mathrm{T} 0: 0.19 \pm 0.01 ; T 6: 0.27 \pm 0.03 \mathrm{~mm}^{2} / \mathrm{kPa} ; \mathrm{p}<0.01\right)$ were enhanced by $\mathrm{P}$. Treatment with $\mathrm{A} / \mathrm{H}$ did not significantly reduce the diameter of $\mathrm{BA}(\mathrm{TO}: 3.92 \pm 0.10$;

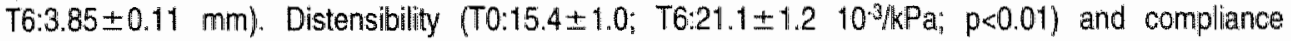
(TO:0.19 $\pm 0.02 ; T 6: 0.25 \pm 0.02 \mathrm{~mm}^{2} / \mathrm{kPa} ; \mathrm{p}<0.01$ ) improved after $\mathrm{A} / \mathrm{H}$.

Table 3. Changes in vessel wall properties of lange arteries duing active treatment and placebo ruth-out.

\begin{tabular}{|c|c|c|c|c|c|}
\hline & & Baseline & $\begin{array}{l}\text { Treatment } \\
6 \text { months }\end{array}$ & $\begin{array}{l}\text { Run-out } \\
7 \text { weeks }\end{array}$ & $\begin{array}{l}\text { Run-out } \\
13 \text { weeks }\end{array}$ \\
\hline \multicolumn{6}{|l|}{ Common carotid antery } \\
\hline \multirow[t]{2}{*}{ Diameter (mim) } & $P$ & $6.49 \pm 0.20$ & $6.34 \pm 0.1 \mathrm{~B}^{* *}$ & $6.46 \pm 0.20^{i \hbar}$ & $6.47 \pm 0.19^{* 2}$ \\
\hline & AlH & $6.61 \pm 0.14$ & $6.36 \pm 0.15^{* *}$ & $6.49 \pm 0.14$ & $6.59 \pm 0.15^{\mathrm{at}}$ \\
\hline \multirow[t]{2}{*}{ Distensibility $\left(10^{3} / \mathrm{kPa}\right)$} & $\mathrm{P}$ & $14.3 \pm 0.8$ & $16.8 \pm 0.7^{* *}$ & $14.3 \pm 0.8^{4 *}$ & $13.7 \pm 0.7^{\star \star 4}$ \\
\hline & AHH & $13.2 \pm 0.8$ & $14.0 \pm 0.7$ & $13.4 \pm 0.7$ & $13.4 \pm 0.9$ \\
\hline \multirow[t]{2}{*}{ Compliance $\left(\mathrm{mm}^{2} / \mathrm{kPa}\right)$} & $P$ & $0.49 \pm 0.04$ & $0.53 \pm 0.03^{*}$ & $0.47 \pm 0.04^{+1+4}$ & $0.46 \pm 0.03^{2 *}$ \\
\hline & AlH & $0.46 \pm 0.03$ & $0.45 \pm 0.03$ & $0.45 \pm 0.03$ & $0.46 \pm 0.04$ \\
\hline \multicolumn{6}{|l|}{ Femoral artery } \\
\hline \multirow[t]{2}{*}{ Diameter (mm) } & $P$ & $8.21 \pm 0.24$ & $8.19 \pm 0.22$ & $8.27 \pm 0.24$ & $8.14 \pm 0.25$ \\
\hline & A/H & $8.28 \pm 0.22$ & $8.22 \pm 0.24$ & $8.18 \pm 0.24$ & $8.15 \pm 0.25$ \\
\hline \multirow[t]{2}{*}{ Distensibility $\left(10^{-3} / \mathrm{kPa}\right)$} & $\mathrm{P}$ & $9.3 \pm 0.7$ & $13.3 \pm 1.4^{n * t}$ & $9.0 \pm 0.6^{*+}$ & $9.2 \pm 0.7^{\star}$ \\
\hline & AH & $9.6 \pm 0.7$ & $11.2 \pm 0.9$ & $9.9 \pm 0.8$ & $10.0 \pm 0.7$ \\
\hline \multirow[t]{2}{*}{ Compliance $\left(\mathrm{mm}^{2} \mathrm{KPa}\right)$} & $\mathrm{P}$ & $0.49 \pm 0.04$ & $0.70 \pm 0.07^{* *}$ & $0.48 \pm 0.03^{++}$ & $0.47 \pm 0.03^{ \pm x}$ \\
\hline & AiH & $0.52 \pm 0.05$ & $0.60 \pm 0.06$ & $0.54 \pm 0.06$ & $0.53 \pm 0.05$ \\
\hline \multicolumn{6}{|l|}{ Brachial artery } \\
\hline \multirow[t]{2}{*}{ Diameter (mm) } & $\mathrm{P}$ & $4.02 \pm 0.15$ & $3.92 \pm 0.14^{*}$ & $3.95 \pm 0.115$ & $3.95 \pm 0.15$ \\
\hline & $\mathrm{AH}$ & $3.90 \pm 0.14$ & $3.85 \pm 0.12$ & $3.88 \pm 0.11$ & $3.7 \theta \pm 0.11$ \\
\hline \multirow[t]{2}{*}{ Distensibility $\left(10^{-3} / \mathrm{kPa}\right)$} & $P$ & $15.1 \pm 0.9$ & $22.9 \pm 1.9^{*}$ & $15.9 \pm 1.1^{+++}$ & $16.2 \pm 1.1^{2 *}$ \\
\hline & $\mathrm{A}_{\mathrm{N}} \mathrm{H}$ & $15.4 \pm 1.1$ & $21.0 \pm 1.3^{* *}$ & $17.2 \pm 1.4^{40}$ & $18.5 \pm 1.2^{\circ}$ \\
\hline \multirow[t]{2}{*}{ Compliance $\left(\mathrm{mm}^{2} / \mathrm{kPa}\right)$} & $\mathrm{P}$ & $0.19 \pm 0.02$ & $0.28 \pm 0.03^{\text {** }}$ & $0.20 \pm 0.02^{2+4}$ & $0.20 \pm 0.02^{* *}$ \\
\hline & AHH & $0.19 \pm 0.02$ & $0.25 \pm 0.02^{* *}$ & $0.20 \pm 0.02^{+4}$ & $0.21 \pm 0.02^{* 4}$ \\
\hline
\end{tabular}

P: perindopril, $n=17 ;$ AH: amiloride/hydrochlorothiazide, $n=19 ;$ Data are mean + s.e.m.

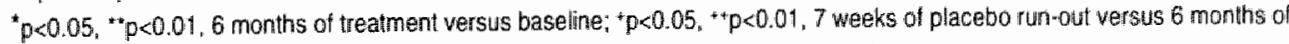
active trealment; " $p<0.05$." $p<0.01,13$ weeks of placebo runtout versus 6 months of active treatinent. 
After discontinuation of the active medication (week 24 10 37), 1 patient in the perindoprit-group and 1 in the diuretic group were withdrawn from the sudy, both because of a sitting DBP $>110 \mathrm{mmiHg}$ after 7 weeks. of placebo. During run-cut, after 7 weeks body weight in both groups had retumed to baseline values. Laboratory values remained within the nomal ranges and changes were not clinically significant. Within the $\mathrm{A} / \mathrm{H}$ group, uric acid retumed to normal at the end of the study. Table 2 summarises the changes in blood pressure and cardiac function during the run-out phase as compared to values at baseline and at 6 months of treatment. Almost all haemodynamic parameters reached pretreatment values after 7 weeks of placebo and remained unchanged until the end of the study. Parameters related to arterial wall properties also reached the pretreatment values in both groups and for each vessell, the effect being aiready visible after 7 weeks of placebo (Table 3 ).

\section{Discussion}

In contrast to previous studies, the present study compares the long-term effects of an ACE inhibitor (perindopril) with those of a diuretic combination (amiloridefhydrochiorothiazide) on vessel wall properties of large arteries. The effect on 3 different arteries was studied: the common carotid artery, an elastic artery, the brachial antery, a muscular artery where atherosclerosis is uncommon, and the femorall artery, a muscular artery where atherosclerosis is common. This is also the first controlled study, investigating whether after long-term treatment (6 months) the effects persist after withdrawal of medication.

Perindopril was used in a dase of $4 \mathrm{mg}$, which is the recornmended starting dose in hypertension (18). The widely used combination diuretic amiloride/hydrochlorothiazide was used at a starting dose of $2.5 \mathrm{mg} / 25$ $\mathrm{mg}$. Doses were titrated and at the end of the active treatment period, mean daifly doses were $7 \mathrm{mg}$ for perindopril $(n=18)$ and $4.5 \mathrm{mg} / 45 \mathrm{mg}$ for amiloride/hydrochlorothiazide $(n=20)$.

In the present study, at the time of inclusion both treatment groups were comparable for demographic, biochemical and haemodynamic parameters, although baseline supine diastolic blood pressure tended (non-significantly) to be lower in the diuretic group. As expected, during the active treatment period, weight decreased more with $\mathrm{A} / \mathrm{H}$ than with perindopril. Both drugs were well tolerated and drug adherence was high. The drop-out rate was relatively low $(7 \%)$ and equally distributed over both groups. After 6 months, the percentage of controlled patients (sitting DBP $\leq 90 \mathrm{mmHg}$ ) was not statistically different between the 2 groups. The average reduction in blood pressure is consistent with previous findings $(2,33)$. In the present study, the elfect of the diuretic on blood pressure was somewhat smaller. In addition, perindopril caused a significantly larger decrease in supine diastolic blood pressure compared to the diurelic combination.

Diameter of the elastic common carotid artery was slightly reduced during treatment with perindopril as well as with $\mathrm{A} / \mathrm{H}$. This could be due to a lower blood pressure (passive phenomenon). With a smaller diameter an antery might be able to distend more $(8,26)$. This might contribute to an increase in distensibility of the carotid artery. However, although arterial diameter was reduced, vessel wall properties of the carotid artery remained unchanged with $\mathrm{A} / \mathrm{H}$ and increased with perindopril. The difference in effect between the two drugs was significant for distensibility and almost significant $(p=0.067)$ for compliance of CCA. Despite a large reduction in blood pressure, arterial diameter of the muscular femoral and brachial arteries did not change or decreased orly slightly. A slight decrease in arterial diameter has also been reported by others $(6,22)$. Distensibility and compliance of the two muscular arteries, however, increased considerably. The changes tended to be larger with perindopril and were somewhat more pronounced in the brachial than in the femoral artery. Since the decrease in blood pressure was not statistically different between $\mathrm{A} / \mathrm{H}$ and perindopril, the more pronounced effects of perindopril suggest an additional drug-induced effect on vessel wall properties.

Data on the effect of diuretics on vessel wall properties of large arteries are inconsistent. Some authors report an unchanged distensibility with a decrease in blood pressure $(7,15)$. In an open study, short-term therapy with a thiazide diuretic increased arterial distensibility (32). In the present long-term double-blind 
study, the increase in vessel wall properties with AH was approximately hall of those seen with perindopril. Previous studies have also demonstrated improvement of vessel wall properties after treatment with ACE inhibitors and have shown that these effects are probably mediated through a combined effect of reduction in blood pressure and a drug-induced relaxation of arterial smooth muscle $(3,28)$.

Chronic treatment with either perindopril or $\mathrm{A} / \mathrm{H}$ did not change heart rate. Cardiac index increased only with perindopril and this was mainly due to an increase in stroke index. Previous data on cardiac function parameters after long-term treatment with ACE inhibitors in essential hypertensive patients are consistent with our findings (35).

ACE inhibitors induce arteriolar vasodilation and a reduction of vascular resistance (27). In the present study systemic vascular resistance index decreased significantly more with perindop ril than $A / H_{\text {, ind icating }}$ a more pronounced dilating effect of perindopril at the arteriolar level. Anyhow, the improvement in vessel wall properties and a lower systemic vascular resistance, as shown in the current study, may result in a reduction of cardiac afterload, since afterload is largely determined by vascular resistance and arterial compliance (34). This might explain the slight increase in stroke index seen with perindopril.

The changes in biochemical parameters were not climically significant, except for uric acid in the A/H group, which increased by $17 \%$. This is a well-known adverse effect of diuretic therapy (21).

In this study, pulse pressure in the brachial artery was used for the calculation of vessel wall properties at different sites. Ideally, pulse pressure should be studied at the site where the vessel wall movement is measured. However, non-invasive methods for measuring pulse pressure are scarce and yet not fully accepted. Therefore, could pulse pressure in this sfudy be influenced by a methodological error? As far as a group of patients is concerned the pulse pressure in the brachial artery is very similar to the pulse pressure in the femoral artery (5). However, due to puise wave reflections, the pulse pressure in the carotid artery might not be represented by that in the brachial artery (20). Since vasodilating agents (like ACE inhibitors) diminish pulse wave reflections, pulse pressure in the carotid artery might decrease more with perindopril than with $\mathrm{A} / \mathrm{H}$. Using the brachial artery as a substitute for the pressure in the carotid artery might therefore overestimate pulse pressure more during perindopril than during $\mathrm{A} / \mathrm{H}$. In that case, the difference in distensibility and compliance between perindopril and the diuretic would be more pronounced and will not change the main conclusions of this study.

After withdrawal of medication, blood pressure, cardiac function and biochemical changes rapidly lafter anly 7 weeks of placebo) retumed to baseline values in both treatment groups. This has been demonstrated in other studies with hypertensive patients (3). In the present study, also arterial diameter, distensibility and compliance of the elastic and muscular arteries regained pre-treatment values. In resistance vessels antihypertensive treatment can induce only a partial reversal of structural changes $(1,13)$. Although the data of the present study do not provide evidence lor a regression in structural alterations in large arteries, a partial reversal of structural changes cannot be excluded, since arterial biopsies were not taken.

Literature data are contradictory with regard to reversibility of structural vascular changes, depending on the models used and treatments given. With diuretics, on the average no reversal effects could be demonstrated (10). Animal as well as human data have shown that after withdrawal of a chronic treatment with perindopril a dissociation between the cardiac and the arterial effects has been shown $(3,16)$. Most antihypertensive drugs lower blood pressure adequately, while only marginally affecting vascular structure (9). Vascular restructuring probably may need a longer time to occur and therefore the duration of the present study might have been too short.

The present study was a double-blind comparative study with a considerable treatment period. Since it was not placebo-controlled, a period effect cannot be excluded for both druggs as far as time-related drug changes are concerned.

In conclusion, at the dosages used, the present study shows in general a more pronounced effect on haemodynamics and large artery properties after long-term treatment with the ACE inhibitor perindopril, as compared to the diuretic, amiloride/hydrochlorothiazide. After discontinuation of either therapy, all effects were rapidly reversed, which suggests rapid reversal of functional changes and does not provide evidence for structural changes in the arterial wall, although small structural changes cannot be excluded. In addition, 
the more favourable effects at the macro as well as at the microcirculatory level with perindopril are likely to cause a lower load for the heart, which, in lum, may diminish the cardiovascular risk (14).

\section{References}

1. Aalkjaer C, Mulwany MJ, Jespersen B, Kaer T, Sorensen SS, Pejersen EB. Morphological and functional abnomaiities of resistance vessels from patients with essential hypertension are not normalized by antihypertensive therapy. $J$ Hypertens 1988;6 (Suppl. 4) :S702.

2. Andrejak $M$, Santonil JP, Carrä $A$, Deruyttere $M$, Magometschnigg $D$. Gotzen $R_{1}$ Stumpe KO. A double-blind comparison of perindopril and hydrochlorothiazide-amiloride in mild to moderate essential hypertension. Fundam Clin Pharmacol 1991:5:185-92.

3. Asmar AG, Panmier B, Santoni JP, Laurent S, London GM, Levy BI, Safar ME. Reversion of cardiac hypertrophy and reduced arterial compliance after converting enzyme inhibition in essential hypertension. Circulation 1988;78:941-50.

4. Benetos A, Asmar $\mathrm{R}$, Vasmant D. Thiäry P. Safar M. Long lasting arterial effects of the ACE inhibitor ramipril. J Hum Hypertens 1991:5:363-68.

5. Benelos $\mathrm{A}_{6}$ Laurent $\mathrm{S}$, Hoeks AP, Boutouyrie PH, Salar ME. Arterial alterations with aging and high blaod pressure. A nonirwasive sludy of carotid and femoral arteries. Atterioscler Thromb 1993;13:90-97.

6. Benetos $A$, Santoni JP\& Safar ME. Vascular effects of intravenous infusion of the angiolensin converting enzyme inhibitor perindoprilat. J Hypertens $11990 ; 8: 819-26$.

7. Bouthier $J A_{4}$, Salar $M E_{a}$ Deschamps $E_{i}$ Tarrade $T$. Haemodynamic effects of an antihypertensive diuretic substance on the forearm circulation of patients with essential hypertension. Drugs Exp Clin Res 1988;X॥V:221-24.

8. Chau NP, Simon A, Vilar J, Cabrera-Fischer E, Pithois-Merli I, Levenson J. Active and passive effects of antihypertensive drugs on large artery diameter and elasticity in human essertial hypertension. J Cardiovasc Pharmacol 1992;19:78-85.

9. Christensen $\mathrm{KL}$, Jespersen $\mathrm{LT}$, Mulwany ML, Development of blood pressure in spontaneously hypertensive rats after withdrawal of long - term treatment relaled to vascular structure. J Hypentens 1989;7:83-90.

10. Dahlöf B. Regression of cardiovascular structural changes - a preventive strategy. Clin Exp Hypertens [A] 1990;A12 877-96.

11. Dahlof $B$, Pennert $K$, Hansson L. Reversal of left ventricular hypertrophy in hypertensive palients. A melaanalysis of 109 treatment studias. Am J Hypertens 1992;5:95-110.

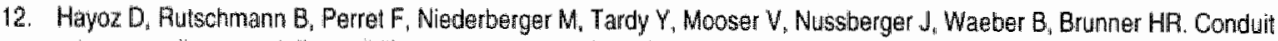
arlery compliance and distensibility are not necessarily reduced in hypertension. Hypertension 1992,20:1-6.

13. Heagerty $\mathrm{AM}$, Bund $\mathrm{SJ}$, Aalkjaer $\mathrm{C}$. Ettects of drug treatment an human resistance arteriole morphology in essential hypertension: direct evidence for structural remodelling of resistance vessels. Lancel 1988:11:1209-12.

14. Kannel WB, Woll PA, MCGee DL, Dawber TR, McNamara P, Castelli WP. Systolic blood pressure, arterial rigidily, and risti of stroke. The Framingham study. JAMA $1981 ; 245: 1225-29$.

15. Laurent S, Lacolley PM, Cuche لIL, Salar ME. Influence of diuretics on brachial artery diameter and distensibility in hypertensive patients. Fundam Clin Pharmacol 1990;4:685-93.

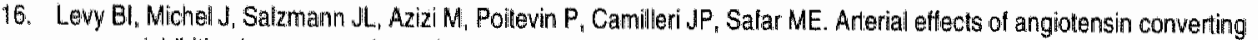
enzyme inhibition in renovascular and spontaneously hypertensive rals. J Hypertens 1988;6 (Suppl. 3) :S23-25.

17. Lewy BI, Michel J.B, Salzmann J-L, Azizi M, Poitevin P, Safar M, Camilleri J.P. Effects of chronic inhibition of converting enzyme on mechanical and structural properties of arteries in rat renovascular hypertension. Circ Res 1988;63:227-39.

48. Luccioni A. Frances Y, Gass R, Gilgenkrantz JM. Evaluation of the dose-effect relationship of perindopril in the treatment of hypertension. Clin Exp Hypertens [A] 1989;A11 (Suppl. 2) :521-34. 
19. Madhavan S, Ooi WL, Cohen $\mathrm{H}$, Alderman MH. Relation of pulse pressure and blood pressure reduction to the incidence of myocardial infarction. Hypentension 1994:23:395:401.

20. ORourke M. Arterial compliance and wave reflection. Arch Mal Coeur Vaiss 1991;84:45-48.

21. Rattery EB. The metabolic effecls of diuretics and other antihypertensive drugs: a perspective as of 1989 . Int $J$ Cardiol $1990 ; 28: 143-50$.

22. Richer $\mathrm{C}$, Thuillez $\mathrm{C}$, Giudicelli JF. Perindopril, converting enzyme blockade, and peripheral arterial hemodynamics in the healthy volunteers J Cardiovasc Pharmacol 1987;9:94-102.

23. Sallar $\mathrm{M}_{4}, \mathrm{Asmar} \mathrm{R}_{\mathrm{a}}$ Bouthier J, Lacolley $\mathrm{P}$, Laurent $\mathrm{S}$. Converting enzyme inhibition and the common carotid circulation in older patients with sustained essential hypertension. Eur Heart $J 4988 ; 9$ (Suppl. D) 75.78 .

24. Safar ME. Pulse Pressure in essential hypertension: clinical and therapeutical implications. J Hypertens 1989;7:769-76.

25. Safar ME, Laurent SL, Bouthier JD, London GM, Minran AR. Effect of converting enzyme inhibitors on hypertensiwe large arteries in humans. J Hypertens 1986:4 (Suppl. 5) :S285-89.

26. Safar ME, Levy Bl, Laurent S, London GM. Hypertersion and the arterial system: clinical and therapeutic aspects. J Hypertens 1990;8 (Suppl. 7) :S113-19.

27. Safar ME Levy BI, London GM. Arterial structure in hypertension and the effects of angiotensin converting enzyme inhibition. J Hypertens 1992;10 (Suppl. 5) :\$51-57.

28. Sanfoni JP, Asmar $R$, Safar ME. Angliotensin converting enzyme inhibition, pulse wave velocity and ambulatory blood pressure measurements in essential hypertension. Clin Exp Hypertens [A] 1989;A11 (Suppl. 2) :535-44.

29. Sihm I, Schroeder AP, Aalkjaer C. Holm Mn Morn B, Mulvany MJ. Thygesen K, Lederballe O. Normalization of resistance artery structure and left ventricular morphology with a perindoprit-based regimen. Can J Cardliol 1994;10 (Suppl. D) :30D-2D.

30. Simon $A C$, Levenson $J_{1}$ Bouthier $J D_{n}$, Safar ME. Effects of chronic administration of enalapril and propranolol on the large arteries in essential hypertension. J Cardiovasc Pharmacol 1985;7 :856-61.

31. Simon AC, Levenson JA, Safar AM, Bouthier JD, Safar ME. ACE inhibition and brachial artery haemadynamics in hypertension. Br J Clin Pharm 1984:18 (Suppl. 2) :243S-7S.

32. Smulyan $H_{1}$ Vardan $S$, Griffiths $A$, Gribbin B. Forearm arterial distensibility in systolic hypertension. J Am Coll Cardiol $1984 ; 3: 387-93$.

33. Thurston $\mathrm{H}$, Mimran $\mathrm{A}$, Zanchetti $\mathrm{A}$, Creytens $\mathrm{G}$, Rorive G, Brown CL, Santoni JP. A double blind comparison of perindopril and atenolol in essential hypertension.J Hum Hypertens 1990:4:547-52.

34. Van Bortel LM, Hoeks APG, Kaol M.JF, Struijker-Boudier HA. Introduction to large antery properties as a targel lor risk reduction by antihypertensive therapy. J Hypertens $1992 ; 10$ (Suppl. 6) :S123-26.

35. Veerman DP, Douma CE, Jacobs MC. Thien T, van Monttrans GA. Effecls of ACE-inhibition on autonomic vascular control as assessed by spectral analysis and on hemodynamics. J Hypertens 1992;10 (Suppl. 4) :S63. 


\section{CHAPTER 8}

\section{DOES LOWERING OF CHOLESTEROL LEVELS INFLUENCE FUNCTIONAL}

PROPERTIES OF LARGE ARTERIES ?

M. Kool, *F. Lustermans, "H. Kragten, H. Struijker Boudier, **A. Hoeks,

"R. Reneman, "H. Rilla, "\%. Hoogendam, and L. Van Bortel

Departments of Pharmacology* *Biophysics and 'Physiology, Cardiovasular Research Institute Maastricht, University of Limburg, Departments of Internal Medicine and Cardiology, *De Wever Hospital, Heerlen. " BMS Medical Department, Woerden, the Netherlands

Based on Eur J Clin Pharmacol 1995 (in press) 


\section{Summary}

Hypercholesterolaemia is a risk factor for atherosclerosis and induces endothelial dysfunction. Endothelial dysfunction may increase vascular tone and arterial stiffness and as a consequence may decrease arterial distensibility (DC) and arterial compliance (CC). It is hypothesised that lipid-lowering therapy may enhance $D C$ and $C C$. Therefore, the present study investigates the effect of lipid-lowering therapy with pravastatin on haemodynamics, DC and CC of the elastic common carotid artery (CCA), and the muscular femoral (FA) and brachial (BA) arteries in patients with primary hypercholesterolaemia.

After a 8 -week placebo run-in period with a low-cholesterol diet, 19 patients with a total cholesterol between 6.5 and $9.0 \mathrm{mmol} / \mathrm{L}$ and triglycerides $<4 \mathrm{mmol} / \mathrm{L}$ entered a double-blind placebo controlled cross-over study. Patients received pravastatin $40 \mathrm{mg} 0 . \mathrm{d}$. or placebo, each for 8 weeks. Throughout the study the lipid-lowering diet was continued.

With pravastatin, total cholesterol, low-density lipoprotein cholesterol (LDL-C) and triglycerides were decreased (total cholesterol:26\%; LDL-C.35\%; triglycerides: $16 \%$ ), while high-density lipoprotein cholesterol (HDL-C) was not changed. Other laboratory values remained within the nomal range. Blood pressure, heart rate, cardiac function and systemic vascular resistance were not influenced by pravastatin. Compared to placebo, diameter, distensibility and compliance of all arteries were not statistically significantly changed with pravastatin.

These data suggesit that, in patients with mild to moderate primary hypercholesterolaemia short-term lowering of plasma cholesterol does not alter haemodynamics and vessell wall properties of large arteries. 


\section{Introduction}

In Western countries, atherosclerasis is a major cause of cardiovascular mortality and morbidity (31). Aherosclerosis is a multifactorial disease and primarily affects large arteries (32). High cholesterol levels are considered a primary risk factor for the development of atherosclerotic disease, while lowering of total and LDL-cholesterol has been shown to reduce the incidence of ischaemic heart disease and retard the development of coronary atherosclerosis $(10,27)$. The early detection of atherosclerosis, before ischaemic vascular complications develop; is a major step in the assessment of human hypercholesterolaemia. Utirasound techniques permit the delection of atherosclerotic plaques, a relatively late leature in the process of atherosclerosis (16). However, early in the development of atherosclerosis, functional disturbances already accur at the site of the endothelium (9). These endothelial changes are associated with a diminished release of endothelium-derived relaxing factor (EDRF), which may influence vascular tone and, hence, arterial stiffness (33). Therefore, decreased compliance might be an early leature of endothelial dyslunction, representing early vascular injury in atherosclerosis, and a higher compliance might protect large arteries from early atherosclerotic changes.

Hypercholesterolaemia itselt also may induce these arterial wall changes (12). Cholesterol is an important rigidifier of natural cell membranes (22). Hypercholesterolaemia may potentiate chronic mild endothelial injury and interfere with membrane fluidity (12). An increased membrane cholesterol content enhances membrane microviscosity and decreases sodium and calcium pump activity. Changes in calcium handling in vascular smooth muscle may be involved in alteration of vascular tone and vessel wall properties of large arteries (22). From these data it can be imagined that - via interaction with endothelial and membrane alterations - patients with hypercholesterolaemia demonstrate functionalchanges in vessel wall behaviour, measured as decreased arterial wall properties. Therefore, lipid-lowering agents may improve vessel wall properties by lowering cholesterol which could lead to a lower cardiovascular risk.

Pravastatin is a relatively new, hydrophilic agent in the class of the 3-hydraxy-3-methylglutaryl(HMG) -CoA-reductase inhibitors (26). Clinical studies have shown that HMG-CoA-reductase inhibitors are more effective in lowering cholesterol and cause fewer adverse effects than the other hypolipidaemic agents (26).

The present study investigates the effect of short-term ( 8 weeks) treatment with pravastatin on functional arterial wall properties of elastic and muscular large arteries in mild to moderate hypercholesterolaemic patients. Arterial wall properties (distensibility and compliance) were determined with a vessel wall movement detector system, with which distensibility and compliance can be studied more directly and accurately than with previous techniques (18). In addition, the effect of pravastatin on blood pressure, cardiac function and systemic vascular resistance was evaluated.

\section{Patients and methods}

Patients - Twenty two outpatients between 18 and 65 years of age and with a known total cholesterol level of $>6.5 \mathrm{mmol} / \mathrm{L}$, determined at least within one year prior to the start of the sludy, were selected and started with a placebo run-in period (week -8 to 0 ). At the end of the run-in period two patients were excluded because of high cholesterol levels ( $>9$ mmol/L) and ane because of use of oestrogens. Nineteen patients (11 males, 8 fiemales) entered the double-blind cross-over study. Patient characteristics al baseline (week 0) are shown in Table 1.

The hypercholesterolaemic patients were compared with 18 normocholesterolaemic controls (total cholesw terol: $5.8 \pm 0.1 \mathrm{mmo} / / \mathrm{L}$ ). Groups were matched for age, weight, height and blood pressure (Table 1 ). 
Table 1. Charactenstics of wolunterers and patients.

\begin{tabular}{|c|c|c|}
\hline & Patients & Vollunteers \\
\hline Number of subjecis & 19 & 18 \\
\hline \multicolumn{3}{|l|}{ Demographics } \\
\hline Gender (maleftemale) & $11 / 8$ & 1177 \\
\hline Age (years) & $52(3564)$ & $51(35-64)$ \\
\hline Weight (kg) & $74(62-98)$ & $73(52-92)$ \\
\hline Height (cm) & $171(157 \cdot 184)$ & $171(149-186)$ \\
\hline \multicolumn{3}{|l|}{ Aisk factors } \\
\hline Alconol use & 7 & 6 \\
\hline glasses/day & $1-3$ & 1.3 \\
\hline Smokers & 8 & 6 \\
\hline cigaretlesiday & $16(4-25)$ & $13(2-25)$ \\
\hline \multicolumn{3}{|l|}{ Haemodynamics } \\
\hline Syslolic blood pressure (mmitg) & $126(97 \cdot 145)$ & $121(98-155)$ \\
\hline Diastolits biood pressure (mmHg) & $77(59-92)$ & $76(67-89)$ \\
\hline Heart rate (beats/min] & $64(45.89)$ & $65(50-82)$ \\
\hline \multicolumn{3}{|l|}{ Lipids } \\
\hline Total cholester of (mmollu! & $7.7 \pm 0.6$ & $5.8 \pm 0.1$ \\
\hline LDL-cholesterol (mmoll't) & $5.6 \pm 0.2$ & na. \\
\hline HOL-cholesterol (monolL) & $1.1 \pm 0.1$ & n.a. \\
\hline Triglycerides (mmol/L) & $2.1 \pm 0.2$ & n.:. \\
\hline
\end{tabular}

Dala are mean (range) or mean \pm s.e.m. in . a: not applicable.

Study design - The study was a multicentre, double-blind, randomised, placebo-controlled cross-over study. At the first visit (week -8) a general medical history was taken. A lipid determination, a routine laboratory screening and a general physical examination were performed. Vessel wall properties and other haemodynamic parameters were assessed in order to familiarise the patients with the examination procedures. Major exclusion criteria were: homozygous familial hypercholesterolaemia, secondary hyperlipicaemia of any cause, established diagnosis of type l, ill, or V hyperlipideamia , lasting trig yceride $>4.0$ mmoll $\|_{n}$ clinical evidence of overt atherosclerotic plaques detected with ultrasound, myocardial infarction, unstable angina pectoris, poorly controlled congestive heart failure, systolic blood pressure $>160$ mmitg or diastolic blood pressure $>95 \mathrm{mmHg}$, severe renal, hepatic or gastrointestinal disease, Quetelet index $>30$, diabetes mellitus, and thyroid dystunction. Patients using concomitant treatment with corticosteroids, sex hormones, antacids, fish oil preparations, lipid-lowering drugs, antihypertensive and anti-anginal drugs, and inhibitors of blood clotting were also excluded.

Selected patients received a lipid-jowering diet and placebo once daily (single-blind) for 8 weeks.

Any lipid-lowering drug was withdrawn at least 8 weeks prior to the first basal lipid determination (week -2). At the end of the placebo rum-in period, patients with a total plasma cholesterol $\geq 6.5 \mathrm{mmol} L \mathrm{Land}<9 \mathrm{mmol}$ $L$ and a plasma total triglyceride $<4$ mmoli $L$, based on the mean of 2 fasting samples one week apart, were included. During the active treatment period (week 0 to 16) patients received pravastatin $40 \mathrm{mg}$ tablets or identical placebo tablets once daily. Each treatment period lasted 8 weeks. Patients were encouraged to continue their dietary habits. Weight, arterial wall properties, blood pressure, heart rate and cardiac function were assessed at baseline and at the end of each treatment period (weeks 8 and 16). Patients were also checked for drug adherence, concomitant diseases, use of concomitant medication and adverse events. 
Blood samples for lipid determination and safety haematologybiochemisty were taken at baseline and at the end of each treatment period. For salety reasons, additional liver function tests were carried oull in weeks 6 and 14. Patients were withdrawn in the case of serious laboratory abnormalities, serious adverse events or development of exclusion criteria.

The study was performed in accordance with the principles of the Declaration of Helsinki (revised 1983) and approved by the Ethical Committees of each participating centre. Intormed consent was obtained Irom all patients.

Methods - All haemodynamic measurements were performed in a quiet room after 15 min of supine rest. For each patient measurements were carried out at the same time of the day. All measurements were made by the same observer. Smoking was not allowed for 24 hours preceding the examination. Laboratory assessments were performed after patients had tasted (sample at least 10 hours after previous meal). Dietary advice (low-chalesterol, low-fat diet) was given by the physician at the start of the study.

\section{Blood pressure and heart rate}

Supine blood pressure and heart rate were recorded every 3 min on the left arm with a Dinamap and the means of these recordings (approximately 10) were taken as the patient's reading (Chapter 2).

\section{Vessel wall properties}

Simultaneously with blood pressure, vessel wall properties of the right elastic common carotid artery (CCA; $1 \mathrm{~cm}$ proximal to the bifurcation), and the right muscular common femoral (FA; $1-2 \mathrm{~cm}$ proximal to the bifurcation) and brachial (BA) arteries were assessed in recumbent position with the vessel wall movement detector system, as described in Chapter 2. From arterial diameter, distension and pulse pressure, vessel wall properties were calculated according to the equations mentioned in Chapter 2 .

\section{Cardiac function}

Cardiac function was assessed with the patient in left lateral position, using an echo Doppler technique (Chapter 2):

\section{Laboratory tests.}

All blood samples were analysed in the same laboratory (De Wever Hospital, Heerlen). To minimise bials, lipid values were witheld from the investigator until the end of the study. Fasting venous blood samples were analysed for total cholesterol (TC), high-densily lipoprotein cholesterol (HDL-C) and triglycerides (TG). Low-density lipoprotein cholesterol (LDL-C) was calculated as TC-(HDL-C+TG/2.2), according to the Friedewald equation (11). Because of intraindividual biological variation (5), the mean of 2 lipid samples, drawn one week apart, was laken. In addition, samples were analysed for creatinine, glucose, total bilirubin, transaminases (ALAT, ASAT), $y$-GT, alkaline phosphatase, creatine kinase, total protein, albumin, haemoglobin and haematocrit, and a blood cell count was pertormed.

\section{Drug adherence}

Patients were asked for their drug adherence at each wisit. In addition, the number of tablets, returned at the end of each treatment period, was counted. 
Data analysis - Statistical analysis was performed for the efficacy-analysable population ( $n=17)$, using the procedure as described by Pocock (29) with non-parametric tests for the cross-over design. Wilcoxon tests were used to test period effects, white Mann-Whitney tests were used for treatment-period interaction. Adverse events were analysed by means of a $\chi^{2}$ test. Data are presented as mean \pm s.e.m. $p<0.05$ was considered statistically significant.

\section{Results}

Namocholesterolaemic subjects did not differ from the hypercholesterolaemic patients with regard to arterial diameter of the elastic common carotid and muscular femoral and brachial arteries. Hypercholesterolaemic patients had a lower femoral artery distensibility $(24 \% ; p<0.05)$.

No carry-over effects could be demonstrated during the intervention study. Drug adherence was $96 \%$ $(86 \%-105 \%)$ during treatment with pravastatin and $97 \%(84 \%-102 \%)$ during placebo. Three patients used concomitant medication (psyllium $14 \mathrm{~g} / \mathrm{day}$; digoxin $0.25 \mathrm{mg} 4 \mathrm{x} / \mathrm{week}$; allopurinol $300 \mathrm{mg} 3 \mathrm{x} /$ week), which remained unchanged throughout the study. Two patients - both receiving pravastatin - dropped out, one because of acute myocardial infarction, and one because of concomitant antihypertensive medication. Adverse events occurred in 4 patients, treated with pravastatim (bowel hyperreactivity, fatigue during exercise, sleeplessness, palpitations) and in 2 palients using placebo (headache, nausea). Adverse events were generally very mild and did not lead to discontinuation or interventional therapy. Laboratory vallues remained within the normal range, except for creatine kinase that showed a 5-fold transitory rise without clinical symptoms in 1 patient with placebo during the first treatment period and in 1 patient with pravastatin. Mean body weight remained unchanged during the study. Changes in the lipid profile during the doubleblind treatment period are shown in Table 2. Compared to placebo, tolal cholesterol (TC) and LDL-

Table 2. Changes in weight, haemodynamics and lipids during placebo and treatment with pravastin for 8 weeks.

\begin{tabular}{|c|c|c|c|}
\hline & Baseline & Placebo & Pravastatin \\
\hline Weight (kg) & $74 \pm 2$ & $74 \pm 2$ & $73 \pm 2$ \\
\hline \multicolumn{4}{|l|}{ Elood pressure, heart rate } \\
\hline Systolic blood pressure (mmHg) & $126 \pm 4$ & $121 \pm 3$ & $124 \div 4$ \\
\hline Diastolic blood pressure (mmitg) & $76 \pm 2$ & $74+2$ & $75 \pm 2$ \\
\hline Pulse pressure (mmHg) & $64 \pm 3$ & $66 \pm 3$ & $66 \pm 3$ \\
\hline Heart rate (beats/min) & $66 \pm 3$ & $66 \pm 3$ & $66 \pm 3$ \\
\hline Cardiac index $\left(L \min , m^{2}\right)$ & $3.2 \pm 0.1$ & $3.3 \pm 0.1$ & $3.2 \pm 0.1$ \\
\hline Stroke index $\left(\mathrm{mL}^{\mathrm{L}} \mathrm{m}^{2}\right)$ & $51 \pm 2$ & $51 \pm 2$ & $49 \pm 2$ \\
\hline SVFl (dyn.s.m. $\left.\operatorname{com}^{5} \cdot \mathrm{m}^{2}\right)$ & $2387 \pm 110$ & $2226 \pm 86$ & $2356 \pm 120$ \\
\hline \multicolumn{4}{|l|}{ Lipids } \\
\hline Total cholesterol (mmolil) & $7.8 \pm 0.2$ & $7.6 \pm 0.3$ & $5.6 \pm 0.2^{* * *}$ \\
\hline LDL wholesterol (mmolll) & $5.7 \pm 0.2$ & $5.5 \pm 0.3$ & $3.6 \pm 0.2^{* * *}$ \\
\hline HDL-chalesterol (mmolit) & $1.2 \pm 0.1$ & $1.3 \pm 0.1$ & $1.3 \pm 0.1$ \\
\hline Triglycerides (mmolh) & $1.9 \pm 0.2$ & $1.9 \pm 0.2$ & $1.6 \pm 0.2^{*}$ \\
\hline
\end{tabular}

n=17; Data aremean \pm s.e.m. . "p<0.05, " p p 0.001, differences between pravastin and placebo. SVRI, systemic wascillar resilstamce index. 
cholesterol (LDL-C) decreased significantly with pravastatin (TC.26\%; LOL-C.35\%; $0<0.001$ ). Triglycenides also decreased with pravastatin (16\%; $<<0.05)$, but HDL-cholestercl (HDL.C) did not change significantly versus placebo. The calculated TC/HDL-C ratio decreased from 6.5 to 4.5 with pravastatin. Blood pressure, heart rate, cardiac function and systemic vascular resistance index did not differ between pravastatin and placebo (Table 2).

Table 3. Changes in vessel wall properties during placebo and treatment with pravastatin for 8 weeks.

\begin{tabular}{|c|c|c|c|c|}
\hline & \multirow[t]{2}{*}{ Controls } & \multicolumn{3}{|c|}{ Hypercholesterola emia } \\
\hline & & Baseline & Placebo & Pravastatin \\
\hline \multicolumn{5}{|c|}{ Common carotid antery } \\
\hline Diameter (mm) & $6.07 \pm 0.08$ & $6.07 \pm 0.16$ & $6.18 \pm 0.15$ & $6.17 \pm 0.15$ \\
\hline $\mathrm{DC}\left(10^{3} / \mathrm{kPa}\right)$ & $18.6 \pm 1.3$ & $16.5 \pm 1.8$ & $17.1 \pm 1.5$ & $17.6 \pm 1.9$ \\
\hline $\mathrm{CC}\left(\mathrm{mm}^{2} / \mathrm{kPa}\right)$ & $0.54 \pm 0.04$ & $0.49 \pm 0.06$ & $0.52 \pm 0.05$ & $0.54 \pm 0.07$ \\
\hline \multicolumn{5}{|c|}{ Common femoral artery } \\
\hline Diameter ( $\mathrm{mm}$ ) & $7.57 \pm 0.26$ & $7.81 \pm 0.21$ & $7.80 \pm 0.23$ & $7.88 \pm 0.19$ \\
\hline $\mathrm{DC}\left(10^{3} / \mathrm{kPa}\right)$ & $17.1 \pm 1.5$ & $13.0 \pm 1.2^{2}$ & $13.5 \pm 1.2$ & $14.5 \pm 1.3$ \\
\hline $\mathrm{CC}\left(\mathrm{mm}^{2} \mathrm{k} \mathrm{kPa}\right)$ & $0.77 \pm 0.09$ & $0.62 \pm 0.06$ & $0.65 \pm 0.06$ & $0.71 \pm 0.07$ \\
\hline \multicolumn{5}{|l|}{ Brachial artery } \\
\hline Diameter (mm) & $3.99 \pm 0.10$ & $3.66=0.08$ & $3.68 \pm 0.10$ & $3.67 \pm 0.10$ \\
\hline $\mathrm{DC}\left(10^{3} / \mathrm{kPa}\right)$ & $21.4 \pm 1.4$ & $21.8 \pm 2.3$ & $21.4 \pm 2.3$ & $22.9 \pm 2.5$ \\
\hline $\mathrm{CC}\left(\mathrm{mm}^{2} / \mathrm{kPa}\right)$ & $0.28 \pm 0.02$ & $0.23 \pm 0.03$ & $0.23 \pm 0.03$ & $0.25 \pm 0.03$ \\
\hline
\end{tabular}

Conirols, normochalesterolaemic subjects, $n=18$; "hypercholesterolaemic patients, $n=17$; Dala are mean \pm

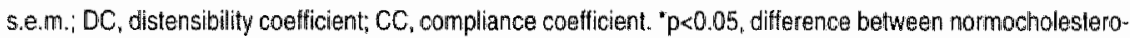
laemic subjects and baseline values of hypercholesterolaemic patients.

Data on vessel wall properties are shown in Table 3. Arterial diameter of the elastic common carotid artery and the muscular femoral and brachial arteries was not changed either with pravastatin or placebo. Im addition, no statistically significant changes were found for arterial distensibility and compliance in all arteries, when compared to placebo.

\section{Discussion}

In the present study the effect of lipid-lowering therapy on vessel wall properties of large arteries was investigated in mild to moderate primary hypercholesterolaemia. An improvement in arterial distensibility and compliance might protect these patients from the complications of atherosclerotic disease. In contrast to other studies $(4,6,25)$, the present study was directed towards detection of functional changes in vessel wall behaviour rather than to structural changes of the vessel wall, such as atherosclerosis.

A number of epidemiological studies have provided evidence for the relationship between serum cholesterol levels and atherosclerotic cardiovascular disease $(19,20,34)$. Stroke and peripheral vascular disease seem 


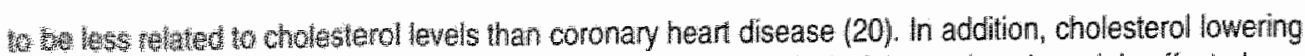

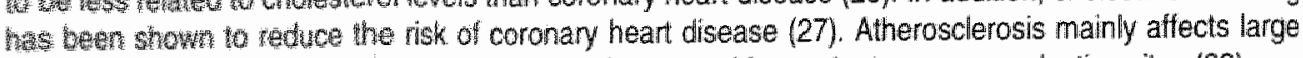

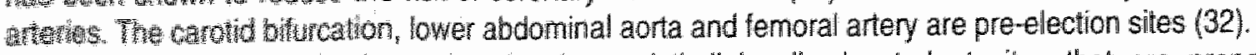

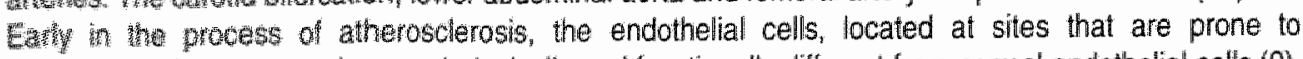

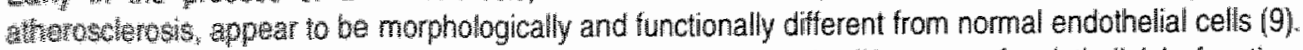

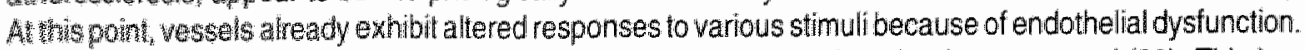

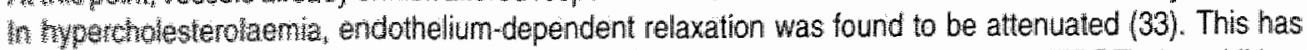

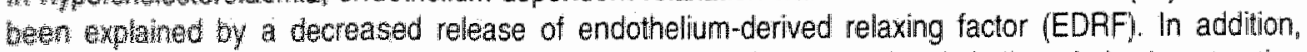
atugranged vasoconstrictor responses, as well as increased release of endothelium-derived contracting Wators (EDCF have ben demonstrated $(24,33)$.

Chonic ondothetial dysi unction may facilitate atherogenesis. Arterial distensibility and compliance could

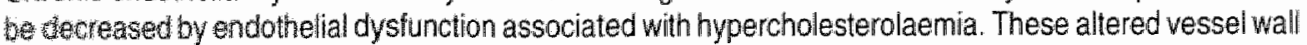
wopeties - hdicating a higher arterial stiffness - might in turn increase the load on the vessel wall and anthance the risk for plaque rupture. The atherosclerotic plaques, found in hypercholesterolaemia, are usually smat, weak and lipid-rich. They often can not be detected with the current diagnostic techniques, while preci-sely these plaques are most prone to disruption (13). Plaque rupture, which is influenced by the citcumerential tensile stress, may eventually lead to acute ischaemic events (30).

Studies on arterial distensibility and compliance in hypercholesterolaemia without the presence of overt atherosclerotic lesions are scarce. In man, the relation between cholesterol and distensibility was found to be weak. Age seemed to be more important for changes in arterial stiffness than atherosclerosis (2). Despite a large difference in the severity of atherosclerosis between different populations, aortic distensibility was found similar (28). However, in patients with arteriosclerosis obliterans of the lower leg, which was used as a model for atherosclerosis, brachial artery distensibility was decreased (23), which would suggest a more generalised modification of large vessels in these patients. Recent studies showed no differences between normochalesterolaemic and hypercholesterolaemic subjects with regard to arterial compliance of the radial and common carotid arteries $(1,15)$. However, the number of patients in these studies was small ( $n=9$ and $n=8$, respectively) and it is unlikely that differences between nomocholesterolaemic and hypercholesterolaemic patients could be detected. Moreover, comparing vessel wall properties of patients in the present study with 18 controls - matched for age, sex, weight, height and blood pressure - a significantly smaller distensibility of the femoral artery in hypercholesterolaemic patients was shown. This could suggest an early involvement of the femoral artery in the development of atherosclerotic changes. in this study, pulse pressure of the brachial artery was used for calculation of vessel wall properties at different sites. Ideally, pulse pressure should be sampled at the site where the vessel wall movement is measured. However, non-invasive methods for measuring pulse pressure are scarce and have not been fully accepted. On the other hand, as far as a group of patients is concerned, the pulse pressure in the brachial artery is very similar to that in the femoral artery, whereas pulse pressure in the carotid antery . due to pulse wave reflections - is lower than that in the brachial artery ( 3 ). Therefore, because brachial pulse pressure is used as a substitute for carotid pulse pressure "the results on vessel wall properties of the carotid artery might be somewhat underestimated. However, since this concept holds for both treatment groups, it is not likely that the main conclusions will be changed.

In previous studies the influence of lipid-lowering therapy on progression and regression of atherosclerotic lesions was on the average relatively small (21). However, human intervention studies hitherto have primarily focussed on the aspect of reversal of plaques, which are in fact a late teature in atherosclerotic disease. The primary aim of the present study was to investigate whether lipid-lowering therapy could improve vessel wall properties of large arteries at an early stage of the disease by improving functional properties of large arteries.

An 8-week treatment period with the HMG-COA reductase inhibitor pravastatin resulted in a significant reduction in tolal cholesterol, $\mathrm{LDL}$-cholesterol and triglycerides. The total cholestero//HDL ratio fell by $31 \%$, which emphasises the favourable action of pravastatin on the lipid profile. These data are consistent with the results of other studies (26). 
Cardiac function, systemic vascular resistance and blood pressure were not affected by the lipid-lowering therapy. As far as is known, hitherto no controlled studies have been performed to investigate the influence of pravastatin on these parameters.

Pravastatin did not induce significant changes in arterial diameter, distensibitity or compliance of elastic and muscular large arteries. Diameter of the carotid artery has been reported to be decreased in hypercholesterolaemic patients when compared to controls (35). However, in this group of patients mean total cholesterol and LDL-chalesterol levels were rather high and the study population also contained patients with cardiovascular complications, including hypertension. Literature data have shown that, in the brachial artery, diameter and blood flow were not different from nomocholesterolaemic subjects in patients with hypercholesterolaemia, although the arterial diameters tended to be somewhat larger in the hypercholesterolaemic group (8). In the latter study it was suggested that cholesterol probably does not influence the arterial circulation under basal conditions, but might be still able to alter large artery reactivity. In general, it is thought that adaptive and compensatory mechanisms tend to preserve an adequate arterial lumen early during atherosclerotic disease (36). The concept is that atherosclerotic arteries undergo remodelling, which preserves the vascular lumen until the laesion becomes moderately advanced (17). The lack of effect on arterial diameter during intervention with pravastatin in the present study might be related to this phenomenon.

Although changes were not statistically significant, a slight increase in distensibility and compliance could be demonstrated with pravastatin. Sample size calculation suggested that 27 patients had to be included to allow a change in distensibility and compliance of more than $20 \%$ to be detected with $80 \%$ power. However, an interim analysis after 19 patients showed that significant results could only be reasonably expected in large numbers $(n=240)$ of patients. However, then it is questionable what the clinical relevance is of statistical changes.

Recently, animal studies have shown that reversal of the decrease in distensibility with atherosclerosis, if any, must be a very slow process. A cholesterol reduction for at least one year was required in monkeys to affect distensibility (7). In addition, a 10-week treatment period with lovastatin only partially reversed the altered vascular responses, associated with endothelial dysfunction and also only partially prevented atherosclerotic plaque formation (14). Therefore, it is possible that the treatment period in the present study was too short to induce functional changes or to improve vessel wall properties. However, as far as the radial artery is concerned, a 6 -month treatment period with simvastatim in non-familiar hypercholesterolaemic patients did not improve vessel wall properties (15).

In summary, the results of the present study indicate that short-term therapy with the cholesterol-lowering agent pravastatin in mild to moderate hypercholesterolaemia improved the lipid profile, but did not incuce obvious functional changes in the arterial wall as far as large artery properties are concerned. It may be that cholestero has anly a minor effect on vessel wall endothelium or that encothelial function is not related to vessel wall properties of large arteries. In addition, with the findings of the present study it can not be ruled out that: 1) regression of possibie hypercholesterolaemic arterial dystunction is not achieved within 8 weeks of treatment, or that 2) more severe hypercholesterolaemia is needed to demonstrate an improvement of arterial wail properties and, as a consequence, a reduction of the load on the arterial wall and the risk for future atherosclerotic complications.

\section{References}

1. Arcaro G. Zenere M. Travia D, Covi G, Muggeo M, Lechi A. Hypercholesterolemia and human endotheliat function and vascular distensibility. Abstractbook Ric Sci Educaz Perm: 1993 (Suppl. 95 ) :23. 


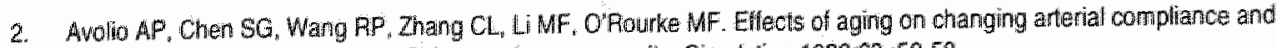
left werntricitar load in a rorthern Chinese untan communty. Circulation $1883,68.50-58$.

3. Benetos A, Laurent S, Hoeks AP. Boutounde PH, Safar WE. Arterial alteraitons with aging and tigh blood pressure. A nonirvaswe study of carotid and lemoral anteries. Arterioscier Thromb 1993,13,90,97.

4. Blankenhom DH. Prevention or reversal of atherowelenosis; review of current evidence. Am J Cardiol $1989,63,38 \mathrm{H}-41 \mathrm{H}$

5. Bookstein L, Gidding S5, Donowan M, Smith FA. Day-lo-day vanabily of serum cholesterol, anglyceride, and high densily lipoprotein cholesterol levels Impact on the assessment of risk according to the national cholesterol education program guideliness. Arch intern Med 1990; $150 ; 05357$.

6. Brown G, Albers JU, Fisher LD, Schaeter SM, Lin J, Kaplan C, Zhao X, Bisson BD, Fitzpatrick VF, Dodge HT. Regression of coronary artery disease as a result of intensive lipid lowering thetapy in men with high levels of apolipoprotein B. N Engl J Med 1990;323:1289-98.

7. Farrar DJ, Bond MG, Riley WA, Samyer UK. Anatomic correlates of aortic pulse wave velocity and carotid artery elasticity duning atherosclerosis progression and regression in monkeys. Circulation 1991:83:1754-63.

8. Fitittil $V$, Giral P, Simon A, Meril I, Del Pino M, Levenson J. Enhamced constriction of the peripherai large artery in response to acute induction al a low-thow state in human hypercholesterolemia. Arteriascler Thromb 1991;1:1:161-66.

9. Favahan WA. Atherosclerosis or lipoprotein induced endothelial dysfunction. Circulation 1992:85:1930-38.

10. Frick $M H_{1}$ Elo $O$, Haapa $K$, Heinonen OP, Heinsalmi $P$, Helo $P$, Huttunen J, Kaitaniemi $P$, Koskinen $P$, Manninen $V$,

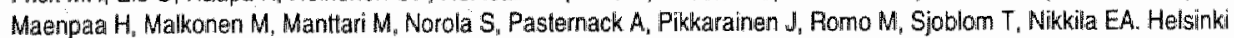
heart study" primary-prevention trial with gemtibrozil in middle-aged men with dyslipiclemia. N Engl J Med 1987,317 $: 1237-45$.

11. Frledewald WT, Levy RI, Frederickson DS. Estimation of the concentration of low-density lipoprotein cholesteroi in plasma "without the use of the preparative ulta-centrituge. Clin Chem 1971;18:499-502.

12. Fusler $V_{\text {in }}$ Badimon L, Badimon JJ, Chesebro JHI. The paihogenesis of coronary artery disease and the acute coronary syndromes. N Engl J Med 1992:326:242-50.

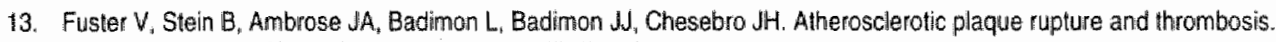
Evolving concepts. Circulation 1990;82 (Suppt. III) : :1-47-\|1-59.

14. Galle 4, Busse $\mathrm{R}$, Bassenge $\mathrm{E}$. Hypercholesterolemia and alherosclerosis change vascular reactivity in rabbits by different mechanisms. Arterioscler Thromb 1991;11:1712-18.

15. Giannattasio $C$. Mangoni AA, Carugo S, Stella ML, Cuspidi C, Stetanoni $P$, Bombelli M, Sega R, Grassi G, Vergani $C$, Manciz G. Arterial compliance in men with familiar hypercholesterolemia. Abstraclbook Fic Sci Educaz Perm 1993 (Stuppl. 95):264.

16. Giral P, Fildtit V. Levenson d; Pihois-Merill, Plainfosse M, Mainardi C, Gold A, Simon A, PCV Melra Group. Relation of risk factors tor cardiowascular disease to eary atheroscherosis detected by ultrasonography in middlle-aged normotensive hypercholesterolemic men. Atherosclerosis 1990;8:5151-59

17. Heistad DD, Lopez AG, Baumbech GL. Hemodynamic determinants of vascular changes in hypertension and

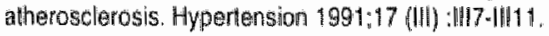

18. Hoeks APG, Brands PJ, Smeets FAM, Reneman RS. Assessment of the distensibility of superficial arteries. Ultrasound Med Bil $1990 ; 16: 121-28$.

19. Jacobs D, Blackburn H, Higgins M, Reed D, Isa H, McMillan G, Nealon J, Nelson J Potter u, Ritkind B, Rossouw J. Shokelle $R_{a}$ Yusui $S$. Report of the conference on low blood cholesterol: mortaity associations. Circulition 1992,86 $: 1046 \cdot 60$.

20. Kannal WB, Castelli WP, Gordon T, MoNamara PM. Serum cholesterd, lipoproteins, and the risk of coronary hear disease. Anm Intern Med 1971:74:1-12.

21. Kramsch DM, Blankenhorn DH. Regression of atherosclerosis: which components regress and what intluences their reversal. Wien klin Wochenschr $1992 ; 104: 2-9$

22. Le Quar-Sang KH, Levenson $\downarrow$, Simon A, Meyer P, Devynck M. Platelek cytosolic free Ca2t concentration and plasma cholesterd in untreated hypertensives. J Hypertens 1987;5 (Suppl. 5) :S251-54.

23. Levenson JA, Simon AC, Maarek BE, Gitelman RJ. Fiessinger JN, Safar ME. Regional compliance of brachial artery and saline infueion in patients with arteriosclerosis obliterans. Arteriosclerosis 1985:5: $80-87$. 
24. Lopez JA. Armstrong ML. Piegors DJ, Heistad DD. Effect of eary and advanced atherosclerosis on vascular responses to serrotonin. thromboxane A2, and ADP. Circulation 1989;79:698-705.

25. MeGowem ME, Mellies MJ. Long-term experience with pravastatin in clinical reseapch trials. Clinical Therapeutics $1993: 15: 57-64$

26. MoTavish D; Sorkin EM. Pravastatin. A review of its pharmacological proparties and therapeulic potential in hypercholesterolemia. Drugs $1991 ; 42: 65-89$

27. Muldoon MF. Manuck SB, Matthews KA. Lowering cholesterol concentrations and martality: a quartitative rewiew of primary prevention trials. BMJ 1990;301:309-14.

28. Nakashima T. Tanikawa J. A study of human aortic distensibitity with retation to atherosclmrosis and aging. Angiology $1971,22: 477-87$.

29. Pocock SJ. Crossover triais.In: Pocock SJ ed. Clinical trialls: a practical approach 8th ed. Chichester. John Wiley \& Sons, $1990: 110-22$.

30. Richardson $\mathrm{PD}$; Davies MJ, Born GVR. Influence of plaque configuration and stress distribution on fissuring of coronary atherosclerotic plaques. Lancet 1989,2(8677):9.41*44.

31. Ross R. The pathogenesis of atherosclerosis-an update. N Engl $\rfloor$ Med 1986;314:488-500.

32. Rubba P, Riccardi G, Pauciullo P, Vaccaro O, Carbone L, Mancini M. Different localization of early arterial Iesions in institin-dependent diabetes mellitus and in familial hypercholesterolemia. Metabolism 1989;38:962-66.

33. Shimokawa $\mathrm{H}$, Vanhoutte PM. Impaired endotheitum-dependent relaxation to aggregating platelets and related vasoaclive substances in porcine coronary arteries in hypercholesterolemia and atherosclerosis. Circ Res 1989;64 $: 900.914$

34. Stamler J. Review of primary prevention trials of coronary heart disease. Acta Med Scand 1985;701:100-128.

35. Wendelhag " Wiklund $\mathrm{O}$. Wikstrand J. Arterial wall thickness in familial hypercholesterolemia. Arterioscler Thromb $1992: 12: 70-77$.

36. Wikstrand J, Wikliund O. Frontiers in cardiowascular science. Quantilalive measurements of atherosclerotic manifestations in humans. Arterioscler Thiramb 1992;12:114-19. 


\section{CHAPTER 9}

ACUTE AND SUBACUTE EFFECTS OF NICORANDIL AND ISOSORBIDE DINITRATE ON VESSEL WALL PROPERTIES OF LARGE ARTERIES AND HAEMODYNAMICS IN HEALTHY VOLUNTEERS

Mirian J. Kool, Janneke J. Spek, Harry A. Struijker Boudier, *Arnold P. Hoeks, *Robert S. Reneman, "René H. van Herwaanden, and Luc M. Van Bortel.

Departments of Pharmacology, *Biophysics and * Physiology, Cardiovasular Research Institute Maastricht, University of Limburg, "E. Merck Nederland B.V., Amsterdam, the Netherlands

Based on Cardiovasc Drugs Therapy 1995, 9:331-337 


\section{Summary}

Nicorandil (N) and Isosorbide dinitrate (ISDN) are vasodilator drugs used in patients with angina. In 24 healthy male volunteers (18-32 years) the acute effect of a single oral dose (20 $\mathrm{mg}$ ) of $\mathrm{N}$ and ISON on arterial diarneter, distensibility, and compliance of the elastic common carotid artery (CCA) and the muscular femoral (FA) and brachial (BA) arteries were investigated. The effects on systollic and diastolic blood pressure (SBP, DBP), heart rate, cardiac index, systemic vascular resistance index, and venous haemodynamics were also assessed. In addition, the subacule effects after 8 days of treatment with $N$. ( $2 \times 20 \mathrm{mg} / \mathrm{day}$ ) and ISDN ( $3 \times 20 \mathrm{mg} / \mathrm{day}$ ) on these parameters were evaluated.

After a 20 mg single oral dose, blood pressure decreased significantly more with ISDN (SBP:6\%; DBP: $14 \%$ ) than with $\mathbb{N}$ (SBP:2\%; DBP:6\%), but after 8 days this decrease in blood pressure was not statistically different between ISDN and $\mathrm{N}$. The diameter of CCA increased more with ISDN (11\%) than $\mathrm{N}(5 \%)$ acutely as well as subacutely (ISDN:12\%; N: $9 \%$ ). Heart rate increased only with ISDN ( $7 \%$ acutelly, $3 \%$ subacutely). No differences between ISDN and nicorandil were found for acute and subacute effects on systemic vascular resistance index, venous haemodynamics, diameter of muscular arteries (FA, BA), and the

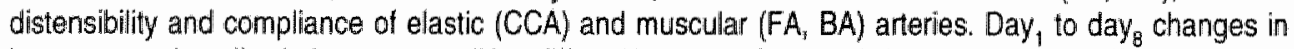
heart rate and cardiac index were small but differed between ISDN and nicorandil. These differences were due to a smaller increase in heart rate and cardiac index at day 8 than at day 1 with ISDN. Data on blood pressure and heart rate are in accordance with drug tolerance seen with ISDN but not with nicorandil. However, ISDN drug tolerance was not seen for the diameter of large arteries.

In conclusion, with dosages used in angina ,compared to nicorandil - a drug with both a potassium channel opening property and a nitratelike action - the pure nitrate ISDN showed a more pronounced decrease in systolic and diastolic blood pressure, a slight increase in heart rate, and more vasodilation of CCA. ISDN drug tolerance was shown for blood pressure and heart rate. In contrast to the well-known venous tolerance during ISDN, there was no ISDN drug tolerance for the effects on diameter of large arteries. No drug tolerance was seen with nicorandill. 


\section{Introduction}

Vasodilator drugs are commoniy used in the management of angina pecioris $(16,23)$. They may decrease systemic vascular resistance and influence vessel wall properties of large arteries. Vessel wall properties of large arteries (distensibility and compliance) reflect arterial stiffness and the buffering capacity of the arterial system. Recently, non-inwasive investigation of vessel wall properties of superficial large alteries has become possible by uitrasound techniques $(2,12,21,26,34)$. Hoeks et al have developed a vessell wall movement detector system with which distensibility and compliance can be measured more directly and accurately than with previous techniques (13). An improwement in arterial compliance may decrease pulse pressure, while a decrease in systemic vascular resistance decreases mean arterial pressure. Together, both arterial compliance and systemic vascular resistance determine left ventricular load. Consequently, an improvement in compliance and/or a decrease in vascular resistance may diminish the risk for cardiovascular mortality and morbidity $(6,24,28)$.

Nicorandil, a nicotinamide derivative, is a recently developed anti-anginal drug that exerts dilatory effects on the venous and arterial system, and induces coronary vasodilation. Consequently, a reduction of cardiac preload and afterload may be achieved $(3,35)$. The precise mechanism of action of nicorandil is not completely defined. Nicorandil has a dual action. In addition to potassium channel opening properties, it exerts a nitrate-like action. Potassium channel openers act by hyperpolarisation of arterial smooth muscle, resulting in vasorelaxation, especially of small arterioles $(32,33)$. They have also shown to dilate vesseis in ischaemic tissue (25). The nitrate moiety of nicorandil induces predominantly venous and large artery dilation. Finally, an increased prostaglandin 12 production has been proposed to contribute to its vasodilating properties (30). "sosorbide dinitrate (ISDN), like nicorandi", is used in the management of angina pectoris, but it has a partial different mechanism of action. ISDN is an organic nitrate and a well-known direct vasodilator. Venous and arterial smooth muscle are relaxed by ISDN. At low concentrations this predominantly results in venodilation, while at higher doses both arteries and veins diliate $(1,23)$.

Both nicorandil and ISDN are nitric oxide donors. This property could be responsible for their vasorelaxing capacity. Nicorandil and ISDN have been reported to reduce systolic blood pressure more than diastolic blood pressure (19). This might be due to a favourable influence on large artery compliance with a reduction in pulse pressure (27). ISDN has been thought to preferentially affect the venous system (preioad reduction), while nicorandil might have a more pronounced effect on large arteries (afterload reduction) $(3,4)$. The subacute effects of each compound as well as the haemodynamic differences between nicorandil and ISDN have not been extensively investigated yet.

The aim of the present study was to evaluate and compare in healthy volunteers the effect of nicorandil and ISDN at dosages commonly used in angina. Healthy volunteers were used because they were able to abstain from co-medication during the study. Venous haemodynamics, blood pressure, cardiac function. and vessell wall properties of elastic and muscular large arteries were studied after a single oral dose (acute effecl) and after a 1-week administration period (subacute effect) of each drug. The drugs were given in doses recommended for the treatment of angina pectoris $(20 \mathrm{mg})(5,15)$. In addition, these doses are known to induce a similar anti-anginal effect.

\section{Subjects and methods}

Subjects - Twenty four apparently healthy male volunteers were recruited by local advertising and found eligible to participate in the study. At selection, their mean age was $23(18-32)$ years, their mean weight was $73(61-86) \mathrm{kg}$, their mean height was $185(175-201) \mathrm{cm}$, and their mean body surtace area was 2.0 $(1.7-2.1) \mathrm{m}^{2}$. At baseline, the electrocardiograms, haemodynamic, and laboratory parameters were within 
the nomal range. All wolunteers were normotensive $(115 \pm 265 \pm 1 \mathrm{mmHg})$ and had a normal resting heant rate ( $59 \pm 2$ beatsimin). Twenty out of 24 volunteers reported using alcohol regularly and 8 were smokers. Mean alcohol consumplion never exceeded 4 glasses/day, and mean cigarette consumption was 10 per day (range 1-20).

Study design - The study was designed as a double-blind, randomised, cross-over study.

\section{Volunteer selection}

At the first screening visit a general medical history was taken. Demographic data were collected, and patients were checked for risk factors, concomitant diseases, and use of concomitant medications. A general physical examination, a routine laboratory screening, and an electrocardiogram were performed. Venous blood samples were analysed for creatinine, glucose, transaminases. (ALAT, ASAT), $\gamma$-GT, alkaline phosphatase, total protein, and albumin. Vessel wall properties and haemodynamic parameters were assessed in order to familiarise the volunteers with the examination procedures.

Exclusion criteria were hypertension (systolic $>160 \mathrm{mmHg}$ or diastolic $>90 \mathrm{mmHg}$ ), angina pectoris, a myocardial infarction or stroke in the preceding 6 months, symptomatic atherosclerosis or presence of overt plaques detected with ultrasound, diabetes mellitus, hepatic or renal disease, and a body mass index $>30$ $\mathrm{kg}^{2} \mathrm{~m}^{2}$. Concomitant medication was not allowed, except for paracetamol.

\section{Active treatment period (day 1-8)}

Baseline values for each parameter were assessed on day 0 . On day 1 each volunteer started to use nicorandil $20 \mathrm{mg}$ (tablets) or ISDN $20 \mathrm{mg}$ (capsules), following a fixed time schedule. Identical placebo tablets and capsules were provided according to a double-dummy method. One tablet together with one capsule were taken three times daily with a 6-hour interval between each dose. The first dose of the day was always taken 12 hours after the last dose of the preceding day. As a consequence, during the ISDN treatment period, ISDN was given three times daily in an asymmetric dose schedule. During the nicorandil treatmenl period the second dose was a placebo. Thus, in fact, nicorandil was given twice daily with a 12-hour interval. Treatment was continued for 8 days, and the two treatment periods were separated by a washout period of at least 3 weeks.

On day 1 and 8 of each treatment period, measurements started 0.5 hour after drug administration and lasted up to 2 hours after ingestion of the drug, which was at the peak effect of both drugs. At each session, vessel wall properties, blood pressure, heart rate, cardiac function, and venous haemodynamics were always assessed by the same investigator. Measurements were performed in a fixed order. Data on concomitant diseases, use of concomitant medication, and adverse events were obtained by questionnaire. Treatment was discontinued in the case of severe adverse events, development of exclusion criteria, or poor drug adherence.

The study was approved by the Ethical Committee of the University of Limburg and was pertormed in accordance with the Declaration of Helsinki (revised version 1983). Written informed consent was obtained from all subjects.

Methods - All haemodynamic measurements were performed in a quiet room with a constant temperature $\left(23-25^{\circ} \mathrm{C}\right)$ after at least 30 minutes of supine rest. Smoking and use of caffeine were not allowed 4 hours prior to examination. Throughout the study each visit was carried out at the same time of the day and by the same investigators. At the start of each session, an indwelling venous cannula was placed in an antecubital vein of the left arm. 


\section{Blood pressure and heart rate}

Supine blood pressure and heart rate were recorded every 3 minutes on the left arm with a Dinamap and the mean of all recordings during $30 \mathrm{~min}$ was taken (Chapter 2). Mean arterial pressure (MAP) was directly measured with this device.

\section{Vessel wall properties}

Vessel wall properties of the right elastic common carotid artery (CCA), and the right muscular common temoral (FA) and brachial (BA) arteries were assessed in recumbent position with the vessel wall movement detector system, as described in Chapter 2. From arterial diameter, distension, and pulse pressure, vessel wall properties were calculated according to the equations mentioned in Chapter 2.

\section{Cardiac function}

Cardiac function was measured with the patient in the left lateral position, using an echo Doppler technique (Chapter 2).

\section{Venous compliance}

Venous compliance was measured with mercury strain-gauge plethysmography (Chapter 2). Patients were in the supine position with the right arm at heart level. tn the left arm a cannulla (Venflon) was inserted into an antecubitall vein to record peripheral venous pressure. Changes in forearm volume were recorded by inflating an upperarm cuff at increasing cuff pressures $(20-50 \mathrm{mmHg})$. With each step $(10 \mathrm{mmHg})$ pressure was kept constant for 3 minutes, unless a plateau phase was reached sooner.

The maximal value of the forearm volume was taken. The unstressed venous volume was determimed by the distension of the forearm at an intravenous pressure of $10 \mathrm{mmHg}$. Venous compliamce was defined as the slope of the pressure-volume curve, as determined with linear regression analysis (7).

\section{Drug adherence}

Volunteers were asked for their drug adherence at the end of each 1-week treatment period (day 8), and the number of returned tablets/capsules was counted.

Data analysis - Efficacy analysis was performed on volunteers who completed the study $(n=22) .95 \%$ Confidence intervals of time-related changes in each drug and of differences in these time-related changes between the two drugs at each time point were calculated for each parameter. If the $95 \%$ confidence interval did not contain zero, the change or difference was considered significant. As a check for carry-over effects, mean values of the measurements of both periods were calculated for each patient and were compared between the two groups of treatment sequences with the Wicoxon rank sum test. Data are presented as mean \pm s.e.m.

\section{Results}

Drug adherence averaged $97 \%$ (at least $84 \%$ ) for nicorandil and $95 \%$ (at least $70 \%$ ) for ISDN as measured by pill counting. Eighteen wolunteers suffered from headache during nicorandil and 22 during ISDN. Two volunteers discontinued the study in the first active treatment period due to headache, one treated with nicorandil and one with ISDN. Other adverse events were generally very mild and equally divided in both groups. The effects on haemodynamics are shown in Table 1 and those on vessel wall properties in Table 2 and in Figure 1. Statisticall analysis revealed no evidence for carry-over effects. As a consequence, the cross-over design was considered valid. 


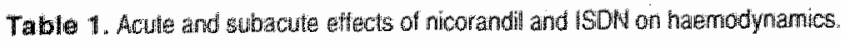

\begin{tabular}{|c|c|c|c|c|c|c|}
\hline & day 0 & $\begin{array}{c}\text { Wicorandi } \\
\text { day } 1\end{array}$ & diay 8 & day 0 & $\begin{array}{l}\text { ISDN } \\
\text { day }\end{array}$ & day 8 \\
\hline \multicolumn{7}{|l|}{ Blood prescure } \\
\hline SBP (mmtg) & $112 \pm 2$ & $110 \pm 2$ & $110 \pm 2$ & $114 \pm 2$ & $107 \pm 1 * \frac{1}{1}$ & $109 \pm 2^{*}$ \\
\hline DBP (minhy) & $64 \pm 1$ & $60 \pm 1$ & $61 \pm 1:$ & $64 \pm 1$ & $55 \pm 1^{*+1}$ & $59 \pm 1$ \\
\hline$\Delta P(m m H)$ & $49 \pm 1$ & $50 \pm 2$ & $50 \pm 2$ & $50 \pm 2$ & $52 \pm 2$ & $50 \pm 1$ \\
\hline \multicolumn{7}{|l|}{ Cardiac Lunction } \\
\hline Heart rate laeatsimin & $60 \pm 2$ & $60 \pm 1$ & $61 \pm 2$ & $58 \pm 2$ & $62 \pm 1 *$ & $60+2$ \\
\hline Cardiac index (Lminim $\left.{ }^{2}\right)$ & $28 \pm 0.1$ & $2.8 \pm 0.1$ & $2.9 \pm 0.1 *$ & $2.8 \pm 0.1$ & $2.9 \pm 0.1$ & $2.8 \pm 0.1$ \\
\hline Stroke index $\left(\mathrm{m} L / \mathrm{m}^{2}\right)$ & $49 \pm 1$ & $50 \pm 1$ & $50 \pm 1$ & $49 \pm 1$ & $49 \pm 1$ & $49 \pm 1$ \\
\hline SVPI (KP S.L." $\left.{ }^{\circ} m^{2}\right)$ & $236 \pm 8$ & $225 \pm 7$ & $225 \pm 8$ & $239 \pm 7$ & $222 \pm 7$ & $232 \pm 6$ \\
\hline \multicolumn{7}{|l|}{ Venous haemodyamics } \\
\hline 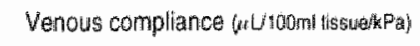 & $498 \pm 17$ & $510 \pm 18$ & $515 \pm 20$ & $495 \pm 22$ & $522 \pm 19$ & $517 \pm 31$ \\
\hline Ungtressed wolume (wt/100m) hissug) & $674 \pm 74$ & $821 \pm 70$ & $676 \pm 80$ & $600 \pm 73$ & $875 \pm 74^{*}$ & $650 \pm 81$ \\
\hline
\end{tabular}

Acute effect: afler a single dose; Subacite eftect: atter a 1-week treatment period; N, nicorandil; ISON, isosorbide dinilrate; SBP, systolic blood pressure; DBP, diastolic blood pressure; $\triangle \mathrm{P}$, puise pressure; SVRI , syslemic vascular resistance index; Unstressed volume was detemined al an iniravenous pressure of $10 \mathrm{mmHg}$. $n=22$, Data are mean \pm s.e.m.; * statistically difterent changes versus baseline: $t$, statistically different changes trom baseline between nicorandil and ISDN; \# statistically different changes vers US day " betweem nicorandil and ISDN.

Table 2. Acute and subacute effects of nicorandil and ISDN on vessel wali properties.

\begin{tabular}{|c|c|c|c|c|c|c|}
\hline & day 0 & $\begin{array}{c}\text { Nlcorandil } \\
\text { day } 1\end{array}$ & day 8 & day 0 & $\begin{array}{l}\text { ISDN } \\
\text { day } 1\end{array}$ & day 8 \\
\hline \multicolumn{7}{|l|}{ Carolid artery } \\
\hline Diameter (mm) & $5.68 \pm 0.06$ & $5.98 \pm 0.07$ & $6.17 \pm 0.08^{1}$ & $5.64 \pm 0.07$ & $6.28 \pm 0.08^{*}$ & $6.31 \pm 0.09^{*+1}$ \\
\hline DC $(10-1 / \mathrm{kPa})$ & $37.7 \pm 1.5$ & $37.9 \pm 1.3$ & $37.0 \pm 1.5$ & $37.2 \pm 1.1$ & $350 \pm 1.2$ & $36.8 \pm 1.3^{8}$ \\
\hline $\mathrm{CC}\left(\mathrm{mm}^{2} / \mathrm{kPa}\right)$ & $0.96 \pm 0.04$ & $1.07 \pm 0.05 *$ & $1.11 \pm 0.06^{\prime \prime}$ & $0.93 \pm 0.02$ & $1.09+0.05^{*}$ & $1.16 \pm 0.05^{\prime \prime}$ \\
\hline \multicolumn{7}{|l|}{ Fenoral artery } \\
\hline Diameler (tomm) & $8.16 \pm 0.13$ & $8.35 \pm 0.14^{\mathrm{in}}$ & $8.41 \pm 0.15^{*}$ & $8.10-10.15$ & $8.35 \pm 0.16^{\circ}$ & $0.36 \pm 0.15^{k}$ \\
\hline $\mathrm{DC}\left(10^{3} / \mathrm{Pa}\right)$ & $18.5 \pm 1.5$ & $18.9 \pm 1.6$ & $17.8 \pm 1.2$ & $18.2 \pm 1.8$ & $17.2 \pm 1.3$ & $17.2 \pm 1.3$ \\
\hline $\mathrm{CC}(\mathrm{mrn} / \mathrm{kPa})$ & $0.96 \pm 0.08$ & $1.03 \pm 0.08$ & $4.0 \pm 0.07$ & $0.93 \pm 0.08$ & $0.93 \pm 0.06$ & $0.95 \pm 0.07$ \\
\hline \multicolumn{7}{|l|}{ Brachial antery } \\
\hline Diameter (ntm) & $3.50 \pm 0.06$ & $3.88 \pm 0.07$ & $3.38 \pm 0.05^{\circ}$ & $3.48 \pm 0.06$ & $3.85 \pm 0.06^{\circ}$ & $3.91 \pm 0.06^{11}$ \\
\hline $\mathrm{DC}\left(10^{3} \mathrm{kPa}\right)$ & $27.6 \pm 2.0$ & $27.3 \pm 1.40$ & $27.2 \pm 1.4$ & $26.5 \pm 1.6$ & $27.3 \pm 1.7$ & $27.1 \pm 1.8$ \\
\hline $\mathrm{CC}\left(\mathrm{min} \mathrm{HPa}^{2}\right.$ & $0.27 \pm 0.02$ & $0.33 \pm 0.02^{*}$ & $0.32 \pm 0.02^{*}$ & $0.25 \pm 0.02$ & $0.32 \pm 0.02^{*}$ & $0.32 \pm 0.02^{\prime}$ \\
\hline
\end{tabular}

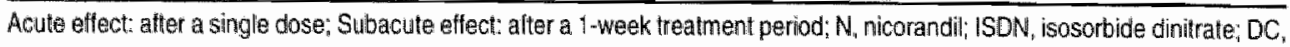
distensibility coeticient, $\mathrm{CC}_{\mathrm{B}}$ compliance coefficient.

$n=22$; Data are mean \# s.e.m.; ", statistically difterent changes versus baseline; $t$, stalistically different changes from baseline between nicorandil and ISDN, statistically different changes versus day 1 between nicorandil and ISDN. 

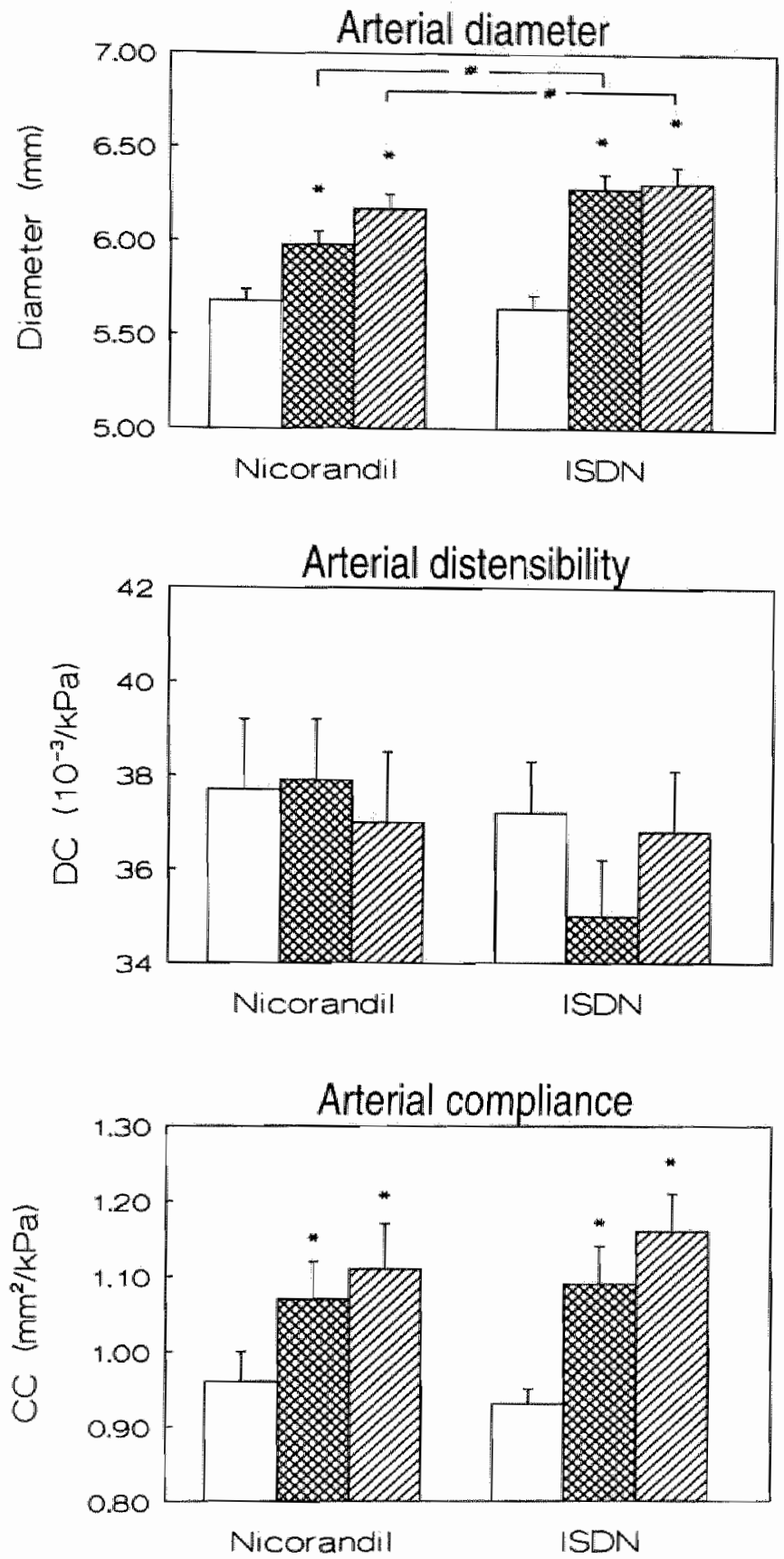

Figure 1. The acuie (single dose) and subacute (1-week treaimeni) eflect of nicorandil and ISDN on vessel wall properties of

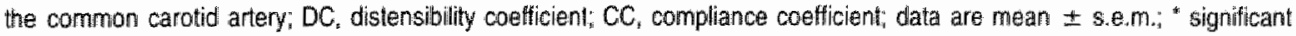
changes between day 1 or day 8 versus baseline; $95 \%$ confidence intervals; 95 , confidence interals. day $0 . \quad \times$ day $1 . \quad C$ day 8 
Systolic and diastolic blood pressure were reduced with ISDN (6\% and $14 \%$, respectively) and with nicorandil (2\% and $6 \%$, respectively). Heart rate only increased with ISDN (7\%). Systemic vasular resistance index (SVRI) significantly decreased with ISDN $(7 \%)$. Venous volume at $10 \mathrm{mmHg}$ was enhanced with $15 \mathrm{DN}(46 \%)$.

With both nicorandil and ISDN arterial diameters of the elastic common carotid artery (N:5\%; ISDN:11\%), and the musular femoral (N:2\%; ISDN:3\%) and brachial arteries (N:11\%; ISDN:11\%) were increased. Arterial compliance of the carotid artery increased with nicorandil (12\%) and ISDN (17\%), and also compliance of the brachial artery was higher with both ricorandih (22\%) nd ISDN (28\%).

\section{Changes from baseline subacute effects}

Systolic blood pressure was reduced with ISDN ( $4 \%$ ) only. Diastolic blood pressure was reduced with ISDN $(8 \%)$ and nicorandil $(5 \%)$. Heart rate only increased with ISDN $(3 \%)$. Cardiac index was slightly enhanced with nicorandil ( $4 \%)$.

The diameter of the elastic common carotid artery increased with ISDN and nicorandil (ISDN:12\%; N.9\%). The diameter of the muscular femoral and brachial arteries was also increased by nicorandil (FA. $3 \%$; BA:9\%) and ISDN (FA:3\%, BA:12\%). Compliance of the carotid and brachial arteries was enhanced with nicorandil (CCA:16\%; BA:19\%) and ISDN (CCA:25\%; BA:28\%).

\section{Differences between nicorandil and ISDN}

The primary aim of the study was to detect differences between nicorandil and ISDN. Systollic as well as diastolic blood pressure decreased more with ISDN than with nicorandil at day 1 . In contrast to nicorandil, heart rate increased with ISDN. Statistically different effects on blood pressure and heart rate between ISDN and nicorandil at day 1 did not persist at day 8 . The diameter of the common carotid artery was significantly larger with ISDN than with nicorandil after a single dose and the effect was maintained after 8 days. Day, to day $y_{8}$ changes differed statistically between ISDN and nicorandil for heart rate, cardiac index, and diameter and distensibility of the common carotid artery.

\section{Discussion}

The primary aim of the present study was to compare the haemodynamic effects of a relatively new anti-anginal drug, nicorandil, with those of a widely used agent, isosorbide dinitrate (ISDN). The effects of nicorandil and ISDN were studied at dosages commonly used in the treatment of angina pectoris, which induced a similar anti-anginal effect $(8,15)$. Headache accounted tor most of the reported adverse events during the treatment period. As in previous studies $(3,5)$, the adverse events with nicorandil were milder than with ISDN. All haemodynamic measurements were performed at the peak effect of both drugs $(3,8)$. Since the study was a comparative study and not placebo-controlled, differences versus baseline have to be interpreled with caution. Systolic and diastolic blood pressure decreased with ISDN and nicorandil. But, after a single oral dose blood pressure was more reduced with ISCN than with nicorandil. These data are consistent with the literature $(9,19,20)$. However, this larger decrease in blood pressure with ISDN did not persist after 8 days. Pulse pressure remained unchanged with both drugs.

In contrast to ISDN, heart rate did not chango with nicorandil, and this is consistent with previous studies $(5,15,31)$. The increase in heart rate with ISDN has been suggested to be a compensation for the decrease in blood pressure (9). As for blood pressure, with ISDN effects on heart rate were attenuated at day 8 compared to day 1. 
In accordance with literature data $(1,14,30)$, changes in cardiac index were absent or small with both agents and in our opinion are of no clinical relevance. Although the systemic vascular resistance index tended to decrease versus baseline with both drugs, the decrease was only statistically significant after a single oral dose of ISDN. Literature data are not conclusive with respect to the effects of both drugs on systemic vascular resistance, but in general it remains relatively unaffected $(19,23,30)$.

Changes in venous compliance versus baseline were not statistically significant with both drugs. In hypertensive patients venous compliance was also not affected with nicorandil (19). Venous retum to the heart is not only influenced by venous compliance, but may also depend on the amount of blood in the "unstressed" volume, which represents the haemodynamically inactive compartment of the venous system (11). In the case of decreased venous tone, blood will be transported from the haemodynamically active compartment into the unstressed volume, while venodilation has been associated with an increased unstressed volume (11). Due to large intra and interindividual wariation, which is reflected in an unstable baseline and large s.e.m., in the present study data on unstressed volume are difficult to interpret. However, data on unstressed venous volume are compatible with the well-known venous tolerance seen with ISDN $(10,36)$. It is not clear whether wenous tolerance might also occur with nicorandil.

Arterial diameter of the elastic common carotid and muscular femoral and brachial arteries increased versus baseline with both drugs. Previous studies with ISDN and nicorandil also have demonstrated an aculte vasodilation of large arteries $(9,18,19)$. With a decrease in blood pressure, arterial diameter was expected to decrease passively. However, for a larger decrease in blood pressure, arterial diameter increased similarly or even more (i.e., the common carotid artery) with ISDN than with nicorandil, which suggests a larger direct relaxing effect on large artery smooth muscle at the dosages used. This arteriall dilation was not attenuated after 8 days.

Arterial distensibility remained unchanged versus baseline with both drugs. Although day, to day ${ }_{8}$ changes. in distensibility of the common carotid artery were statistically significant between both drugs, changes. were small and within the margins of error of the device (17) and, as a consequence, probably not relevant. Arterial compliance of the common carotid and brachial artery increased versus baseline with nicorandil and ISDN. An increase in large artery compliance after ISDN has been shown previously 19,18). However, as in the present study, the increased compliance after ISDN was not obligatorily associated with improvement of arterial distensibility $(18,19,29)$. Due to the larger diameter and an unaltered distensibility, arterial compliance was enhanced in elastic and muscular arteries. This indicates an improvement in the buffering function of the arterial system, which in urn determines cardiac afterlaad. Compliance of the muscular femoral artery did not change with any of the two drugs. Whether this is due to a different behaviour of the femoral artery or to a lower reproducibility of compliance measurements of this artery reflected by the larger s.e.m. - is not clear.

The attenuated effects at day 8 versus day 1 on blood pressure, heart rate, and possibly also on systemic vascular resistance are compatible wilth drug tolerance during ISDN. This has also been found by other authors $(10,22)$. Data in the present study are compatible with the well-known venous tolerance with ISDN $(10,22)$. However, there was no drug tolerance on large artery dilation. The present study did not reveal ewidence for drug tolerance with nicorandil.

In conclusion, with the dosages used nicorandil had a smaller effect on blood pressure and heart rate than ISDN. Vasodilation of large arteries occurred with both drugs, but dilation of the carotid artery was more pronounced with ISDN. Arterial compliance of elastic and muscular arteries were improved both with nicorandil and ISDN. The improvement in arterial compliance was mainly due to an increase in arterial diameter. Since arterial compliance is an important determinant of cardiac afterload, an improved compliance might contribute to a lower afterload. ISDN drug tolerance could be shown for haemodynamic parameters such as blood pressure and heart rate. In contrast to the well-known venous tolerance with ISDN, no tolerance on large artery dilation could be observed. There was no evidence of drug tolerance with nicorandil. 


\section{References}

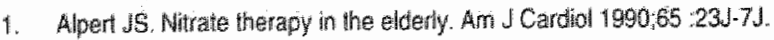

2. And JO, Klause J, Mersch F. The diameter of the intact carotid artery in man and its change with puse pressure.

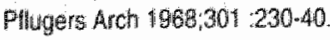

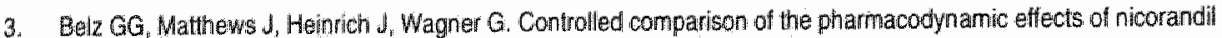
(S0-75) and isosorbide dinitrate in man. Eur J Phamacoll 1984;26:681-85.

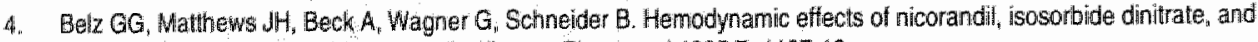
dinydralazine in heathy volunteers. J Cardiovase Pharmacol 1985;7:1107-12.

5. Camm $A$, Maltz MB. A controlled single-dose study of the etficacy, dose response and duration of action of micorandil in angina pectoriss. Am $\mathrm{J}$ Caroiol $1989 ; 63 ; 61 \mathrm{~J}-5 \mathrm{~J}$.

6. Dame $B$, Girerd $x$, Salar $M$, Cambien $F$, Guize L. Pulsatile versus steady component of blood pressure: a cross-sectional anatysis and a prospective analysis on cardiovascular mortality. Hypertension 1989;13:392-400.

7. Forconi $S_{\text {, Jagenau }} A_{1}$ Guerrini $M_{i}$ Peceni $S_{\text {; }}$ Cappeli $R$. Strain gauge plethysmography in the study of circulation af the limbs. Anglology 1979,30:487-97.

8. Frydman AM, Chapelle P, Diekmann H, Bruno $R$, Thebault JJ, Bouthier J, Caplain H, Ungethuem W. Gaillard C, Le L.jboux A, Renard A, Gaillot J. Pharmacokinelics of nicorandill. Am J Cardiol 1989;63:25J J33J.

9. Frydman AM, Satar ME, Simon AC, Levenson JA, Gaillot J Roland E. Isosorbide dinitrate: relationship between pharmacokinetics and brachial artery hemodynamics in essential hypertension. Angiology $1986,37: 5811-89$.

10. Ghio $S$, de Servi S, Perotti R, Eleuteri E, Montamartini $C$, Specchia G. Different susceptibility to the development of nitrogycerin folerance in the arlerial and venous circulation in humans. Effects of M-acetylcysteine administration. Circulation $1992 ; 86: 798-802$.

11. Greenway CV, Lautt WW. Blood volume, the venous system, preload, and cardiac output. Can \& Physiol Pharmacol 1986;64:383-87.

12. Gustafsson $D$, Stale H. Bjorkman J, Gennser $G$. Deriwation of haemodynamic information from ultrasonic recordingls of aortic diameler changes. Ultrasound Med Biol 1989; $15: 189-99$.

13. Hoeks AFG, Brands PJ, Smeets FAM, Renernan RS. Assessment of the distensibility of superficial arteries. Ullirasound Mod Boll 1990;16:121-28.

14. Kambara $H$, Nakamura $Y$, Tamaki $S$, Kawai $C$. Beneficial eftects of nicorandil on cardiowascular hemodynamics and ieft ventricular function. W Cardiovasc Pharmacol 1887;10 (Suppl. 8) :S104-8.

15. Kinoshita M. Sakai K. Phamacology and therapeutic effects of nicorandil. Cardiovasc Drugs Ther 1990;4:1075-88.

16. Koch - Weser J. Wasodilator drugs in the treatment of hypertension. Arch Intern Med 1974:133:1017-28.

17. Kool MJF, van Merode T, Beneman RS, Hoeks APG, Struyker Boudier HAJ, Van Bortel LMAB. Evaluation of reproducibitty of a vessel wall movement detector system for assessment of large artery properties. Cardiovasc Res $1994,20610.14$.

18. Laurant $S_{\text {, }}$ Arcaro $G$, Benelos $A_{4}$, Lafleche $A$, Hoeks $A$, Satar M. Mechanism of nitrate-induced improvement an arterial compliance depends on wascular territory. J Cardiovaso Pharmacol 1992;19:641-49.

19. Levenson "S, Bouthier J, Chau NP "Rolan E, Simon AC. Eftedts of nicorandll on arterial and venous vessels of the lorearm in systemic hypertension. Am J Catdiol 1989;63:40 J-3J.

20. Levenson \&, Simon A, Bouthier w, Benetos. A, Satar ME. Isosorbide dinitrate and pulsatile arterial hamodynamia: wariables in hypertension. Eur Heart J 1986; $7: 898-903$.

21. Levenson JA, Peronneat PA, Simon A. Satar ME Pulsed Doppler: determination of diameter , blood tlow velocity, and wolume flow of brachial artery in man. Cardiovasc Fes 1981:15:164-70.

22. Makhou N, Dakak N, Flugeman MY, Merdler A, Shefer A, Schneeweiss A, Halon DA, Lewis BS. Nitralle lolerance in heart fallure: Differential venous, pulomonary and systemic arterial effects. Am J Cardiol 1990;65:28J-31J.

23. Needleman P. Con PB, Johnson EM. Drugs used for the treatment of angina: organic nitrates calcium channel blockers, and madrenergic antagonists. In: Goodman Gimar, A, Rall TW, Nies AS, Taylor P, eds. Goodman and Gilman's the pharmacological basis of therapeutics 8th ed. New York: Pergamon Press, 1990:764-84. 
24. ORourke M. Systolic blood pressure: anterial compliance and early wawe reflection, and their modification by antihypertensive therapy. J Hum Hypertens 1989;3:47-52.

25. Quast $U$, Cook NS. Moving together: $K+$ channel openers and ATP-sensitive $K+$ channels. TiPS 1989:11:431-35.

26. Riley WA, Barnes. RW, Evans GW, Burke GL. Ultrasonic measurement of the elastic modulus of the common carotid artery. The atherosclerosis risk in communities (ARIC) study. Stroke 1992;23:952-56.

27. Safar ME, Bouthier JA, Levenson JA, Simon $A C$. Feripheral large arteries and the response to antihypertensive treatment. Hypertension $1983 ; 5$ (III) : $1163-68$.

28. Safar ME, Levy BI, Laurent S, London GM. Hypertension and the arterial system: clinical and therapeutic aspects. J Hypertens 1990;8 (Suppl. 7) :S113-19.

29. Safar ME, London GM, Bouthier JA, Levenson JA, Laurent S. Brachial artery cross-sectional area and distensibility before and after arteriolar wasodilatation in men with sustained essential hypentension. J Cardiovasc Pharmacol 1987:9 $: 734-42$.

30. Silke $B$, Verna SP, Ali MS, Goldhammer $E$, Taylor SH. Effects of nicorandil on left ventricultar hemodynamics and volume at rest and during exercise-induced angina pectoris. Am J Cardiol 1989;63:49J-55J.

31. Solal AC, Jaeger $P, B$ Bouthier J. Jullierd J, Dahan M, Gourgon $R$. Hemadynamic action of nicorandil in chronic congestive heart failure. Am J Cardial 1989;63 :44J-8.J.

32. Struijker Boudier HAJ, Messing MWJ, van Essen $\mathrm{H}$. Preferential small arteriolar vasodilation by the potassium channel opener, BRL 38227, in conscious spontaneousiy hypertensive rats. Eur J Pharmacol 1992;218:191-93.

33. Taira N. Nicorandil as a hybrid between nitrates and polassium channel activators. Am J Cardiol 1989;63:18.J-24.J.

34. Tardy Y, Meister JJ, Perret F, Brunner HR, Arditi M. Non-invasive estimate of the mechanical properties of peripheral arteries from ultrasonic and photoplethysmographic measurements. Clin Phys Physiol Meas 1991;12 39-54.

35. Thorrmann J, Schiepper M, Kramer W, Gottwik M, Kindler M. Effectiveness of nicorandill (SG-75), a new fong-acting drug with nitroglycerin effacts, in patients with coronary artery disease: improved left ventricular function and regional wall motion and abolition of pacing-induced angina. J Cardiovasc Pharmacol 1983:5:371-77.

36. Zelis R, Mason DT. Isosorbide dinitrate, effect on the vasodilator response to nitrogilycerin. JAMA $1975 ; 234: 166-70$. 


\section{CHAPTER 10}

GENERAL DISCUSSION 


\section{Determinants of reproducibility of non-invasive measurements of large artery properties}

Initially, mast data on large artery properties (distensibility and compliance) were derived from animal and in vitro studies, but these results can not simply be extrapolated to the human situation in vivo. In addition, distensibility and compliance were used indifferently, because it was not possible to measure them separately in an accurate manner. With the vessel wall movement detector system as used in the presen: thesis local distensibility and compliance of superficial elastic and muscular large arteries can be assessed non-invasively and more directly than with previous techniques (Chapter 3). The reproducibility of this vessel wall movement detector system is influenced by method-related factors and by physiological variations (Table 10.1).

Table 10.1. Faclors influancing reproducibility of vessel wall movement measurements.

\begin{tabular}{|l|c|}
\hline Methodi-related variation & Physiological variation \\
\hline & \\
$\checkmark$ Technical repraducibility & $\checkmark$ Time-related variation \\
$\checkmark$ Observers' skill & Short-term variation \\
$\checkmark$ Number of measurements & Diumal variation \\
$\checkmark$ Blood pressure recording & Seasonal wariation \\
& $\checkmark$ Other influences i.e. meal \\
\hline
\end{tabular}

\section{A Method-related factors}

\section{Technical reproducibility}

Technical reproducibility of the vessel wall movement system plays a role with respect to adequate measurements of arterial distension and diameter $(\Delta \mathrm{D}$ and $\mathrm{D}$, respectively). However, the theoretical accuracy of the device is good ( 3 , m for distension).

\section{Qbservors" skill}

Observers" skill is determined by the presence of well-trained investigators. Intraobserver and interobserver variation is largely dependent on the investigator's skill. With the vessel wall movement system a coefficient of variation below $10 \%$ for distension and below $5 \%$ for arteriall diameter is reached for the elastic common carolid artery, which means an acceptable observer reproducibility. Reproducibility of muscular large arteries is silightly lower (see physiological variation).

\section{Number of measurements}

The number of measurements may also influence reproducibility of vessel wall movement measurements. A further improvement of accuracy may be achieved by averaging a larger number of recorded heart beats 
(regression to the mean). A recording time of 5-6 seconds per measurement gives approximately 5 distension waveforms on condition that heart rate is $50-60$ beats/min. Hore measurements will result in a better accuracy. For example, the intraobserver coefficient of wariation for arterial diameter and distension of the common carotid artery with 3 measurements $(4.0 \%$ and $9.0 \%$, respectively; average of approximately 15 heart beats) was improved with 4 measurements (diameter $3.6 \%$, distension $8.9 \%$; average of approximately 20 heart beats). However, in view of the larger cost in time needed lor 4 measurements and the relatively small improvement in coefficient of variation, the 4 measurements procedure was considered not to have a better cost-benefit ratio than the 3 measurements procedure. Similar results were obtained for the muscular femoral and brachial arteries (unpublished data).

\section{Blood pressure recording}

Finally, non-invasive blood pressure recording at the site of and simultaneously with vessel wall movements detection ${ }_{1}$ causes a major problem. At present, the most acceptable way of pressure recording is to choose a blood pressure recording place as close as possible to the location of vessel wall movement measurements in order to estimate local blood pressure, as accurately as possible. Whereas mean arterial pressure is relatively constant, pulse pressure differs along the arterial tree. In addition, boosting of pulse pressure by pulse wave reflections is common in the carotid artery, while it is not common in the brachial artery $(67,68)$. In the absence of pulse wave reflections, a good correlation is found between carotid and brachial blood pressure (98). In that case, the Dinamap device - measuring blood pressure in the brachial artery non-invasively - can be used. The accuracy of the Dinamap has been evaluated and was considered good $(14,20,96)$. The Finapres is also a semi-automated device, measuring beat-to-beat blood pressure at the finger. Finapres biood pressure recordings have been used to estimate blood pressure at the site of the brachial or radial artery $(47,70)$. The Finapres device can accuratelly monitor changes in pressure $(94,96,114)$. However, in case of peripheral vasoconstriction the Finapres pressure recorded in the finger may be considerably lower than in the systemic circulation $(96,130)$. On the other hand, during dynamic exercise systolic finger pressure is considerably higher compared to intra-arterial brachial pressure (52). It is known that in conditions, such as ageing, hypertension, vasoconstriction, or use of antihypertensive drugs the issue of wave reflections may increasingly become important. However, despite this short distance between the sites of pressure (as assessed with Finapres) and vessel wall movement recordings, estimation of pulse pressure still is not fully correct. The reason for this is that in more distal peripheral arteries pulse pressure is higher because of a smaller diameter of these vessels. In addition, interfering wave reflections may increase pulse pressure.

in this respect, we could demonstrate considerable differences between Dinamap blood pressures and Finapres blood pressures in uncomplicated diabetic subjects (Table 10.2.1). Pulse pressure of the diabetic patients did not differ from that of matched control subjects, when using the Dinamap. However, pulse

Table 10.2.1. Pulse pressure from Dinamap and Finapres in diabetic patients and contubls.

\begin{tabular}{crrrr}
\hline & \multicolumn{2}{c}{ Finapres } & \multicolumn{2}{c}{ Dinamap } \\
& IDDM & Controls & IDOM & Conirols \\
\hline $\operatorname{SBP}(\mathrm{mmHg})$ & $127 \pm 3$ & $118 \pm 2$ & $118 \pm 2$ & $115 \pm 2$ \\
$\mathrm{DBP}(\mathrm{mmHg})$ & $61 \pm 2$ & $60 \pm 2$ & $69 \pm 1$ & $68 \pm 1$ \\
$\triangle \mathrm{P}(\mathrm{mmHg})$ & $66 \pm 2$ & $58 \pm 2^{2}$ & $49 \pm 1$ & $48 \pm 2$
\end{tabular}

IDDM, uncomplicated insulin-dependent diabetic subjects (n=2:5); Controls, presumed healthy subjects, matched for age. gender, and blood pressure $(n=25)$; SBP, systolic blood pressure; DBP, diastolic biood pressire; $\triangle P$. pulse pressure: " p<0.05; mean \pm s.e.m. 
Table 10.2.2. Pulse pressune from Dinamap and Finapres in habitual smokers (n=12), before and atter smoking one cigurette.

\begin{tabular}{lrrrr}
\hline & \multicolumn{2}{c}{ Finapres } & \multicolumn{2}{c}{ Dinamap } \\
& Betore & After & Before & After \\
\hline SBP (mmHg) & $115 \pm 4$ & $140 \pm 3^{* * *}$ & $112 \pm 2$ & $118 \pm 3^{* * *}$ \\
DBP (mmHg) & $56 \pm 2$ & $63 \pm 2^{* * *}$ & $69 \pm 1$ & $73 \pm 1^{* * *}$ \\
$\Delta P(\mathrm{mmHg})$ & $58 \pm 3$ & $67 \pm 3^{* *}$ & $43 \pm 2$ & $45 \pm 2$
\end{tabular}

$\overline{S B P}$, systolic biood pressure; DBP, diastolic blood pressure; $\triangle P$, pulse pressure; " $" \mathrm{p}<0.01$ and ${ }^{*+t} p<0.001$, difference betore and immediately after smoking one cigarette; mean \pm s.e.m.

pressure assessed by Finapres was significantly higher in diabetics than in controls. In addition, in habitual smokers pulse pressure was higher in the finger artery than in the brachial artery (Table 10.2.2). After smoking a cigarette these smakers showed a considerable increase in pulse pressure in the finger artery, but not in the brachial artery. These data suggest that changes in sympathetic tone (as with smoking) can change pulse pressure in the finger arteries more than in the brachial artery. The higher finger pulse pressure in the diabetic patients might de due to early changes in smaller arteries and arterioles in these subjects. It is obvious that the use of inaccurate pulse pressure data may have important consequences for the calculations of distensibility and compliance.

Another problem might arise when peripheral blood pressure values are used to reflect central aortic pressure. Due to pulse wave travelling and reflection phenomena, especially systolic blood pressure can differ as much as $20 \mathrm{~mm} \mathrm{Hg}$ between central and peripheral sites (64). To overcome these problems, applanation tonometry has been proposed as a non-invasive method to record local pulse pressure (12). Applanation tonometry can not be used to record absolute pressure, but may be used to record pulse pressure. To perform accurate measurements with lhis technique, a solid background (bone) is necessary. If pressure measurements are performed simultaneously with arterial distension measurements, then only the contralateral sile can be used for pressure measurements. In healthy volunteers that will cause no problems, but in patients with (undetectable) atherosclerotic plaques this may be a source of error. Therefore, this technique is not yet fully accepted.

Finally, based on pulse wave transfer functions, resynthesis of ascending aortic pressure from recordings of brachial or radial arteries, seems to become a promising technique for adequate blood pressure recording (64).

\section{B Physiological variations}

\section{Time-related factors}

Time-related factors, such as short-term variation within minutes, diurnal variation, and seasonal variation in vessel wall properties are merely important to reproducibility of large artery properties. Short-term variation in vessel wall properties may explain the higher variability in muscular arteries when compared to elastic large arteries. A larger spontaneous short-term variation in these muscular arteries, which are under permanent neurohumoral control (50), may influence reproducibility negatively. Apart from short-term variation, a diumal variation in vessel wall properties of elastic and muscular arteries is present (see discussion part II). Data on seasonal variation in vessel wall properties are not available, but may be suspected, since for blood pressure and for the occurrence of some cardiovascular diseases a seasonal variation has been shown $(15,41)$. 


\section{Other influences}

Other influences, such as taking meals could also interfere. However, compared to parameters of cardiac function, the influence of meals on vessel wall properties was less pronounced (Chapter 4). From the above it can be concluded that assessment of vessel wall properties with the vessel wall movement detector system can be measured with acceptable reproducibility when performed under standardised conditions, i.e. examining on the same moment of the day throughout a study.

\section{Future research}

Future research must be directed towards improvement of blood pressure recording techniques and towards development of techniques to measure local pulse pressure simultaneously with vessel wall movements in order to improve the accuracy of the assessment of vessel wall properties. Attention must be paid to pulse wave reflections, since these interfere with accurate assessment of pulse pressure. 


\section{Vessel wall properties as a cardiovascular risk factor}

\section{A Influence of physiological conditions}

Arterial blood pressure can be seen as the sum of a static component (mean arterial pressure) and a dynamic component (pulse pressure) superimposed on it (104). Recently, the interest in the dynamic part of blood pressure has increased. Large artery properties, distensibility and compliance, play an important role in determining the dynamic behaviour of the vessel. Distensibility reflects the elastic properties of a large antery, while compliance describes its buffering function. Related to this, distensibility is thought an important determinant of the pulsatile stress on the vessel wall, while compliance is a major determinant of cardiac afterload (124). A decrease in distensibility and compliance may have important implications for the risk of carcliowascular disease, because the risk of stroke, heart failure and atherosclerotic disease may become increased. On the other hand, a decrease in large artery properties may become a consequence of disease or physiological changes. Various physiological conditions may influence vessel wall properties and therefore, indirectly cardiovascular risk can be affected (Table 10.3). Data on arterial stiffness, which is the inverse of distensibility $(92,113)$, and on cardiowascular risk are shown.

Table 10,3. Influence of physiological conditions on arterial stiffness and cardiovascular risk.

\begin{tabular}{|c|c|c|}
\hline Physlological conditions & Arterlal stiffness & Cardiovascular misk \\
\hline \multicolumn{3}{|l|}{ Time-related lactors } \\
\hline short-term variation & $\boldsymbol{N}$ and $\boldsymbol{\psi}$ & $?$ \\
\hline diurnal variation & at aight & T early morning \\
\hline seasonal variation & $?$ & $?$ \\
\hline Age & $T$ & T \\
\hline Gender & male sfemale & malestemale \\
\hline \multicolumn{3}{|l|}{ Race } \\
\hline oriental & $\downarrow$ & $\downarrow$ \\
\hline blacks & $y$ & 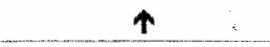 \\
\hline High salt intake & $\uparrow$ & $(\uparrow)$ \\
\hline High sall-sensitivity & 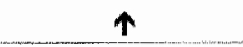 & $?$ \\
\hline Obesity & $=$ or $\mathrm{r}$ & $=$ or $\mathrm{T}$ \\
\hline Physical axercise & $\downarrow$ & $\Downarrow$ \\
\hline Stress & $(\mathbf{P})$ & $\mathrm{T}$ \\
\hline Smoking & N\# & $\boldsymbol{1}$ \\
\hline
\end{tabular}




\section{Time-related factors}

\section{Short-term variation}

Short-term variations in arterial stiffness may occur spontaneously and are difficult to control. These: variations are probably due to alterations in vascular tone. Endothellial function plays an important role in the regulation of vascular tone. The short-term variations might be an adaptation mechanism to maintain shear forces at the site of the endothelium at a constant level (50). Due to these short-term variations, arterial stiffness may become increased during certain time periods and are decreased in other time periods. Whether these increases in stiffness are related to an enhanced cardiovascular risk is not known yet.

\section{Diurnal variation}

Like blood pressure and heart rate, arterial stiffness of elastic and muscular arteries shows a diurnal variation (Chapter 4). Nocturnal vasodilation of large arteries is probably due to a lower sympathetic tone at night. Since arterial compliance is preserved throughout the day, the buffering capacity of elastic and muscular arteries seems not affected. Diurnal variation in blood pressure and heart rate has been related to the time of occurrence of cardiovascular disease. Myocardial infarction (88), sudden cardiac death (87), myocardial ischaemia (100) and stroke (79) occur more frequently in the early morning hours. The most important trigger mechanism for this phenomenon is considered to be an increased sympathetic drive to the heart and blood vessels during the early morning hours, resulting in a higher blood pressure and heart rate (38). In addition, it is suggested that subjects that do not show a fall in blood pressure at night (non-dippers) have a higher risk of left ventricular hypentrophy and stroke when compared to those who do show a nocturnal fall of blood pressure (dippers) $(91,125)$. Thus, the absence or presence of a diurnal blood pressure pattern might increase cardiovascular risk. For arterial stiffness the significance of the stress of awakening - with a sharp increase in noradrenalin - is not elucidated yet, neither has a clear relation been shown between a diurnal variation in arterial stiffness and an increased cardiovascular risk. It is possible that the increase in heart rate puts a higher pulsatile stress on the vascular wall and hence the risk of endothelial damage and acute cardiovascular events might become increased (124). Prospective studies are now performed to study the relation between diurnal variation and cardiovascular morbidity and mortality in more detail.

\section{Seasonal variation}

The trequency of cardiovascular events seems not equally distributed throughout the year $(134,135)$. it might be suspected that seasonal variations influence arterial stiffness and hence may increase cardiovascular risk, but at present no data are available on this issue.

\section{Age}

It is now well known that ageing runs in parallel with a gradual increase in arterial stiffness of elastic large arteries, an increase in pulse pressure, higher pulse wave velocity and increased pulse wave reflections $(66,99,105)$. A pathological condition, such as hypertension, may aggravate these age-related changes. Clinical studies have suggested that arterial stiffness is lowest at the age of $20(11,84)$. The results of different studies suggest that after that age, arterial stifness gradually increases $(11,65,99)$, suggesting that irreversible changes - due to structural alterations - might have occurred in large arteries from the age of 20. The higher arterial stiffness contributes to an increase in ventricular load. An increase in peak systolic stress and pulse pressure with increasing age may enhance the pulsatile stress on the arterial wall. This 
will result in a greater risk of rupture of an atherosclerotic plaque and hence acute cardiovascular complications $(39,40)$. Epidemiological data have contirmed the increase in cardiovascular morbidity and montality with advancing age and found it particularly related to a higher systollic pressure (61). With regard to age eftects, arterial stiffress could be used as an early marker of vascular ageing.

\section{Gender}

An intuence of gender on arterial stiffness has been demonstrated in a few studies, but data are inconsistent either indicating a higher arterial stiffness in males $(10,123)$, or a higher arterial stiffness in lemales compared to males at all ages (85). In the latter study the number of subjects investigated was smaller, especially in the female group, which might have influenced the results. Epidemiological data show a lower incidence of cardiovascular disease in females through middle age when compared to males, but this gender difference decreases with advancing age. Maybe, a steeper increase in systolic pressure in women over 45 years of age is important for an increased risk of stroke and coronary heart disease in women of this age $(60)$. The findings suggest an increased arterial stiffness and an increased cardiovascular risk with the onset of menopause (58), but a clear relationship between sex hormones and cardiovascular risk is lacking.

\section{Race}

Cardiovascular risk in black subjects appears to be higher than in white subjects. The prevalence and severity of hypertension in US blacks is higher than in white subjects $(63,108,110)$. In addition, the complications of hypertension in US black individuals are more severe with regard to stroke, renal failure and congestive heart failure, while ischaemic heart disease and myocardial infarction are rare $(63,108)$. However, blacks from the West Indies working in England had similar blood pressure compared to non-blacks, and African blacks have also low blood pressures (63). Much of the excess cardiovascular morbidity and mortality in US blacks has been related to their lower socio-economic status, less well management of hypertension in US blacks and a higher prevalence of risk factors, such as smoking, obesily, dyslipidaemia and diabetes (63). Another possible explanation for an increased cardiovascular risk in US blacks could be that they are more salt sensitive (see salt-sensitivity) and show abnormalities in salt ( $\mathrm{NaCl}$ ) transport (63). In addition, their cardiovascular system is exposed to elevated levels of blood pressure for a higher proportion of the day (46). This can imply a higher load on the arterial wall and a considerable increase in arterial stiffness, but large artery properties in black subjects have not been investigated yet.

Since arterial stiffness is higher in occidental than in oriental populations (6.8), it is likely that race forms a possible intervening risk factor. Coronary heart disease has been shown to occur more frequently in occidental populations (43). Maybe this is a gene-related problem, maybe a difference in litestyle, because longitudinal studies in migrating populations from oriental subjects have shown that higher living standards and westernisation of communities are associated with increased cardiovascular morbidity and mortality (80). At present, also modernisation programs within one country lead to an increased prevalence of cardiovascular disease within the oriental countries themselves (8). A recent study has shown that oriental subjects showed a lower medial thickness throughout the aortic trunk, while aortic circumference was greater, when compared to occidental subjects (127). A difference in the amounts of elastin or collagen of the arterial wall between oriental and occidental populations may be suspected, explaining an increased arterial stiffness in a population with less vascular elastin. A difference in salt-handling might also play a role. 


\section{High salt intake and salt-sensitivity}

Salt on itself may increase arterial stiffness $(7,8)$, but the underlying mechanism is rather complex (106). Although epidemiological and intervention studies suggest a relation between dietary salt intake and blood pressure (36), there is controversy about the role of salt in the pathogenesis of hypertension (129) and in cardiovascular disease (13). Salt-sensitivity influences arterial stiffness. Salt-sensitive borderline hypertensive subjects showed an increase in arterial stiffness of elastic and muscular arteries, as compared to salt-resistant borderline hypertensive subjects (32).

\section{Obesity}

Arterial stiffness may increase in obese subjects, but data are scarce (Chapter 1). Obese subjects are considered to have an increased risk of cardiovascular disease (51). On the other hand, obesity in other studies had only a weak predictive value with respect to cardiovascular disease (51) or cardiovascular mortality was lower in obese subjects $(31,115)$. In one study, hypertension even seems to be more benign when associated with obesity (9). However, an important confounding factor in the latter study could have been the use of the same cuff size for lean and obese subjects (102). Apart from that, the distribution of body fat may be more important than the overall degree of obesity with regard to cardiovasculat risk (23). The relation between body mass index and arterial stiffness is probably low (123).

\section{Physical exercise}

Based on epidemiological data, regular physical exercise is generally recommended tor the prevention of cardiovascular disease (33). A program of regular moderate exercise lowers resting mean arlerial blood pressure, associated with a decrease in systemic vascular resistance (54). Since in the latter study cardiac function, plasma cholesterol, sympathetic activity and insulin sensitivity were also favourably influenced, it was thought that increased physical activity should reduce development of cardiovascular disease. In healthy normotensive cyclists we could demonstrate that a local adaptation takes place in the exercising limb with vasodilation and a decreased arterial stiffness. However, a training program did not affect vessel wall properties (131). It is most likely that changes in vessel wall properties need a long time to develop and are merely a pressure-related phenomenon (18). Exercise could also influence the endothelium via periodic increases in shear stress (18) and so exert a favourable influence on large artery properties.

\section{Smoking}

Cigarette smokers are at high risk of cardiovascular disease (117). Although in the study of the present thesis relatively young habitual smokers are comparable to non-smokers regarding arterial stiffness, smoking one cigarette already increases arterial stiffness in these subjects (Chapter 5). Repeated increases in arterial stiffness caused by each cigarette may accelerate vascular ageing and enhance the risk for endothelial damage and disruption of atherosclerotic plaques $(39,40)$. In particular, relatively young people are prone to acute cardiovascular events by disruption of weak, lipid-rich, small (not detectable) plaques. Therefore, the repeated acute increases in arterial stiffness (decreases in arterial distensibility) due to one cigarette seem to be more harmful than the chronic effects. Indeed cardiowascular risk has been shown to increase with the number of cigarettes smoked per day (133). Smoking may be extra harmful to the arterial wall when other cardiovascular risk factors, such as hypertension and hypercholesterolaemia are present. Therefore, stop smoking would be advisable also in these relatively young subjects. 


\section{Stress}

Excessive psychological stress has been mentioned as a cardiovascular risk factor ( 97 ). The effect of pure psychological stress on large artery properties has not been investigated, but with an increase in sympathetic activity it could be expected that stress may increase arterial stiffness. After a cold pressor test, which increases sympathetic activity, arterial stifiness of the radial artery increased, with a decrease in radial artery diameter and an increase in mean arterial finger blood pressure (55). Mental stress did not change arterial diameter of the medium-sized muscular radial artery, while blood pressure and heart rate was enhanced by this form of stress (48). In the latter study no data on arterial stifiness were available.

\section{B Influence of pathological conditions}

Apart from physiological factors, several pathological conditions may also influence arterial stiffness (arterial distensibility) (Table 10.4).

Table 10.4. Influence of pathological conditions an arterial sittmess and cardiovascular risk.

\begin{tabular}{|c|c|c|}
\hline Pathological conditions & Arterial stittness & Cardiovascular risk \\
\hline \multicolumn{3}{|l|}{ Hypertension } \\
\hline systolo-diastolic & $\uparrow$ & $\uparrow$ \\
\hline borderline & $\uparrow$ & $\uparrow$ \\
\hline isolated systolic & $\uparrow$ & $\uparrow$ \\
\hline pulmonary & $\uparrow$ & $\uparrow$ \\
\hline \multicolumn{3}{|l|}{ Diabetes mellitus } \\
\hline non-insulin dependent & $=1+$ & $\uparrow$ \\
\hline Insulin-dependent & $=1 \downarrow$ & $\uparrow$ \\
\hline Atherosclerosis & $(\mathbf{N})$ & $\uparrow$ \\
\hline Hypercholesterolaemia & $\uparrow \downarrow$ & $\uparrow$ \\
\hline \multicolumn{3}{|l|}{ Other diseases } \\
\hline congestive heart failure & $\uparrow$ & $\uparrow$ \\
\hline Marfari's syndrome & $\uparrow$ & $\uparrow$ \\
\hline renal failure & $\uparrow$ & $\uparrow$ \\
\hline
\end{tabular}




\section{Hypertension}

In general, arterial stiffness of proximal elastic and muscular arteries is thought to be increased in essential hypertension and also in borderline hypertension (Chapter 1), although isobaric compliance of distal muscular arteries may be increased, suggesting a better buffering capacity in hypertensives (70). Isobaric compliance is of interest with regard to intrinsic wall properties of arteries. Arterial compliance at the operating pressure is an important determinant of cardiac afterload.

Borderline as well as established hypertension may induce functional (increased arterial stiffness, vasodilation) and structural changes (increased wall thickness), accelerating the ageing process of the arterial wall (83). The consequence of the increase in arterial stiffness may be that these patients are at a higher risk of cardiovascular morbidity and mortality. Indeed epidemiological data have shown that hypertensive patients bear a high cardiovascular risk and that this risk is more related to systolic than to diastolic pressure $(29,61,103)$. In addition "patients with isolated systolic hypertension and borderline hypertension have also a higher cardiovascular risk $(56,57,112)$. Therefore, early diagnosis of increased arterial stiffness may allow an earlier treatment of hypertension, which might be more accurate in preventing cardiovascular complications.

\section{Diabetes mellitus}

Cardiovascular risk is increased in diabetic patients $(44,59)$. In the non-insulin dependent diabetic group arterial stiffness has been found to be increased $(71,128)$, although a recent study could not reveal any difference in large artery compliance between non-insulin dependent diabetics and control subjects (81). In this - generally older - patient group other factors, such as age, hypertension and obesity may have been confounding variables. In insulin-dependent diabetic subjects the findings are inconsistent with a possible increase $(71)$ or decrease $(121,122)$ in arterial stiffness in these patients. In our own study young, uncomplicated, insulin-dependent diabetics showed no evidence of an increased arterial stiffness, nor could a relation be found between arterial stiffness and duration of the disease, actual glucose or HbA1c values (Chapter 6). However, in this relatively small group there was a trend for a greater stiffness of the temoral artery. Since the femoral artery of diabetic patients is prone to early atherosclerosis, an increased femoral stiffness might be an early feature of athercsclerotic disease and subsequently of a higher cardiovascular risk.

\section{Atherosclerosis and hypercholesterolaemia}

Subjects with hypercholesterolaemia and atherosclerosis are at high cardiovascular risk $(19,42,119)$. Coronary and carotid atherosclerosis have been associated with an increased arterial stiftness $(30,49,86,116)$, but in some studies the effects of age may form a confounding variable $(30,90)$. In patients with peripheral vascular disease a regional increase in arterial stiffness was found (34), but also arterial stiffness in an artery where atherosclerosis is uncommon was increased (74). However, in the temoral arteries of atherosclerotic patients an obvious increase in stiffness could not be demonstrated (personal communication). Endothelial dysfunction (functional change) is an early feature in atherogenesis, already present in hypercholesterolaemia before atherosclerotic plaques (structural change) are present. Endotheliall dystunction may increase vascular tone and arterial stiffness. However, it was shown that the relation between cholesterol level and arterial stiffness is weak (123). In patients with hypercholesterolaemia (familial and non-familiar) even a lower arterial stiffness has been reparted (72). Moreover, in Japanese subjects aortic stiffness was. lower and ischaemic heart disease lower in subjects using a fish diet (45), suggesting a lavourable effect of low cholesterol on arterial elasticity and cardiowascular risk. In established atherosclerotic disease arterial stiffness is found increased (Chapter 1). In addition, we found 
that the femoral artery was stiffer in mild to moderate hypercholesterolaemia, indicating that this artery must be early affected in the course of atherosclerosis (Chapter 8 ).

\section{Other diseases}

In several other diseases, such as congestive heart failure, Marfan"s syndrome and renal failure an increased arterial stiffness has been shown (Chapter 1). Patients with congestive heart failure are at high cardiovascular risk $(4,93)$. In end-stage renal failure coronary heart disease is an important cause of mortality and morbidity (101) and also patients with Marfan"s syndrome are at high cardiovascular risk, mainly because of early aortic dilatation and related complications (89).

\section{Is increased arterial stiffness a cardiovascular risk factor?}

From the above it is clear that arterial stiffness is increased in a number of pathophysiological conditions and diseases, such as ageing, smoking and hypertension. The aforementioned conditions are considered to increase the cardiovascular risk. Since data are inconsistent or lacking in the remaining siluations, future research is needed.

\section{Future research}

Seasonal behaviour of vessel wall properties cq. arterial stiffness may be investigated. The relation between time-related variations (short-term, diurnal, seasonal) in vessel wall properties and cardiovascular morbidity and mortality might be of interest to know. Studies on vessel wall properties with regard to gender, race, obesity and stress also have to be extended before vessel wall properties can be used as a measure of cardiovascular risk under these conditions. In addition, the effects of weight reduction on large artery properties with a possible reduction in cardiovascular risk can give insight into the relation between obesity and arterial stiffness.

Data have to be collected in large groups of patients with insulin-dependent diabeles mellitus. As, apart from chronic hyperglycaemia and high $\mathrm{HbAic}$ levels, hyperinsulinaemia has been thought to increase arterial stiffness, knowledge of insulin levels in this population is valuable. The group of non-insulin dependent diabetics could be subject of research, since previous data on these subjects largely depend on measurements with different techniques often in one arterial segment per study. Maybe from the results in these large patient groups it becomes possible to identify a cutt-off point from which vessel wall properties in diabetic patients deteriorate and macrovascular complications develop. Factors postponing this point of no return are important to search for.

Future research could also be focussed on vessel wall properties and the relation with early endothelial dysfunction. Patients with severe hypercholesterolaemia could be investigated and the effects of therapy evaluated.

Early detection of increased arterial stiffness could identify subjects at risk, before they have developed irreversible arterial wall changes or vascular ischaemic complications.

Overall, evaluation of vessel wall properties in a large population study is necessary to see how distensibility and compliance values are distributed in presumed healthy people, in that case, a relation with different risk factors could be evaluated more accurately. 


\section{Vessel wall properties and influence of pharmacological intervention}

\section{A Antihypertensive treatment}

It has been shown that antihypertensive treatment is effective in reducing cardiovascular morbidity and mortality. A meta-analysis of placebo-controlled studies showed that pharmacological antihypertensive treatment induced a $42 \%$ reduction in the incidence of stroke and a $14 \%$ reduction in coronary events (21). With a consistent reduction in the incidence of stroke, a curvilinear ( $J$-curve) relation has been described for the extent of blood pressure reduction through antihypertensive therapy and the occurrence of myocardial infarction (2). The explanation for this feature might be that with a diastolic blood pressure below $85 \mathrm{mmHg}$, coronary perfusion pressure may become too low to provide adequate oxygen supply in patients with cardiac ischaemia (25). However, information on the J-curve is largely retrospective. Recently, it was shown that this J-curve relationship between diastolic blood pressure and myocardial infarction only is present in high risk groups, such as patients with left ventricular hypertrophy and coronary artery disease (25). In addition, the J-curve was seen especially in eiderly patients (22). To date, it is suspected that blood pressure lowering due to preceding illness (62) and a high pulse pressure because of stiffer arteries (109) may increase cardiac mortality in these patients more than antihypertensive treatment on itself (22). Indeed, a high pretreatment pulse pressure may be the best predictor of cardiovascular complications in hypertensive patients (77). Since arterial distensibility (arterial stiffness) is important in determining pulse pressure, the effect of antihypertensive therapy on arterial stiffness may be of value.

While the blood pressure lowering capacity of antihypentensive agents may be similar, the effect on arterial stiffness is not uniform for the different classes of antilypertensive drugs (Table 10.5).

Table 10.5. Eflect of firstline antihypertensive agents on arterial stiffness and cardiowascular mortality and morbidity in hypertension.

\begin{tabular}{lcc}
\hline Firstline drug & Arterial stiffness & $\begin{array}{c}\text { Cardiovascular morbidity } \\
\text { and mortality }\end{array}$ \\
\hline ACE inhibitors & $\downarrow$ & $?$ \\
\hline Calcium antagonists & & $?$ \\
dinydropyridine & $\downarrow$ & $?$ \\
non-dinydropyridine & $\downarrow$ & $\downarrow$ \\
$\beta$-Blockers & & $\downarrow$ \\
non-selective & $=/ \downarrow$ & $?$ \\
selective $\beta$, & $\downarrow$ & $\downarrow$ \\
vasodilating & $=/ \downarrow$ & \\
\hline Diuretics & &
\end{tabular}

increase; $\boldsymbol{\psi}$ decrease; $=$ no change; $?$ not known. 
In general, only ACE inhibitors, calcium antagonists, $\beta$-blockers with vasodilating propenties, some selective $\beta_{1}$ - blockers and nitrates have shown a favourable effect on arterial stiffiness, although real long-term studies ( 3 months) are lacking. In contrast to the idea that the widely used diuretics do not have an effect on arterial stiffness, we have shown that the long-term effect (6 months treatment) of a thiazide diuretic combination on arterial stiffness (distensibilify) is beneficial (Chapter 7). On the other hand, we could demonstrate that the diuretic effect is less pronounced than that of the ACE inhibitor perindopril. The effect of perindopril on systemic vascillar resistance was greater than with the diuretic. Since the afterload of the heart is largely determined by large artery properties (including arterial stifiness) and by systemic vascular resistance, these data suggest a more favourable influence on cardiac afterload for the ACE inhibitor on the lang term.

It is always the question, whether the reduction in blood pressure is responsible for the improvement in vessel wall properties (indirect effect), or that large artery properties are decreased through a direct action of the drug on the vessel wall. An increased arterial compliance may be the result of [1] pure vasodilation or [2] an increased distensibility (lower stiffness) or [3] a combination of both. This pattern is different for the various antihypertensive drugs. It seems logical to select antihypertensive drugs that influence large artery properties beneficially, but it is not known whether this choice also is directly related to a decrease in cardiovascular morbidity and mortality. In addition, it remains an open question whether a decrease in distensibility (increased stiffness) and compliance due to structural changes can be reversed.

It has been demonstrated that after discontinuation of antihypertensive therapy, all positive effects on large artery properties are rapidly reversed, suggesting that functional rather than structural changes have occurred $(1,5)$. However, it might be that vascular restructuring in hypertension still needs a longer time to occur, so that structural changes had not taken place yet. Biopsies would be necessary to investigate structural changes, but for the moment human biopsies are only available from subcutaneous vessels. With ACE inhibitors indeed a reversal of structural changes could be demonstrated in these small vessels after chronic treatment (111).

In the end, the most important effect of antihypertensive therapy is a reduction of cardiovascular morbidity and mortality, which are largely determined by a reduction in stroke, a reduction in myocardial infarction due to coronary (atherosclerotic) artery disease, or a reduction in cardiac hypertrophy, which may result in heart failure.

Stroke - No data are available of ACE inhibitors and calcium antagonists, but an indirect beneficial effect on stroke might be suspected through the blood pressure lowering effect of these drugs. $\beta$-Blockers $(82,132)$ and diuretics $(78,126)$ have been shown to prevent stroke in hypertensive patients.

Myocardial intarction - Calcium antagonists can slow down atherosclerotic disease (75), but a direct effect on the incidence of myocardial infarction has not been shown yet. $\beta$-Blockers reduce mortality from myocardial infarction $(24,26)$. Diuretics are only effective for coronary heart disease prevention in the elderly $(3,109)$.

Cardiac hwpertrophy - ACE inhibitors have shown beneficial effects on ventricular hypertrophy and in patients with heart failure $(27,28,95,118,120)$. $\beta$-Blockers are moderately effective in reversing left ventricular hypertrophy (28). Although diuretics were thought to have no effect on left ventricular hypertrophy (27), a recent meta-analysis showed that the reduction in left ventricular mass did not significantly differ with each of the aforementioned antihypertensive agents (35). This would suggest reduction of cardiac hypertrophy and subsequent improvement of cardiovascular risk with each of the classes of firstline antihypertensive drugs.

Overall, a direct relation between vessel wall properties and cardiovascular mortality and morbidity has not been shown yet, but an indirect relation by decreasing cardiac afterload and stress on the vessel wall may be suspected with some agents. 


\section{B Cholesterol lowering treatment}

Lowering cholesterol in patients with hypercholesterolaemia decreases the risk of atherosclerolic complications and reduces mortality from coronary artery disease $(16,17,37,76)$. A recent study with the cholesterol lowering agent simvastatin showed a significant reduction of cardiovascular mortality in patients with mild to moderate hypercholesterolaemia (107). On the other hand, a meta-analysis showed that in the population as a whole the relation between serum cholesterol and total mortality is not as linear as thought previously (53). In that study, a low as well as a high cholesteral level was associated with an increased total mortality. In mild to moderate hypercholesterolaemic patients we could not demonstrate an effect on arterial stiffness of an 8-week treatment period with pravastatin, a cholesterol lowering agent (Chapter 8). Since the lipid profile improved significantly, in this study there was no obvious relation between cholesterol and arterial stiffness. In addition, in a population of 250 subjects, cholesterol was only a minor determinant of arterial stiffness, compared to mean arterial pressure, age and gender (123). A longer treatment period may be needed to detect changes in arterial stiffness or larger patient groups may be necessary. However, then it is the question whether such changes would be clinically relevant.

\section{Angina pectoris}

Patients with angina pectoris are at high risk to develop an acute coronary event. Vasodilator drugs, used to decrease cardiovascular risk ${ }_{1}$ are an essential part of therapy within this patient group (69). Improvement of large artery properties has been described with the older nitrates, explaining in part the favourable effect on cardiac afterload of these drugs. However "these have all been acute studies, while in general patients use nitrates continuously.

In healthy volunteers, nicorandil, a new anti-anginal drug with nitrate-like actions and potassium channel opening properties, also increased arterial compliance through a vasodilatory effect, but the effect on arterial compliance was less pronounced than that of isosorbide dinitrate both acutely and after one week of therapy (Chapter 9). Arterial stiffness was not significantly lowered by either nicorandil or isosorbide dinitrate. An advantage of the new drug could be that it does nat cause drug tolerance or reflextachycardia. Whether these results also are valid in patients with angina has to be evaluated yet.

Nitrates are thought to preferentially reduce systolic pressure and are therefore recommended for the treatment of isolated systolic hypertension (73). In our healthy volunteers with a normal pulse pressure this effect was not seen.

\section{Future research}

Concerning antihypertensive agents, long-term studies on reversal of structural changes deserve attention in future research. Techniques to investigate structural changes in vivo should be improved and used more frequently in clinical trials. Maybe non-invasive techniques that measure vessel wall thickness and smooth muscle mass more accurately than at present will become available. Ultimately, changes in functional and structural aspects of the arterial wall must be related to effects on cardiovascular morbidity and mortality. The optimal drug for the individual hypertensive patient should reduce morbidity and mortality, should be cheap, and should give a good drug adherence. Such a drug is expected [1] to provide adequate blood pressure reduction, [2] to improve large artery elasticity, [3] to reverse structural changes, if any, and [4] to have low incidence of side effects. 
For nitrates it would be of interest to investigate their effect on vessel wall properties in isolated systolic hypertension as a possible way to reduce cardiovascular risk in these patients.

Long-term evaluation of different therapy regimens in hypercholesterolaemia is needed to draw conclusions on a possible reduction in arterial stiffness and cardiovascular complications.

Finally, it is possible that the predictive value of vessel wall properties with regard to future cardiovascular complications may be of more value than all these separate cardiovascular risk factors, such as smoking, cholesterol, obesity, hypertension, diabetes mellitus etc. Apart from progressive atherosclerosis $(39,40)$, cardiac hypeitrophy seems a key cardiovascular risk factor. Therefore, the consequence of additional research might be that an individual's value of large artery properties together with information on cardiac hypertrophy contributes to the individual cardiovascular risk. In addition, large artery properties might be used as a follow-up parameter for the effects of therapeutic interventions.

\section{References}

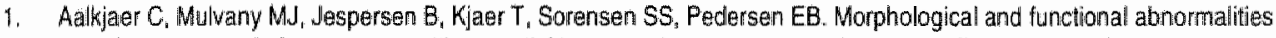
of resistance vessels from patients with essential hypertension are not momalized by anlihypertensive therapy. J Hypertens 1988;6 (Suppl. 4) :S702.

2. Alderman MHH, Ooi WL, Madhavan $\mathrm{S}$, Cohen $\mathrm{H}$. Treatmentinduced blood pressure reduction and the risk of myocardial infarction. JAMA 1989;262:920-24,

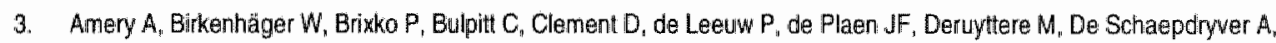
Dollery $C$, Fagard R, Felikamp H, Forette $F$, Forte J, Hamdy $B_{n}$ Henry JF, Koistinen $A_{a}$ Leonetti $G$, Lund-Johansen $P$, Morris J, Nissinen A, O'Brien E, OMalley K. Terzoll L. Tuomilehto J, Webster $J_{q}$ Williams B. Influence of antihypertensiwe drug treatment on morbidity and mortality in patients over the age of 60 years. EWPHE results: subgroup analysis based on entry stratilication. I Hypertens 1986;4 (Suppl. 6) :S642-47.

4. Applefeld MM. Chronic congestive heart lailure: Where have we been ? Where are we heading ? Am $\mathrm{J}$ Med 1986;80 (Suppl. 2B) :73-77.

5. Asmar RG, Pannier B, Santoni JP, Laurent S, Londion GM, Levy BI, Satar ME. Reversilon ol cardiac fypertrophy and reduced arterial compliance after converting enzyme inhibition in essential hypertension. Circulation 1988;78:941-50.

B. Awolio AP, Chen SG, Wang $\mathrm{AP}$, Zhang $\mathrm{CL}$, LIMF, O'Rourke MF. Eftects of aging on changing arterial compliance and left ventricular load in a northmon Chinese wrban community. Circulation 1983;68:50-58.

7. Avolio AP, Clyde KM, Beard TC, Cooke HM, Ho KKL, O'Rourke MF. Improwed artertal distensibility in nomotensive subjects on a low salt diet. Arteriosclerosis 1986;6:166-69.

3. Avolio AP, Dang FQ, Li WQ, Luo YF, Huang ZD, Xing LFF, O'Rourke MF. Effects of alging on arterial distensibility in populations with high and low prevalence of hypertension; a comparison between urban and rural communities in China. Circulation $1985 ; 71: 202-10$.

9. Barrett-Connor $E$, Khaw K. Is hypertension more benign when associated with obesity? Circulation 1985;72:53-60.

10. Basket $J_{1}$, Lewis $\mathrm{RA}$, Basaly MG, Gosling $\mathrm{RG}$. Changes in carotid artery compliance with age. Age Ageing $1990 ; 19$ 241.46 .

11. Benetos $A_{1}$ Laurent S. Hoeks AP, Boutowyrie PH, Safar ME. Arterial alterations with aging and high blood pressure. A noninvasive study of carotid and femoral arteries. Arterioscler Thromb 1993;13:90-97.

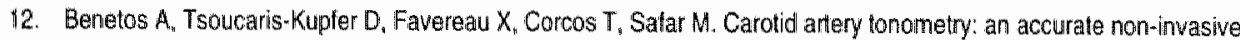
method for centrall aortic pulse pressure evaluation. J Hypertens 1991;9 (Suppl. 6) :S144-45.

13. Blaustein MP, Hamlyn JMy. Pathogenesis of essential hypertension. A lirk between dietary sall and high blood pressure. Hypertension $1991: 18$ :II-184-111-195. 
14. Borow KM, Newburger JW. Noninwasive estimation of central aortic pressure using the oscilometric method lor analyzing systemic artery pulsatile blood flow: comparative study of indirect systolic, diastolic, and mean brackial anery pressure with simultaneous diecl ascending aortic pressure measurements. Am Heart $1982,103: 879-86$.

15. Brennam PJ, Greenberg G, Mall WE, Thompson SG. Seasonal wartation in arterial blood pressure. BNH 1982;285 :919-23.

16. Brown G, Albers JJ, Fisher LD. Schaeter SM, Lin J, Kaptan C, Zhao X, Bisson BD, Fitzpatrick VF, Dodge HT. Regression of coronary antery disease as a result of intersive bipid-lowering therapy in men with high levels of apotipoprotein B. N Eng J Med 1990;323:1289-98.

17. Buchwald H, Vanco RL. Matts JP, Long JM, Fitch LL, Campbell GS, Pearce MB, Vellin AE, Edmiston WA, Smink RD, Sawn HS, Campos CT. Hansen BU, Tuma N, Karnegis JN, Sanmarco ME, Amplatz K, Castantada Zuniga Wh, Hunter DW, Bissett JK, Weber Fll, Stevenson JW, Leon AS, Chaimers TC, POSCH graup. Effect of partial lleal bypass surgeny on mortality and morbidity from coronary heart disease in patients with hypercholesterclemia. N Engl J Med 1990,323 :946-55.

18. Cameron JD, Dart AM. Exercise fraining increases total systemic arterial compdiance in humans. Am to Physiol 1994:266:H693-701.

19. Castelli WP. Garrison AJ, Wilson PWF, Abbott FD, Kalousdian S, Kannel WB. Indidence of coronary heart disease and lipoprotein cholesterol levels. The Framingham Study JAMA 1986;256:2835-38.

20. Colan SD, Fuji A, Borow KM, MacPherson D, Sanders SP, Noninvasive determination of systolic, diastiolic and end-systolic blood pressure in neonates, infants and young children: comparison with central aortic piessure measurements. Am J Cardiol 1983;52:867-70.

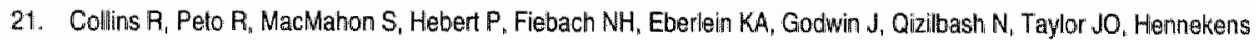
$\mathrm{CH}$. Blaod pressure, stroke, and coronary heart disease. Part 2 , short-term reductions in blood pressure; overview of randomised drug trials in their epidemiological context. Lancet 1990;335:827-38.

22. Coope J, Warrender TS. Lowering blood pressure. Lancet 1987;2:518.

23. Corrao JM, Becker RC, Ockene 1S, Hamilton GA. Coronary heart disease risk factors in women. Cardiology 1990;77 (Suppl. 2):8-24.

24. Cruickshank JM: blockers and primary prevention revisited. Cardiovasc. Rev Rep 1990;11:10-16.

25. Cruickshank JM. J curve in antihypertensive therapy. Does ti exist ? A personal point of view. Cardiovasc Drugs Their $1994: 8: 757-60$.

26. Cruickshank JM, Pennert $K$, Sorman AE, Thorp JM, Zacharias FM, Zacharias FJ. Low mortality from all causes, including myocardial infarction, in well-controlled hypertensives treated with a bela-blocker plus other hypertensiwes. $J$ Hypertens $1987 ; 5: 489 \cdot 98$.

27. Dahiof B. Regression of cardiovascular stuctural changes - a preventive strategy. Clin Exp Hypertens [A] $1990 ; A 12$ $: 977 \times 96$.

28. Dahiót B. Pennert $K$, Hansson L. Reversal of left ventricular hypertrophy in hypertensive patients. A metaanalysis of 109 treatment sludies. Am J Hypertens 1992;5:95-110.

29. Darne B, Girerd X, Safar M Cambien F, Guize L. Pulsalile versus steady component of blood pressure: a cross-sectional analysis and a prospective analysis on cardiovascular mortality. Hypertension 1989;13:392-400.

30. Dart AM, Lacombe F, Yeoh JK, Cameron $J D$, Jennings GH, Laufer E, Esmore DS. Aortic distensibility in patients with isolated hypercholesterolaamia, coronary artey disease, or cardiac iransplant. Lancet 1991:338, (1):270-73.

31. Dimond GE. Hypertension, body weight and coronary heart disease. Arch Intern Med 1963:112:550.

32. Draaijer $P$, Kool M., Maessen JM, Van Bontel LM, de Leeuw PW, van Hooff JP, Leunissen KM: Vascular distensibilly and compliance in salt-sensitive and salt-resistant borderline hypertension. al Hypertens 1993;1:1:199-1207.

33. Eichner ER. Exercise and heart disease: epidemiology of the "Exercise Hypothesis", Am J Med 1983;75:1008-23.

34. Eliakim M, Sapoznikow D. Weimman J. Fulse wave velocity in healthy subjects and in patients with various distase states. Am Heart d 1971,82:448-57.

35. Fagard R, Lifhen P, Staessen J, This L, Amery A. Mechamical and ather factors relating lo left ventricular hypertrophy. Blood Pressure 1994;3 (Suppl. 1):5-10.

36. Freis ED. Salt wolume and the prevention of hypertension. Circulation 1976;53:589-95. 


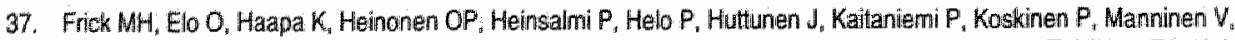
Maenpaa $H_{4}$ Malkonen M, Mantiari $M$, Norola S, Pastemack A, Pikkarainen J, Romo M, Sjoblom T, Nikkila EA. Helsinki theart study: primary-prevention trial with gemfibrozit in middle-aged men with dystipidemia. N Engl.J Med 1987;317 $: 1237-45$.

38. Furlani $R_{r}$ Guzzetti $S$, Crivellaro W, Dassi S, Tineli $M$, Baselli $G$, Cerutti $S$, Lombardi F, Pagani M, Malliani A. Continuous 24-hour assessment of the neural regulation of systemic arterial pressure and RR variabilitities in ambulant subjects. Circulation 1990;81:537-47.

39. Fuster $\mathrm{V}$, Badimon $\mathrm{L}_{\mathrm{a}}$ Badimon $\mathrm{J}$, , Chesebro $\mathrm{JH}$. The pathogenesis of coronary artery disease and the acute coronary syndromes. N Engl J Med 1982;326:242-50.

40. Fuster $V_{b}$ Badimon $L$, Badimon $J_{3}$ Chesebro $J H$. The pathogenesis of coronary artery disease and the acute coronary syndromes. N Engl J Med 1992;326 :310-18.

41. Giaconi S, Palombo C, Genovesi-Ebert A, Marabotti C, Volterrani D, Ghione S. Long-term reproducibility and evaluation of seasonal influences on blood pressure monitoring. J Hypertens 1988;6 (Suppl. 4) :64-66.

42. Gordon T, Kannel WB, Castelli WP. Dawber T. Lipoproteins, cardiowascular disease, and death. The Framingham study. Arch Intern Med 1981:141:1128-31.

43. Gore I, Nakashima T, Imai T, White PB. Coronary atherosclerosis and myocardial infarction in Kyushu, Japan, and Boston, Massachusetts. An J Cardial 1962:10 :400-406.

44. Green A, Borch-Johnsen $K_{\text {, Andersen }} \mathrm{PK}_{\text {" }}$ Hougaard P, Keiding N, Kreiner $S$, Deckert T. Relatiwe mortality of type 1 (insulin-dependerit) diabetes in Denmark: 1933-1981. Diabetologia 1985;28:339-42.

45. Hamazaki $T$, Urakaze M, Sawazaki $S$, Yamazaki $K$, Taki H, Yano S. Comparison of pulse wave velocity of the aorta between inhabitants of fishing and farming villages in Japan. Atherosclerosis 1988;73:157-60.

46. Harshfield GA, Alpert BS, Willey ES, Somes GW, Murphy JK Dupaul LM. Race and gender influence ambulalony blood pressure palterns of adolescents. Hypertension 1989;14:598-603.

47. Hayoz $D$, Tardy $Y$, Perret $F$, Waeber $B$, Meister JJ, Brunner HA. Non-invasive determination of arterial diameter and distensibility by echo-tracking techniques in hypertension. J Hypertens 1992;10 (Suppl. 5) :S95-S100.

48. Hayoz D, Tardy Y, Rutschmann B, Waeber B, Meister J, Brunner HR. Effedt of mental stress on the tone of a medium-sized muscular artery. J Hypertens 1992;10 (Suppl. 6) :S57-59.

49. Hirail $T$, Sasayama S, Kawasaki T, Yagi S. Stiffness of systemic arteries in patients with myocardial infarction. A noninwasive method to predict severity of coronary atherosclerosis. Circulation 1989:80:78-86.

50. Hofstra L, Willigers JM, Huvers FC, Schaper NC, Kester ADM, Kilslaar PJEHM, Hoeks APG. Short-term variation in the elastic properties of a muscular artery in humans. Clin Sci 1994;66:567-74.

51. Hubert HB, Feinleib M, MCNamara PM, Castelli WP. Obesity as an independent risk factor for cardiovascular disease: a 26-year follow-up of participants in the Framingham Study. Circulation 1983;67:968-76.

52. Idema FN, van den Meiracker AH, Imholz BPM, Man in 't Veld AJ, Settels JJ, Ritsema van Eck HJ, Schalekamp MAOH. Comparison of Finapres non-invasive bealt-to-beat linger blood pressure with intrabrachial artery pressure during and after bicycle ergometry. J Hypertens 1989;7 (Suppl. 6) :S58-59.

53. Jacobs D, Blackburn H, Higgins M, Reed D, Iso H. Mcilillan G, Neaton J, Nelson J, Potter J, Rifkind B, Rossouw J, Shekelle R, Yusuf S. Peport of the conference on low blood cholesterol: mortality associations. Circulation 1992;86 :1046-60.

54. Jennings $G$, Nelson L, Nestel P, Esler M, Korner P, Burton D, Bazelmans J. The effects of changes in physical activity on major cardiovascular risk factors, hemodynamics, sympathetic function and glucose utilization in man; a controlled study of lour levels of activity. Circulation 1986;73:30-40.

55. Joannides $\mathrm{F}$, Moore $\mathrm{N}$, Fichard $\mathrm{V}$, Godin M, Thuiliez $\mathrm{C}$. Adaptation mcanique des artres musculaires l'lvation aigu de la pression artrielle chez l'homme. Apports de la mesure de l'paisseur de la parol artrielle. Arch Mai Coeur Vaiss $1993 ; 86: 1219-23$.

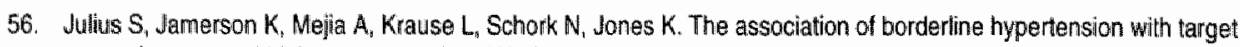
organ changes and higher coronary risk. JAMAA 1990;264:354-58.

57. Jullus S, Schork MA. Borderline hypertension: a critical review. J Chron Dis 1971;23:723-54.

58. Kannel WB, Hjortland MC, MCNamara PM. Menopause and risk of cardiovascular disease. The Framingham Study. Ann Intern Med 1976;85; 447-52. 
59. Kannel WB, McGee DL. Diabetes and glucose tolerance as risk factors for cardiovascular disease: The Framingham study. Diabetes Care 1979:2:120-26.

60. Kannel WB, Sorlie P. Hypertension in Framingham.In: Paul O, ed. Epidemiology and control of hypertension New York: Grune and Stratton, $1975: 553-92$.

61. Kannel WB, Woll PA, McGee DL, Dawber TR, McNamara P, Castelli WP. Systolic blood pressure, arterial rigidity, and risk of stroke. The Framingham study. JAMA 1981;245:1225-29.

62. Kannel W, Sorlie P. Castelli WP, McGee DL. Blood pressure and survival after myocardial infarction: the Framingham study. Am J Cardiol 1980;45:326-30

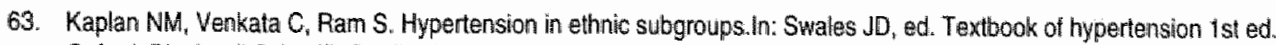
Oxford: Blackwell Scientific Publications, 199: :811-28.

64. Karamanoglu M, O'Rourke MF. Avolio AP, Kelly RP. An analysis of the relationship between central aortic and peripheral upper iimb pressure waves in man. Eur Heart $J 1993 ; 14: 160-67$.

65. Kawasaki T, Sasayama S, Yagi S, Asakawa T. Hirai T. Non-invasive assessment of the age rolated changes in stiffness of major branches of the human arteries. Cardiovasc Res 1987;21:678-87.

66. Kelly $R$, Hayward $C_{1}$ Avolio $A_{2}$ O'Rourke $M$. Noninvasive determination of age-related changes in the human arterial pulse. Circulation 1989;80:1652-59.

67. Kelly $R$, Karamanoglu M, Gibbs $H$, Avolio $A$, O'Rourke M. Noninwasive caratid pressure wave registration as an indicator of ascending aortic pressure. J Vasc Med Biol 1989:1:241-47.

68. Kelly RP, Gibbs HH, O'Rourke MF, Daley JE, Mang K, Morgan JJ, Avolio AP. Nitroglycerin has more favourable effects on left ventricular afterload than apparent from measurement of pressure in a peripheral antery. Eur Heart $y$ 1990;11 :138-44.

69. Koch - Weser J. Vasodilator drugs in the treatment of hypertension. Arch Intern Med 1974:133:1017-20.

70. Laurent S, Hayoz D, Trazzi S, Boutouyrie P, Waeber B, Omboni S, Brunner HR, Mancia G, Safar M. Isobario compliance of the radial artery is increased in patients with essential hypertension. J Hypertens 1993;11:89-98.

71. Lehmann $\mathrm{ED}_{n}$ Gosling RG, Snksen PH. Arterial wall compliance in diabetes. Diabetic Med 1992;9:114-19.

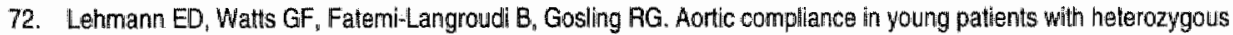
familial hypercholesterolaemia. Clin Sci 1992;83:717-21.

73. Levenson J, Bouthier J, Chau NP, Rolan E, Simon AC. Effects of nicorandil on arterial and venous vessels of the forearm in systemic hypertension. Am $\downarrow$ Cardiol 1989;63 ;40J-3J.

74. Levenson JA, Simon AC, Maarek BE, Gitelman RJ, Fiessinger JN, Safar ME. Regional compliance of brachial artery and saline infusion in patients with arteriosclerasis obliterans. Arteriosclerosis 1985;5:80-87.

75. Lichtlen PA, Hugenhaltz PG, Rafllenbeul $W$, Hecker $H_{1}$, wast $S$, Deckers JW. Retardation of angiographic progression of coronary artery disease by mifendipine. Lancel 1990;336:172-74.

76. Lipid Research Clinics Program. The lipid research clinics coronary. Primary prevention trial resulhs. I. Feduction in incidence of coronary heart disease. JAMA 1984;251:351-74.

77. Madhavan $\mathrm{S}_{8} \mathrm{Co}$ WL, Cohen $\mathrm{H}$, Alderman MH. Relation of puise pressure and blood pressure reduction to the incidence of myocardial infarction. Hypertension 1994;23:395-401.

78. Management Committee of the Australian Therapeulic Trial in Mild Hyperlension. The Ausiralian Therapeutic Trial in Mild Hypertension. Lancet 1980;1:1261-67.

79. Marler JA, Price TR, Clark GL, Muller JE, Robertson T, Mohr JP, Hier DB, Wolf PA, Caplan LR, Foulkes MA, Morning increase in onset of ischemic stroke. Stroke 1989;20:473-76.

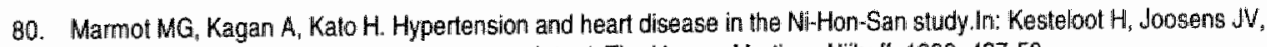
eds. Epidemiology of arterial blood pressure 1si ed. The Hague: Martinus Nighott, $1980: 437-52$.

81. McVeigh G, Brennan G, Hayes $\mathrm{B}$, Cohn J Finkelstein S. Vascular abnormalities in mon-insulin-dependent diabetes metlitus identified by arterial wavelorm analysis. Am J Med 1993;95:424-30.

82. Medical Research Council Working Party. MRC trial of treatment of mild hypertension; principal results. BMJ 1985;291 :97-104. 
B3. Wan Merode T, Brands $P$ J. Haeks APG, Aeneman RS. Faster aging of the carotid artery bituration in bordertine hypentersive subjects. J Hypentens $1993,11: 171-76$.

84. van Metode T. Hich PJ, Hoeks APG, Rieneman RS. Noninvasive assessment of artery wall properties in chitdren aged $4-19$ years. Pediatr Res $1988,259496$.

85. Van Merode T, Hidk P.lu, Hoelus APG. Smeets FAM, Reneman RS. Differences in carotid artery wall properties between presumed healthy men and women. Uitrasound Med Bio 1988:14.571.74:

86. Whothiadd in PH, Underwood SA, Bogren HG. Firmin DN, KItpstein RH, Rees RS, Longmore DB. Regional aortic complance studied by magnetic resonance imaging: the effects of age, training and coronary artery disease. Br Heart $\mathrm{J}$ $1989 ; 62: 90-96$.

87. Muller JE, Ludner PL, Willich SN, Tofler GH, Ayimer G, Kangas I, Stone PH. Circadian variation in the frequency of sudden cardiac death. Circulation 1987;75:131:38.

88. Muller JE, Stone PH, Tur ZG, Rutheriord JD, Czeisler CA, Parker C, Poole WK, Passamani E, Foberts R, Robentson T, Sobel BE, WHerson JT, Braumwald E, MLLIS Study Group. Circadian variation in the trequency of onset of acute myocardial infarction. N Engl J Med 1985;313:1315-22.

89. Murdoch JL, Waker BA, Haipern BL, Kuzma JW, Mckusick WA. Life expectancy and causes of death in the Martan syndrome. N Engl J Med 1972;2B6:804-8.

90. Wakashima T. Tanikawa $\mathrm{d}$. A study of human aortic distensibility with relation to atherosclerosis and aging. Angiology $1971 ; 22: 477-87$.

91. OBrien E, Sheridan J, OMalley K. Dippers and non-dippers. Lancet 1988 (1) :397.

92. O'Rourke M. Arterial stiffness, systolic blood pressure, and logical treatment of arterial hypertension. Hypertension $1990 ; 15: 3396-47$

93. Packer M. Sudden unexpected death in patients with congestive heart failure: a second fromtier. Circulalion $1985 ; 72$ $681-85$

94. Parali G, Casadei F, Groppell A, Di Rienzo M, Mancia G. Comparision of finger and intra-arterial blood pressure moniloring al rest and during laboratory lesting. Hypertension 1989;13:647-55.

95. Pfeffer MA, Braunwald $E_{1}$ Moya LA, Basta $L_{n}$ Brown EJ, Cuddy TE, Davis. BR, Gellman EM, Goldman $S$, Flaker GC, Klein M. Lamas GA, Packer M, Rouleau d, Rouleau JL, Ruthentord J, Wertheimer JH, Hawkins CM, The SAVE Imvestigators. Elfect of captopril on mortality and morbidity in patients with left ventricular dysfunction after myocardial infarction. Results of the survival and ventricular enlargement trial. N Engl I Med 1992;327:669-77.

96. Pickering TG. Blood pressure measurement. In: Pickering TG, ed. Ambulalory monttoring and bload pressure variability. Part 1 1 ist ed. London: Science Press Ltd, $1990.2,1-2.16$.

97. Pickering TG. Does psychological stress contribute to the development of hypertension and coronary heart disease? Eup J Clin Pharmacol 1990;39:S1-57.

98. Reneman PS, wan Merode T, Brands P., Hoeks APG. lnhomogeneities in arterial wall propenties under mormal and pathological condituns. I Hypertens $1992 " 10$ (Suppl. 6) :S35-40.

99. Reneman FS, wan Merode T, Hick P. Muytjens AMM, Hoeks APG. Age-related changes in carotid artery wall properties in men. Uitrasound Med Biol 1986"12;465-7\%"

100. Rocco NB, Barry J Campbell S, Nabel E, Cook EF, Goldman L, Selwyn AP. Circadian wariation of Iransient myocardial ischemia in patients with coronary artery disease. Circulalion 1987;75:395 400.

101. Rostand $\mathrm{SG}$, Gretes JC, Kirk KA, Rutsky EA, Andreol TE. Ischemic heart disease in patients with uremila undergoing maintenance hemodialysis. Kidney Int 1979,16:600m511.

102. Aussell AE, Wing LMH, Smith SA, Aylward PE, McRitchie RJ, Hassam RM, West MJ, Chalmers JP. Optimal size of cuff bladder for indirect measurement of arterial pressure in adults. J Hypertens 1989;7:607-13.

103. Futan GH, Kuller LH, Neaton JD. Wentworth DN, McDonald RH, Smith WM. Mortality associated with diastolic hypertension and isolated systolic hypentension among men screened for the Multiple Pisk Factor Untervention Trial. Circullation $1988 ; 77: 504-14$

104. Satar $M$. Therapeutic trials and large arteries in hypertension. Am Heart $\mathrm{J} 1988 ; 115: 702-10$.

105. Satar M. Ageing and its effects on the cardiovascular system. Drugs 1990"39 (Suppl. 1):1-8. 
106. Safar M, Laurent S, Safavian A, Pannier B, Asmar R. Sodun and large arteries in hypertension. Effects of indapamide. Am J Med 1988; 8 (Suppl. 1B):15\%19.

107. Scandinavian Simvastatin Surval Sudy Group. Randomised trial of cholesterol lowering in 4444 patients with coronary heart disease: the Scandinavian Simvastatin Suvival Sudy (4S). Lancet 1994:344:1383.189.

108. Seedat YK. Varying responses to hypotensive agents in dilllerent racial groups: black versus white differences. J Hypertens $1989: 7: 515 \cdot 18$.

109. SHEP Cooperative Research Gitoup. Prevention of stroke by anthypertensive drug treatment in older persons with isolated systolic hypertension. JAMA 1991;265:3255-64.

110. Shuman NB. Treatment of hypertension in black patients with angiolensin converting anzyme inhibilors. J Nati Med Assoc 1988;80:265-72.

111. Sihm I, Schroeder AP, Aalkjaer $C_{1}$ Holm M, Morn B, Mulvaryy M, Thygesen K, Lederballe O. Normalization of resistance artery structure and left ventricular momphology with a perindoprif-based regimen. Can J Cardiol 1994:10 (Suppl. D) :300 $: 20$.

112. Silagy CA, Mckieil JJ. Epidemiological aspects of isolated systolic thypertension and implications for future research. Am $J$ Cardiol 1992:69:213-18.

113. Simon $A C$, O'Rourke M, Levenson $\$. Arterial distensibility and ils effect on wave refliection and cardiac loading in cardiovascular disease. Coron Artery Dis $1991 ; 2: 11111-20$.

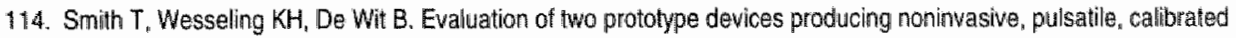
bload pressure measurement from a finger. J Clin Monit 1985:1 :17-29.

115. Sokolow M, Perloff D. The prognosis of essenthal hypertension treated conservatively. Oirculation 1961;23:697.

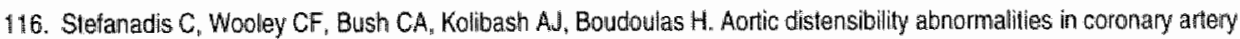
disease. Am J Cardioll 1987;59:1300 *1304.

117. Stokes J, Kannel WB. Wolf PA, Cupples LA, D'Agostino RB. The relative importance of selected risk factors for various manifestations of cardiowascular disease among men and women from 35-64 years: 30 years of follow up in the Framingharm study. Circulation 1987;75 (Suppt. V) : V65-73.

118. The CONSENSUS Trial Study Group. Effects of enalapril on mortality in severe congestive heart failure. N Engl J Mied $1987 ; 316: 1429-35$.

119. The Expert Pamel. Report of the National Cholesterol Education Program expert panel on detection, evaluation, and treatment of thigh blood cholesterol in adults. Arch Intern Med 1988" $148: 36-69$.

120. The SOLVD Investigators. Effect of enalapril on survival in patients with reduced left ventricular ejection fractions and congestive heart failure. N Engl J Med 1991;325:293-302.

121. Thordarson $H$. Thorgeirsson $G$, Helgason $T$. Aortic stifhess in insulin-dependent diabelics: an echocardiographic study. Diabetic Med $1986,3: 449 \times 54$.

122. Treese $N$, Ungem-Stemberg $\vee$ A, Cordes $U$, Beyer $J$. Intluence of norepinephrine on vessel geometry of the intact femoral artery in juwenile insuline dependenl diabetics. Evidence of early diabetic angiopathy in central arteries. $Z$ Kardiol $1982 ; 7 \%: 60-64$.

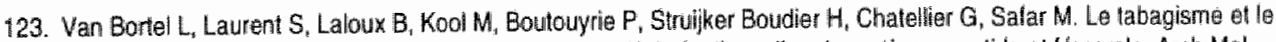
cholesterol total sant de faibles déterminants des propriétés fantionnelles des arteres carolide et lemorale. Arch Mal Coeur Vaiss 1993;86 ('Suppl. 14).

124. Van Bortel LW, Hoeks APG, Kool M.JF, Siruijker-Boudier HA. Introduction lo large artery properties as a target for risk reduction by anthypertensive therapy. JHypertens $1992 ; 10$ (Suppl. 6$\}: 5123-26$.

125. Verdecchia P. Schillaci G, Guerriere M, Gatteschi C, Benemio G, Boldrini F. Porcellati C. Circadian bliood pressure changes and left ventricular hypertrophy in essential hypertension. Circulation 1990;81:528-36.

126. Veterans Administration Cooperative Study Group on Anthypertensive Agents. Effects of ireatment on motbidlty in hypertension. 11. Results in patients with diastolic blood pressure averaging 90 through $114 \mathrm{~mm} \mathrm{Hg}$. JAMA 1970;213 $: 1143-52$.

127. Virmani $R$, Awalio AP, Merginer WJ, Robinowizz M, Herderick EE Comhill JF, Guo SY, LiU TH, Ou DY, O'Rourke M. Effect of aging on aonic morphology in populations with high and low prevelence of hypertension and atherosclerosis Am J Pathol 1991:139:1119-29. 
128. Wahiquist WL, LO CS, Myers KA, Simpson RW, Simpson JM. Putative deferminants of arterial wall compliance in NIDDM. Diabetes Care 1988:11:787-90.

129. Watt $G C M_{i}$ Foy CWW. Dietary sodium and arterial pressure: problems of studies within a single population. ل Epidemicl Commun Health $1982,36: 197-201$.

130. Wesseling KH, Settels $\mathrm{J}$, Van Der Hoeven GMA, Nijboer JA, Butijn MWT, Dorlas JC. Effects of penpheral valisoconstriction on the measurement of blood pressure in a finger. Cardiovasc Res 1985;19:139-45.

131. Wijnen JA, Kool MJ, Kooman JP, van Baak M, Hoeks AP, Struijker Boudier HA, Van Bortel LM. Vessel wall properties of large arterles and endurance training. J Hypertens 1993;11 (Suppl. 5) :S88-89.

132. Wikstrand $J$, Warnoid $\mathrm{I}$, Olsson $G$, Tuomilehto $\mathrm{J}$, Elmfedt $D$, Berglund $G$. Primary prevention with metoprolol in patients with thypertenision: moitality results from the MAPHY study. JAMA 1988;259:1976-82.

133. Willett WC, Green A, Stampfer MJ, Speizer FE, Colditz GA, Rosner B, Monson RR, Stason W, Hennekens CH. Relative and absolute excess risks of coronary heart disease among women who smoke cigarettes. N Engl J Med $1987 ; 317: 1303-9$.

434. Woodhouse PR, Khaw KT. Plummer M. Seasconal variation of blood pressure and its relationship to ambient temperature in an elderly population. J Hypertens 1993;11:1267-74.

135. Woodhouse PA, Khaw KT, Plummer M, Foley A, Meade TW. Seasonal variations of plasma fibrinogen and factor VII activity in the elderly: winter infections and death from cardiovascular disease. Lancet 1994;343 (I) :435-39. 


\section{CHAPTER 11 표}

SUMMARY 


\section{Summary}

Distensibility and compliance are vessel wall properties of large arteries describing the elastic properties and buffering capacity of these vessels, respectively. Distensibility is the relative change in volume of an artery per change in pressure and represents the elasticity of large arteries. It is an important determinant of the pulsatile stress on the vessel wall. Compliance is defined by the absoluie change in volume per change in pressure. Since it reflects the buffering capacity of large arteries, it is an important deteminant of left ventricular afterload. A decrease in distensibility or compliance is thought to be related to a higher risk of stroke, heart failure and atherosclerotic disease. Vessel wall properties of large arteries may be a valuable tool to identity a person's individual cardiovascular risk.

Chapter 1 reviews the significance of vessel wall properties in general and for cardiovascular disease more particularly. Determinants of arterial compliance are discussed and an overview is given of different techniques to evaluate large artery properties in humans. The effects of age, gender, race, obesity, salt intake and physical exercise on large artery properties are reviewed (1.3). While severall physiologic conditions may negatively influence disiensibility and compliance, a decrease in distensibility ar compliance may enhance the risk of cardiovascular disease, in turn. Data on vessel wall properties and some important pathologic conditions, such as hypertension, diabetes mellitus and atherasclerosis are reported (1.4). The effects of different antihypertensive agents on vessel wall properties are mentioned in 1.5.

Chapter 2 describes the methods for haemodynamic measurements as used in the studies in the present thesis. As large artery properties were investigated with a recently developed and modified vessel wall movement detector system, a detailed description of this system is given. With the present device, arterial distensibility and compliance of elastic and muscular large arteries can be determined. Reproducibility measurements were necessary to evaluate this new technique. In Chapter 3 data on reproducibility of the vessel wall movement detector system are presented. The system shows a good technical reproducibility and a fairly good intraobserver variability with a coefficient of variation lower than $10 \%$ for distension and diameter of the common carotid artery. In the muscular femoral and brachial arteries variation was larger (about $12.13 \%$ ), most likely due to a greater spontaneous variation in distension in these vessels, which are under permanent neurohumoral control. Interobserver variability was larger than intraobserver variability and might be influenced by differences in observers' skill and short-term variation in vessel wall properties.

A day-night pattern could be demonstrated for vessel wall properties in healthy volunteers (Chapter 4). Nocturnal vasodilation may be due to a lower sympathetic activity at night. Although elastic properties also decreased at night, arterial compliance (buffering capacity) was preserved throughout the day (4.1). The influence of several hormones, such as atrial natriuretic peptide, noradrenalin, renin and prorenin were investigated (4.2), but they do not seem to have a simple relation with vessel wall properties. A classic daynight pattern, such as known from blood pressure and heart rate, was found for noradrenalin and prorenin. Noradrenalin increased in the morning when the subjects were still in bed and therefore is likely to be related to the stress of awakening.

Various cardiovascular risk factors have shown to be associated with a decrease in distensibility and compliance. The acute and chronic effects of cigarette smoking were investigated in Chapter 5 . Results indicated that in habitual smokers smoking one cigarette causes an acute decrease in distensibility and compliance of both elastic and muscular arteries, while - except for a higher heart rate - no obvious long-term effects of smoking could be demonstrated in these middle-aged subjects. The acute effects of smoking on the long term may be harmful to the endothelium and may form a risk for acute coronary events rather than the chronic effects.

In young, uncomplicated insulin-dependent diabetic patients vessel wall properties of elastic and muscular large arteries were not obviously reduced when compared with healthy controls (Chapter 6). However, femoral artery distensibility was decreased in diabetic patients, suggesting an early vascular dysfunction at this site. Therefore, this artery may be more prone to atherosclerotic changes in these patients. No 
correlation could be detected between duration of disease, actual glucose or HbA to levels and vessel wall properties.

The effect of therapeutic intervention on distensibility and compliance depends on the disease treated and the agents used. In essential hypertension long-term treatment (6 months) with an ACE inhibitor (perindopril) resulted in a more pronounced improvement of vessel wall properties than treatment with a thiazide drug (amiloride/hydrochlorothiazide) combination, although the effect on blood pressure was comparable (Chapter 7). This suggests that the effect on vessel wall properties in case of the ACE inhibitor is not only due to a decrease in blood pressure (indirect), but also due to a direct action on the arterial wall. Consequently, the afterload of the heart will be more decreased with the ACE inhibitor than with the diuretic. Total peripheral resistance was also more reduced with perindopril than with amiloride/hydrochlorothiazide, indicating another beneficial influence of the ACE inhibitor on cardiac afterload. However after cessation of therapy, the basal situation returned, suggesting a need for a longer treatment period.

Hypercholesterolaemia is considered another risk factor of atherosclerosis. An early feature of atherosclerosis is endothelial dysfunction which may increase vascular tone and arterial stiffness. In mild to moderate hypercholesterolaemic patients a short-term ( 8 weeks) lowering of plasma cholesterol with pravastatin did not alter haemodynamics or improve vessel wall properties of large arteries, while there was a significant improvement of the fipid profile (Chapter 8). Since vessel wall properties were almost similar between mild hypercholesterolaemic subjects and controls, the lack of effect of cholesterol lowering on vessel wall properties was to be expected. On the other hand, there was a trend for a decrease in arterial stiffness of the femoral artery during cholesterol lowering therapy. A longer treatment period may be necessary to improve vessel wall properties and reduce cardiovascular risk.

In Chapter 9 the acule and subacute effects of isosorbide dinitrate (ISDN) and nicorandlil, a nitrate-like agent with potassium channel opening properties, on arterial and venous parameters were investigated in healthy volunteers. In dosages used in angina pectoris, the pure nitrate ISDN induced a more pronounced decrease of blood pressure and greater vasodilation of the common carotid artery, compared to nicorandil. ISDN drug tolerance could be demonstrated for blood pressure, heart rate and venous dynamics, but not for arterial dynamics. No drug tolerance was seen with micorandil.

Finally, in Chapter 10 different factors that could influence and improve the vessel wall movement measuring technique are discussed. Issues for future research are proposed. They include studies on physiologic factors that influence vessel wall properties (i.e. gender, race) in order lo define more precisely the different risk factors with regard to distensibility and compliance. The consequence of additional research might be that an individual's value of large antery properties could contribute to a more personal cardiovascular risk profile, while it also may become a follow-up parameter for the effects of therapeutic interventions. 


\section{CHAPTER 12}

SAMENVATTING 


\section{Samenvatting}

Distensibiliteit en compliantie żijn vaatwandeigenschappen van grote arteriēn die respectievelijk de elastische eigenschappen en de bufferende capaciteit van deze arteriën beschriliven. Distensibiliteit is gedelinieerd als de relatieve verandengng in volume van een arterie per verandering in druk. Distensibiliteit geeft aldus de elasticiteit van een grote arterie weer en is een belangrijke determinant voor de intermitterende (pulsatiele) stress op de vaatwand. Compliantie is gedefinieerd als de absolute verandering in wolume van een arterie per werandering in druk. Compliantie bepaalt het bufferend vermogen varn grote arteriên, d.w.z. de mate watin grote arterièn telkens opnieuw de systolische vloedgolf vanuit het hart kunnen opvangen. Compliantie is een belangrijke determinant voor de nabelasting van de linker ventrikel van hel hart. De gedachte is dal een vermindering van distensibiliteit en compliantie geassocieerd is met een hoger risico op het ontwikkelen van cerebrowasculaire accidenten (met name stroke), hartfalen en atherosclerotische vaatwandveranderingen. Vaatwandeigenschappen van grote arteriën zouden een waardevol instrument kunnen zijn om iemands persconlijk algeheel cardiovasculair risico aan te geven.

In Hoofostuk 1 wordt de betekenis en het belang van vaatwandeigenschappen in het algemeen en wan vaatwandeigenschappen bij cardiovasculaire aandoeningen meer in het bijzonder besproken en toegelicht. Bepalende factoren ten aanzien van arteriële compliantie worden bediscussiëerd. Een overzicht wordt gegeven van de verschillende technieken waarmee vaatwandeigenschappen in de humane situatie onderzocht kunnen worden. Tevens wordt een overzicht gegeven van de effecten van leetijd, geslacht, ras, obesitas, zoutinname en fysieke inspanning op de vaatwandeigenschappen (1.3). Enerzijds kunnen verscheidene fysiologische condities distensibiliteit en compliantie negatief be invloeden. Anderzijds kan een wermindering varn distensibiliteit en compliantie op zijn beurt het risico op cardiovasculaire aamdoeningen verhogen. De gegevens die bekend zijn met betrekking tot vaatwandeigenschappen en enkele belangrijke pathologische condities, zoals hypertensie, diabetes mellitus en atherosclerose worden in paragraaf 1.4 gerapporteerd. De effecten van de verschillende klassen antihypertensiva op waatwandeigenschappen worden in paragraaf 1.5 besproken.

In Hoofostuk 2 worden de methoden, die gebruikt zilin voor de hemodynamische metingen in de studies van dit proefschrift, beschreven. Aangezien de vaatwandeigenschappen onderzocht werden met een recent ontwikkeld en gemodificeerd vaatwand detector systeem, wordt een gedetailleerde beschrijving van dit systeem gegeven. Met het huidige systeem kunnen distensibiliteit en compliantie van elastische en musculaire grote arteriën bepaald worden. Reproduceerbaarheidsmetingen waren noodzakelijk om deze nieuwe techniek op zijn waarde te kunnen beoordelen.

In Hoofdstuk 3 worden de resultaten van de reproduceerbaaheidsstudie van het vaatwand detector systeem gepresenteerd. Het systeem heeft een goede technische reproduceerbaarheid. De variatie binnen éen onderzoeker (intraobsenver variabiliteit) is, met een variatiecoëfficiënt van minder dan 10\% voor dislensie en diameter wan de elastische a. carotis communis, vrij goed te noemen. De variatiecoëfficiënt voor deze parameters van de musculaire a. femoralis en a. brachialis was groter (12-13\%). Zeer waarschijnlijk is dit een gevolg van een grotere spontane variatie in distensie van deze bloedvaten, die aan een permanente neurohumorale controle onderhevig zijn. De variatie tussen verschillende onderzoekers (interobserver variabiliteit') was groter dan de intraobserver variabiliteit. Dit zou te maken kunnen hebben met verschillen in evaring tussen de onderzoekers en korte-termijn variatie in vaatwandeigenschappen zeell.

In een groep van gezonde viljwilligers kon een dag-nacht patroon aangetoond worden voor vaatwandeigenschappen (Hoofdstuk 4). Vasodilatathe gedurende de nacht kan een gevolg zijn van sen lagere activiteit van het sympathisch zenuwstelsel. Hoewel de elastische eigenschappen (distensibiliteit) ook afnamen 's nachts, bleef het bufferend vermogen (compliantie) behouden gedurende dag en nacht ( 4.1 ). De inwloed van verschillende hormonen, zoals ANP (atrial natriuretic peptide), noradrenaline, renine en prorenine, werd onderzocht in relatie tot het dag-nacht patroon van vaatwandeigenschappen (4,2), doch deze relatie lijkt, indien aanwezig, zeer complex. Een klassiek dag-nacht patroon, zoals dat ook gezien 
wordt bij bloeddruk en hartfrequentie, werd gevonden woor noradrenaline en prorenine. De noradrenaline spiegel nam fors toe in de ochtenduren, op het tijdstip dat de vrijwilligers nog in bed lagen. Derhalve lijkt deze stijging van noradrenaline gerelateerd te zijn aan de stress van hel ontwaken.

Verscheidene cardiovasculaire risicofactoren zijn geassocieerd met een verminderde distensibiliteit en compliantie. In Hoofdstuk 5 werden in dit verband de acute en chronische effecten van thet roken van sigaretten op vaatwandeigenschappen onderzocht. De resultaten van deze studie toonden aan dat in gewoonte rokers het roken van één sigaret een acute vermindering van distensibiliteit en compliantie van elastische en musculaire arteriën tot gevolg heeft. Daarentegen werden, met uitzondering van een hogere hartfrequentie, geen evidente chronische effecten van het roken van sigaretten gezien binnen deze groep van gewoonterokers van middelbare leeftijd. De telkens terugkerende acute effecten van roken kunnen op de lange termïn schadelijk zijn voor het vaatendotheel en zouden, meer dan de chronische effecten, een verhoogd risico kunnen vormen woor het onstaan van acute coronaire aandoeningen.

Bij jonge, insuline-athankelijke diabeten, die geen complicaties van de ziekte hadden ontwikkeld, waren de vaatwandeigenschappen van elastische en musculaire arteriën niet evident verminderd, wanneer zij vergeleken werden met gezonde vrijwilligers (Hoofdstuk 6). De distensibiliteit van de a. femoralis was echter wél verminderd in de grcep van diabetes patiënten. Dit suggereert vasculaire dysfunctie in een vroeg stadium in dit bloedvat bij diabetes patiënten zonder aanwijzingen voor aanwezigheid van andere complicaties. Dientengevolge zou deze arterie meer gevoelig kunnen zijn voor atherosclerotische vaatwandweranderingen. In deze studie kon geen relatie aangetoond worden tussen de duur van de ziekte, de actuele glucosespiegel of het $\mathrm{HbA1c}$ gehalte en vaatwandeigenschappen.

Het effect van therapeutische interventies op distensibiliteit en compliantie hangt af van de aard van de ziekte die behandeld wordt en de aard van de interventie. Bij een groep patiënten met essentiële hypertensie resulteerde een langdurige behandeling ( 6 maanden) met een ACE-remmer (perindopril) - bij een vergelijkbaar effect op de bloeddruk - in een meer uitgesproken verbetering van vaatwandeigenschappen dan een behandeling met een thiazidecombinatie (amiloride hydrochlorothiazide) (Hoofdstuk 7). Deze gegevens suggereren dat het effect op vaatwandeigenschappen in het geval van de ACE-remmer niet alleen het gevolg is van een indirect effect (namelijk via een daling van de bloeddruk), doch dat het ook een direct effect op de arteriële vaatwand betreft. Ais gevolg hiervan zal de nabelasting van het hart met de ACE-remmer meer gedaald zijn bij gebruik van de ACE-remmer dan bij gebruik van het diureticum. De totale perifere weerstand was eveneens meer gedaald tijdens gebruik van perindopril dan van amiloride/ hydrochlorothiazide, hetgeen een additioneel gunstig effect van de ACE-remmer op de nabellasting van het hart inhoudt. Na het staken van de therapie werd echter wrij snel voor alle parameters weer de uitgangssiluatie bereikl, waarmee gesuggereerd wordt dat een nog langere behandelingsperiode noodzakeligk is.

Hypercholesterolemie wordt beschouwd als een risicolactor voor atherosclerose. In een vroege fase van atherosclerose zijn reeds kenmerken aanwezig var endothe lialle dysfunctie met als mogelijke consequentie een toename van de vaatwandspanning en een verhoogde arteriële stijfheid. Bij patiënten met milde tot matige hypercholesterolemie trad geen verandering op in hemodynamische parameters of vaatwand. eigenschappen ten gevolge van een kortdurende ( 8 weken) behandeling met pravastatine, terwijl een significante verbetering van het lipidenprofiel werd gezien (Hoofdstuk 8). Aangezien vaatwandeigenschappen lussen patiënten met milde hypercholesterolemie en een controlegroep nagenoeg gelijk waren, kon het uitblijven van het effect van cholesterolverlaging op vaatwandeigenschappen verwacht worden. Anderzijds was een tendens aanwijsbaar voor een verminderde stijfheid van de a. lemoralis bij de patiënten die behandeld werden met pravastatine. Mogelijk is een langere behandelingsperiode noodzake lijk om de valatwandeigenschappen bij deze patiënten te verbeteren en het cardiovasculaire risico te reduceren.

In Hoofdstuk 9 wordt een studie gepresenteerd ower de acute en subacute effecten van isosorbide dinitraat (ISDN) en nicorandil, een nitraatachtig middel met kaliumkanaalopenende eigenschappen, op arteriële en veneuze parameters van gezonde vrijwilligers. In doseringen die gebruikt worden bij de behandeling van angina pectoris, veroorzaakte het pure nitraat ISDN, vergeleken met nicorandil, een meer uitgesproken 
Werlaging van de bloeddruk en een grotere vasodilatatie van de a. carotis communis. Tolerantie effecten konden bij ISON aangetoond worden voor bloeddruk, hartfrequentie en veneuze hemodynamische parameters, doch niet voor arterielle hemodynamische parameters. Tolerantie effecten werden niet aangetoond bij gebruik van nicorandil.

Tenslotte worden in Hoofdstuk 10 de verschillende factoren die de meettechniek van vaatwandeigenschappen kunnen beïnvloeden en verbeteren bediscussiëerd. Onderwerpen voor toekomstig onderzoek op dit gebied worden voorgesteld. Hiertoe behoren studies naar fysiologische factoren die vaatwandeigenschappen be invloeden (0.a. geslacht en ras). Dit met het oogpunt om meer nauwkeurig de verschillende risicofactoren met betrekking tot distensibiliteit en compliantie in kaart te kunnen brengen. De consequentie van additioneel toekomstig onderzoek zou kunnen zijn dat de individuele waarde van iemands vaatwandeigenschappen kan bijdragen aan een meer persoonlijk gedefinieerd cardiovasculair risicoprofiel, terwijl deze waarde ook een follow-up parameter kan zijn bij de beoordeling van de effecten van therapeutische interventies. 
DANKWOORD 


\section{Dankwoord}

Dit proeischrift is tot stand gekomen dankzij de medewerking en hel enthousiasme van veel mensen. Hiervoor wil ik vanal deze plaats een aantal personen met name bedanken.

Allereerst, mijn co-promotor Luc Van Bortel, die mij de mogelijkheid bood om de verschillende studies le doen, maar die wooral steun en toeverlaat is geweest, wanneer de apparatuur het begat, de experimenten niet liepen zoals ze zouden moeten lopen of de schrifinspiraties vastliepen. Luc, je hebt mij voortdurend de mogelijkheid geboden om ook internationaal onze studieresultaten te presenteren. Vrijwel altijd had je tijd om onze apparatuur in en buiten Nederland te verslepen en daarmee multicentrische studies mogelijk te maken. Je was altijd bereid om problemen op te lossen en mee te denken over de onderzoeksresultaten. Bedankt ook voor het geduld dat je had lijdens de schriffase en je bereidheid, ondanks je vele andere werkzaamheden, om je kritische commentaar op de diverse stukken te leveren. De ideeën, die voortdurend ontsproten aan je brein, hebben geleid tot hard werken, maar hebben onze samenwerking alleen maar in positieve zin be invloed.

Mijn promotores, Prof. dr. H.A.J. Strujiker Boudier, Prof. dr. A.S. Reneman en Prof. dr. A.P.G. Hoeks vormden onathankelijk van elkaar een stimulans in de afrondingstase wan dit proefschrift. Met name denk ik aan de plezierige bijeenkomsten, waar constructief de verschillende studies en artikelen besproken konden worden. Bovendien spreek ik een extra woord van bewondering uit voor Arnold Hoeks, die een nimmer aflatend geduld toonde voor wat betreft de technische aspecten van het vaatwand detector systeem. Door zijn uitleg en kritische opmerkingen ten aanzien van de technische principes werd ik af en toe overbluft, maar dat heeft onze contacten zeker miet benadeeld.

De leden van de beoordelingscommissie, Prof. dr. P. W. de Leeuw en Prof. dr. J. de Haan dank ik yoor hun bereidwilligheid om het manuscript te beoordelen. The willingness of $d r$. $S$. Laurent to review the manuscript is greatfully acknowledged.

Frans Smeets, Peter Brands, Jean Willigers en Tiny van Merode waren belangrijke en soms onmisbare krachten. Frans, Peter en Jean waren altijd bereid mij in een radeloze bui te voorzien van hulp, met name wanneer "het systeem" op till sloeg en onze metingen ten behoeve van de verschillende studies nief dreigden door te gaan. Hoewel hierbij menig zweetdruppeltje vloeide, konden jullie altijd wel een oplossing bedenken. Tiny heeft mij vooral in de beginperiode wegwijs gemaakt in het veld van de vaatwandeigenschappen. Samen hebben we daarna nog de reproduceerbaarheidsstudie mogen uitvoeren. Van haar specifieke ervaring op dit gebied heb ik veel geleerd.

Van Emile Cheriex heb ik de grondbeginselen van de echografische cardiac output metingen geleerd. Hem wil ik bedanken voor zijn uitleg en waardevolle aanwijzingen bij het eigen maken van de techniek. Jos Hülkenberg wil ik bedanken voor de hulp die hij tijdens de multicentrische studies heeft geboden. Zijn hulp met betrekking tot het transport van onze "vaatwandkar" was zeer welkom, maar ook van zijn rol als zogenaamde klusjesman heb ik altijd dankbaar gebruik kumnen maken. Dhr. Dooren en Frans Slangen hebben als chauffeurs een onmisbare bijgedrage geleverd aan het transport. Hiervoor mijin dank.

Monique Fuss-Lejeune was voor mij een onmisbare assistente, met name bij het opvangen van de patienlen en de verwerking van de bloedmonsters. Jet Bost heeft veel energie gestoken in de laboratoriumbepalingen. Samen wil ik hen bedanken woor de prettige wijze waarop we al die tijd hebben kunnen samenwerken.

Marita Braam-van Neer heeft bij de 24-uurs studie haar nachtrusit opgeofferd om mee te helpen bij de verwerking van de bloedmonsters. De studenten Carla Oude Elberink en Willem Sanders hebben tijdens hun wetenschapsstage mij bij de rokersstudie heel fijn kunnen helpen, vooral bij de plethysmografische metingen. Mieke Aarsen heeft mij bij de diabetenstudie in Amsterdam op een hele prettige wijze kunnen bijstaan. Voor al deze mensen geld: Bedankt!

Binnen de vakgroep tarmacologie heb ik altijd op een plezierige manier kunnen werken en samenwerken. Ten gevolge van de onderzoekswerkzaamheden kon ik lang niet altijd bij iedere samenkomst van de groep aanwezig zijn, maar de ontspannen, doch accurate wijze van werken aldaar heeft mij zeer aangesproken. 
Hoewel ik nu op een andere werkplek ben gestationeerd, zal ik deze periode niet snel vergeten en probeer ik de contacten met jullie nilet te verliezen.

Sjel Wijnen en Janneke Spek waren en zịn nog steeds twee heel fijne collega's. Samen hebben we op onze kamertjes in het BMC en later op Randwyck heel wat uurtjes doorgebracht. We hebben elkaar daarbij altijd goed kunnen helpen bij de verschillende onderzoken, samen veel lief en leed gedeeld, maar vooral ook veel plezier gehad. Misschien kunnen we in de toekomst (ieder wanuit zijn eigen werkplek) nog cens. een ge integreerd onderzoek doen.

Mia Hogenboom en Els Geurts vormden een steunpilaar op secretarieel gebied. Bedankt met name voor de tijden dat jullie op hel laatste nippertje al die abstracts hebben getikt en voor de momenten dat jullie vriendelijk bleven (maar owerspannen moeten zijn geraakt) van al die bellende proefpersonem, wanneer er weer eens een advertentie voor een onderzoek was geplaatst. Bovendien bedankt voor het versturen en bezorgen van past in de tijd dat ik niet meer bij de valkgroep werkzaam was.

Dr. Lustermans, dr. Kragten, dr. Breed, dr de Cré en zijn assistente Hedwig dank ik hartelijk voor de mogelijkheid die zij mij gaven om de onderzoeken ook in hun kliniek en met hun patiënten te kunnen uitvoeren. Zonder hun medewerking waren de multicentrische studies niet mogelijk geweest.

Bij deze wil ik ook alle patiënten en proefpersonen, die deelgenomen hebben aan de verschillende onderzoeken, bedanken. Zij hebben vaak tijd noch moeite gespaard om toch te kunnen deelnemen aan een protocol.

De financiële steun bij de interventiestudies werd geleverd door de fima's Servier, Bristol-Myers Squibb en Merck Nederland. We hebben altijd in een prettige en open sfeer met elkaar kunnen samenwerken. Voor René wil ik ook hier mijn dank uitspreken, want hij heeft veel van zijn kostbare tijd besteed aan de lay-out van dit proefschrift. Mimi heeft heel enthousiast en creatief gewerkt om de omslag van dit boekje te verfraaien.

Mijn ouders wil ik vooral bedanken voor de mogelijkheden die zij mij telkens geboden hebben om te studeren. Samen met Lisette (en later ook Richard), François en iedereen van mijn schoontamilie hebben jullie voortdurend interesse in mijn werk getoond, hetgeen mede een stimulans geweest is om door te zetten en dit proefschrift af te ronden.

Lieve Bert, jouw aanwezigheid is met name in de laatste fase van dit proefschrift heel erg belangrijk geweest. Je hebt de totstandkoming van dit boekje vrijwel op de voet gevolgd, je was altijd heel erg ge interesseerd in mijn werk. Jouw optimistische attitude en voortdurende steun, gaven mij de kracht om ook tijdens minder goede momenten de draad weer op te pakken. Omdat je zelf ook met de laatste loodjes bezig bent, hebben we vele uren samen en toch onafhankelijk van elkaar kunnen werken. Met plezier en een beetje weemoed zal ik blijven terugdenken aan deze tijd. Bert, jij hebt nooit getwijfeld aan het tot stand komen van dit boekje. Nu dit er is, zal ik ook voor jou de komende tijd nog meer een steun kunnen zijn. Op dit moment is mijn laatste woord van dank voor jou " merci! 


\section{Papers}

1. MJ Kool, JA Winen, AP Hoeks, HA Struyker Boudier, LM Van Bortal. Diumal pattern of vessel-wall properties of large arteries in healthy men. 3 Hypertension 1991.9 (Suppl. 6) : S108-S109.

2. JAG Winnen, H Kuipers; MJF Kool, APG Hoeks, MA van Baak, HAJ Struiker Boudier, FT J Verstappen, LMAB Van Bortel. Vessel wall properties of large anteries in trained and sedentary subjects. Bas Res Cardial 1991, 86 (Suppl. 1) :25-29.

3. Mu Kool, HA Struikker-Boudier, JA Winnen, AP Hoeks, LM van Bortell. Eflects of diumal variability and exercise training on properties of large arteries. J Hypertension 1992, 10 (Suppl. 6) :S49-S52.

4. LMM Van Bontel ,AP Hoeks, MJ Kool, HA Siruijker-Boudier, Introduction to large artery properties as a target for risk reduction by anthypertensive therapy. $J$ Hypertension 1992,10 (Suppl. 6) :S123-S126.

5. JA Winnen, MJ Kool, JP Kooman, MA van Baak, AP Hoeks, HA Struijker Boudier, LM Ban Bortel. Vessel wall properties af large arteries and endurance training. I Hypertiension 1993, 11 (Suppl. 5) :S8B-S89.

6. MJ Kool, FA. Lustermans, JG Breed, HA Struyker-Boudier, AP Hoeks, LM Van Bortel. Effect of perindopril and amiloride/ hydrochlorolhiazide on haemodynamics and vessel wall properties of large arteries. J Hypertension 1993, 11 (Suppl. 5) :S362-S363.

7. MJF Kool, APG Hoeks, HAJ Struijker Boudier, RS Reneman, LMAB Van Bortel. Short- and long-term effects of smoking on arterial wall properties in habituall smokers. JACC 1993 $22: 1881-1886$.

8. P Draaijer, MJ Kool, JM Maessen, LM van Bortel, PW de Leeuw, JP van Hooff, KM Leunissen. Vascular distensibility and compliance in salt-sensitiwe and salt-resistant bordertine hypertension. J Hypertension 1993, $11: 1199-1207$.

9. MJF Kooll, T van Merode, RS Reneman. APG Hoeks, HAJ Struyker Boudier, LMAB Van Bortel. Evaluation of reproducibility of a vessel wall movement detector system for assessment of large artery properties. Cardiovascular Research 1994, $28: 610-614$.

10. MJ Koal, JA Wijnen, FH Derkx, HA Struijker Boudier, LM Van Bortel. Diurnal variation in prorenin in rellation to ather humoral factors and hemodynamics. AJH 1994, $7: 723-730$.

11. JAG Wijnen, MJF Kool, MA wan Baak, H Kuipers, CHA de Haan, FTJ Verstappen, HAJ Strujker Boudier, LMAB Van Bortel. Effect of exercise training on ambulatory blocd pressure. Int J Sports Med 1994, 15:10-15.

12. LMAB Van Bartel, M.JF Kool. Vessel wall properties of large arteries in hypertension and effect of antihypertensive treatment. Can J Cardiol 1994, 10 (Suppl. D) :370-400.

13. P Draaijer, MJF Kool, LMAB Van Bortel, F Nieman, PW de Leeuw, JP van Hooft, KML Leunissen. Vascular compliance in sodium-sensitive and sodium-resistant borderline hypertensive patients. Kidney Int 1995, 47:169-176.

14. MJ Kool, J Lambert ${ }_{i}$ CD Stehouwer, AP Hoeks, HA Struijker Boudier, LM Van Bortel. Vessel wall properties of large arteries in uncomplicated IDDM. Diabetes Care 1995, $18: 618-624$.

15. Mu Kool, uJ Spek, HA Struyker Boudlier, AP Hoeks, RS Reneman, RH van Herwaarden, LM Van Bortel. Acute and subacute effects of nicorandil and isosorbide dinitrate on vessel wall properties of large arteries and hemodynamics in healthy volunteers. Cardiovasc Drugs Ther 1995, 9:331-337.

16. MJJF Starmans-Kool, MMF Fickers, MAG Pannebakker. An unwanted side effect of hydroxyurea in a patient with idiopathic myelolibrosis. Ann Hematol 1995, $70: 279-280$.

17. LMAB Van Borlel, MJF Kool, JJ Spek. Large artery distensibility and compliance in hypertension. Disparate effects of anthypertensive drugs. Am J Cardiol 1995 (in press)

18. LM Van Bortel, MJ Kool, HA Struijker Boudier. EHects of antihypertensive agents on local arterial distensibility and compliance. Hypertension 1995 (in press)

19. M Kool, F Lustermans, H Kragten, H Struijker Boudier, A Hoeks, R Reneman, H Rilla, I Hoogendam, L Van Bortel. Does lowering of cholesterol levels influence functional properties of large arteries. Eur J Clin Pharmacol 1995 (in press)

20. MJ Kool, FA Lustermans, JG Bireed, HA Struijker Boudier, AP Hoeks, RS Reneman, LM Van Bortel. The influence of perindopril and diuretic combination amiloride/hydrochlorothiazide on the vessel wall properties of large arteries in hypertensive patients. J Hypertens 1995 (in press) 


\section{Abstracts}

1. MJF Kool, LMAB Van Bortel, JAG Winer, APG Hoeks, HAJ Struijker Boudier, Circadian rhytthm and vessel wall properties of large arteries. Meth J Med 1990, 37 :A38-39.

2. MJF Kool, LMAB Van Bortel, JAG Wignen, APG Hoeks, HAJ Strufiker Boudier. Circadian rhythm and vessel wall properties of large arteries. Proceedings 31th Dutch FEDERA Neeting $1990: 149$.

3. MJF Kool, JAG Winen, APG Hoeks, HAJ Struiker Boudier, LMAB Van Bortel. Vessel wall properties and circadian thythm in large arteries. Eur J Pharmacoll 1990, $183: 825$.

4. JAG Winen, MJF Kool, H Kuipers, MA van Baak, HAJ Struiker Boudier. FTJ Verstappen, LMAB Van Bortel. Vessel wall properties of large arteries in trained and sedentary subjects. Abstract book symposium "Pharmacology of wascular and cardiac remodelling

5. L Van Bortel, M Kool, J Wijnen, H Struijker Boudier. Beta- adrenoceptor blockiade, and beta-1 selectivity of nebivolol and atenoto|, Abstracts ist Int Nebivalol Investigators' meeting, September 13-16, $1990: \mathrm{C} 11$

6. LMAB Van Bortel, MA van Baak, MJF Kool, JAG Wijnen, HAJ Struijker Boudier. Beta-adrenoceptor blockade, antihypertensive effect and exercise tolerance with nebvolot and atenolol. Pharmaceut Wkbl Sci Ed 1990, 12 (Suppl. $J)$ :J4.

7. LMAB Van Bortel, MJF Kool, JAG Wijnen, HA.J Struijker Boudier. $\beta$-Adrenoceptor blockade and $\beta_{4}$-selectivity of nebivolol and atenolol. Drug Invest 1991, 3 (Suppl. 1) :173.

8. LMAB Van Bortel, MJF Kool, JAG Wijnen, HAJ Siruijker Boudier $\beta$-Adrenoceptor blocking propenties and antihypertensive effect differ between nebivollol and atenolo: Nent $J$ Med 1991, 39 :A62.

9. MJIF Kool, T wan Merode, APG Hoeks, LMAB Van Bortel. Reproducibility measurements with mew vassel wall movement detector system. Neth لMed 1991, 39 :A66.

10. M.JF Kool, JAG Wijnen, H Kujpers, MA van Baak, HAJ Strujiker Boudier, LMAB Van Bortel. Do vessel wall properties of superficial arteries differ between endurance-trained and sedentary subjects? Neth J Med 1991, 39 :A67.

11. LMAB Van Bortel, MJF Kool, FHM Derkx, JAG Wijnen, HAJ Struifker Boudler. Diumal variation in humoral tactors. Pharmaceut Whbi Sci Ed 1991, 13 (Suppl. L) :L5.

12. MJJ Kool, JAG Wijnen, HAJ Struifker Boudier, LMAB Van Bortel. Vessel wall properties of large arteries show a diumal variation. Pharmaceut Whbl Sci Ed 1991, 13 (Suppi, L) :L5.

13. JAG Wijnen, MJF Kool, MA van Baak, HAJ Strüjker Boudier, LMAB Var Bortel. Exercise Iraining does not lower ambulatory blood pressure in sedentary male subjects. Eur Heart J 1991, 12 (Suppl.) :29.

14. MJF Kool, FHM Derkx, JAG Wijnen, HAJ Struijker Boudier, LMAB Van Bortel, Prorenin and renin do not have the same diumal variation. Eur theart J 1991, 12 (Suppi.) : "151.

15. MJF Kool, JAG Wijnen LMAB Van Bortel, HAJ Struijker Boudier. Circadian pattern of vessel wall properties of largo arteries in healthy men. Ficerca Sci Educ Perman 1991 (Suppl. 90) :345.

16. MJF Kool "FHM Derkx, JAG Wijnen, HAJ Siruiliker Boudier, LMAB Van Bortel. Different diumal variation in prorenin and renin. Ricerca Sei Educ Perman 1991, (Suppl. 90);346.

17. MJF Kool, T van Merode, APG Hoeks, LMAB Van Bontel. Reproducibility ofl a newly developed wessel wall movement detector system. Ricerca Sci Educ Perman 1991, (Suppl. 90):347.

18. JAG Winen, MJF Kad, H Kulpers, MA van Baak, HAJ Struijker Boudier, LMAB Van Bortel. Differences in vessel wall properties of superficial anteries in cyclists and sedentary subjects. Ricerca Sci Educ Perman 1991, (Suppl. 900):775.

19. JAG Winen, MF Kool, LMAB Van Bortel, MA van Baak. HAJ Strujker Boudier. Exarcise training and ambuatory blood pressure in sedentary male subjects. Ricerca Sci Educ Perman 1991 (Suppl.90) :774.

20. P Draaijer, M Kool, L v Bortel, K Leunissen. Arterial distensibility (DC) and compliance (CC) in salt-resistant and salt-sensitive borderline hypertensive patients (SPBHT vS SSBHT). J Alm Soc Nephrology 1991, $2: 474$.

21. HAJ Struiker-Boudier, MJF Kool, JAG Winen, $L M A B$ Van Bortel. Circadian changes and effect of exercise training. Functional and structural properties of large arteries. A workshop of the ISH on arterial compliance, Paris 6 th 7 th March, 1992 
22. LMAB Van Borte;, APG Hoeks, MJF Kool, HA.4 Struiker. Boudier. Large artery properties as a target for risk reduction by antihypertensive therapy. Functional and siructural properties of large arteries. A workshop of the ISH on arterial compliance, Paris 6th-7th March, 1992

23. MJF Kool, APG Hoeks, HAJ Struijker-Boudier, LMAB Van Bortel. Acute effect of smoking on large artery compliance. Neht J Med 1982,40:A59.

24. MJF Kool, APG Hoeks, HAJ Strujiker-Boudier, LMAB Van Bortel. Vessel wall properties in habitual smokers. Neth J Med 1992, 40 :A5B-A59.

25. MJF Kool, APG Hoeks, HA.J Struiker-Boudier, LMAB Van Bortel. Effects of smoking on large artery compliance. Pharmaceut Wkbi Sci Ed 1992, 14 (Suppli. D) :D4.

26. LMAB Van Bortel, JAG Winen, MJF Kod, MA Van Baak, HAJ Struijker Boudier. Effect of exercise training on ambulatory blood pressure J Hypertension 1992, 10 (Suppl, 4):S106.

27. P Draaijer, M Kool, L van Bortel, $P$ de Leeuw, KML. Leunissen. Arterial distensibility $(\mathrm{DC})$ and compliance $(C C)$ in saft-resistant and salt-sensitive borderline hypertensive patients (SRBHT wS SSBHT). J Hypertension 1992, 10 (Suppl. 4).

28. LMAB Van Bortel, M.JF Kool, T van Merdde, APG Hoeks, RS Reneman, HAJ Strujiker Boudier. Non-invasive measurements of arterial compliance: reproducibility. Abstract book Wth World conference on clinicall pharmacology and therapeutics 1992 : P-404-03.

29. LMAB Van Bottel, MJF Kool, JAG Wijnen, HAJ Struijker Boudlier. Nebivolol: not only a $\beta$,-sellective adrenoceptor antagonist. Abstract book Vth World conference on clinical pharmacology and therapeutics 1992:P-404-03.

30. LMAB Van Bortel, MJF Kaol, JGS Breed, J De Cre, FAT Lustermans, JMV Mooij; HHW Thijssen. Hemodynamic effects of nebivolol and atenolol. Arch Pharmacol 1992 345 (Suppl.) :R16-63.

31. MJF Kool, J Lambert, AJM Donker, HAJ Struijker Bouddier, LMAB Van Borrel. Large artery compliance in young insulindependent diabetes mellitus. J Hypertension 1993,11 (Suppl. 5) :S442.

32. M Kool, A Hoeks, H Struijker Boudier, R Reneman, L Van Bortel. Are the acute effects of smoking on arterial wall properties the trigger for acute cardiovascular ewents in habilual smokers? Eur Heart J 1993, 14 (Suppl.) :362.

33. M Kool, F Lustermans, J Breed, H Struijker Boudier, A Hoeks, L Van Bortel. Effects of Coversyl(B) and Moduretic mitis(i) on blood pressure, cardiac function and wessel wall properties of large arteries. Eur Heart d 1993, 14 (Suppli) :65.

34. MJF Kool, J Lambert, AJM Donker, HAJ Struigker Boudier, LMAB Van Bortell, Vessel wall properties of large arteries in young insulin-dependent diabetes mellitus (IDDM). Neth J Med 1993, 43 :A30.

35. L Van Bortel, S Laurent, B Lałoux, M Kool, P Boutouyrie, Struïkker Boudier, G Chatellier, M Safar. Le tabagisme et le. cholesterol total sont de faibles determinants des propriélés lonctionneiles des artères carotide et fémorale. Arch Mal Coeur Vaiss, $16-17$ décembre, 1993

36. LMAB Van Bortel, MJF Kool, FAT Lustermans, JGS Breed, APG Hoeks, HAJ Strujiker Boudier. Does antihypertensive lreatment with an ACE inhibitor and a diuretic result in different effects on hemodynamics and wessel wall properties of large arteries? Pharmaceut Wkbl Sci Ed 1993, 15 (Suppl E.) E4.

37. J Lambert, MMF Kool, LMAB Van Bortel, CDA Stehouwer, HAJ Struilker Boudier, AJM Donker. Vessel wall properties in insulindependent diabetes mellitus (IDDM). EASD 1993

38. P Draaijer, M Kool, L van Bortel, $P$ de Leeuw, J van Hooft, K Leunissen. Large artery compliance in sodium-sensitive and sodiun-resistant borderline hypertension. Ricerca Sci Educ Perman 1993 (Suppl. 95) :198.

39. LMAB Van Bortel, JA Wijnen, MJ Kool, JP Kooman, MA van Baak, HA Struyker Boudier. Vessel wall properties of large arteries and endurance training. Plicerca Sci Educ Perman 1993 (Suppt. 95) :784.

40. MJF Kool, APG Hoeks, HA,J Struijker Boudier, RS Feneman, LMAB Van Bortel. Acute and chrenic effects of smoking on arterial wall properties in habitual smokers. Ricerca Sci Educ Perman 1993, (Suppl. 95) :365.

41. MJJF Kool, FAT Lustermans, JGS Breed, HAJ Slruyker Boudier, APG Hoeks, LMAB Van Bortel. Effects of perindopril and amiloride/hydrochlorolhiazide on haemodynamics and vessel wall properties of large arteries. Ricerca Sci Educ Perman 1993, (Suppl. 95): 365.

42. L Van Bortel, S Laurent, B Laloux, M Kool, P Boutouyrie H Strujiker Boudier, G Chatellier, M Safar. Le tabagisme et le cholesterol total sont de taibles determinants des propriètés fonctionnelles des artères carotide et fémorale. Arch Mal Coeur Vaiss, 16-17 décembre, 1993, 24. 
43. I Spek, M Kool, A Hoeks, H Siruiker Boudier, L Van Boriel. Subacute eftechs of nicorandi and ISON on vessiel wall properties of large arteries and cardiac tunction. Pharmaceut Whol So Ed 1993, 15 (Supp) L. LS.

44. MGF Koof FAT Lustemans, JA Kragter, HAJ Struyker Boudier, I Hoogendam, LMAB Wan Bortel. An wohtweek treatment with pravastatin does not improve vessel wall properties ol large arteries in patiem ts with mild hypercholesterolemia. Pharmaceut Whbl Sci Ed 1994,16 [SUppl. D) :D7.

45. LMAB Van Bortel, MJF Kool, FAT Lustemans, JGS Breed, HA, Strugker Boudier, APG Hoeks EHect of perindopril and amiloride hydrochlorothiazide on blood pressure, cardiac function and wessel wall properties of laige anterites. Abstractbook salelite symposium Xlth World Congress ol Cardiology, Berlin, September 13, 1994

46. MAF Kool "FAT Lustermans, JGS Breed, HAJ Strujker Boudier, APG Hoeks, LMAB War Bortel. Does lreatment with perindopril and amiloride/hydrochiorothiazide result in different effects on hemodynamics and vessel wall properties of large arteries. Neth J Med 1994, 44 :A52.

47. Jl Spek, MJF Kool, APG Hoeks, HAJ Struijker Boudier, AHBM van Herwaarder, LMAB Van Bortel. Subacute effects of micorandifi and ISDN on hemodynamics and large artery properties. Neth J Med 1994, 44:A85.

48. MJF Kool, LMAB Van Bortel, S Laurent, B Laloux, G Chateller, HAJ Struijker Boudier, M Salar. Determinants, of the wall properties of the carotid and lemoral arteries, Neth J Med 1995, $46: A 70-A 71$ :

49. M.JF Kool, FAT Lustermans, HA Kragten, HA.J Struyker Boudier, H Rilla, L.MAB Van Bortel. Lowering cholesterol in patients with mild hypercholesterolemia does not improve functional properties of large arteries. Neth J Med 1995,46 :A70.

50. LMAB Wan Bortel, MJF Kool, HAJ Struijlker Boudier. Effects of antitypertensive agents on carotid arterial compliance. Abstractbook of second workshop "Structure and function of large arteries". Paris, Jantuary 20-21, 1995

51. L. Wan Bortel, M Kool. Vessel wall properties of large arteries in hypertension, eflects of perindopril vs. diuretic therapy. Abstractbook of symposium: "From hypertension to congestive heart failure". Istanbul, Tukey, April 29, 1995.

52. MJF Kool, FAT Lustermans, JA Kragten, HAJ Struyker Boudier, H Rila, LMAB Van Bortel. Effect of pravastatin on vessel wall properties of large arteries in hypercholesterclemic patients. Abstractbook EAS, 1995 


\section{- CURRICULUM VITAE}




\section{Curriculum Vitae}

\section{Mirian Kool}

1964, 7 mei geboren te Heerlen, Nederland.

1976 - 1982 gymnasium-ß opleiding aan het Sint Maartenscollege, Maastricht, Nederland.

1982 - 1988 studie geneeskunde aan de Rijksuniversiteit Limburg, Maastricht Nederland.

1986, september doctoraal diploma geneeskunde.

1988, december basisartsdiploma, Rijksuniversiteit Limburg, Maastricht, Nederland.

1989 - 1993 assistent in opleiding, vakgroep farmacologie, divisie klinische farmacologie (Dr. L.M.A.B. Van Bortel en Prof. dr. H.A.J. Struijker Boudier), Rijksuniversiteit Limburg, Maastricht, Nederland.

1993 - heden assistent geneeskundige in opleiding tot internist (Dr. F.A.T. Lustermans), de Wever Ziekenhuis, Heerlen, Nederland.

1995 erkenning als arts-klinisch farmacoloog. 
